Florida International University FIU Digital Commons

$6-25-2018$

\title{
Azido- and Triazolyl-modified Nucleoside/tide Analogues: Chemistry, Fluorescent Properties, and Anticancer Activities
}

Zhiwei Wen

zwen001@fiu.edu

DOI: $10.25148 /$ etd.FIDC006844

Follow this and additional works at: https:// digitalcommons.fiu.edu/etd

Part of the Nucleic Acids, Nucleotides, and Nucleosides Commons, and the Organic Chemicals Commons

\section{Recommended Citation}

Wen, Zhiwei, "Azido- and Triazolyl-modified Nucleoside/tide Analogues: Chemistry, Fluorescent Properties, and Anticancer Activities" (2018). FIU Electronic Theses and Dissertations. 3789.

https://digitalcommons.fiu.edu/etd/3789 


\section{FLORIDA INTERNATIONAL UNIVERSITY}

Miami, Florida

\section{AZIDO- AND TRIAZOLYL-MODIFIED NUCLEOSIDE/TIDE ANALOGUES:}

CHEMISTRY, FLUORESCENT PROPERTIES, AND ANTICANCER ACTIVITIES

A dissertation submitted in partial fulfillment of

the requirements for the degree of

DOCTOR OF PHILOSOPHY

in

CHEMISTRY

by

Zhiwei Wen 
To: Dean Michael R. Heithaus

College of Arts, Sciences and Education

This dissertation, written by Zhiwei Wen, and entitled Azido- and Triazolyl-modified Nucleoside/tide Analogues: Chemistry, Fluorescent Properties, and Anticancer Activities, having been approved in respect to style and intellectual content, is referred to you for judgment.

We have read this dissertation and recommend that it be approved.

$\begin{array}{r}\hline \text { Kevin O'Shea } \\ \hline \text { Kathleen Rein } \\ \hline \text { David Becker } \\ \hline \text { Anthony J. McGoron } \\ \hline \text { Stanislaw F. Wnuk, Major Professor }\end{array}$

Date of Defense: June 25, 2018

The dissertation of Zhiwei Wen is approved.

Dean Michael R. Heithaus College of Arts, Sciences and Education

Andrés G. Gil Vice President for Research and Economic Development and Dean of the University Graduate School

Florida International University, 2018 
(C) Copyright 2018 by Zhiwei Wen

All rights reserved. 


\section{DEDICATION}

I would like to dedicate this dissertation to my wife Bixia Zhu, my parents Suhui Wen and Sanju Zhou, and my mentor Dr. Stanislaw F. Wnuk for their support.

感谢碧霞一直来的支持, 感谢你一直陪我走南闯北, 漂洋过海。让我不管到哪

里, 都有一个家。感谢我的父母一直来的理解和鼓励。子曰: “父母在, 不远游, 游必有方”。望时机成熟, 可常伴左右。 


\section{ACKNOWLEDGMENTS}

Writing this dissertation gave me not only a chance to summarize my motivating anticancer research but also a good time to reflect on the help and support I have got from people around me during pursuing my $\mathrm{Ph} . \mathrm{D}$. at FIU in this five years.

I would first like to thank my mentor Dr. Stanislaw Wnuk for his outstanding supervision, support, friendship, and trust in me. I feel proud and lucky to get opportunity to be involved in the research on bioorganic chemistry of nucleoside/tides with applications in anticancer medicine, which I have my passion and enthusiasm for. I do appreciate everything, related to not only my research but also my personal life and future career development, he has done for me. Words cannot describe how thankful I am.

Many thanks go to my committee members, Dr. O'Shea, Dr. Rein, Dr. Becker, and Dr. McGoron for their valuable time and advice on my research. I'd also like to thank Dr. Yong Liang for his training in Dr. Wnuk's lab and thank Dr. Jufang Peng and my undergraduate students Paloma, Anna, and Laura for their hard-work and contribution to my projects. Special thanks go to my collaborators, Dr. Sevilla and Dr. Adhikary (Oakland University) for the radical investigation, Dr. Liu (FIU) for enzymatic DNA synthesis, Dr. Miksovska (FIU) for fluorescent study, Dr. Schols and Dr. Liekens (KU Leuven) for antiviral and cytostatic evaluation, Dr. Glazer (Yale University) for oncology study, and Dr. Guilarte and Dr. Barbieri (FIU) for cell imaging. My sincere thanks go to all my lab mates as well as all the faculties and staffs in our department for the help and support. I also thank Wiley for the copyright permission for reuse of prodrug results published at Arch. Pharm. for my dissertation.

Finally, I wish to thank Graduate School for the Dissertation Year Fellowship. 


\begin{abstract}
OF THE DISSERTATION
AZIDO- AND TRIAZOLYL-MODIFIED NUCLEOSIDE/TIDE ANALOGUES: CHEMISTRY, FLUORESCENT PROPERTIES, AND ANTICANCER ACTIVITIES

By
\end{abstract}

Zhiwei Wen

Florida International University, 2018

Miami, Florida

Professor Stanislaw F. Wnuk, Major Professor

Two classes of C5 azido-modified pyrimidine nucleosides were synthesized and explored as radiosensitizers. The 5-azidomethyl-2'-deoxyuridine (AmdU) was prepared from thymidine and converted to its cytosine counterpart (AmdC). The 5-(1-azidovinyl) modified 2'-deoxyuridine (AvdU) and 2'-deoxycytidine (AvdC) were prepared employing regioselective Ag-catalyzed hydroazidation of 5-ethynyl pyrimidine substrates with $\mathrm{TMSN}_{3}$. AmdU and AmdC were converted to 5'-triphosphates AmdUTP and AmdCTP, and incorporated into DNA-fragments via polymerase-catalyzed reaction during DNA replication and base excision repair. Radiation-mediated prehydrated electrons formed in homogeneous aqueous glassy $(7.5 \mathrm{M} \mathrm{LiCl})$ systems in the absence of oxygen at $77 \mathrm{~K}$ led to site-specific formation of $\pi$-type aminyl radicals $(\mathrm{RNH} \bullet$ ) from AmdU, AmdC, AvdU, and AvdC. The ESR spectral studies and DFT calculations showed RNH• undergo facile conversion to thermodynamically more stable $\sigma$-type iminyl radicals, $\mathrm{R}=\mathrm{N} \bullet$. For AmdU, conversion of $\mathrm{RNH} \bullet$ to $\mathrm{R}=\mathrm{N} \cdot$ was bimolecular involving $\alpha$-azidoalkyl radical as intermediate; however, for $\mathrm{AvdU}, \mathrm{RNH} \bullet$ tautomerized to $\mathrm{R}=\mathrm{N} \bullet$. Our work provides the first evidence for the formation of $\mathrm{RNH} \bullet$ attached to $\mathrm{C} 5$ position of azidopyrimidine 
nucleoside and its facile conversion to $\mathrm{R}=\mathrm{N} \bullet$ under reductive environment. These aminyl and iminyl radicals can generate DNA damage via oxidative pathways. The azidonucleosides were successfully applied as radiosensitizers in EMT6 cancer cells in both hypoxic and normoxic conditions. To explore the generation and reactivity of 2'-deoxyguanosin- $\mathrm{N} 2-\mathrm{yl}$ radical $(\mathrm{dG}(\mathrm{N} 2-\mathrm{H}) \cdot)$ postulated to generate from guanine moiety towards $\bullet \mathrm{OH}, 2$-azido-2'-deoxyinosine $\left(2-\mathrm{N}_{3} \mathrm{dI}\right)$ was prepared by conversion of 2-amino group in protected $\mathrm{dG}$ into 2-azido via diazotization with tert-butyl nitrite followed by displacement with azide and deprotection. The investigation of $\mathrm{dG}(\mathrm{N} 2-\mathrm{H}) \bullet$ generated from 2- $\mathrm{N}_{3} \mathrm{dI}$ and its subsequent reactions using ESR will be discussed.

Cycloaddition between 5-ethynylpyrimidine or 8-ethynylpurine nucleosides and $\mathrm{TMSN}_{3}$ in the presence of $\mathrm{Ag}_{2} \mathrm{CO}_{3}, \mathrm{CuI}$, or $\mathrm{CuSO}_{4} /$ sodium ascorbate provided $\mathrm{N}$ unsubstituted 1,2,3-triazol-4-yl analogues of the parental DNA bases (i.e. 5-TrzdU, 5-TrzdC, 8-TrzdA, and 8-TrzdG). These novel triazolyl nucleosides showed excellent fluorescent properties: 8-TrzdA exhibits the highest quantum yield $\left(\Phi_{\mathrm{F}}\right)$ of $44 \%$ while 8-TrzdG had $\Phi_{\mathrm{F}}$ of $9 \%$. The 5-TrzdU and 5-TrzdC showed a large Stokes shift of $\sim 110 \mathrm{~nm}$. The application of these fluorescent nucleosides to cell imaging and DNA modifications will also be discussed. 


\section{TABLE OF CONTENTS}

CHAPTER

PAGE

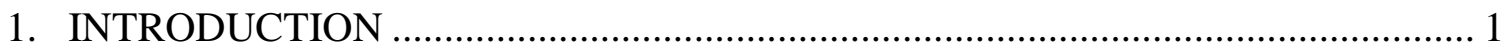

1.1. Anticancer nucleoside/tide analogues .................................................................. 1

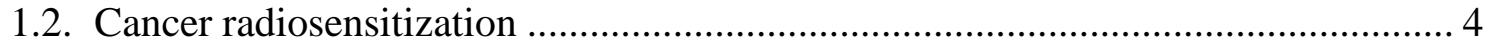

1.2.1. Radiotherapy …………………………….................................... 4

1.2.2. Radiosensitizers (Radiosensitizing agents) ............................................... 5

1.2.3. Hypoxia and hypoxia-selective radiosensitizers ......................................... 8

1.3. Azido-modified nucleoside/tide analogues as biological probe for click reaction 10

1.4. Anticancer and radiosensitizing properties of azido-modified nucleoside/tide

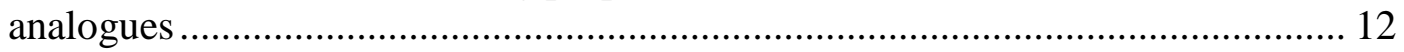

1.4.1. Anticancer activities of azido-modified nucleoside/tide analogues.............. 12

1.4.2. Azido-modified nucleoside/tide analogues as radiosensitizers..................... 13

1.5. Formation of aminyl radicals on prehydrated one-electron attachment to azido-modified nucleosides and their subsequent reactions................................... 14

1.6. Electron-hole transfer in DNA ......................................................................... 17

1.7. Fluorescent nucleosides for investigating nucleic acid structure, location, activation, and interactions ................................................................................ 19

1.8. Concept of prodrugs ..................................................................................... 26

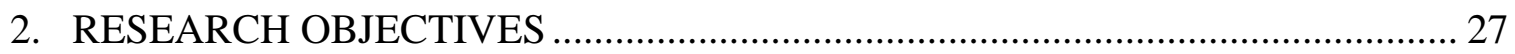

Objective 1: Exploring C5 azido-modified pyrimidine nucleosides as radiosensitizers 27

Objective 2: 2-Azido-2'-deoxyinosine as probe to investigate elusive guanine-based

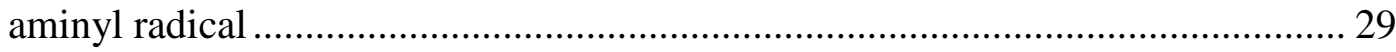

Objective 3: N-unsubstituted 1,2,3-triazol-4-yl nucleosides: Chemistry and

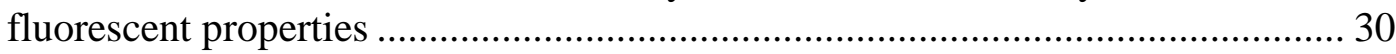

Objective 4: Antiviral and cytostatic evaluation of 5-(1-halo-2-sulfonylvinyl) and 5-(2-furyl)uracil nucleoside prodrugs .................................................................. 31

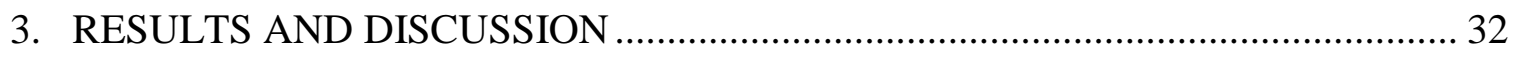

3.1. Pyrimidine nucleosides with azidomethyl and azidovinyl modification at $\mathrm{C} 5$

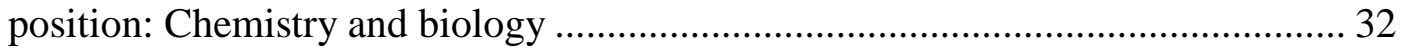

3.1.1. Synthesis of AmdU, AmdC, and their phosphoramidite analogues ............. 32

3.1.2. Synthesis of $\mathrm{AvdU}$ and $\mathrm{AvdC}$ by $\mathrm{Ag}_{2} \mathrm{CO}_{3}$ catalyzed hydroazidation.......... 38

3.1.3. Polymerase-catalyzed incorporation of AmdU 5'-triphosphate and AmdC 5'-triphosphate into DNA .......................................................................... 41

3.1.4. One-electron formation of aminyl radicals from 5-azidomethyl and 5-azidovinyl pyrimidine nucleosides and their subsequent reactions .......... 50

3.1.5. Radiosensitizing effect of 5-azidomethyl and 5-azidovinyl pyrimidine nucleosides in aerobic and hypoxic cells .................................................... 58

3.2. The 2-azido-2'-deoxyinosine as precursor to study elusive guanine-based aminyl

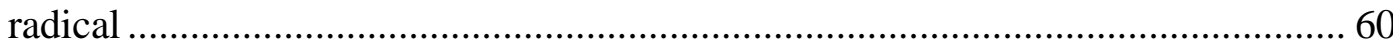

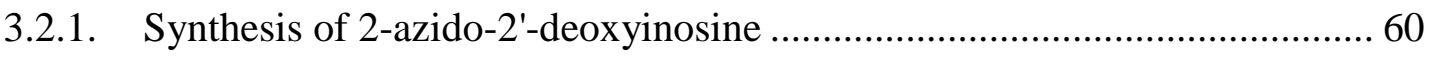


3.2.2. The formation of 2-aminyl radical from 2-azido-2'-deoxyinosine and subsequent radical transfers characterized using electron spin resonance... 62

3.3. Design, synthesis, fluorescent properties, and cell imaging of $1 \mathrm{H}-1,2,3$-triazol-

4-yl analogues of C5 pyrimidine and C8 purine nucleosides. 63

3.3.1. Synthesis of 5-(1H-1,2,3-triazol-4-yl) pyrimidine and 8-(1H-1,2,3-triazol-

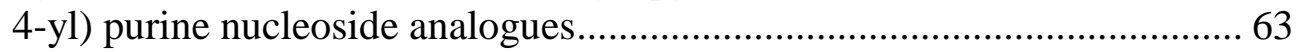

3.3.2. Stabilities of N-unsubstituted triazolyl nucleosides...................................... 71

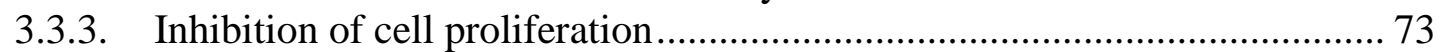

3.3.4. Fluorescent properties of triazolyl nucleosides.......................................... 73

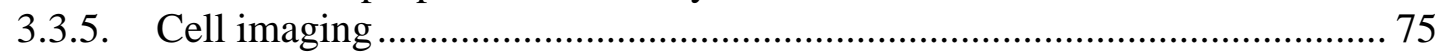

3.3.6. Polymerase-catalyzed incorporation of 8-TrzdA into DNA and fluorescent sensitivities to varied microenvironments................................................ 78

3.4. Antiviral and cytostatic evaluation of 5-(1-halo-2-sulfonylvinyl) and 5-(2-furyl)

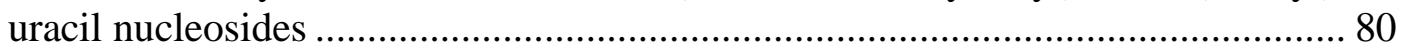

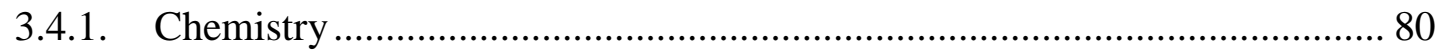

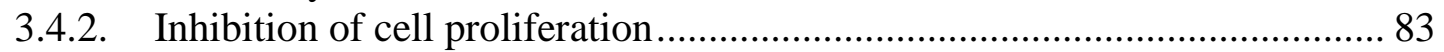

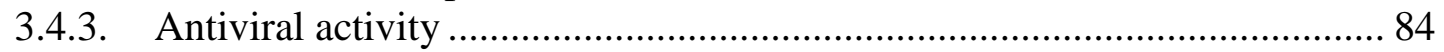

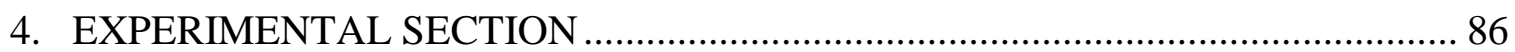

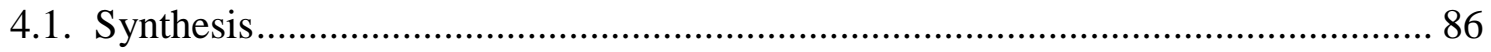

4.1.1. General Procedure …………………………….................................. 86

4.1.2. Synthesis of pyrimidine nucleosides with azidomethyl and azidovinyl modification at C5 position and their 5'-phosphates ..................................... 86

4.1.3. Synthesis of 2-azido-2'-deoxyinosine ........................................................ 97

4.1.4. Preparation of triazolyl nucleoside analogues .......................................... 100

4.1.5. Synthesis of 5-(1-halo-2-sulfonylvinyl) and 5-(2-furyl) uracil nucleoside

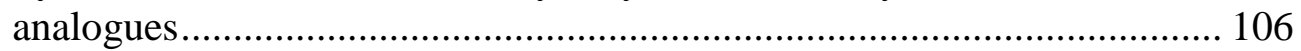

4.2. Polymerase-catalyzed synthesis of azidomethyl-modified DNA........................ 113

4.3. ESR studies of aminyl radical and its conversion to iminyl radical..................... 115

4.4. Radiosensitizing effect of 5-azidomethyl and 5-azidovinyl pyrimidine

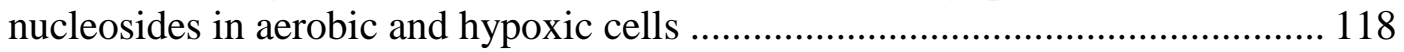

4.5. Fluorescent properties of triazolyl nucleosides .................................................. 119

4.6. Cell microscopy studies of triazoles............................................................... 120

4.6.1. Using primary mouse astrocytes .......................................................... 120

4.6.2. Using mouse pre-adipocytes transfected with pMX-puro-GFP.................. 120

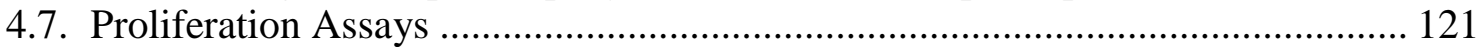

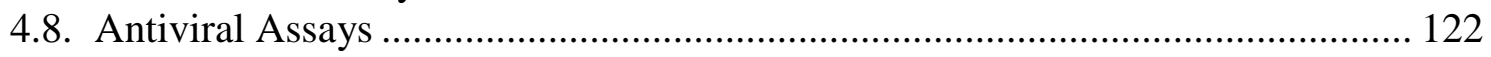

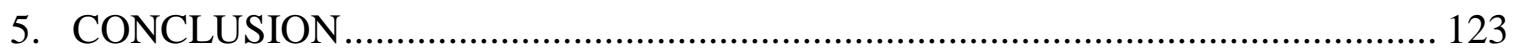

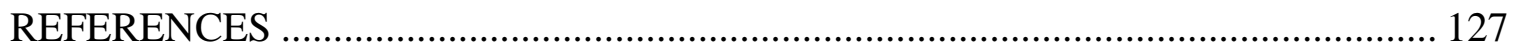

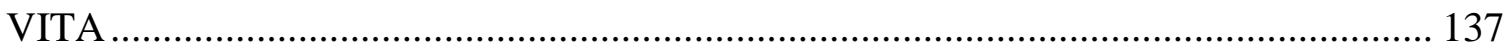




\section{LIST OF TABLES}

TABLE

PAGE

Table 1. Estimated new cases of cancer and deaths in USA, 2018 ............................... 1

Table 2. The approximate number of DNA lesions per Gy per cell induced by ionizing radiation 5

Table 3. Azido-modified biomolecules for labeling and tracking 11

Table 4. Radiosensitizing effect of azidomethyl and azidovinyl pyrimidine nucleosides at $100 \mu \mathrm{M}$ concentration in aerobic and hypoxic EMT6 cells 60

Table 5. Synthesis of 5-(1H-1,2,3-triazol-4-yl) pyrimidine nucleoside analogues........... 64

Table 6. Synthesis of 8-(1H-1,2,3-triazol-4-yl) purine nucleoside analogues.

Table 7. Synthesis of p-substituted phenyl triazoles via cycloaddition catalyzed by

$\mathrm{CuSO}_{4} /$ sodium ascorbate (Method C)

Table 8. Photophysical data for 8-TrzdA (46), 8-TrzdG (47), 5-TrzdC (48), 5-TrzdU

(39), and their analogues

Table 9. Inhibitory effects of 5-(1-substituted-2-tosylvinyl) and 5-(2-heteroaryl)uracil nucleosides on the proliferation of murine leukemia cells (L1210), human T-lymphocyte cells (CEM), and human cervix carcinoma cells (HeLa).

Table 10. Anti-herpesvirus activity of 5-(1-substituted-2-tosylvinyl) and 5-(2-heteroaryl)uracil nucleosides in HEL (human embryonic lung) fibroblasts 85

Table 11. Activity of 5-(5-heptylfur-2-yl)-2'-deoxyuridine against Parainfluenza virus . 85

Table 12. Oligonucleotide Sequences of primers and templates for polymerasecatalyzed synthesis of azido-modified DNA 


\section{LIST OF FIGURES}

FIGURE

PAGE

Figure 1. Approved anticancer nucleoside/tide drugs................................................ 2

Figure 2. General mechanisms of anticancer activities of nucleoside/tide analogues ........ 3

Figure 3. Structures of C5 halogenated pyrimidine bases and nucleosides ..................... 6

Figure 4. Platinum analogues applied clinically as a radiosensitizers ............................. 7

Figure 5. Mechanism of the anticancer activity of cisplatin ........................................... 8

Figure 6 . Radiosensitizers activated by irradiation-induced prehydrated electron........... 10

Figure 7. Azido-modified pyrimidine nucleoside/tide analogues ................................. 12

Figure 8. Fluorescence of the natural purine and pyrimidine bases ............................. 19

Figure 9. Canonical fluorescent nucleobase analogues ........................................... 20

Figure 10. Non-canonical fluorescent nucleobases .............................................. 21

Figure 11. Fluorescent nucleobase serving as powerful tools for investigating the

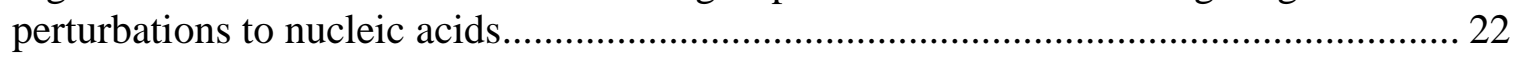

Figure 12. Structure and the fluorescent properties of $N$-substituted triazoles............... 23

Figure 13. A simplified illustration of the prodrug concept ..................................... 26

Figure 14. 2'-Deoxyuridine and 2'-deoxycytidine with azidomethyl and azidovinyl

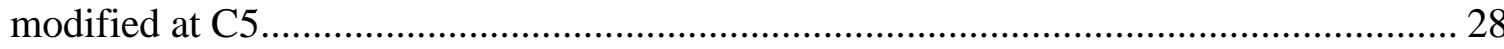

Figure 15. A plausible generation of 2'-deoxyguanosin-N2-yl radical (dG(N2-H)•) from

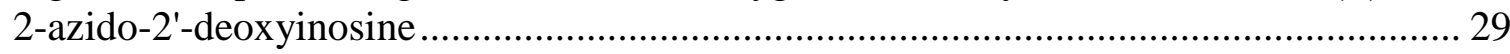

Figure 16. Fluorescent N-unsubstituted 1,2,3-triazol-4-yl nucleosides ......................... 30

Figure 17. 5-(1-Halo-2-sulfonylvinyl) and 5-(2-furyl) uracil nucleosides prodrugs ........ 31

Figure 18. ${ }^{1} \mathrm{H}(\mathrm{A})$ and ${ }^{31} \mathrm{P}(\mathrm{B})$ NMR spectra of AmdU phosphoramidite 60 single diastereomer 
Figure 19. ${ }^{1} \mathrm{H}(\mathrm{A})$ and ${ }^{31} \mathrm{P}(\mathrm{B}) \mathrm{NMR}$ spectra showing decomposition of phosphoramidite

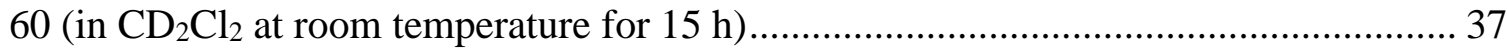

Figure 20. Incorporation of AmdUTP 20 into duplex DNA by pol I and pol $\beta$............ 45

Figure 21. Extension of an incorporated AmdUTP 20 into a duplex DNA by pol I (A-C) and pol $\beta$ (D-E) during DNA leading and lagging strand synthesis and BER. 46

Figure 22. Ligation after incorporation of AmdUTP 20 into duplex DNA during lagging strand maturation and BER.

Figure 23. Incorporation of AmdCTP into duplex DNA by pol $\beta$

Figure 24. ESR spectra of AmdU 18 after radiation-produced prehydrated one-electron attachment at $77 \mathrm{~K}$ and stepwise annealing as well as simulated spectra.....

Figure 25. ESR spectra of AmdC after radiation-produced prehydrated one-electron attachment at $77 \mathrm{~K}$ and stepwise annealing as well as simulated spectra.

Figure 26. ESR spectra of AvdU 21 after radiation-produced prehydrated one-electron attachment at $77 \mathrm{~K}$ and stepwise annealing as well as simulated spectra.....

Figure 27. Radiosensitizing effect of 5-azidomethyl and 5-azidovinyl pyrimidine nucleosides at $100 \mu \mathrm{M}$ concentration on EMT6 cells (A) normoxic, (B) hypoxic conditions

Figure 28. Stability of triazolyl nucleosides at $37{ }^{\circ} \mathrm{C}$ in aqueous solution 72

Figure 29. Normalized fluorescence emission, absorption, and excitation spectra for (A) 8-TrzdA, (B) 8-TrzdG, (C) 5-TrzdC, and (D) 5-TrzdU in $\mathrm{MeOH}$

Figure 30. Fluorescence microscopy images and phase photos of primary mouse astrocytes cells treated with 8-TrzdA, 8-TrzdG, 5-TrzdC, and 5-TrzdU.... 76

Figure 31. Fluorescence microscopy images of fixed pMX-puro-GFP transfected 3T3-L1 mouse pre-adipocytes treated with 8-TrzdA and 5-TrzdU ....

Figure 32. ${ }^{1} \mathrm{H}(\mathrm{A})$ and ${ }^{31} \mathrm{P}(\mathrm{B}) \mathrm{NMR}$ of 8 -TrzdATP 79

Figure 33. Proposed incorporation of 8-TrzdATP into DNA 80

Figure 34. Structures of 5-(1-substituted-2-tosylvinyl) 121-127 and 5-(2-heteroaryl) 128-133 uracil nucleosides tested. 


\section{LIST OF SCHEMES}

SCHEME

PAGE

Scheme 1 . The rationale for the direct/indirect effects of irradiation in radiotherapy........ 5

Scheme 2. The mechanism for the hypoxia-selectivity of tirapazamine ........................ 9

Scheme 3. The mechanism of formation of aminyl radicals on electron attachment to

azido compounds in $\gamma$-irradiated aqueous glassy system. 14

Scheme 4. Formation of aminyl radicals in methyl 2-azido-2-deoxy- $\alpha$-D-

lyxofuranoside and subsequent intramolecular $\mathrm{H}$-atom transfer and ring opening

Scheme 5. Prehydrated one-electron attachment to azido group on 3'-AZT(A) and 3'-AZddG (B): Aminyl radical formation and subsequent reactions 15

Scheme 6. Mechanism of RNA/DNA single-strand breaks upon generation of sugar radicals 16

Scheme 7. Radical reactions of guanine with hydroxyl radicals and subsequent reactions 17

Scheme 8. Strategies for the synthesis of 5-TrzdU 24

Scheme 9. Reported strategies for the synthesis of N-unsubstituted triazoles 25

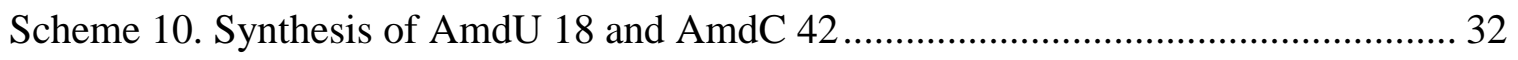

Scheme 11. Attempted one-step synthesis of AmdU............................................... 33

Scheme 12. Synthesis of AmdU phosphoramidite precursor for potential solid-phase preparation of azido-modified DNA fragments 34

Scheme 13. Strategies for the synthesis of 5-(1-azidovinyl)-2'-deoxyuridine (AvdU, 21) and 5-(1-azidovinyl)-2'-deoxycytidine (AvdC, 43). 38

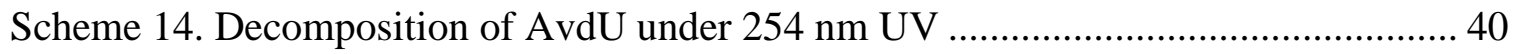

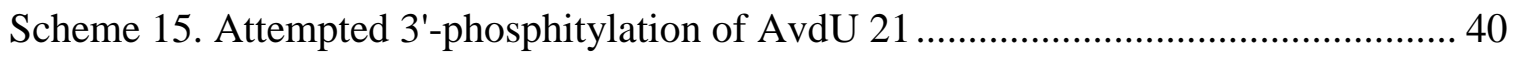

Scheme 16. Preparation of tributylammonium pyrophosphate (TBAPP) ...................... 41

Scheme 17. Synthesis of AmdUMP, AmdUTP, and AmdCTP ................................... 42 
Scheme 18. Attempted synthesis of AvdUTP 76 ............................................................ 43

Scheme 19. Attempted post-synthetic procedure for AvdUTP 76 .................................. 43

Scheme 20. Formation of $\pi$-type aminyl radical from AmdU 18 and its bimolecular conversion to the $\sigma$-type iminyl radical .................................................................... 52

Scheme 21. Tautomerization of the $\pi$-type aminyl radical generated from AvdU 21 to

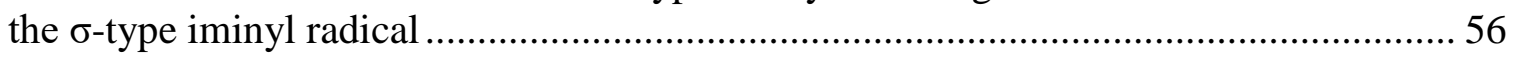

Scheme 22. Attempted one-step synthesis of 2-azido-2'-deoxyinosine ............................... 61

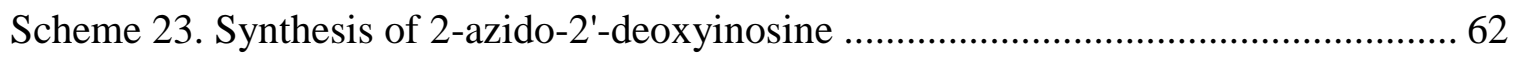

Scheme 24. Synthesis of 4-N-Boc protected 3',5'-di-O-acetyl-5-ethynyl-2'-

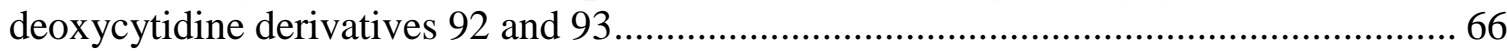

Scheme 25. Synthesis of 3-N-Boc-3',5'-di- $O$-acetyl-5-ethynyl-2'-deoxyuridine $94 \ldots . . . . . .66$

Scheme 26. Attempted conversion of vinylazides to triazoles ......................................... 70

Scheme 27. Mechanism for the formation of $\mathrm{N}$-unsubstituted 1,2,3-triazoles ................. 71

Scheme 28. Synthesis of TrzdATP ………............................................................... 78

Scheme 29. Synthesis of 5-(fur-2-yl)- or 5-(5-heptylfur-2-yl)uracil nucleosides by

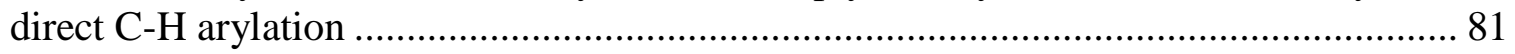

Scheme 30. Synthesis of 5-(fur-2-yl)- or 5-(5-heptylfur-2-yl)uridine and their 5'-esters. 82 


\section{LIST OF ABBREVIATIONS}

\begin{tabular}{|c|c|}
\hline $2-\mathrm{N}_{3} \mathrm{dI}$ & 2-azido-2'-deoxyinosine \\
\hline 3'-AZT & 3'-azido-3'-deoxythymidine \\
\hline 5-TrzdC & 5-(1H-1,2,3-triazol-4-yl)-2'-deoxycytidine \\
\hline 5-TrzdU & 5-(1H-1,2,3-triazol-4-yl)-2'-deoxyuridine \\
\hline 8-TrzdA & 8-(1H-1,2,3-triazol-4-yl)-2'-deoxyadenosine \\
\hline 8-TrzdG & 8-(1H-1,2,3-triazol-4-yl)-2'-deoxyguanosine \\
\hline Ac & acetyl \\
\hline AIBN & azobisisobutyronitrile \\
\hline AmdC & 5-azidomethyl-2'-deoxycytidine \\
\hline AmdCTP & 5-azidomethyl-2'-deoxycytidine 5'-triphosphate \\
\hline AmdU & 5-azidomethyl-2'-deoxyuridine \\
\hline AmdUMP & 5-azidomethyl-2'-deoxyuridine 5'-monophosphate \\
\hline AmdUTP & 5-azidomethyl-2'-deoxyuridine 5'-triphosphate \\
\hline Ar & aromatic (NMR) \\
\hline AvdC & 5-(1-azidovinyl)-2'-deoxycytidine \\
\hline AvdU & 5-(1-azidovinyl)-2'-deoxyuridine \\
\hline$\beta$ & beta \\
\hline BER & base excision repair \\
\hline Boc & tert-buyloxycarbonyl \\
\hline br & broad (NMR) \\
\hline calcd & calculated (HRMS) \\
\hline
\end{tabular}




\begin{tabular}{|c|c|}
\hline CEP & $N, N$-diisopropylamino-2-cyanoethoxyphosphinyl \\
\hline $\mathrm{CEPCl}$ & $N, N$-diisopropylamino-2-cyanoethoxychlorophosphine \\
\hline CuAAC & copper-catalyzed $[3+2]$ azide-alkyne cycloaddition \\
\hline${ }^{\circ} \mathrm{C}$ & degrees Celsius \\
\hline $\mathrm{d}$ & doublet (NMR) \\
\hline DBU & 1,8-diazabicyclo[5.4.0]undec-7-ene \\
\hline DCM & dichloromethane \\
\hline $\mathrm{dG}(\mathrm{N} 2-\mathrm{H}) \bullet$ & 2'-deoxyguanosin-N2-yl radical \\
\hline diAcAmdU & 3',5'-di- $O$-acetyl-5-azidomethyl-2'-deoxyuridine \\
\hline DIAD & diisopropyl azodicarboxylate \\
\hline DIPEA & $N, N$-diisopropylethylamine \\
\hline DMAP & 4-dimethylaminopyridine \\
\hline DMF & $N, N$-dimethylformamide \\
\hline DMSO & dimethylsulfoxide \\
\hline DMT & 4,4'-dimethoxytrityl \\
\hline $\mathrm{DMTCl}$ & 4,4'-dimethoxytrityl chloride \\
\hline DNA & Deoxyribonucleic acid \\
\hline dsDNA & double-stranded DNA \\
\hline $\mathrm{EC}_{50}$ & concentration to reduce virus-induced cytopathogenicity by $50 \%$ \\
\hline EDC & ( $N$-dimethylaminopropyl)- $N^{\prime}$-ethyl-carbodiimide \\
\hline EPR & electron paramagnetic resonance \\
\hline ESR & electron spin resonance \\
\hline $\mathrm{g}$ & $\operatorname{gram}(\mathrm{s})$ \\
\hline
\end{tabular}




\begin{tabular}{|c|c|}
\hline $\mathrm{h}$ & hour(s) \\
\hline HCMV & human cytomegalovirus \\
\hline HEL & human embryonic lung \\
\hline $\mathrm{HFCCs}$ & hyperfine coupling constants \\
\hline HIV & human immunodeficiency virus \\
\hline HPLC & high performance liquid chromatography \\
\hline HRMS & high resolution mass spectroscopy \\
\hline HSV & herpes simplex virus \\
\hline $\mathrm{Hz}$ & hertz \\
\hline $\mathrm{IC}_{50}$ & half maximum inhibitory concentration \\
\hline$J$ & coupling constant in $\mathrm{Hz}$ (NMR) \\
\hline $\mathrm{L}$ & $\operatorname{liter}(\mathrm{s})$ \\
\hline $\mathrm{m}$ & milli; multiplet (NMR) \\
\hline M & moles per liter \\
\hline $\min$ & minute(s) \\
\hline mol & mole(s) \\
\hline MS & mass spectrometry \\
\hline$m / z$ & mass to charge ratio (MS) \\
\hline NAs & nucleoside/tide analogues \\
\hline NBS & $N$-bromosuccinimide \\
\hline NPE & $p$-nitrophenethyl \\
\hline NPEOH & $p$-nitrophenethyl alcohol \\
\hline
\end{tabular}




\begin{tabular}{|c|c|}
\hline ODN & oligodeoxynucleotide \\
\hline$\%$ & percentage \\
\hline $\mathrm{POCl}_{3}$ & phosphoryl chloride \\
\hline pol I & DNA polymerase I \\
\hline $\operatorname{pol} \beta$ & DNA polymerase $\beta$ \\
\hline $\mathrm{PO}(\mathrm{OMe})_{3}$ & trimethyl phosphate \\
\hline q & quartet (NMR) \\
\hline quin & quintet (NMR) \\
\hline$R_{f}$ & retention factor \\
\hline RNA & ribonucleic acid \\
\hline $\mathrm{RP}$ & reverse phase (HPLC) \\
\hline $\mathrm{rt}$ & room temperature \\
\hline s & second(s); singlet (NMR) \\
\hline SPAAC & strain-promoted alkyne-azide cycloadditions \\
\hline ssDNA & single-stranded DNA \\
\hline $\mathrm{t}$ & triplet (NMR) \\
\hline TBA & tributylamine \\
\hline TBAF & tetra- $n$-butylammonium fluoride \\
\hline TBAPP & tributylammonium pyrophosphate \\
\hline TBDMS & tert-butyldimethylsilyl \\
\hline TBDMS-Cl & tert-butyldimethylsilyl \\
\hline$t-\mathrm{Bu}$ & tert-butyl \\
\hline TEA & trimethylamine \\
\hline
\end{tabular}




$\begin{array}{ll}\text { TFA } & \text { trifluoroacetic acid } \\ \text { THF } & \text { tetrahydrofuran } \\ \mathrm{TK}^{+} & \text {wild-type thymidine kinase } \\ \mathrm{TK}^{-} & \text {thymidine kinase--deficient } \\ \mathrm{TLC} & \text { thin layer chromatography } \\ \mathrm{TMS} & \text { trimethylsilyl } \\ \mathrm{t}_{\mathrm{R}} & \text { retention time (HPLC) } \\ \mu & \text { micro } \\ \mathrm{UV} & \text { ultraviolet } \\ \mathrm{VZV} & \text { Varicella Zoster virus }\end{array}$




\section{INTRODUCTION}

\subsection{Anticancer nucleoside/tide analogues}

Globally, cancer is the second most common cause of death and is responsible for one out of every six deaths. The cancerous cells undergo uncontrolled growth, avoid programmed cell death, as well as invade into tissues and form metastases. It was estimated that there will be around 1.7 million new cancer cases and around 600 thousand deaths caused by cancer in USA in 2018 (Table 1). ${ }^{1}$ Cancer, a genetic disease, arises from the changes to genes, which would be inherited from parents, unrepaired errors during cell divisions, or DNA damages from certain environmental exposure (like unhealthy diet, tobacco, etc.)

Table 1. Estimated new cases of cancer and deaths in USA, 2018

\begin{tabular}{|c|c|c|}
\hline & Estimated New Cases & Estimated Deaths \\
\hline All Sites & $1,735,350$ & 609,640 \\
\hline Digestive system & 319,160 & 160,820 \\
\hline Genital system & 286,390 & 62,330 \\
\hline Breast & 268,670 & 41,400 \\
\hline Respiratory system & 253,290 & 158,770 \\
\hline Urinary system & 150,350 & 33,170 \\
\hline Others & 457,490 & 153150 \\
\hline
\end{tabular}

Types of treatments of cancer include surgery, radiotherapy, chemotherapy, immunotherapy, hormone therapy, targeted therapy, and stem cell transplant. As a chemist, I am most interested in the chemotherapy, radiotherapy, and their combination. Among the anticancer drugs, nucleoside/tide analogues (NAs) have been approved by US Food and Drug Administration (FDA) and European Medicines Agency (EMA) and been in clinical use for the treatment of various cancers for about 49 years since the first approved nucleoside analogue, i.e., cytarabine, for the treatment of acute myeloid leukemia. ${ }^{2}$ Some 
currently approved NAs as anticancer agents are summarized in Figure 1, in which the modifications to the natural nucleoside/tides were highlighted in red. The approval of some new nucleoside/tide analogues drugs in the past decade proves that nucleoside/tide analogues still have excellent potential for the cancer treatment.<smiles>Nc1ccn(C2OC3C(O)C(O)C3O2)c(=O)n1</smiles>

Cytarabine (1)

Pfizer, 1969

Acute myeloid leukaemia Acute lymphocytic leukaemia Lymphomas

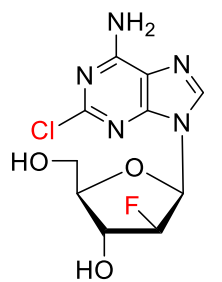

Clofarabine (5)

Genzyme, 2004

Acute lymphocytic leukaemia

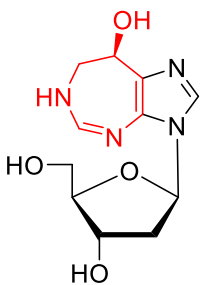

Deoxycoformycin (9) Hospira Inc, 1991 Hairy cell leukemia Chronic lymphocytic leukaemia

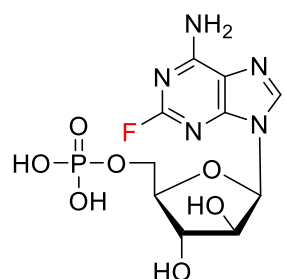

Fludarabine (2)

Genzyme, 1991

Chronic lymphocytic leukaemia

Non-Hodgkins lymphoma

Acute myeloid leukaemia

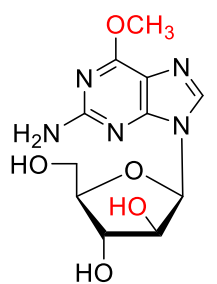

Nelarabine (6)

SmithKline Beecham, 2005

T-cell acute lymphoblastic leukaemia

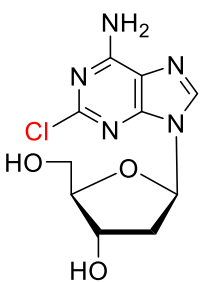

Cladribine (3)

Janssen-Cilag, 1993

Hairy cell leukaemia

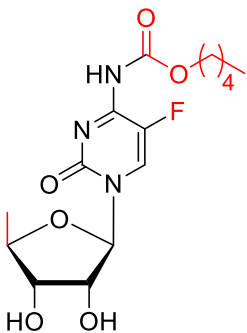

Capecitabine (7) Hoffmann-La Roche, 1998

Metastatic breast cancer Metastatic colorectal cancer

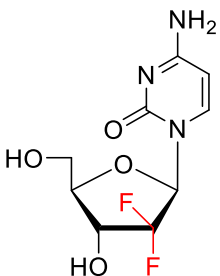

Gemcitabine (4) Eli Lilly and Co, 1996 Non-small lung cancer Pancreatic cancer Bladder cancer Breast cancer

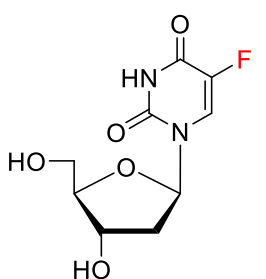

Floxuridine (8) Hospira, 1970 Advanced colon cancer kidney cancer stomach cancer<smiles>Nc1ncn(C2OC(CO)C(O)C2O)c(=O)n1</smiles>

Azacitidine (10)

Celgene, 2004

Myelodysplastic syndrome<smiles>Nc1ncn(C2CC(O)C(CO)O2)c(=O)n1</smiles>

Decitabine (11)

Eisai Inc. and Janssen Cilag, 2006

Myelodysplastic syndrome

acute myeloid leukemia

Figure 1. Approved anticancer nucleoside/tide drugs

The differences between the nucleoside/tide analogues and their counterpart are tiny (Figure 1). Like gemcitabine 4, its difference from its counterpart deoxycytidine is the two fluorine atoms at $\mathrm{C}^{2}$ position instead of two hydrogen atoms. Nevertheless, this tiny 
difference endows the NAs with anticancer properties. ${ }^{3}$ As demonstrated in Figure 2, firstly the NAs are taken up into cells through nucleoside transporters, organic anion/cation transporters, or peptide transporters. ${ }^{2}$ Then, the nucleosides mimic natural nucleosides and are metabolically phosphorylated by nucleoside kinase, nucleoside monophosphate kinase and nucleoside diphosphate kinase. The NAs would interact with and inhibit important proteins. Nucleotides may also be incorporated into DNA/RNA and block the division of cancer cells. The inhibition of important proteins (enzymes) and incorporation into DNA would both lead to the apoptosis of tumor cells. ${ }^{2,3}$

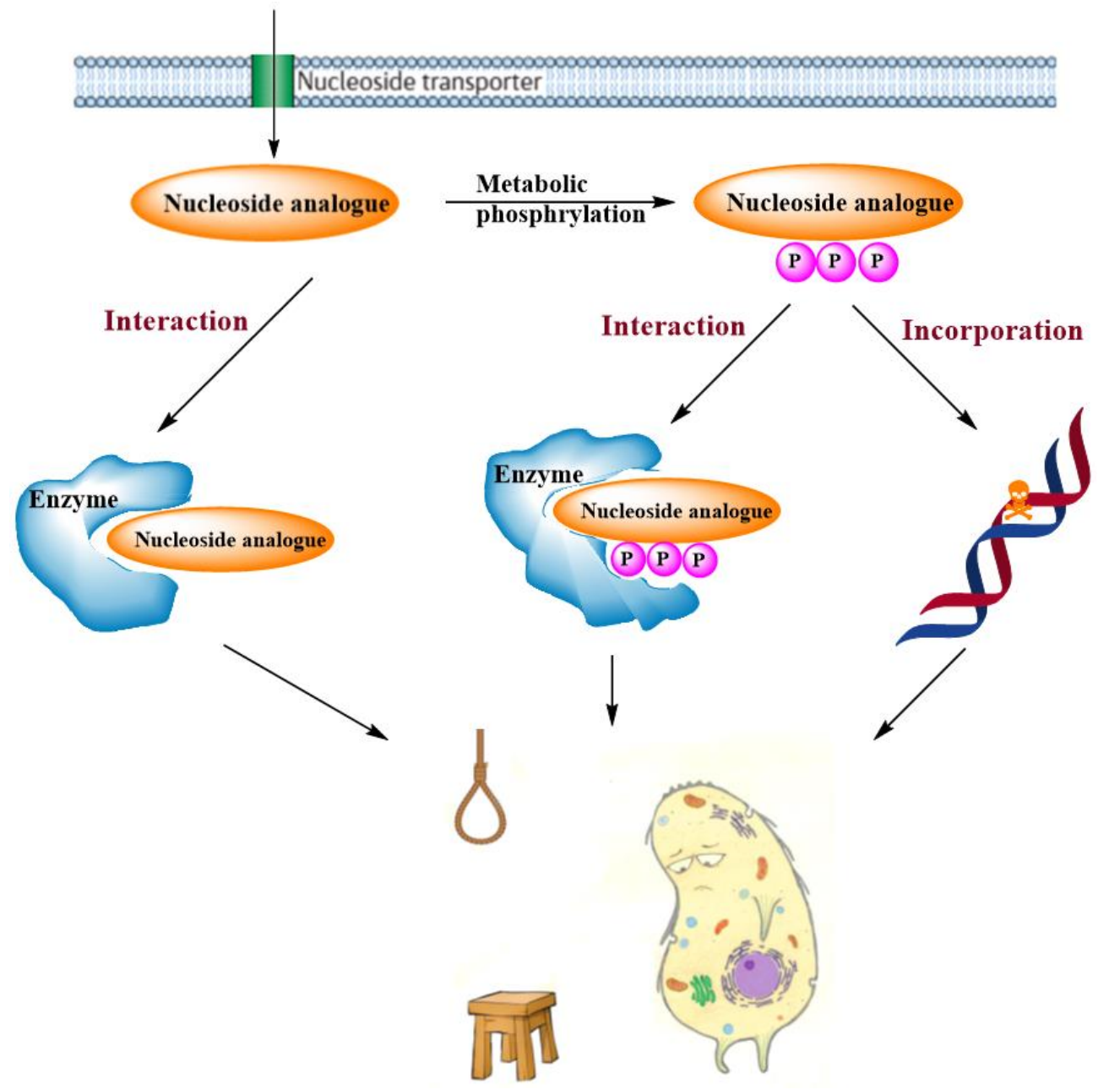

Figure 2. General mechanisms of anticancer activities of nucleoside/tide analogues 


\subsection{Cancer radiosensitization}

\subsubsection{Radiotherapy}

Radiotherapy and its combination with other treatments (e.g., surgery, chemotherapy) are applied for the treatment of most common types of cancers to cure or control tumors., Even though new types of cancer treatment with better selectivity against cancerous cells, ${ }^{6}$ like immunotherapy and targeted therapy, are emerging, almost half of all the cancer patients are still treated with radiotherapy. ${ }^{7}$

The mechanism of ionizing radiation during the radiotherapy is illustrated in Scheme 1. The interaction of ionizing radiation with materials inside cancerous cells includes direct and indirect effects. ${ }^{7,8}$ Water in the cells undergo radiolysis to give ionized water cation $\left(\mathrm{H}_{2} \mathrm{O} \bullet^{+}\right)$and electrons. The water cation reacts with another water to yield reactive oxygen species (ROS) hydroxyl radicals $\left(\mathrm{HO} \bullet\right.$, which is related to oxidative DNA damage. ${ }^{9}$ The electron generated from water radiolysis is solvated to offer prehydrated electron $\mathrm{e}_{\mathrm{aq}}^{-}$, which further interact with oxygen to give superoxide $\left(\mathrm{O}_{2} \bullet^{-}\right)$or with hydronium $\left(\mathrm{H}_{3} \mathrm{O}^{+}\right)$to give hydrogen atom $(\mathrm{H} \bullet)$. The electrons are related to the reductive DNA damage. Approximately, the electrons with low energy are responsible for $67 \%$ of DNA damage, while the highly reactive $\mathrm{HO} \bullet$ is responsible for the remaining $33 \% .{ }^{10}$ This DNA damage caused by the radicals generated from the radiolysis of water is named as indirect effect (Scheme 1). On the other hand, the ionizing radiation would also directly ionize the base or backbones of DNA fragments, which is named as direct effect.

DNA damage from the ionizing radiation includes damage to base or sugar, single/double-strand breaks, cross-linking of DNA and other biomolecules like DNA or 
proteins, and so on. The DNA lesion frequency is revealed in Table $2 .{ }^{11}$ The DNA damage results in the death of cancerous cells. ${ }^{12-14}$

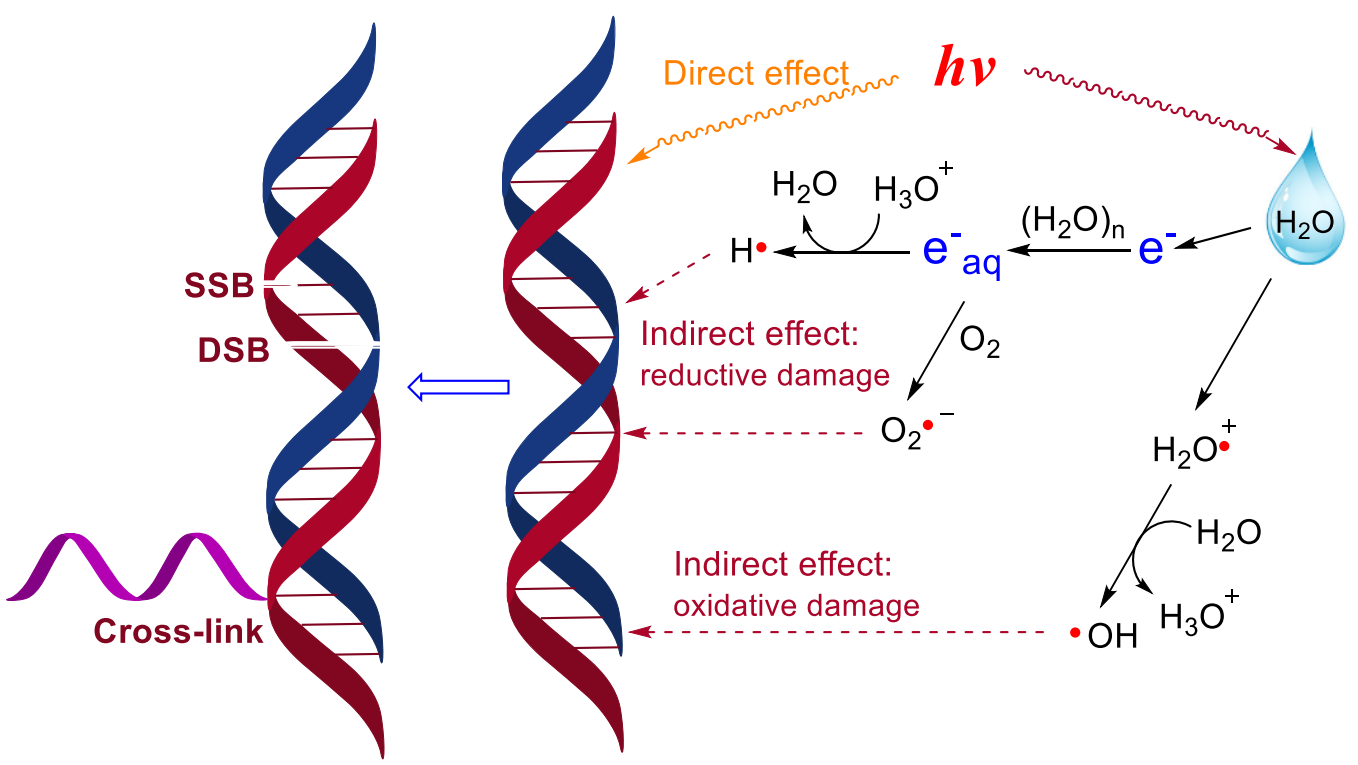

Scheme 1. The rationale for the direct/indirect effects of irradiation in radiotherapy

Table 2. The approximate number of DNA lesions per Gy per cell induced by ionizing radiation

\begin{tabular}{|l|l|}
\hline DNA damage induced by ionizing radiation & Approximate number/Gy in one cell \\
\hline DNA DSB (double-strand breaks) & 40 \\
\hline DNA SSB (single-strand breaks) & 1000 \\
\hline DNA-DNA cross-links & 30 \\
\hline DNA-protein cross-links & 150 \\
\hline Damage at base & 2,000 \\
\hline Damage at sugar-phosphate backbone & 1,000 \\
\hline
\end{tabular}

\subsubsection{Radiosensitizers (Radiosensitizing agents)}

A high dose of ionizing radiation leads to both acute and cumulative side effects, ${ }^{15}$ thus it is significant to enhance the radiosensitiveness of tumor cells during radiotherapy to lower the dose of radiation required for same surviving fraction. Radiosensitizers have been developed to enhance the sensitiveness of cancerous cells to radiotherapy. ${ }^{3,16}$ Radiotherapy 
employing radiosensitizers is used for most cancer patients and improves the survival compared to radiotherapy alone. ${ }^{3}$ Radiosensitizers include small molecules, macromolecules, and nanomaterials. ${ }^{8}$ The most conventional radiosensitizers include halogenated nucleosides, gemcitabine, and platinum analogues. ${ }^{3,7}$

The C5 halogenated pyrimidine bases and nucleosides are well-investigated as radiosensitizers in cancer radiotherapy., ${ }^{3,7,17,18}$ 5-Bromo-2'-deoxyuridine (5-BrdU, 12, Figure 3) has been recognized as a radiosensitizing agent with potential clinical applications. ${ }^{17}$ However, owing to toxicity of 5 -BrdU, it did not show any increase in patient survival during phase III clinical trials and the trials were called off. ${ }^{19}$ On the other hand, 5-fluorouracil (5-FU, 13, Figure 3) via protracted venous infusion has become a typical treatment of rectal ${ }^{20}$ and pancreatic cancers. ${ }^{21}$ The radiosensitizing effect of 5fluorouracil is believed to derive from its inhibition of thymidylate synthase, which stops the DNA replication. The complex protracted venous infusion lasting for one to two months may lead to infection and/or thrombosis. As a consequence, capecitabine (7, Xeloda, Figure 1) was developed as a prodrug suitable for oral taken. ${ }^{22}$ Capecitabine is used for the treatment of colorectal cancer, breast cancer, oesophageal cancer, and gastric cancer. $^{23}$

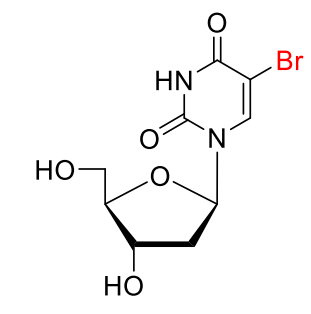

5-Bromo-2'-deoxyuridine (5-BrdU, 12)

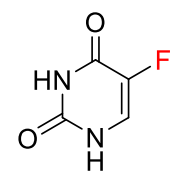

5-Fluorouracil $(5-\mathrm{FU}, 13)$

Figure 3. Structures of C5 halogenated pyrimidine bases and nucleosides 
Gemcitabine (4, Figure 1) was explored as radiosensitizer to enhance the sensitiveness of human colon carcinoma cells to radiation. ${ }^{24}$ The radiosensitizing effect of gemcitabine is a result of inhibition of ribonucleotide reductase, which depletes the dATP pools. The cells progressing into $\mathrm{S}$ phase suffer from the depletion of dATP and the consequent misincorporation and misrepair of wrong bases, which generate DNA lesions that lead to the cell apoptosis. ${ }^{3}$

In addition to the nucleoside-based radiosensitizers, there are various non-nucleosidesbased radiosensitizing agents, among which platinum analogues have been applied clinically as a radiosensitizers to treat various cancerous tumors. ${ }^{3}$<smiles>N[Pb](N)(Cl)Cl</smiles>

Cisplatin (14)

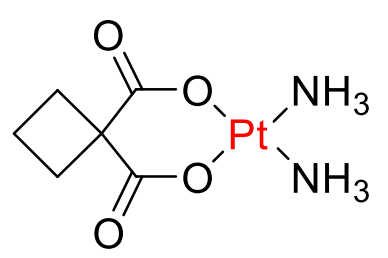

Carboplatin (15)

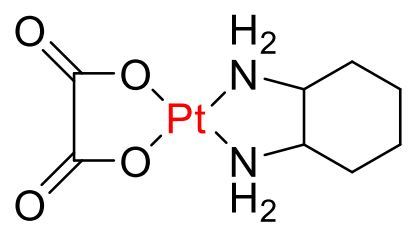

Oxaliplatin (16)

Figure 4. Platinum analogues applied clinically as a radiosensitizers

Cisplatin analogues (Figure 4) are well known to interfere with DNA replication by forming 1,2-intrastrand crosslinks with two adjacent guanine/guanine (90\%) along DNA fragment as well as with adjacent guanine and adenine, which induces apoptosis of fast proliferating cells (Figure 5). ${ }^{25}$ The mechanisms of the radiosensitizing effect of cisplatin analogues include formation of more toxic platinum intermediates from the interaction between the cisplatin and free radicals induced by irradiation (Irradiated hypoxic solutions of cisplatin were more toxic than unirradiated solutions), ${ }^{26}$ enhanced uptake of carboplatin into cells induced by irradiation, ${ }^{27}$ and repression of DNA repair. ${ }^{28}$ 


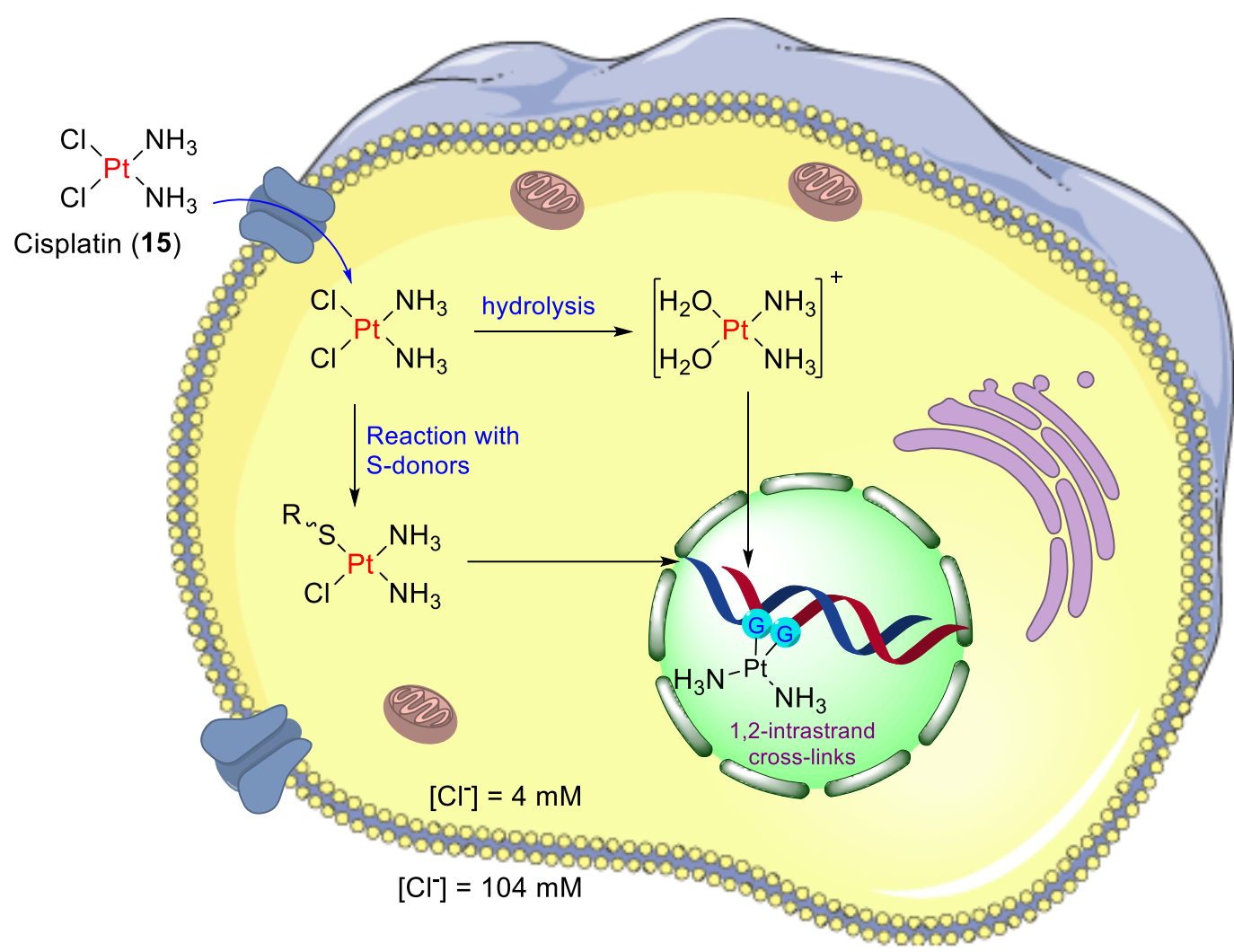

Figure 5. Mechanism of the anticancer activity of cisplatin

\subsubsection{Hypoxia and hypoxia-selective radiosensitizers}

Tumor cells replicate quickly and require nutrients from blood vessels. As solid tumors grow, angiogenesis allows the generation of new vascular beds to support the cancerous cells. ${ }^{29}$ Nevertheless, the morbid tumor vascular bed formed during the angiogenesis is twisting and irregular and thus lacks the ability to deliver blood to every part of the tumors. As a consequence, solid tumors encompass regions with transient and chronic low concentration of oxygen, which is named as transient hypoxia and chronic hypoxia, respectively. ${ }^{30-32}$

The partial pressure of oxygen $\left(\mathrm{pO}_{2}\right)$ in human tumors is less than $5 \mathrm{mmHg}$, while the $\mathrm{pO}_{2}$ in the surrounding normal cells is higher than $30 \mathrm{mmHg}$. As discussed in section 1.2.1 
and shown in Scheme 1, oxygen is essential for the sensitiveness of cancerous cells in radiotherapy. The tumor cells under hypoxic microenvironment are resistant to radiotherapy and chemotherapy. ${ }^{30}$ On the other hand, the existence of hypoxia, unique features of solid tumors that is not found in normal cells, offers an chance for tumorselective therapy.

One of the strategies exploiting the tumor hypoxia is to design prodrugs activated by hypoxia. Tirapazamine (17, TPZ, Scheme 2), the first developed specific cytotoxin for hypoxia, was demonstrated for its antitumor activity. ${ }^{33}$ The mechanism for the hypoxiaselectivity of TPZ 17 was shown in Scheme $2 .{ }^{30}$ TPZ 17 undergoes one-electron reduction by reductases or aquated electron from radiolysis of water to give tirapazamine radicals (TPZ•). TPZ• further decays to hydroxyl radical $(\mathrm{HO} \bullet)$ or benzotriazinyl radical $(\mathrm{BTZ} \bullet)$, which poisons the topoisomerase II and leads to DNA double-strand breaks. ${ }^{33}$

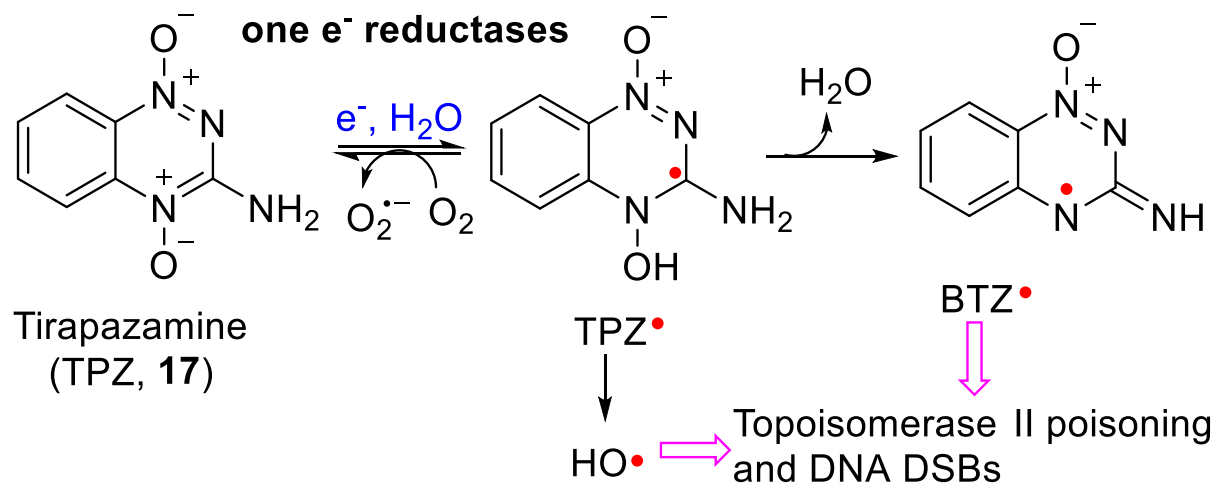

Scheme 2. The mechanism for the hypoxia-selectivity of tirapazamine

However, the cells under hypoxic condition usually lack reductase enzymes and cofactors. Thus, developing radiosensitizers activated by irradiation-induced prehydrated electron is more attractive than activation by enzymes. Cobalt(III) complexes, ${ }^{34}$ nitrobenzyl quaternary ammonium salts, ${ }^{35}$ and oxypropyl-substituted 5-fluorouracil 
derivatives ${ }^{36}$ (Figure 6) were demonstrated to be capably triggered by ionizing radiation under hypoxic conditions. Nevertheless, none of the compounds has yet shown undisputed radiosensitizations in hypoxic tumors. As a result, more effort and research should be dedicated to the development of new hypoxia-selective radiosensitizers activated by irradiation.

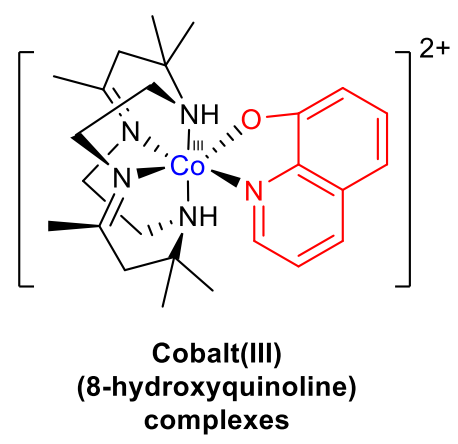

Wilson, W. R. and coworkers, Radiat. Res. 2004, 162, 315-325.

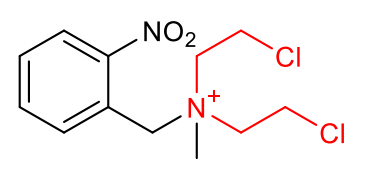

Nitrobenzyl quaternary ammonium salts

Wilson, W. R. and coworkers, Radiat. Res. 2002, 158, 753-762.<smiles>CC(=O)Cn1cc(F)c(=O)[nH]c1=O</smiles>

Oxypropyl-substituted 5-fluorouracil derivatives

Nishimoto, S.-i. and coworkers, Jpn. J. Cancer Res. 2000, 91, 433-438.

Figure 6. Radiosensitizers activated by irradiation-induced prehydrated electron

\subsection{Azido-modified nucleoside/tide analogues as biological probe for click reaction}

Because of the various novel properties, azido modified small molecules and biomacromolecules have been designed and investigated for a variety of applications including serving as biological probes for cycloaddition click reaction for bioconjugation, anticancer and antiviral agents, and potential radiosensitizers. ${ }^{37-42}$

The absence of azides in almost all creatures and their inert reactivity with water, amines, oxidant, or other functional groups abundant in biological systems endow the azides with exquisite bioorthogonality. The bioorthogonal ligations employing azides include Staudinger ligation of azides with phosphines as wells as click reactions between azides and strain-promoted alkyne or terminal alkyne catalyzed by copper (Table 3$).{ }^{43}$ 
Table 3. Azido-modified biomolecules for labeling and tracking

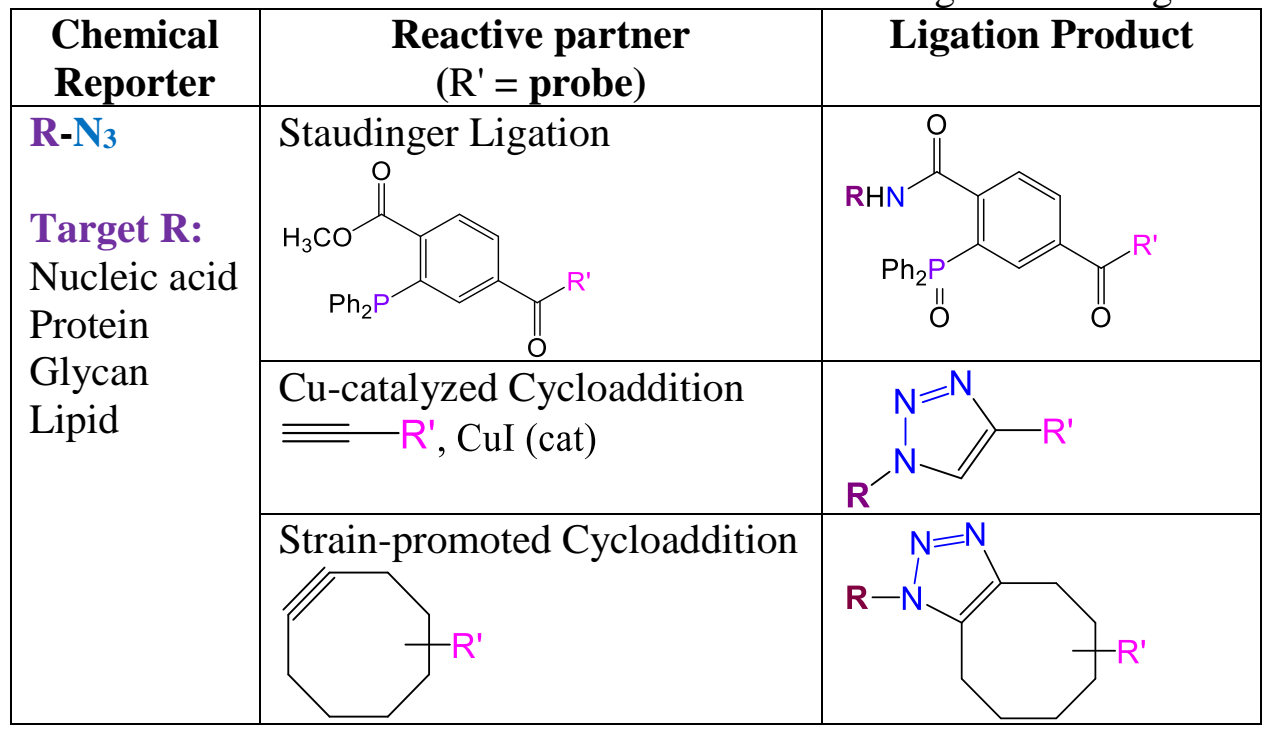

In 2002, Sharpless and Meldal brought the Huisgen [3+2] cycloaddition between azide and alkyne into focus by employing copper as a catalyst. ${ }^{44,45}$ The copper-catalyzed [3+2] azide-alkyne cycloaddition (CuAAC) could proceed smoothly under mild reaction condition in aqueous media to form 1,2,3-triazoles, and thus is biocompatible. The toxic copper limits the application of CuAAC in living cells and animals. The strain-promoted azide-alkyne cycloaddition (SPAAC) "click" reactions developed by Bertozzi in $2004^{46}$ expanded the application of [3+2] azide-alkyne cycloaddition in covalent interaction of biomolecule/biomolecule and biomolecule/probe in living systems. Azide as a reactive reporter introduced into a target biomolecule like nucleic acid, protein, glycans, and lipids reacts with probe or other biomolecules modified with terminal alkyne/cyclooctyne via CuAAC or SPAAC to label and track biomolecules. ${ }^{43,47} \mathrm{CuAAC}$ and SPAAC are broadly used for bioorthogonal conjugation, new drug discovery, and proteomic profiling. ${ }^{48-51}$

The chemically stable 5-azidomethyl-2'-deoxyuridine (AmdU, 18, Figure 7), as opposed to the highly photolyzable 5-azido-2'-deoxyuridine (5-AdU), ${ }^{52}$ serves as a 
substrate for the synthesis of clickable triazoles. ${ }^{40,53-57}$ AmdU $\mathbf{1 8}$ was able to be metabolically incorporated into DNA in living cells for click labeling of DNA. ${ }^{40}$

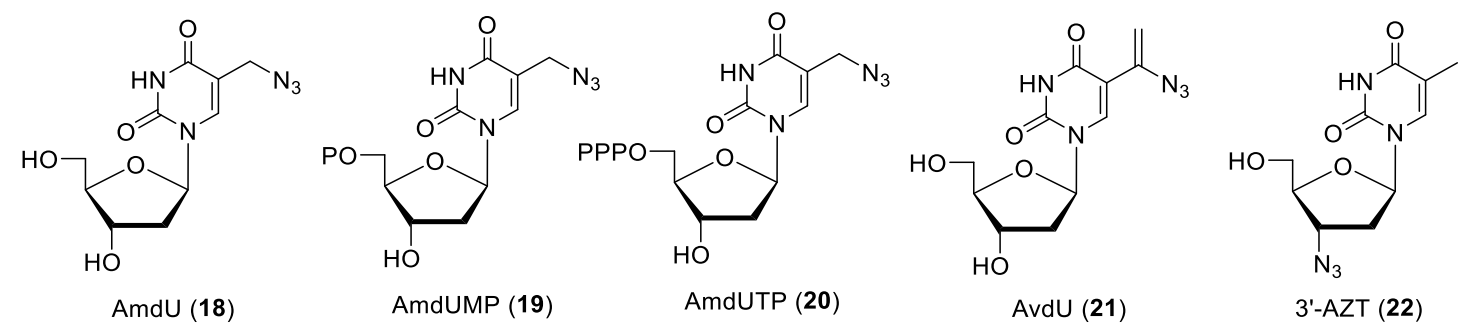

Figure 7. Azido-modified pyrimidine nucleoside/tide analogues

\subsection{Anticancer and radiosensitizing properties of azido-modified nucleoside/tide analogues}

\subsubsection{Anticancer activities of azido-modified nucleoside/tide analogues}

Azido-modified pyrimidine nucleoside analogues were reported to exhibit anticancer and antiviral activities. The 3'-azido-3'-deoxythymidine (3'-AZT, 22, Figure 7), first prepared by Horwitz in $1964,{ }^{58}$ has been widely investigated for its anticancer and antiviral activities. The 3'-AZT has been commonly used to treat HIV positive patients benefit from its antihuman telomerase reverse transcriptase activity ${ }^{59}$ and also used as a radiosensitizer for tumors of patients also carrying HIV. ${ }^{60}$ The mechanism of the formation of reactive aminyl radical responsible for the radiosensitivity of 3'-AZT will be detailed in section 1.5.

The AmdU 18 and its monophosphate (AmdUMP 19, Figure 7) ${ }^{61,62}$ inhibited thymidylate synthetase activity derived from calf thymus and Ehrlich ascites tumor. ${ }^{61,63}$ They also inhibited thymidine kinase activity ${ }^{64}$ and consequently affected the growth of murine sarcoma 180 and L1210, ${ }^{41,62}$ and the replication of herpes simplex virus type 1 (HSV-1). ${ }^{41,65,66}$ The AmdU 5'-triphosphate (AmdUTP, 20) was found to be a substrate for DNA polymerases and PCR amplification. ${ }^{57}$ Moreover, the clickable triazole adducts of 
5-AdU ${ }^{67}$ were incorporated into oligodeoxynucleotides; but, an attempt to synthesize the peptide-siRNA covalent conjugates from AmdU-derived triazole was unsuccessful. ${ }^{53}$

The 5-(1-azidovinyl)-2'-deoxyuridine (AvdU, 21) proved inhibitory to the replication of HSV-1 and VZV and became highly cytostatic against HSV-1 and HSV-2 TK gene transfected FM3A tumor cells; the cytostatic effect was enhanced by 5 -fold after short exposure to UV irradiation at $254 \mathrm{~nm} .{ }^{68} \mathrm{AvdU} 21$ showed also anti-mycobacterial activities in submicromolar range. ${ }^{69}$

\subsubsection{Azido-modified nucleoside/tide analogues as radiosensitizers}

The 3'-AZT 22 (Figure 7) has been employed as a radiation sensitizer in radiotherapy of tumors for HIV positive patients. ${ }^{60}$ Zhou and his colleagues reported their results on the investigation of the effects of 3'-AZT 22 combining with $\gamma$-radiation on telomere length, activity of telomerase, DNA single/double-strand breaks, and of its radiosensitizing effects in human malignant glioma cell line U251. ${ }^{70}$ The 3 '-AZT 22 suppressed the telomerase activity and slowed down DNA strand breaks repair. The changes in radiosensitivity were quantified by the sensitization enhancement ratio (SER). The 3'-AZT $22(800 \mu \mathrm{M})$ enhanced the radiosensitivity at 2 Gy $\gamma$-radiation of U251 cells with SER of 1.37 . The 3'-AZT 22 also increased the radiosensitivity of Hep- 2 cells. ${ }^{71}$

In addition to the radiosensitizing effect, 3'-AZT 22 was also reported to enhance cytotoxicity of the anticancer drugs in the irradiated cancerous cells. The 3'-AZT 22 was able to enhance the radiosensitizing effects of (E)-2'-deoxy-(fluoromethylene)cytidine (FMdC) on human colon cancer cells. ${ }^{72}$ Various concentration $(25 \mu \mathrm{M}$ to $100 \mu \mathrm{M})$ of $\mathbf{2 2}$ was added immediately before irradiation of the cancerous cells treated with FMdC. The combination of FMdC and 3'AZT 22 gave SER ranging from 1.25 to 2.26. 


\subsection{Formation of aminyl radicals on prehydrated one-electron attachment to azido-modified nucleosides and their subsequent reactions}

The formation of neutral and reactive aminyl radicals on prehydrated one-electron attachment to azido-modified nucleosides in $\gamma$-irradiated aqueous glassy $(7.5 \mathrm{M} \mathrm{LiCl})$ systems was characterized using electron spin resonance spectroscopy (ESR). ${ }^{42,73}$ $\gamma$-Irradiated chloride ion in glassy system at $77 \mathrm{~K}$ produced chlorine radical and electron (Scheme 3), which was solvated to yield aquated electron. Electron attachment to the azido group led to azide anion radical intermediate $\mathbf{I}\left(\mathrm{RN}_{3}{ }^{{ }^{-}}\right)$, which formed nitrene anion radical intermediate II $\left(\mathrm{RN}^{\cdot}{ }^{-}\right)$after the loss of $\mathrm{N}_{2}$. Subsequently, rapid protonation of $\mathrm{RN}^{{ }^{-}}$- from the solvent led to $\mathrm{RNH} \bullet$ formation.

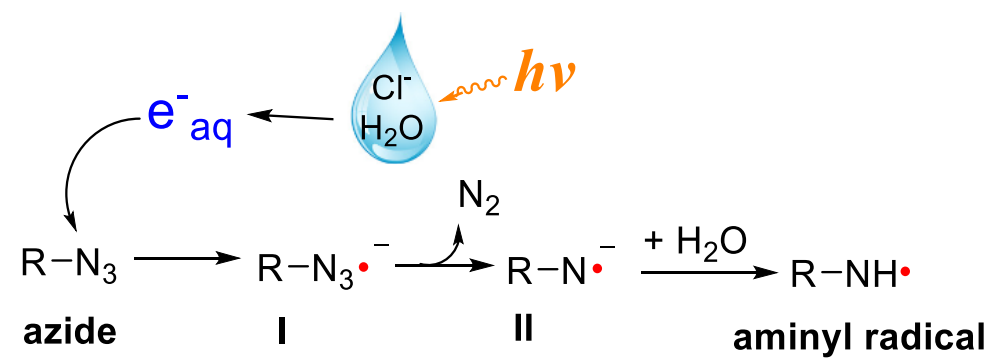

Scheme 3. The mechanism of formation of aminyl radicals on electron attachment to azido compounds in $\gamma$-irradiated aqueous glassy system

Radical at C5' position (C5'•) was reported to cause DNA strand breaks and associate unaltered base release. ${ }^{9}$ To prove that the ring-opened $\mathrm{C} 4{ }^{\prime} \bullet$ is an intermediate in mechanism of C5'• mediated unaltered base release, methyl 2-azido-2-deoxy- $\alpha$-D-lyxofuranoside (23, Scheme 4) as well as other azido-modified pentofuranoses were prepared and used for the ESR study (Scheme 4). ${ }^{73}$ In methyl 2-azido-2-deoxy- $\alpha$-D-lyxofuranoside, the aminyl radical (I, Scheme 4) at the 2 position undergoes intramolecular $\mathrm{H}$-abstraction to give $\mathrm{C5}^{\prime} \bullet$ (II), which further undergoes intramolecular conversion to the ring-opened C4'•(III). 


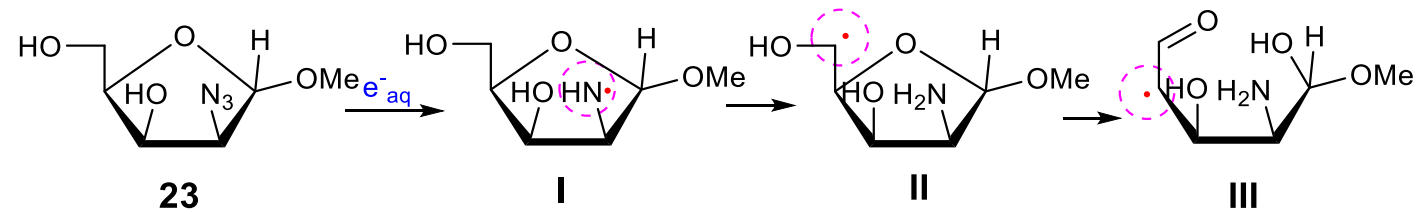

Scheme 4. Formation of aminyl radicals in methyl 2-azido-2-deoxy- $\alpha$-D-lyxofuranoside and subsequent intramolecular $\mathrm{H}$-atom transfer and ring opening

In 3'-AZT 22, the aminyl radical at the C3'-site of sugar moiety underwent a bimolecular $\mathrm{H}$-atom abstraction either from the methyl group at $\mathrm{C} 5$ to give $\mathrm{dUCH}_{2} \bullet$, from the $\mathrm{C}^{\prime}$-atom to give $\mathrm{C}^{\prime} \bullet$, or from the $\mathrm{C} 3^{\prime}$-atom to give $\mathrm{C} 3^{\prime} \bullet$ of a proximate $3^{\prime}$-AZT (Scheme 5A). ${ }^{42}$ On the other hand, the aminyl radical at the C3' site from 3'-azido-2',3'dideoxyguanosine (3'-AZddG, 24) resulted in one-electron oxidation of guanine base to give $\mathrm{G}(\mathrm{N} 1-\mathrm{H}) \bullet($ Scheme $5 \mathrm{~B})$. The radicals formed at sugar are known to lead to strand breakage in RNA (Scheme 6A) and DNA (Scheme 6B), and further affects the apoptosis of cancer cells. ${ }^{9,17}$ The structural DNA damage, like formamidopyrimidines (e.g., FapyG) and 8-oxopurines (e.g., 8-oxoG), formed from the guaninyl radicals are cytotoxic. ${ }^{74}$

(A)
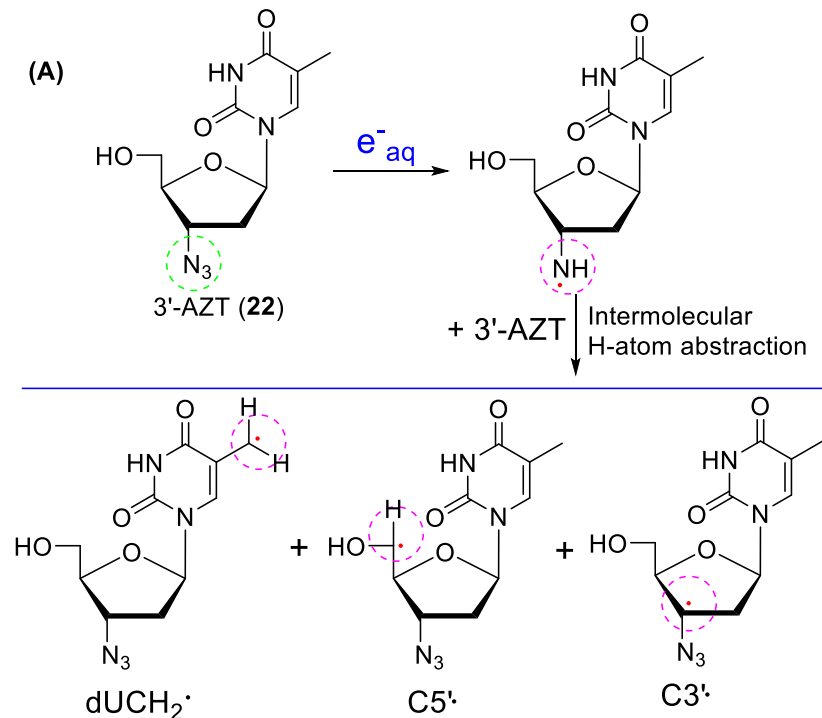

$(55 \%)$

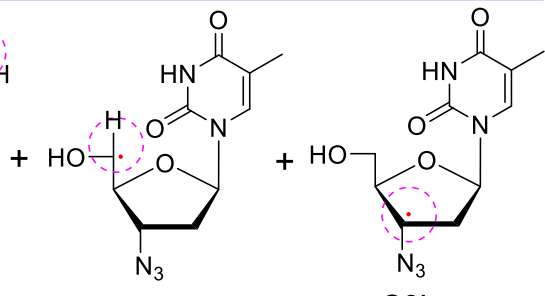

$(35 \%)$
C3'.

$(10 \%)$
(B)

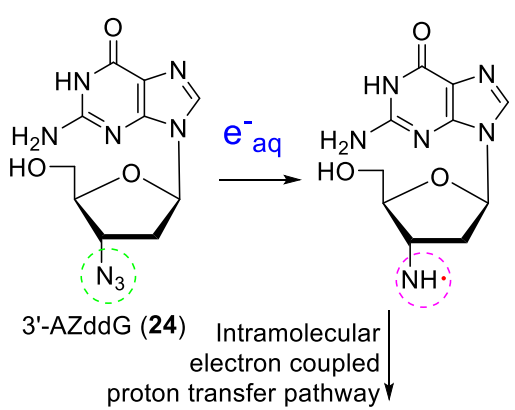

Scheme 5. Prehydrated one-electron attachment to azido group on 3'-AZT(A) and 3'-AZddG (B): Aminyl radical formation and subsequent reactions 
(A) RNA breakage

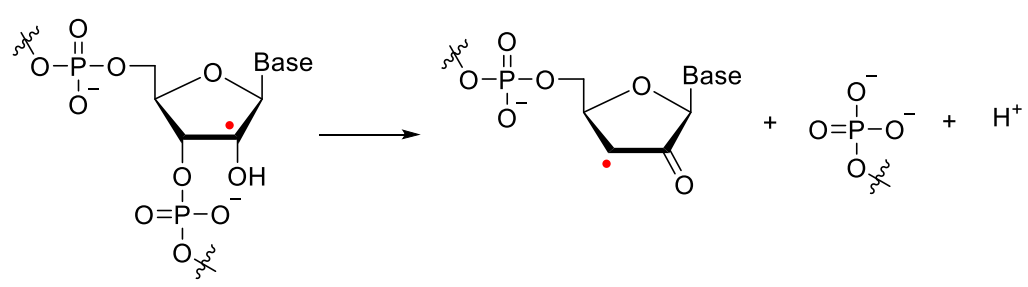

(B) DNA breakage

i. C1'-radical

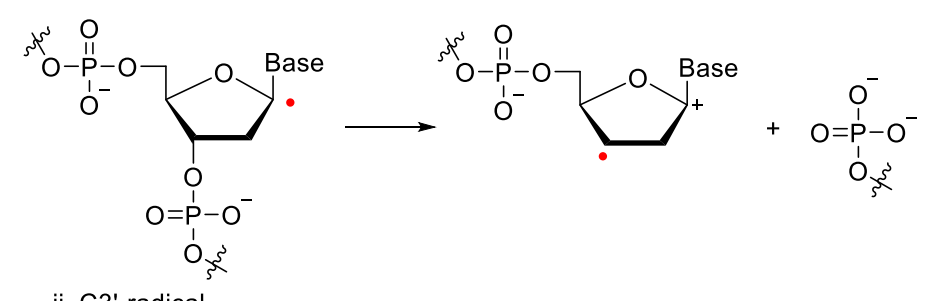

ii. C3'-radical

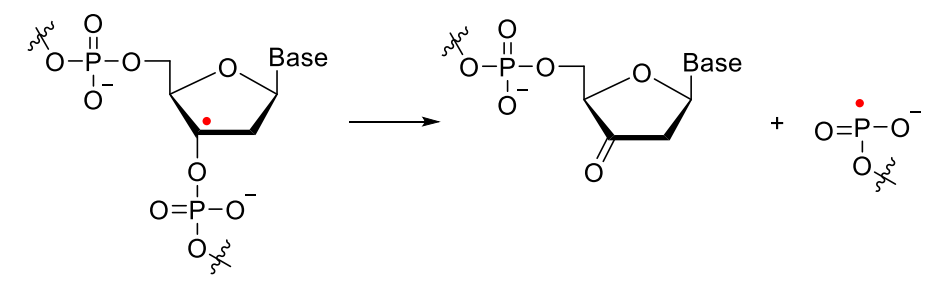

iii. C5'-radical

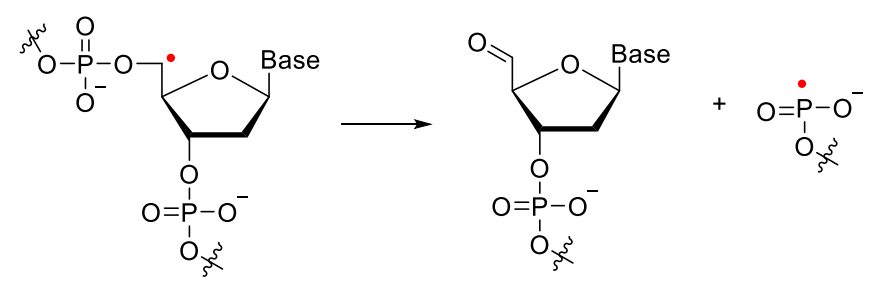

Scheme 6. Mechanism of RNA/DNA single-strand breaks upon generation of sugar radicals

The azido group in 3 -AZT 22 rather than the thymine moiety was proved to be the predominant site of electron capture, as a result of the higher electron affinity of the azido group in $\mathbf{2 2}$ than the most electron affinic DNA base, thymine. ${ }^{42}$ The formation of the reactive aminyl radicals in $\gamma$-irradiated system and their subsequent reactions provides a plausible mechanism for the radiosensitizing effects of $3^{\prime}-\mathrm{AZT}^{60,70,72,75}$ and meanwhile suggest that the azido-modified nucleoside/tide analogues are possible to be explored as potential radiosensitizing agents in hypoxia (bioreductive) microenvironments. 


\subsection{Electron-hole transfer in DNA}

As discussed at section 1.2.1 (Scheme 1), hydroxyl radical HO• generated from ionizing irradiation causes DNA damage by reaction with guanine residues having the lowest oxidation potential. ${ }^{76,77}$ Deeper understanding of the pathways for $\gamma$-radiolysis damage to nucleic acids and how cancerous cells respond to radiotherapy would help the design of new treatments and improve current-existing therapies. Thus, it is essential to understand reactions of guanine with the reactive radicals, like hydroxyl radical during the radiolysis, and the subsequent reactions.

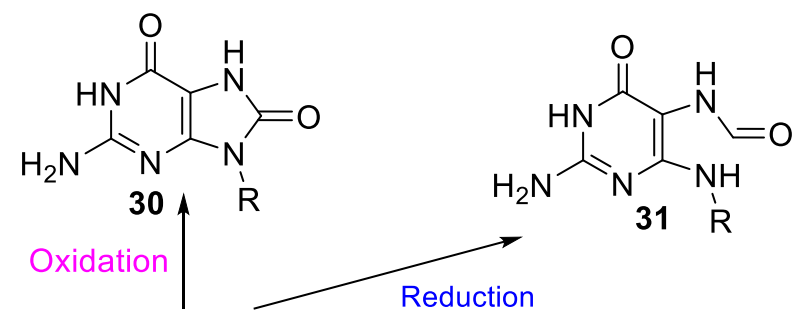<smiles>[R]N1c2nc(N)[nH]c(=O)c2N[C@]1(O)[C@H](C)O</smiles>

29<smiles>[R]C[C@H](CO)[C@@H](C)[C@H](C)O</smiles><smiles>[R]N1C=NC2C(=O)NC(N)=NC21O</smiles>

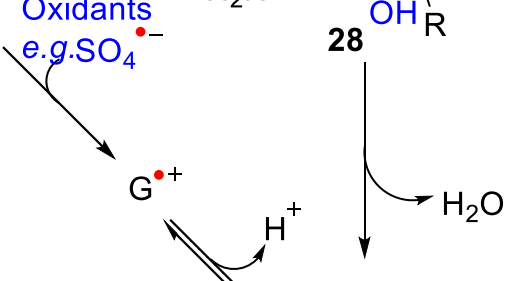<smiles>[R]n1cnc2c(=O)nc(N)[nH]c21</smiles>

Scheme 7. Radical reactions of guanine with hydroxyl radicals and subsequent reactions

One-electron oxidation of guanine 25 by oxidants leads to the formation of $\mathrm{G}^{\bullet+}$, which undergoes deprotonation to give guanyl radical 27 (Scheme 7) ${ }^{78}$ The reaction between the 
guanine $\mathbf{2 5}$ and hydroxyl radical was studied using optical absorption. On the basis of the absorption, the major radical (65\%) was assigned to $\mathrm{C} 5 \cdot$ generated from the addition of $\mathrm{HO} \bullet$ at $\mathrm{C} 4$, which further dehydrate to yield radical $27{ }^{79,80}$ In addition to the $\mathbf{2 8}, 17 \%$ of $\mathrm{HO} \cdot$ involves in the addition at $\mathrm{C} 8$ to provide radical $\mathbf{2 9}$, which is further converted into 8-oxoG 30 and FapyG 31 via oxidation and reduction, respectively. In 2009, Chatgilialoglu reevaluate the reactivity of guanine towards $\mathrm{HO} \cdot$. Based on the DFT-TD calculations they assign the major radical to guan-N2-yl radical $(\mathrm{G}(\mathrm{N} 2-\mathrm{H}) \cdot \boldsymbol{0}, 26) .{ }^{81}$ The more favored formation of $\mathbf{2 6}$ from $\mathrm{H}$-atom abstraction from $\mathbf{2 5}$ by $\mathrm{HO} \bullet$ than the formation of $\mathbf{2 8}$ was further established by a Car-Parrinello molecular dynamics study. ${ }^{82}$

The 8-substituted (e.g., $\mathrm{Cl}, \mathrm{Br}$ 32, $\mathrm{I}$, and $\mathrm{N}_{3}$ ) guanine derivatives were designed for investigating the formation and tautomerizations of one-electron-oxidized guanine. ${ }^{77}$ The pulse radiolysis technique with optical absorption detection and DFT calculations reveal the formation of radicals $\mathbf{2 6}$ as well as N3 $\bullet$ with iminic and aminic forms, the tautomers of 27..$^{77,83,84}$

As mentioned in section 1.5, ESR could be applied as a powerful tool to characterize radicals from the reaction between guanine and $\mathrm{HO} \bullet$ Nevertheless, ESR was not popular for identifying the radicals in previous research. An attempt was made to use ESR to investigate the formation of $\mathrm{dG}(\mathrm{N} 2-\mathrm{H}) \cdot \mathbf{2 6}$ from hydrazine was not successful and the resulting product dG was the evidence for the formation of $\mathbf{2 6}$ during the photolysis. ${ }^{85}$

On the basis of the formation of aminyl radicals on prehydrated one-electron attachment to $3^{\prime}$-AZT $\mathbf{2 2}^{42}$ (detailed at section 1.5), it is possible to explore azido-modified guanine derivatives as efficient precursors for investigation of elusive guanine-based aminyl radical under reducing conditions. 


\subsection{Fluorescent nucleosides for investigating nucleic acid structure, location, activation, and interactions}

The natural purine and pyrimidine bases in nucleic acids have weak fluorescent properties (Figure 8). ${ }^{86}$ Modified fluorescent nucleoside analogues with minimal perturbation to the natural DNA/RNA structures have attracted attention for their application to studying the perturbations to the nucleic acids such as abasic site from depurination/depyrimidination, ${ }^{87}$ base flipping, ${ }^{88}$ interaction between DNA/RNA and ligands, ${ }^{89,90}$ and so on. ${ }^{91,92}$

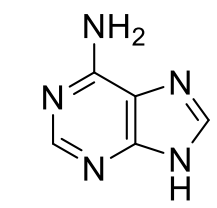

adenine $\Phi_{\mathrm{F}} \quad 0.026 \%$

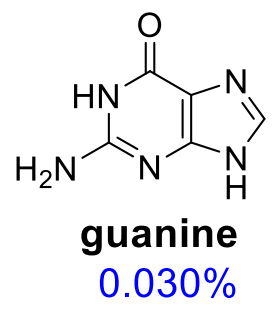<smiles>Nc1cc[nH]c(=O)n1</smiles>

cytosine<smiles>Cc1c[nH]c(=O)[nH]c1=O</smiles>

thymine

$0.010 \%$

Figure 8. Fluorescence of the natural purine and pyrimidine bases

Recently, Dr. Kool at Stanford University published a comprehensive review in Nature Chemistry on the design of various fluorescent nucleobases and their application as powerful tools for investigating DNA and RNA. ${ }^{93}$ The modification to purines (Figure 9A) and pyrimidines (Figure 9B) includes substitution, conjugated ring substitution, ring structure modification, conjugated linker extension, and ring fusion. This type of modifications shown in Figure 9 preserves the hydrogen bonding structures (highlighted in red), and thus retains the abilities of paring to their counterparts and some or most of the enzyme recognition. This group of fluorescent nucleobases is named as canonical fluorescent nucleobases. 
(A) Modification of canonical purines<smiles>Cn1cnc2c(N)ncnc21</smiles><smiles>C#Cc1nc(C#C)c2ncn(CC)c2n1</smiles><smiles>Cn1cnc2c([Y]3CCCC3)nc(N)nc21</smiles><smiles>Cn1cnc2c(=O)[nH]c(N)nc21</smiles>
$\underset{\text { modification }}{\stackrel{\text { chemical }}{\longrightarrow}}$<smiles>CC1CCc2c(N)ncnc21</smiles><smiles>CC(C)n1c2c(c3c(N)ncnc31)CCCC2</smiles>

(B) Modification of canonical pyrimidines<smiles>CCn1ccc(N)nc1=O</smiles>

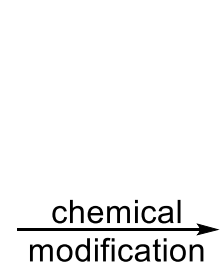<smiles>CC1CNc2nc(=O)n(C(C)C)cc21</smiles><smiles>CCn1c2c(c(N)nc1=O)CCCC2</smiles><smiles>N#CC1CCCc2c(N)nc(=O)[nH]c21</smiles><smiles>CCn1ccc(=O)[nH]c1=O</smiles><smiles>Cn1cc(C2CCC[Te]2)c(N)nc1=O</smiles>

Characteristics: paring ability enzyme recognition

Figure 9. Canonical fluorescent nucleobase analogues

On the other hand, non-canonical fluorescent nucleobases with more varied photophysical properties have also been developed (Figure 10). Since the fluorophore structures are not necessarily confined to the natural nucleobases, theoretically they can be any fluorescent architectures. The more widely varied emissive spectra would allow non-canonical fluorescent nucleobases wider applications in biochemistry and biology. Accompanying the advantages, the shortcomings of non-canonical fluorescent nucleobases consist of the loss of base-paring ability and limited recognition by base-related enzymes. 


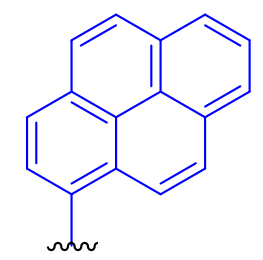<smiles>Cn1cnc2c1ncn1ccnc21</smiles>
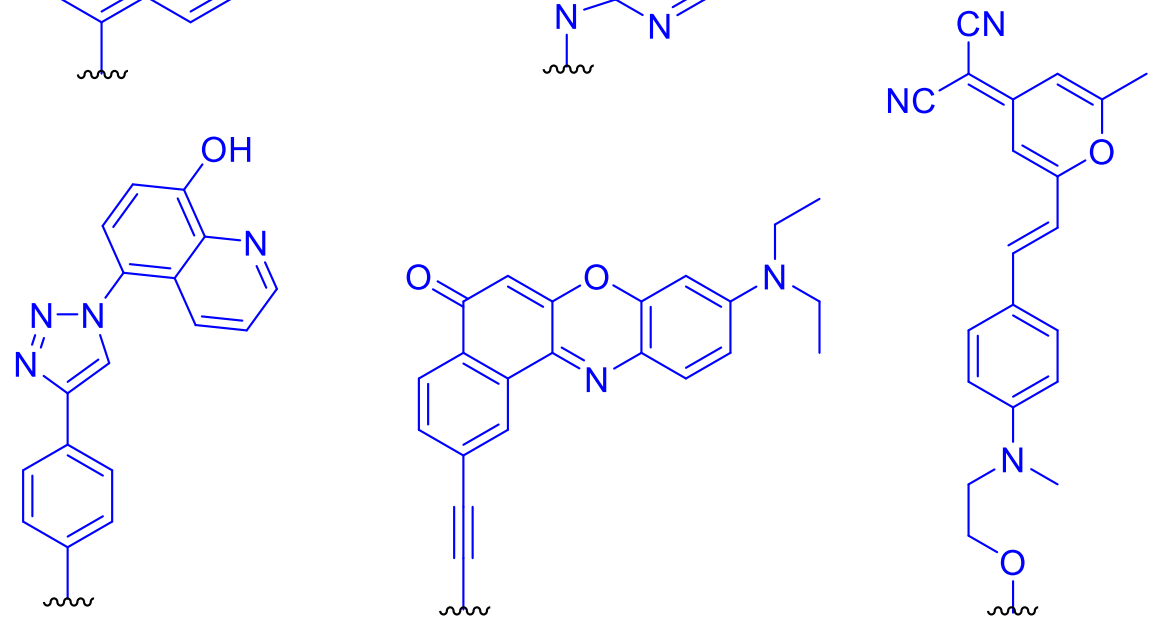

Figure 10. Non-canonical fluorescent nucleobases

The novel fluorescent properties, especially the varied quantum yield under different microenvironments, make fluorescent nucleosides valuable tools for investigating nucleic acid interactions, location, activities, and structure. Some examples are shown in Figure 11. Serva and coworkers employed 2-aminopurine for the study on DNA base flipping (Figure 11A). ${ }^{88} \mathrm{Kim}$ and coworkers used 8-pyrenylethynyl-2'-deoxyadenosine to detect base mismatch (Figure 11B). ${ }^{94}$ Tor and coworkers at UCSD explored the 5-furyl-2'deoxyuridine to locate abasic sites at DNA duplex (Figure 11C) ${ }^{87}$ They also used 5-furyluridine to examine the interaction between RNA fragments and small molecules and to detect small molecules utilizing the increasing fluorescent intensity with increasing concentration of small molecules (Figure 11D) ${ }^{89}$ In Dr. Wnuk's lab, the strain-promoted azide-alkyne cycloaddition (SPAAC) "click" reactions were applied to form fluorescent triazoles in cells for cell imaging. ${ }^{51}$ The frequency domain fluorescence lifetime imaging microscopy (FD-FLIM) in MCF-7 cells is shown in Figure 11E. 


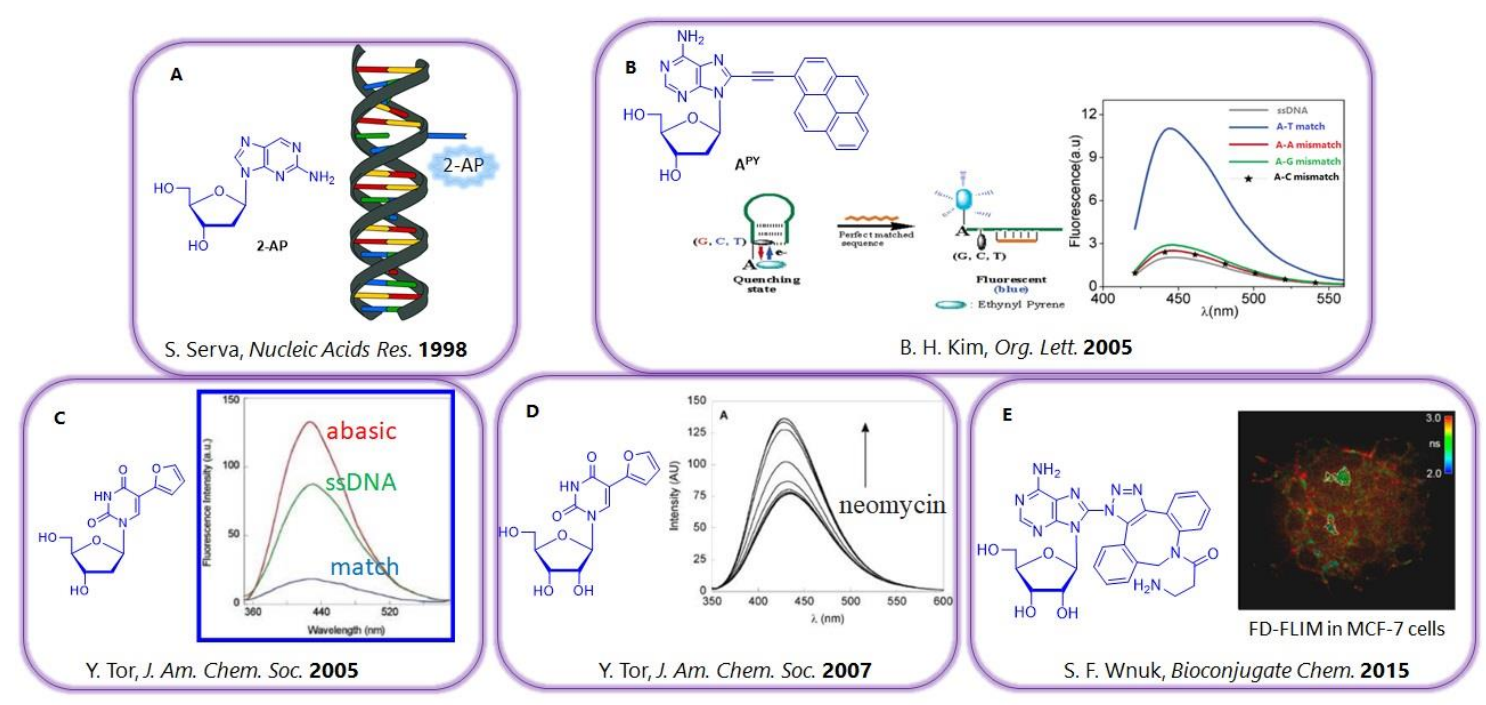

Figure 11. Fluorescent nucleobase serving as powerful tools for investigating the perturbations to nucleic acids

Among the fluorescent nucleosides, I was most interested in the triazolyl adenosine nucleosides because of their complex and interesting different fluorescent properties varied by $\mathrm{N} 1$ or $\mathrm{C} 4$ of the triazolyl moiety attached to the adenine base. The 2 - or 8 -azidopurine and 5-azidopyrimidine nucleosides were synthesized and ligated with cyclooctynes via strain promoted click chemistry to form 2- or 8-(1,2,3-triazol-1-yl) $\left(\Phi_{\mathrm{F}}=0.6-10.6 \%\right)$ and 5-(1,2,3-triazol-1-yl) pyrimidine $\left(\Phi_{\mathrm{F}}=0.9-1.3 \%\right)$ for the application to living cell fluorescent imaging (e.g., 33 in Figure 12). ${ }^{51}$ The 2-(1,2,3-triazol-1-yl)adenosine analogues 34 with triazole at C2 position gave relatively higher quantum yield of $20 \%,{ }^{95}$ while 8-(1,2,3-triazol-1-yl)-7-deazapurine nucleoside analogues 35 showed moderate quantum yields $\left(\Phi_{\mathrm{F}}=0.2-1.4 \%\right)$ and a large Stocks shifts. ${ }^{96}$ The photo-physical characterization of a series of 2-(4-amino-5-(1H-1,2,3-triazol-4-yl)-7H-pyrrolo-[2,3-d]pyrimidin-7-yl) and 2-(4-amino-3-(1H-1,2,3-triazol-4-yl)-1H-pyrazolo[3,4-d]pyrimidin-1-yl) analogues showed that compounds with a nitrogen atom in position 8 showed an approximately ten-fold increase in quantum yield $\left(\Phi_{\mathrm{F}}=\sim 5 \%\right)$ and decreased Stokes shift compared to 
analogues with a carbon atom in position $8\left(\Phi_{\mathrm{F}}=\sim 0.6 \%\right) .{ }^{97}$ The $8-(1 H-1,2,3-$ Triazol-4yl)adenosine derivatives $\mathbf{3 7}$ and $\mathbf{3 8}$ with the base attached to $\mathrm{C} 4$ position of triazole had promising quantum yield as high as $64 \% .{ }^{98}$ It is noteworthy that the 8-(1,2,3-triazol-1-yl) adenosines $\mathbf{3 3}$ and $\mathbf{3 6}$ display fluorescence properties with significantly lower quantum yields than the 8-(1,2,3-triazol-4-yl) adenosines $\mathbf{3 7}$ and $\mathbf{3 8}{ }^{99}$

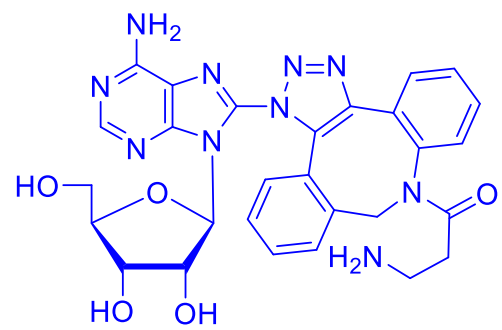

$33 \Phi_{\mathrm{F}}=11 \%$

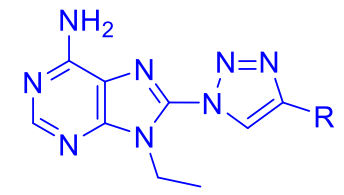

$36 \Phi_{\mathrm{F}}=0.21-0.64 \%$

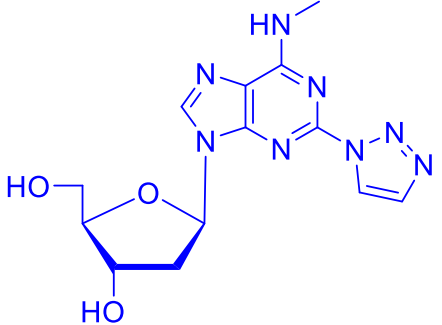

$34 \Phi_{\mathrm{F}}=20 \%$

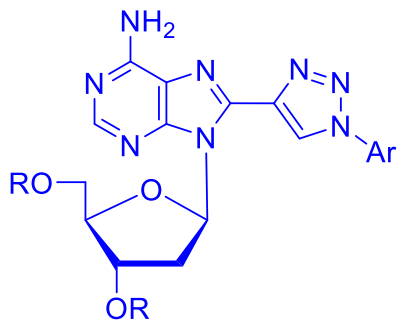

$37 \Phi_{\mathrm{F}}=3-38 \%$

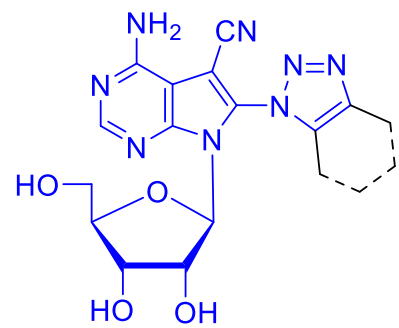

$35 \Phi_{\mathrm{F}}=0.2-1.4 \%$

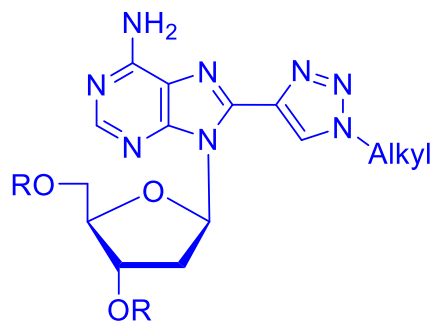

$38 \Phi_{\mathrm{F}}=49-64 \%$

Figure 12. Structure and the fluorescent properties of $N$-substituted triazoles

According to the criteria ${ }^{87}$ of designing new fluorescent nucleosides: $(i)$, sensitiveness to the microenvironment, (ii) absorption and emission at long wavelengths, (iii), high emission quantum efficiency, (iv) minimalistic modification, $N$-unsubstituted $1 H$-1,2,3triazol-4-yl modified adenine analogues as well as the other three nucleic acid bases would have novel fluorescent properties.

The 5-(1H-1,2,3-triazol-4-yl)-2'-deoxyuridine (5-TrzdU, 39, Scheme 8) was synthesized by general CuAAC click reaction to give $\mathbf{4 0}$ followed by POM-deprotection (Scheme 8). ${ }^{100}$ The 5-TrzdU was also prepared via nucleobase-exchange reaction catalyzed 
by thymidine phosphorylase from thymidine (41) to $1 H$-1,2,3-triazol-4-yl. ${ }^{101}$ The 5-TrzdU incorporated into DNA via solid-phase ODN synthesis stacks in the major groove and increases the stability of the DNA duplex. ${ }^{100}$

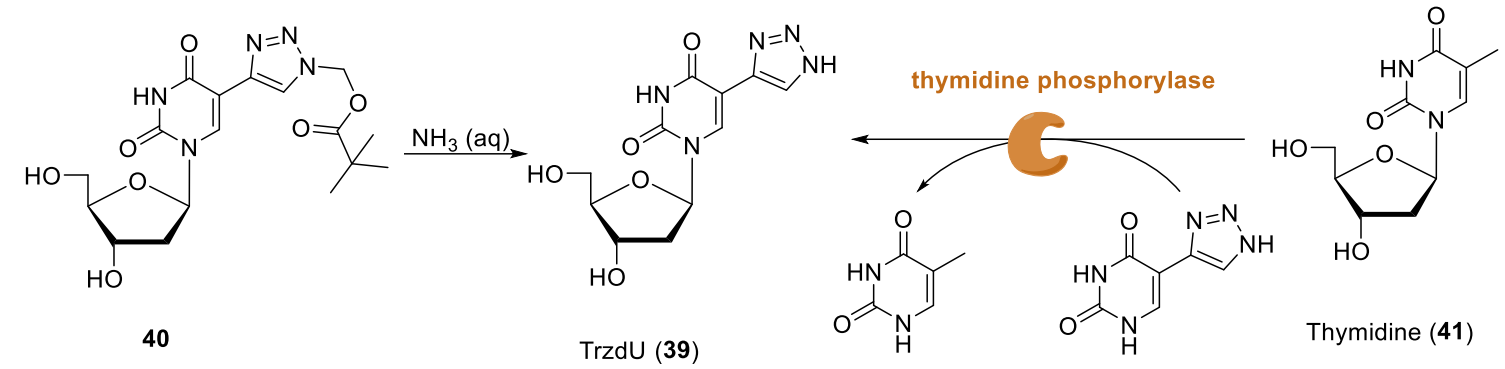

Scheme 8. Strategies for the synthesis of 5-TrzdU

The strategies developed for the synthesis of $N$-unsubstituted triazoles (Scheme 9) includes the $[3+2]$ cycloaddition of terminal alkynes and trimethylsilyl azide $\left(\mathrm{TMSN}_{3}\right)$ using $\mathrm{CuI}$ as catalyst, ${ }^{102} \mathrm{Pd}^{103}$ or $p$-toluenesulfonic acid ${ }^{104}$ catalyzed cyclization between activated alkene and sodium azide, and deprotection of $N$-substituted triazole intermediates prepared by general CuAAC click reactions. ${ }^{96,105,106}$ All of these reaction conditions may be applied to synthesize the $N$-unsubstituted triazoles-modified nucleosides. 
(A) Direct reaction with terminal alkyne

a) Y. Yamamoto, Eur. J. Org. Chem. 2004

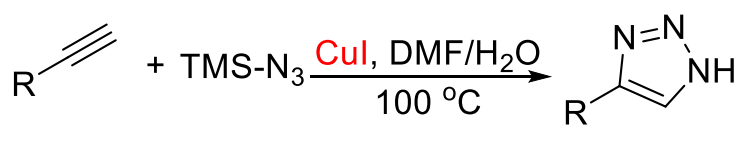

(B) Direct reaction with activated alkene

b) F. Aznar, Angew. Chem. Int. Ed. 2006

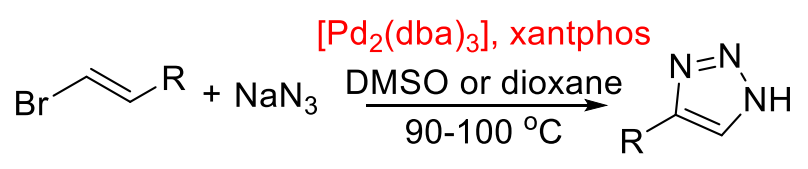

c) Z.-H. Guan, Org. Lett. 2014

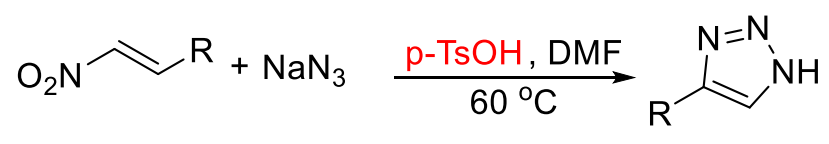

(C) CuAAC click reaction followed by deprotection

d) V. V. Fokin, Org. Lett. 2008

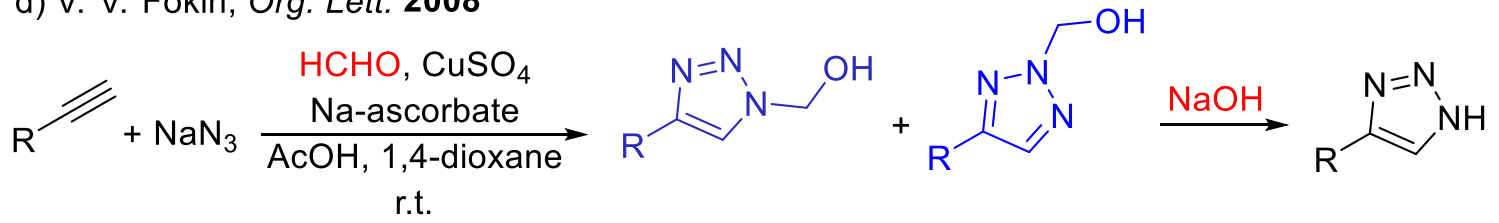

e) D. Y. Chi, Tetrahedron 2017

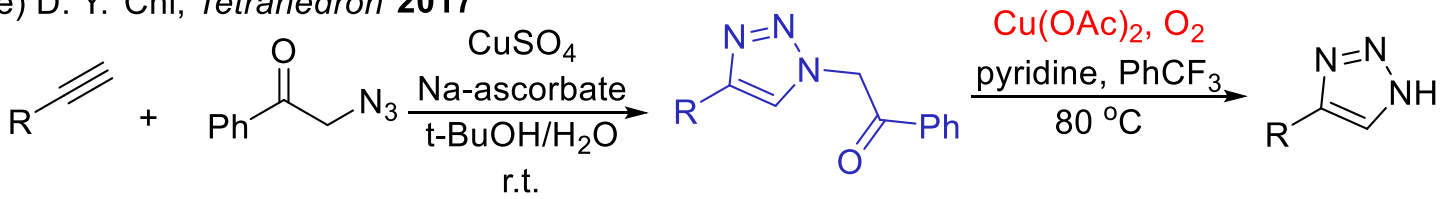
r.t.

f) T. E. Nielsen, Org. Lett. 2010

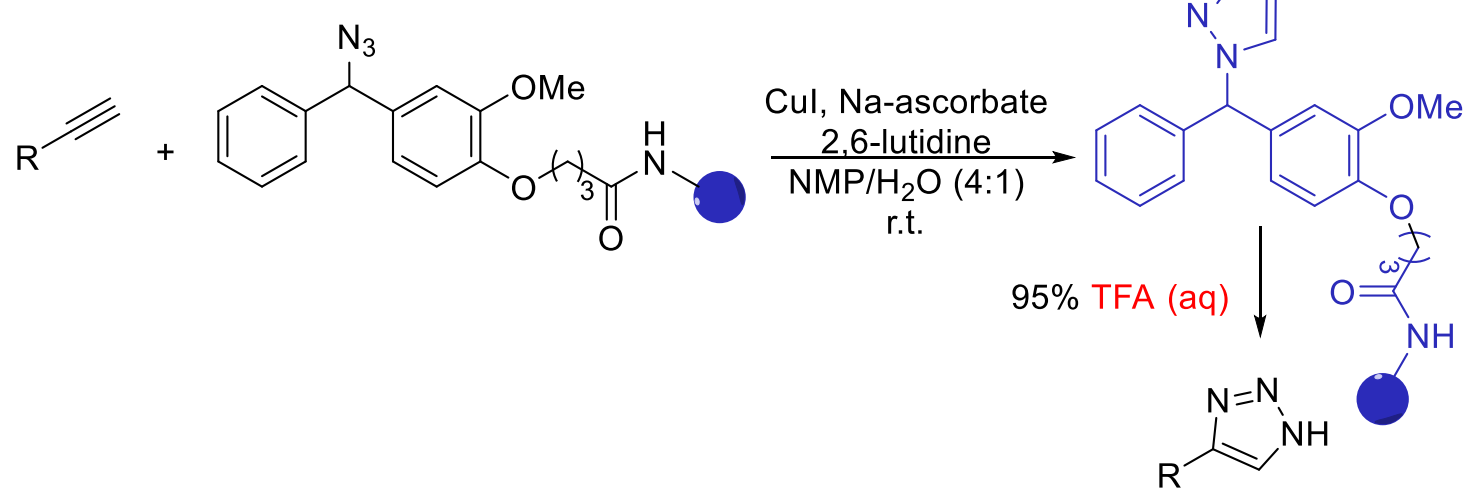

Scheme 9. Reported strategies for the synthesis of $N$-unsubstituted triazoles 


\subsection{Concept of prodrugs}

The anticancer activity of drugs would be limited by their inadequate diffusion into cancerous cells, especially into cells of a solid tumor under hypoxic condition. ${ }^{107}$ Designing chemically modified prodrugs, which are inactive, bio-reversible derivatives of active drug molecules, is a promising strategy to enhance pharmacokinetics of drug delivery. As shown in Figure 13, first prodrugs can pass through the physiological membranes more easily than the drugs. After entering the cells, the prodrugs undergo an enzymatic and/or chemical transformation and then the active parent drug can be released. Around $20 \%$ of all small molecular drugs approved in 2000-2008 were prodrugs. ${ }^{108}$ Even though designing a new prodrug can be challenging, the prodrug approach shows a practical path to minimize some undesirable properties of investigational drugs or commercially available drugs. Designing proTides is another gorgeous strategy that skips the metabolic phosphorylation and meanwhile increases the uptake of drugs. ${ }^{109}$

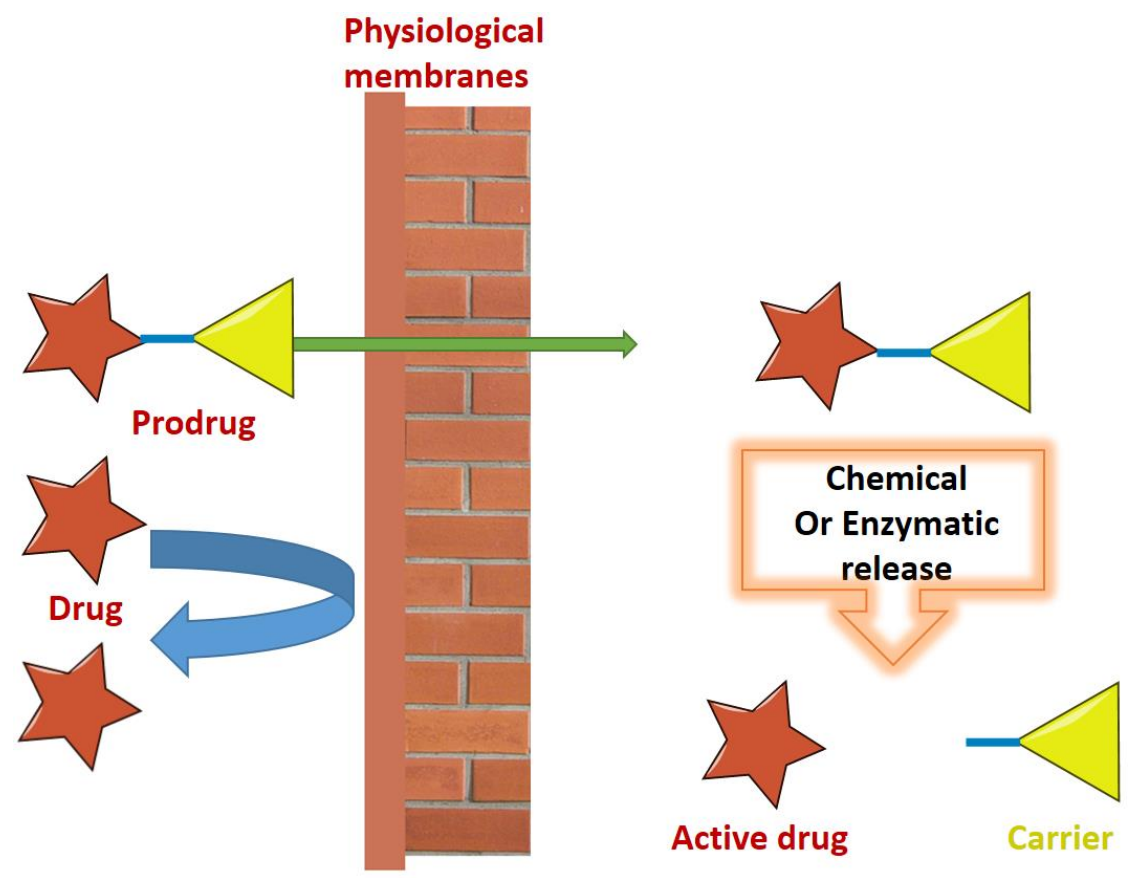

Figure 13. A simplified illustration of the prodrug concept 


\section{RESEARCH OBJECTIVES}

The discovery of copper-catalyzed [3+2] azide-alkyne cycloaddition (CuAAC) developed by Sharpless and Meldal in $2002^{44,45}$ as well as strain-promoted azide-alkyne cycloaddition (SPAAC) "click" reactions developed by Bertozzi in $2004^{46}$ led to the application of azide as a reactive reporter introduced into a target biomolecule like nucleic acid, protein, glycans, and lipids to label and track biomolecules. ${ }^{43,47}$ Click chemistry is now widely used for bioorthogonal conjugation, new drug discovery, and proteomic profiling. ${ }^{48-51}$ However, in my dissertation I have explored the application of the azide group beyond the click chemistry. On the basis of the original discovery from Sevilla's group $^{42}$ on the formation of neutral and reactive aminyl radicals upon one-electron attachment to the azido group in 3'-AZT, I have investigated C5 azido-modified pyrimidine nucleosides as precursors to the reactive aminyl radicals. I also planned to investigate their application as anticancer radiosensitizing agents.

\section{Objective 1: Exploring C5 azido-modified pyrimidine nucleosides as radiosensitizers}

The first objective of my dissertation was to investigate if C5 azido-modified pyrimidine nucleosides (AmdU 18, AvdU 21, AmdC 42, AvdC 43, Figure 14) can act as radiosensitizers under both normoxic and hypoxic microenvironments. To serve as useful radiosensitizing agents, the $\mathrm{C} 5$ azido-modified pyrimidine nucleosides are required to a) be easily synthesized chemically and be stable under biological environment, b) be able to generate active radicals under normoxic and/or hypoxic condition, c) be able to be incorporated into DNA and not block further polymerization, d) and eventually show radiosensitizing effect in cancerous cells. 

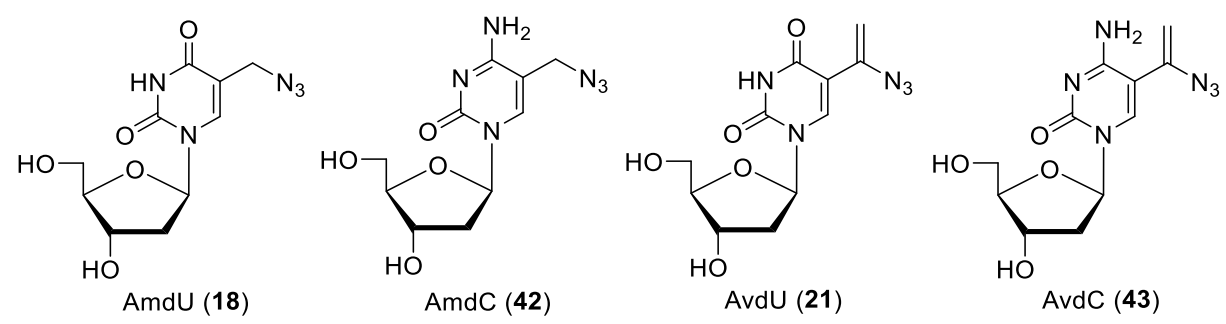

Figure 14. 2'-Deoxyuridine and 2'-deoxycytidine with azidomethyl and azidovinyl modified at $\mathrm{C} 5$

Initially, I chose to synthesize and explore the chemistry and biochemistry of AmdU 18. Contrary to the 5-azido-2'-deoxyuridine, in which the azido group is attached directly to the pyrimidine base, AmdU $\mathbf{1 8}$ was reported to be stable in aqueous solution. ${ }^{40} \mathrm{AmdU}$ was also reported to be able to be enzymatically ${ }^{57}$ and metabolically ${ }^{40}$ incorporated into DNA. AmdU could be conveniently prepared by bromination of protected thymidine and subsequent displacement of bromide with sodium azide. ${ }^{40}$ The 5-Azidomethyl-2'deoxycytidine (AmdC, 42), in turn, could be obtained by conversion of the uracil ring in the protected AmdU to cytosine. Another class of C5 azido-modified pyrimidine nucleosides I explored were 5-azidovinyl derivatives of 2'-deoxyuridine (AvdU, 21) and 2'-deoxycytidine $(\mathrm{AvdC}, \mathbf{4 3})$ in which azido group is attached to $s p^{2}$ hybridized carbon. The synthesis of AvdU 21 and AvdC $\mathbf{4 3}$ could be accomplished via silver-catalyzed hydroazidation of 5-ethynyl pyrimidines nucleoside substrates.

The formation of aminyl radicals on electron attachment to azido-modified nucleosides in $\gamma$-irradiated aqueous glassy $(7.5 \mathrm{M} \mathrm{LiCl})$ systems and the subsequent reactions would be characterized using electron spin resonance (ESR). Unlike elongation terminator 3'-AZT 22, the 5-azidomethyl (18 and 42) and 5-azidovinyl (21 and 43) pyrimidine nucleosides with modification moieties at the 5-postion of pyrimidine bases were expected not only 
able to be metabolically/enzymatically incorporated into DNA but also allow DNA elongation after incorporation during the DNA replication. To test this hypothesis, the corresponding C5 azido-modified nucleoside triphosphates will be synthesized and evaluated for their ability for polymerase-catalyzed incorporation and further extension during DNA replication and base excision repair (BER). The radiation response of cells in the presence of azido-modified nucleosides in vitro will be examined in both aerobic and hypoxic condition of selected cancerous cells.

\section{Objective 2: 2-Azido-2'-deoxyinosine as probe to investigate elusive guanine-based aminyl radical}

The second objective of my dissertation was to explore the generation and reactivity of 2'-deoxyguanosyl radical $\mathbf{4 5}$ postulated to be generated during the ambident reactivity of the guanine moiety in 2'-deoxyguanosine $(\mathrm{dG})$ towards hydroxyl radicals $(\mathrm{HO} \bullet)$ by direct hydrogen abstraction from the $\mathrm{NH}_{2}$ moiety rather than the addition at $\mathrm{C} 4$ position ${ }^{81}$ (Figure 15). Based on the previous knowledge that one-electron reduction of azido group generates aminyl radicals, ${ }^{42,73}$ I proposed that 2-azido-2'-deoxyinosine (2- $\left.\mathrm{N}_{3} \mathrm{dI}, 44\right)$ could serve as convenient substrate for the generation of elusive guaninyl aminyl radical 45. If successful, the structure of radical $\mathbf{4 5}$, its tautomers, and subsequent reactions will be investigated to understand nucleic acid damage pathways induced by $\gamma$-radiolysis.
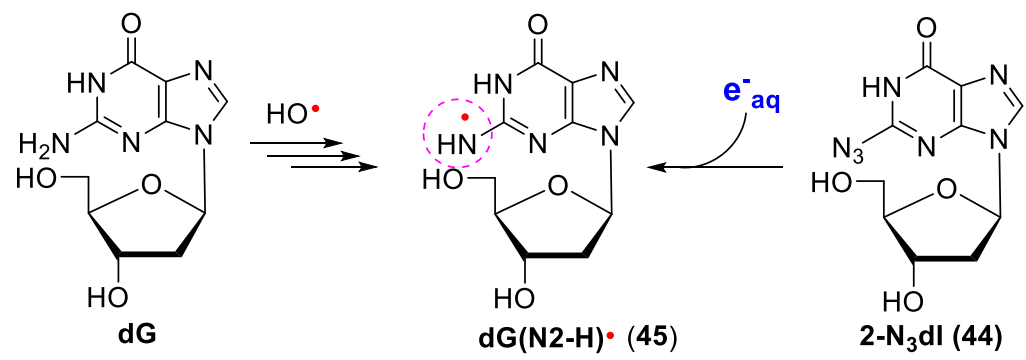

Figure 15. A plausible generation of 2'-deoxyguanosin-N2-yl radical (dG(N2-H)•) from 2azido-2'-deoxyinosine 
Synthesis of the 2- $\mathrm{N}_{3} \mathrm{dI} \mathbf{4 4}$ could be accomplished by conversion of 2-amino group in the protected 2'-deoxyguanosine into 2-azido group via diazotization reaction with tertbutyl nitrite followed by nucleophilic displacement with azide and deprotection. The formation of 2-aminyl radical from 2- $\mathrm{N}_{3} \mathrm{dI} \mathbf{4 4}$ and subsequent radical transfers will be characterized using electron spin resonance (ESR).

\section{Objective 3: $N$-unsubstituted 1,2,3-triazol-4-yl nucleosides: Chemistry and}

\section{fluorescent properties}

Fluorescent nucleosides serve as powerful molecular tools for investigating nucleic acid structures, activities, locations, and interaction with other biomolecules or small molecules. ${ }^{93}$ The $N$-alkyl/aryl substituted 1,2,3-triazol-4-yl adenine showed higher quantum yield than 1,2,3-triazol-1-yl adenine. ${ }^{98,99}$ In light of the criteria of designing new fluorescent nucleosides, i.e., high emission quantum efficiency and minimalistic modification, the third objective of my dissertation was to synthesize $\mathrm{N}$-unsubstituted 8(1H-1,2,3-triazol-4-yl)-2'-deoxyadenosine (8-TrzdA, 46). I also plan to expand this goal to other three nucleosides of natural DNA and prepare 8-(1H-1,2,3-triazol-4-yl)-2'deoxyguanosine (8-TrzdG, 47), 5-(1H-1,2,3-triazol-4-yl)-2'-deoxycytidine (5-TrzdC, 48), and 5-(1H-1,2,3-triazol-4-yl)-2'-deoxyuridine (5-TrzdU, 39) (Figure 16).

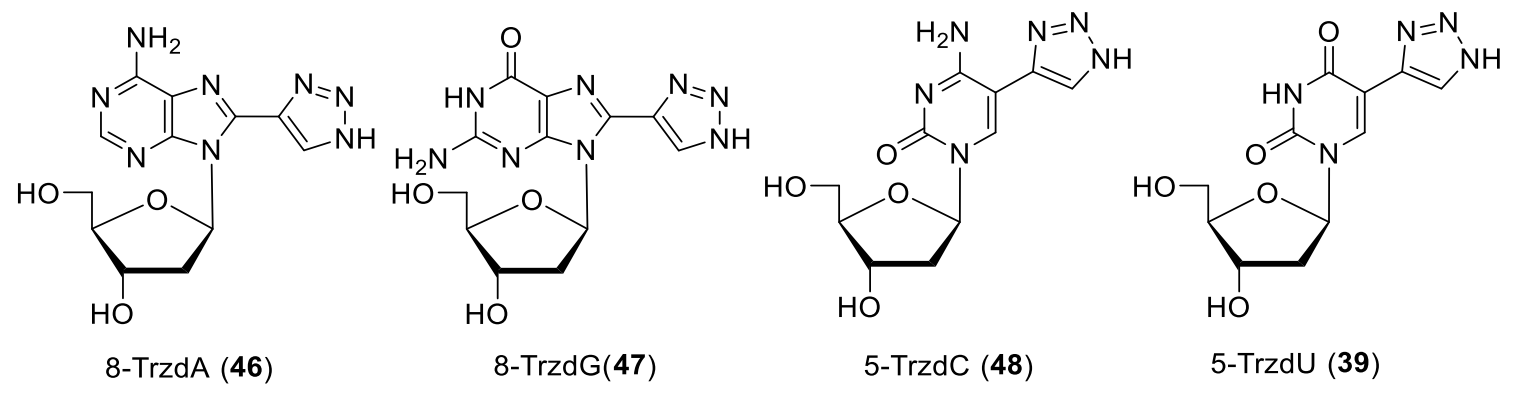

Figure 16. Fluorescent $N$-unsubstituted 1,2,3-triazol-4-yl nucleosides 
From several strategies developed for the synthesis of $N$-unsubstituted 1,2,3-triazoles, I expect Yamamoto's procedure for the cycloaddition of alkynes with $\mathrm{TMSN}_{3}$ catalyzed by $\mathrm{CuI}^{102}$ should provide C5-pyrimidine and C8-purine triazol-4-yl nucleosides. Other catalysts, like $\mathrm{CuSO}_{4}$ /sodium ascorbate and $\mathrm{Ag}_{2} \mathrm{CO}_{3}$ will be also tried to optimize the cycloaddition between alkynyl nucleosides and $\mathrm{TMSN}_{3}$. The $N$-unsubstituted 1,2,3-triazol4-yl nucleosides (46-48 and 39) would be converted to 5'-triphosphates and their incorporation into DNA by polymerase-catalyzed reactions will be investigated. If triazolyl derivatives show good fluorescent properties they will be also explored for the potential application in cell imaging and investigating the perturbations to nucleic acids.

\section{Objective 4: Antiviral and cytostatic evaluation of 5-(1-halo-2-sulfonylvinyl) and}

\section{5-(2-furyl)uracil nucleoside prodrugs}

My fourth objective was to evaluate the antiviral and cytostatic activities of the prodrugs recently synthesized in Dr. Wnuk's lab, uracil nucleosides substituted at C5 with 1-halo-2-sulfonylvinyl (Figure 17, 49) ${ }^{110}$ or heteroaren-2-yl scaffolds (Figure 17, 50). ${ }^{111}$ In order to have a comprehensive biological evaluation of these uracil nucleosides analogues, I planned to increase uptake of compounds into cells by improving the lipophilicity of these compounds by esterification of the hydroxy group at sugar (Figure 17, 51) and/or incorporation of a permanent long lipophilic alkyl chain in the furan ring (Figure 17, 52).

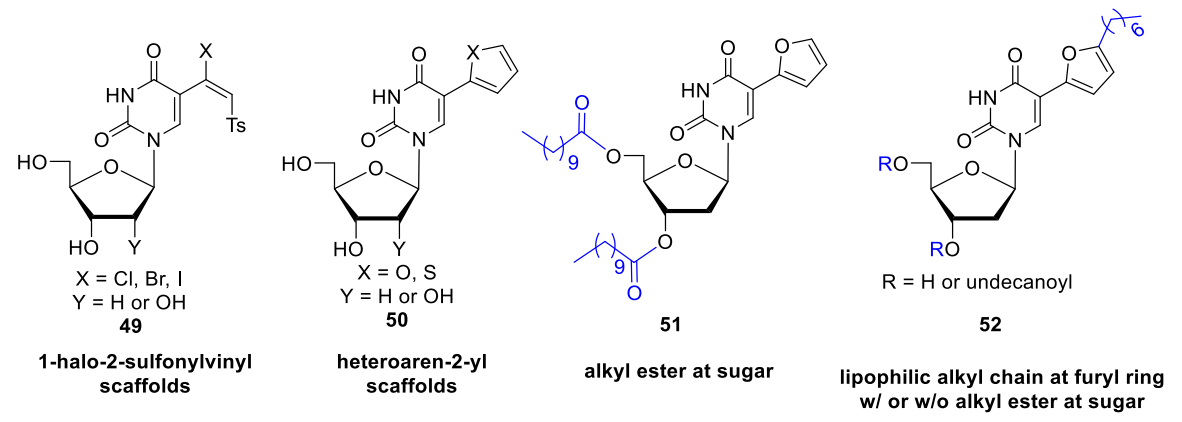

Figure 17. 5-(1-Halo-2-sulfonylvinyl) and 5-(2-furyl) uracil nucleosides prodrugs 


\section{RESULTS AND DISCUSSION}

\subsection{Pyrimidine nucleosides with azidomethyl and azidovinyl modification at C5 position: Chemistry and biology}

\subsubsection{Synthesis of AmdU, AmdC, and their phosphoramidite analogues}

The 5-azidomethyl-2'-deoxyuridine (AmdU, 18) was synthesized from thymidine 41 by successive (a) protection of sugar hydroxyl with tert-butyldimethylsilyl group (to give 53), (b) $i$, bromination with $N$-bromosuccinimide (NBS); followed by $i$, displacement of bromide with $\mathrm{NaN}_{3}$ (to give 54), and (c) desilylation with tetra-n-butylammonium fluoride (TBAF) with overall $45 \%$ yield (Scheme 10). ${ }^{40,54}$ The ${ }^{1} \mathrm{H}$ NMR data of $\mathbf{1 8}$ were in good agreement with those published $\left[\right.$ e.g., $\left.\delta 4.06\left(\mathrm{~s}, 2 \mathrm{H}, \mathrm{CH}_{2} \mathrm{~N}_{3}\right)\right] .{ }^{40}$ Treatment of 54 with 2,4,6-triisopropylbenzenesufonyl chloride (TIPBSCl), in the presence of triethylamine (TEA)/ 4-dimethylaminopyridine (DMAP) followed by in situ displacement of the resulting aryl sulfate with $\mathrm{NH}_{4} \mathrm{OH}$ provided 55. Subsequent desilylation with TBAF provided 5-azidomethyl-2'-deoxycytidine (AmdC, 42) in 76\% overall yield from 54 (Scheme 10). Treatment of AmdU 18 with acetyl anhydride in the presence of DMAP/TEA in $\mathrm{ACN}$ at room temperature for $1 \mathrm{~h}$ gave more lipophilic 3',5'-di- $O$-acetyl-AmdU $\mathbf{5 6}$ (70\%).

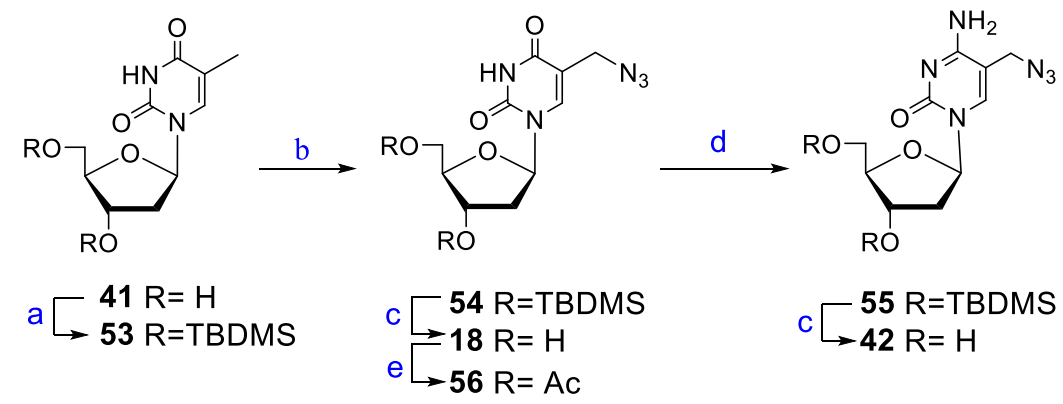

Reagents and conditions: (a) TBDMSCl, imidazole, $50{ }^{\circ} \mathrm{C}$, overnight. (b) (i) NBS, azobisisobutyronitrile (AIBN), benzene, reflux, 1 h; (ii) $\mathrm{NaN}_{3}$, DMF, $60{ }^{\circ} \mathrm{C}, 1$ h. (c) TBAF, THF, rt, 4 h. (d) (i) TIPBSCl, TEA, DMAP, $\mathrm{CH}_{2} \mathrm{Cl}_{2}$, rt, $1 \mathrm{~h}$; (ii) aq. $\mathrm{NH}_{4} \mathrm{OH} / \mathrm{THF}$, rt overnight. (e) acetic anhydride, DMAP, TEA, ACN, rt, $1 \mathrm{~h}$.

Scheme 10. Synthesis of AmdU 18 and AmdC 42 
Since the synthesis of AmdU required multistep procedure (including protection and deprotection steps), I attempted synthesis of AmdU directly from thymidine via direct C$\mathrm{H}$ activation of the methyl group (Scheme 11) using $\mathrm{C}-\mathrm{H}$ azidation protocols reported for the synthesis of alkyl azide. ${ }^{12}$ Thus, treatment of thymidine $\mathbf{4 1}$ with tosyl azide $\mathbf{5 7}$ in the presence of $\mathrm{Na}_{2} \mathrm{~S}_{2} \mathrm{O}_{8}$ and base showed that all the starting material was converted to a new spot on TLC, which had same $R_{f}$ as AmdU. Potassium iodide and sodium thiosulfate solutions were used to quench excess oxidant $\mathrm{Na}_{2} \mathrm{~S}_{2} \mathrm{O}_{8}$. The reaction residue was column chromatographed to give a new product which was confirmed to be 5-(dimethoxymethyl)$2^{\prime}$-deoxyuridine $\mathbf{5 8}^{113}$ rather than AmdU 18. The presence of two methoxy group at the 3.22 and $3.24 \mathrm{ppm}$ in ${ }^{1} \mathrm{H}$ NMR and downfield shifted signal for acetal carbon at $97.9 \mathrm{ppm}$ in ${ }^{13} \mathrm{C}$ NMR was diagnostic for structure $\mathbf{5 8}$. The spectroscopic data for $\mathbf{5 8}$ were also in agreement with the reported data for acetal $\mathbf{5 8}$ prepared by reaction of 2'-deoxyuridine-5aldehyde with $\mathrm{MeOH} .{ }^{113}$ Modification of the procedure shown in Scheme 11 (like removing the tosyl azide 57) would provide a convenient one-step synthesis of 5(dimethoxymethyl)-2'-deoxyuridine $\mathbf{5 8}$, which can serve as precursor to 5-formyl-2'deoxyuridine. Compound $\mathbf{5 8}$ showed anti-orthopoxvirus activity in micromolar range. ${ }^{113}$

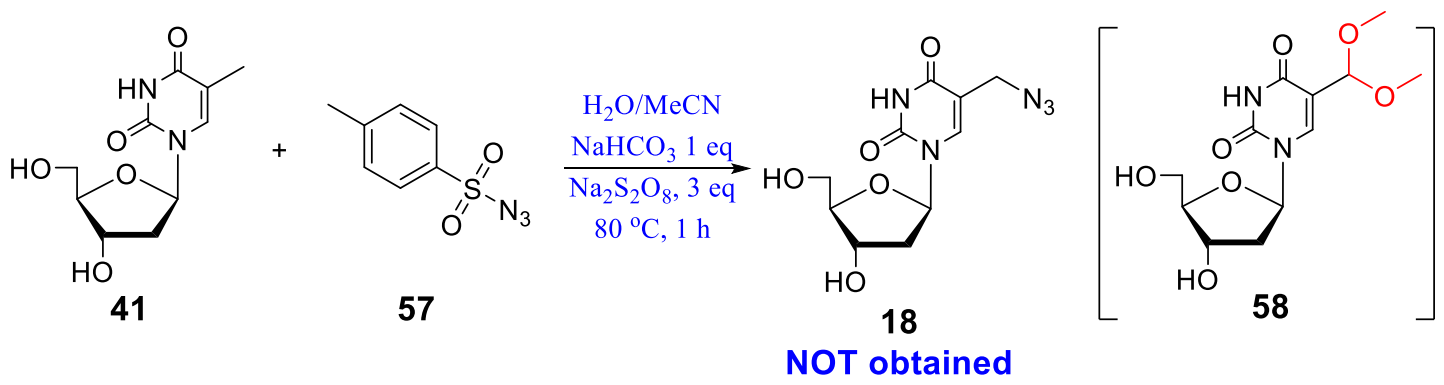

Scheme 11. Attempted one-step synthesis of AmdU

To study the formation of aminyl radicals and their subsequent reactions along DNA fragments, I made an attempt to introduce AmdU 18 into oligonucleotides using solid- 
phase oligodeoxynucleotides (ODN) synthesis (Scheme 12). Such a phosphoramidite approach is believed to be not applicable for the synthesis of azido-modified ODN presumably due to Staudinger reduction. ${ }^{114}$ The synthesis of phosphoramidite precursor 5'-(4,4'-dimethoxytrityl)-3'-( $N, N$-diisopropylamino-2-cyanoethoxychlorophosphinyl)AmdU (5'-DMT-3'-CEP-AmdU, 60) for solid-phase ODN synthesis is shown in Scheme 12. Thus, AmdU 18 was selectively tritylated with 4,4'-dimethoxytrityl chloride (DMTCl) at the 5'-position to give 5'-DMT-protected AmdU 59. The phosphitylation at the 3'-position of $\mathbf{5 9}$ with $N, N$-diisopropylamino-2-cyanoethoxychlorophosphine in the presence of $N, N$-diisopropylethylamine (DIEA) was completed in 10 min to give two phosphoramidite diastereomers $\mathbf{6 0}$. The DCM solution of $\mathbf{6 0}$ after extraction was dried over anhydrous $\mathrm{Na}_{2} \mathrm{SO}_{4}$ and used for solid-phase ODN synthesis without any further treatment.

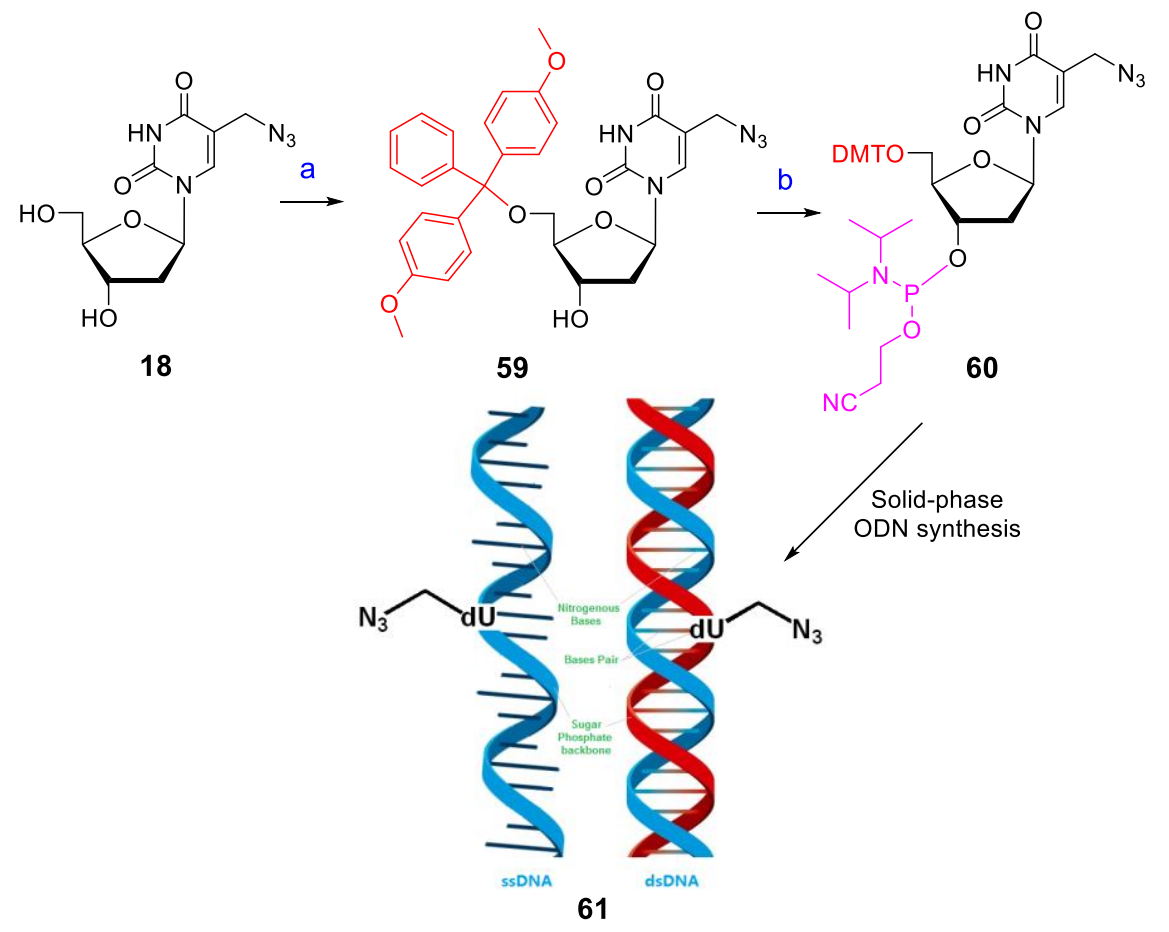

Reagents and conditions: (a) DMTCl, pyridine, rt, $2 \mathrm{~h}$; (b) 2-Cyanoethyl $\mathrm{N}, \mathrm{N}$ diisopropylchlorophosphoramidite, DIPEA, DCM, rt, 10 min.

Scheme 12. Synthesis of AmdU phosphoramidite precursor for potential solid-phase preparation of azido-modified DNA fragments 
For NMR and HRMS characterization, the solvent after extraction was removed under high vacuum [ice/acetone bath $\left.\left(-10^{\circ} \mathrm{C}\right)\right]$. The residue was column chromatographed (hexane/EtOAc/TEA) to give 5'-DMT-3'-CEP-AmdU 60 as a separable mixture of two diastereomers with $75.6 \%$ isolated yield as white solid. The structure of the phosphoramidite 60 was confirmed by ${ }^{1} \mathrm{H}$ NMR, ${ }^{13} \mathrm{C}$ NMR, ${ }^{31} \mathrm{P}$ NMR as well as HRMS (see experimental section for completed data). The ${ }^{1} \mathrm{H}$ NMR and ${ }^{31} \mathrm{P}$ NMR of one of the two diastereomers (first eluted from column) is shown in Figure 18. The single ${ }^{31} \mathrm{P}$ peak at $148.8 \mathrm{ppm}$ (Figure 18, B) indicates that phosphoramidite were obtained as single diastereomers after column chromatography. Interestingly, contrary to AmdU where methylene protons for $\mathrm{CH}_{2} \mathrm{~N}_{3}$ group in ${ }^{1} \mathrm{H}$ NMR resonates as singlet at $\delta$ 4.06, diastereotopic protons in $\mathrm{CH}_{2} \mathrm{~N}_{3}$ group of $\mathbf{6 0}$ were split into two doublets ( $\delta 3.32$ and 3.57, ${ }^{2} J=13.4 \mathrm{~Hz} ;$ Figure 18A).

The $\mathrm{CH}_{2} \mathrm{Cl}_{2}$ solution of phosphoramidite $\mathbf{6 0}$ can be stored under $-20{ }^{\circ} \mathrm{C}$ for over two months. However, it decomposes within $24 \mathrm{~h}$ when stored in a solid form even under low temperature $\left(-20^{\circ} \mathrm{C}\right)$ or in solution at ambient temperature. Figure 19 showed formation of new peaks resulting from decomposition of $\mathbf{6 0}\left(\mathrm{CD}_{2} \mathrm{Cl}_{2} / \mathrm{rt} / 15 \mathrm{~h}\right)$ in both ${ }^{1} \mathrm{H}$ NMR $(\delta 5.67-$ 6.28 ppm: presumed signal from the terminal olefin $\left.\mathrm{CH}_{2}=\mathrm{CHCN}\right)$ and ${ }^{31} \mathrm{P}$ NMR $(\delta$ 12.70, 14.34) spectra. Phosphoramidite $\mathbf{6 0}$ was also found to be unstable (removal of DMT-group) in $\mathrm{CHCl}_{3}$, and thus during any process, $\mathrm{CHCl}_{3}$ would be avoided.

It is noteworthy that $\mathbf{6 0}$ is one of the first examples of azidonucleoside phosphoramidite building blocks which we attempted to employ for the synthesis of azido-modified DNA fragments using solid-phase ODN synthesis. 

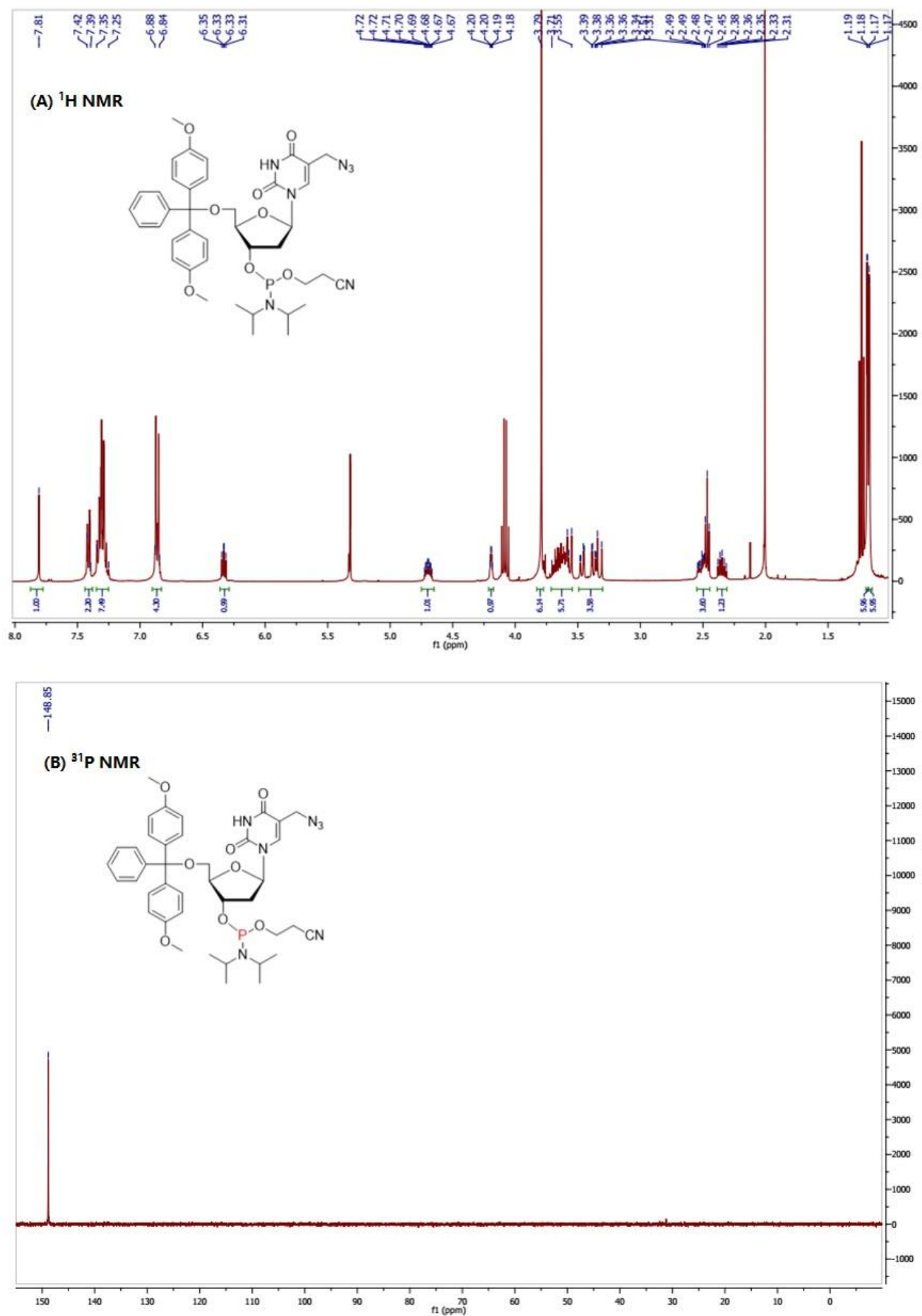

Figure 18. ${ }^{1} \mathrm{H}(\mathbf{A})$ and ${ }^{31} \mathrm{P}$ (B) NMR spectra of AmdU phosphoramidite 60 single diastereomer 

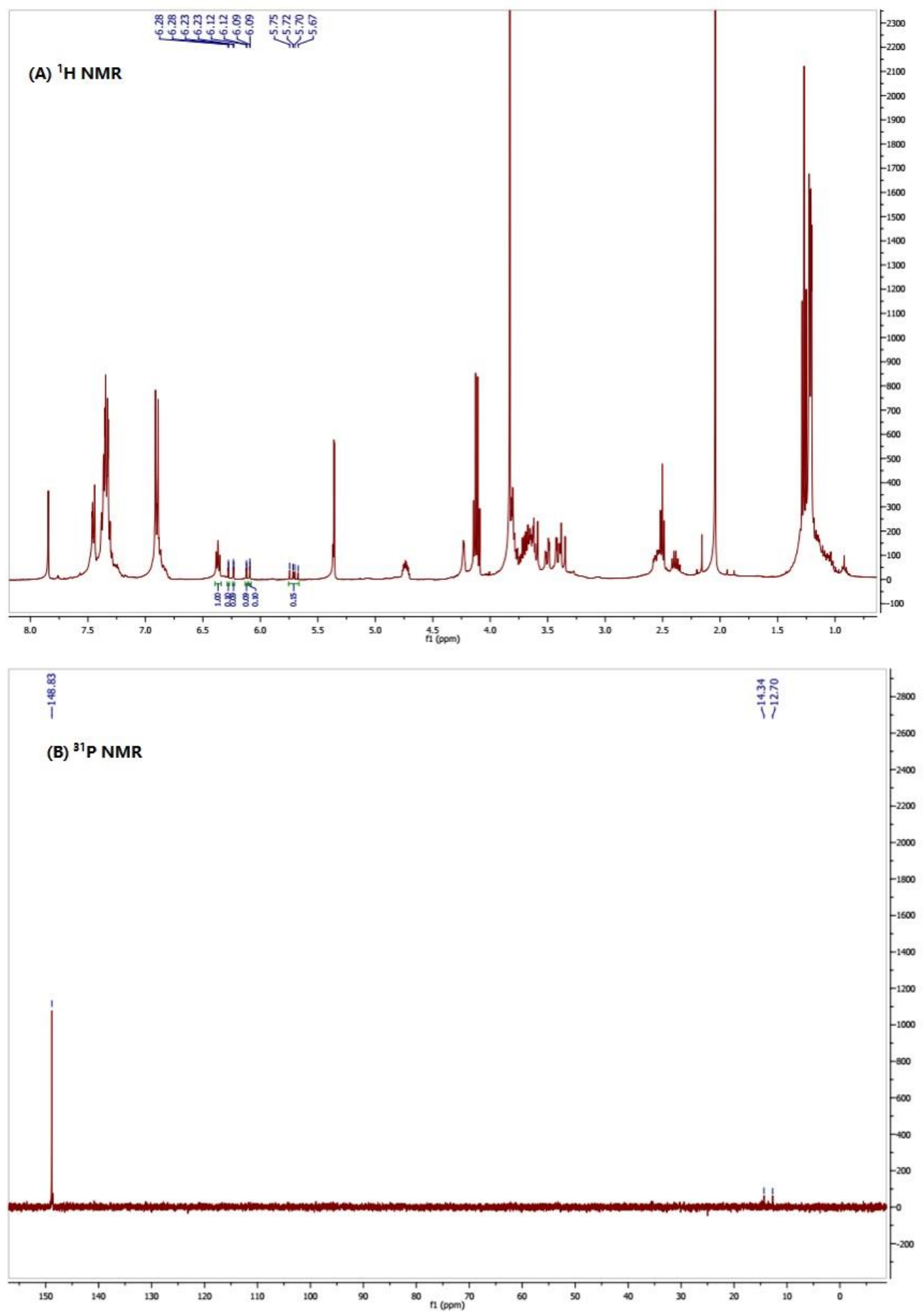

Figure 19. ${ }^{1} \mathrm{H}(\mathbf{A})$ and ${ }^{31} \mathrm{P}(\mathbf{B})$ NMR spectra showing decomposition of phosphoramidite 60 (in $\mathrm{CD}_{2} \mathrm{Cl}_{2}$ at room temperature for $15 \mathrm{~h}$ ) 


\subsubsection{Synthesis of $\mathrm{AvdU}$ and $\mathrm{AvdC}$ by $\mathrm{Ag}_{2} \mathrm{CO}_{3}$ catalyzed hydroazidation}

From several methods developed for the synthesis of vinyl azides, ${ }^{37,115-117}$ I adopted hydroazidation of alkyne with trimethylsilyl azide $\left(\mathrm{TMSN}_{3}\right)$ in the presence of $\mathrm{Ag}_{2} \mathrm{CO}_{3}$ as catalyst. ${ }^{115}$ Thus, reaction of readily available acetyl-protected 5-ethynyl-2'deoxyuridine ${ }^{110,118} \mathbf{6 2}$ with $\mathrm{TMSN}_{3}$ in the presence of $\mathrm{Ag}_{2} \mathrm{CO}_{3}$ produced regioselectively $\alpha$-vinyl azide 64 in 52\% yield (Scheme 13). Deacetylation of 64 yielded 5-(1-azidovinyl)2'-deoxyuridine (AvdU, 21) in $90 \%$ yield. Peaks of the two terminal olefin protons at $\delta$ $5.00 \mathrm{ppm}$ and $5.91 \mathrm{ppm}$ in ${ }^{1} \mathrm{H}$ NMR and two vinylic carbons at $\delta 101.3$ and $137.4 \mathrm{ppm}$ in ${ }^{13} \mathrm{C}$ NMR were diagnostic for structure 21.
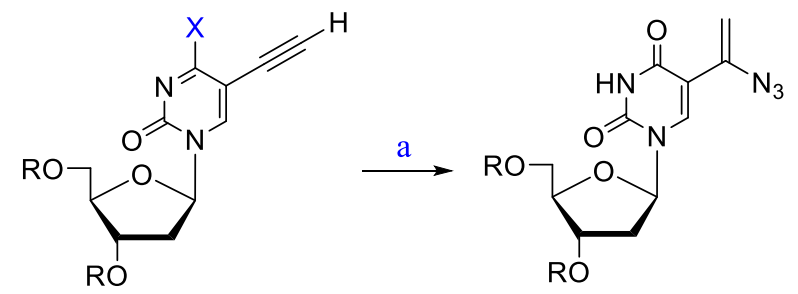

$$
\begin{aligned}
& \text { 62: } R=A c, X=O H \\
& \text { 63a: } R=A c, X=N_{2} \\
& \text { 63b: } R=H, X=\mathrm{NH}_{2}
\end{aligned}
$$
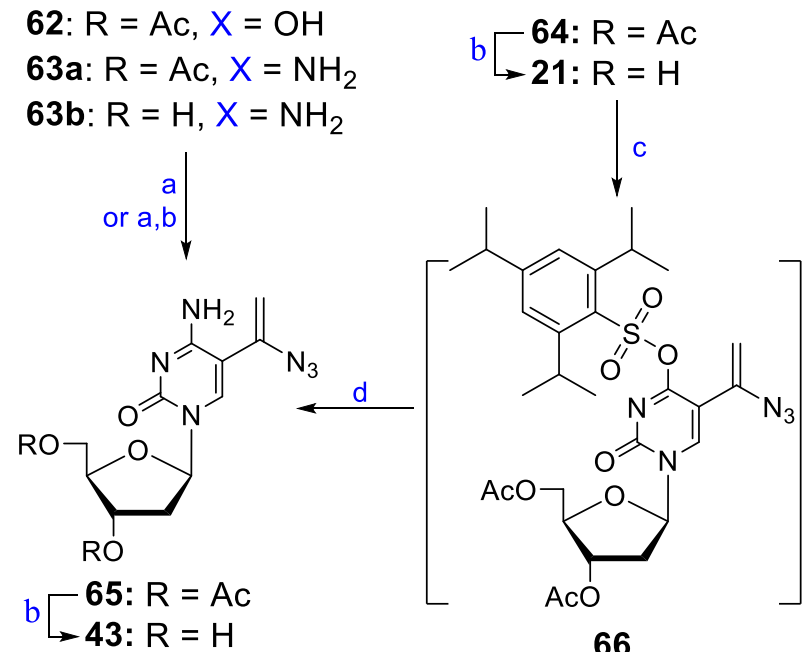

Reagents and conditions: (a) TMSN $3, \mathrm{Ag}_{2} \mathrm{CO}_{3}, \mathrm{H}_{2} \mathrm{O}$, DMF, $80{ }^{\circ} \mathrm{C}, 1 \mathrm{~h}$; (b) $\mathrm{NH}_{3} / \mathrm{MeOH}, 0{ }^{\circ} \mathrm{C}$ to rt, overnight. (c) TIPBS-Cl, DMAP, TEA, $\mathrm{CH}_{2} \mathrm{Cl}_{2}$, rt, 1 h; (d) aq. $\mathrm{NH}_{3}$, THF, rt, overnight.

Scheme 13. Strategies for the synthesis of 5-(1-azidovinyl)-2'-deoxyuridine (AvdU, 21) and 5-(1-azidovinyl)-2'-deoxycytidine (AvdC, 43). 
Hydroazidation of the $3^{\prime}, 5^{\prime}$-di-O-acetyl-5-ethylnyl-2'-doxycytidine $\mathbf{6 3 a}^{119}$ with $\mathrm{TMSN}_{3} / \mathrm{Ag}_{2} \mathrm{CO}_{3}$ gave desired vinyl azide $\mathbf{6 5}$ in addition to a fluorescent by-product, which was characterized as 3',5'-di-O-acetyl-5-(1H-1,2,3-triazol-4-yl)-2'-deoxycytidine (diAc-5TrzdC, 83, see Table 5 at section 3.3.1.1). The chemistry of these 1,2,3-triazol-4-yl analogues will be further discussed at section 3.3. Deacetylation of $\mathbf{6 5}$ provided 5-(1-azidovinyl)-2'-deoxycytidine (AvdC, 43) in 51\% overall yield from 63a. AvdC 43 was also obtained in a $34 \%$ yield by hydroazidation of the unprotected 5-ethynyl-2'deoxycytidine ${ }^{120}$ 63b. A third method to prepare AvdC 43 was developed via conversation of uracil ring in $\mathbf{6 4}$ to a cytosine counterpart. Thus, treatment of 64 with 2,4,6-triisopropylbenzenesulfonyl chloride (TIPBSCl) followed by treatment of the resulting 4-O-TIPBS-protected intermediate 66 with aq. $\mathrm{NH}_{3}$ afforded AvdC 43.

The vinylazides were reported to be involved in thermal- and photo-induced reactions, ${ }^{121}$ thus the decomposition of AvdU 21 under UV was carried out to investigate the potential application of AvdU 21 as a UV-activated/enhanced drug (Scheme 14). The UV-induced reaction was performed in a dark box equipped with a $254 \mathrm{~nm}$ UV lamp (UVG-11, 4 W, 0.16 Amps). After 1.5 h UV irradiation, AvdU 21 in the $\mathrm{MeOH}$ solution was all converted to two major products, which were characterized by NMR to be 5-formyl-2'-deoxyuridine 67 and 5-azirinyl-2'-deoxyuridine 68 . This result would support the reported enhancement of the cytotoxicity of AvdU by UV light. ${ }^{68}$ 
<smiles>C=C(N)c1cn(C2CC(O)C(CO)O2)c(=O)[nH]c1=O</smiles>

21

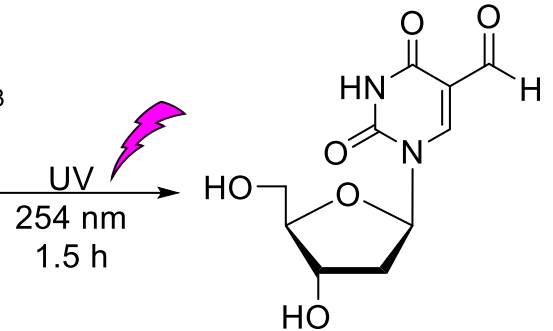

67

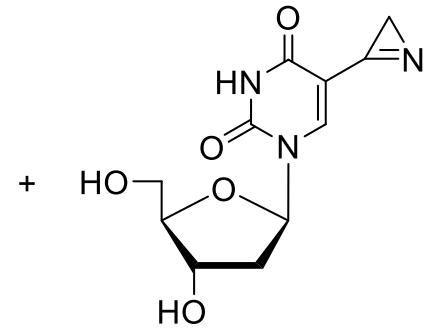

68

Scheme 14. Decomposition of AvdU under 254 nm UV

Synthesis 3'-CEP-5'-DMT-AvdU 70 (Scheme 15) was also attempted following the procedure developed for AmdU (Scheme 12). Treatment of AvdU 21 with DMTCl in pyridine provided 5'-DMT-AvdU $(69,60 \%)$. After the phosphitylation, the desired phosphoramidite diastereomers could be observed on TLC with $90 \%$ conversion. However attempted purification on silica gel column resulted in excessive decomposition most probably as a result of the higher reactivity of the vinyl azide, ${ }^{121}$ as compared to the alkyl azides, towards Staudinger reduction.

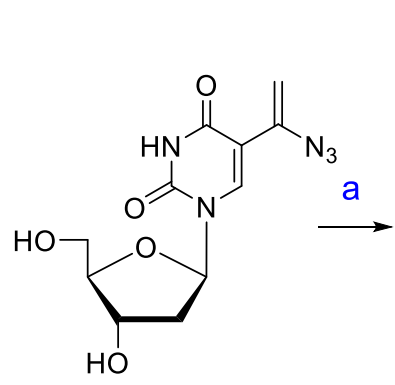

21

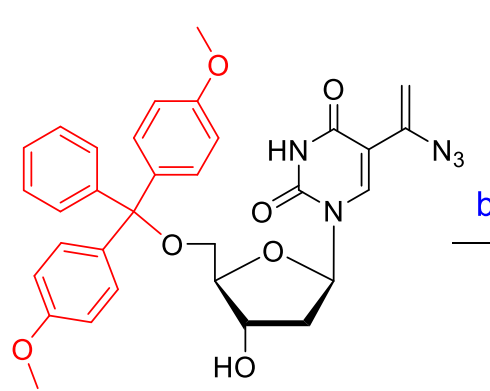

69

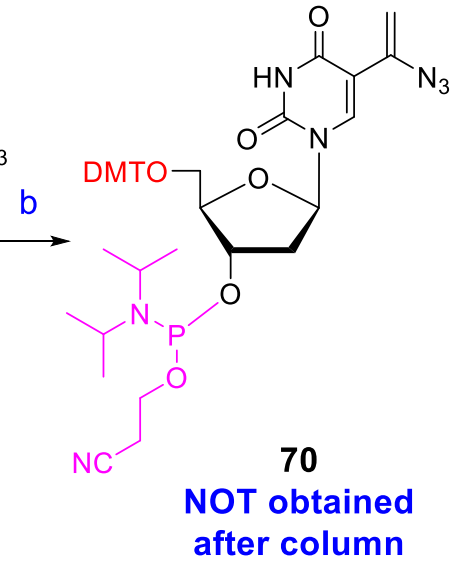

after column

Reagents and conditions: (a) DMTCl, pyridine, rt, 2 h; (b) 2-Cyanoethyl $N, N$ diisopropylchlorophosphoramidite, DIPEA, DCM, rt, 10 min.

Scheme 15. Attempted 3'-phosphitylation of AvdU 21 


\subsubsection{Polymerase-catalyzed incorporation of AmdU 5'-triphosphate and AmdC 5 '-triphosphate into DNA}

\subsubsection{Synthesis of $\mathrm{C} 5$ azido-modified pyrimidine nucleotides}

I attempted to synthesize C5 azido-modified pyrimidine nucleotide to investigate their polymerase-catalyzed incorporations into DNA. Moreover, these nucleotides can be used to study the effect of phosphate moiety on the subsequent radical reactions of the initial aminyl radicals generated from the azido group.

For the triphosphorylation, tributylammonium pyrophosphate (TBAPP, 73), one of the necessary starting materials, was prepared by modified ion-exchange procedure using DOWEX $^{\mathrm{R}}$ 50WX2 hydrogen form (Scheme 16). ${ }^{122}$ Sodium pyrophosphate 71 aqueous solution $(0.5 \mathrm{M}, \mathrm{pH}=9)$ was passed through DOWEX resin $(15 \mathrm{~g}$ resin per $1 \mathrm{mmol}$ sodium pyrophosphate) to give pyrophosphoric acid 72 aqueous solution $(\mathrm{pH}=1)$, into which 2 equivalents of tributylamine (TBA) was added. The resulting mixture was stirred at rt until homogeneous solution $(\mathrm{pH}=4-5)$ was obtained. Water was evaporated and coevaporated with acetonitrile to dry. The residue was dried under high vacuum for $24 \mathrm{~h}$ to give TBAPP 73 as a pale solid, into which argon was filled and DMF was added to prepare $0.5 \mathrm{M}$ solution for the triphosphorylation. The Dowex Resins can be recycled by washing the column with 2 column volumes of 5\% (1.5 M) $\mathrm{HCl}$ and then with sufficient DI water until the $\mathrm{pH}$ return to be around 6 .

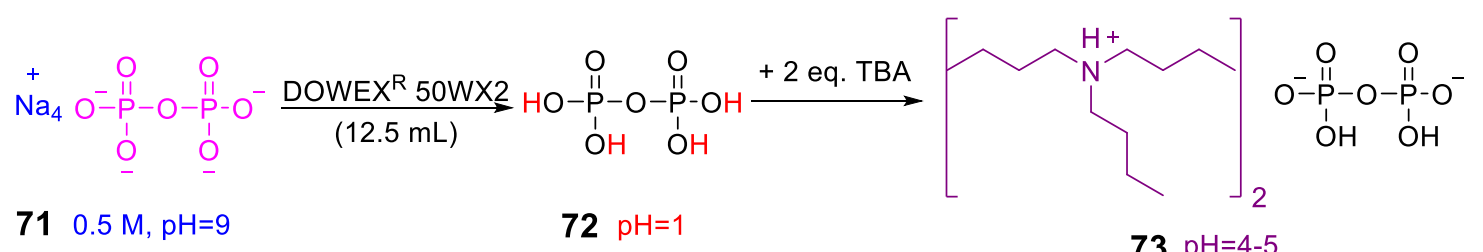

Scheme 16. Preparation of tributylammonium pyrophosphate (TBAPP) 
AmdU 5'-monophosphate (AmdUMP, 19, 70\%, Scheme 17) was prepared via the phosphorylation of AmdU 18 with $\mathrm{POCl}_{3}$ employing modified Yoshikawa protocols ${ }^{123,124}$ in the presence of proton sponge followed by quenching of the crude reaction mixture with triethylammonium bicarbonate buffer $(\mathrm{TEAB})$ and purification on a DEAE-Sephadex column. The reaction of AmdU 18 with $\mathrm{POCl}_{3}$ in the presence of proton sponge followed by addition of $0.5 \mathrm{M}$ TBAPP in DMF and then tributylamine (TBA) yielded AmdU 5'-triphosphate (AmdUTP, 20, 76\%, Scheme 17) after DEAE-Sephadex purification. The phosphates were characterized by ${ }^{1} \mathrm{H},{ }^{13} \mathrm{C},{ }^{31} \mathrm{P}$ NMR as well as HR-MS (see experimental section for the data). The ${ }^{31} \mathrm{P}$ NMR showed two doublet peaks at $\delta-10.80(J=19.8, \gamma)$ and $\delta-11.64(J=19.8, \alpha)$ as well as one triple peak at $\delta-23.25(J=19.7, \beta)$. The proton sponge was used to accelerate the phosphorylation and provide reaction conditions suitable for acid-labile deoxynucleosides by neutralizing the formed $\mathrm{HCl}^{123}$ The AmdC 42 was converted to AmdC 5'-triphosphate (AmdCTP, 74, 23\%) by analogous phosphorylation (Scheme 17).

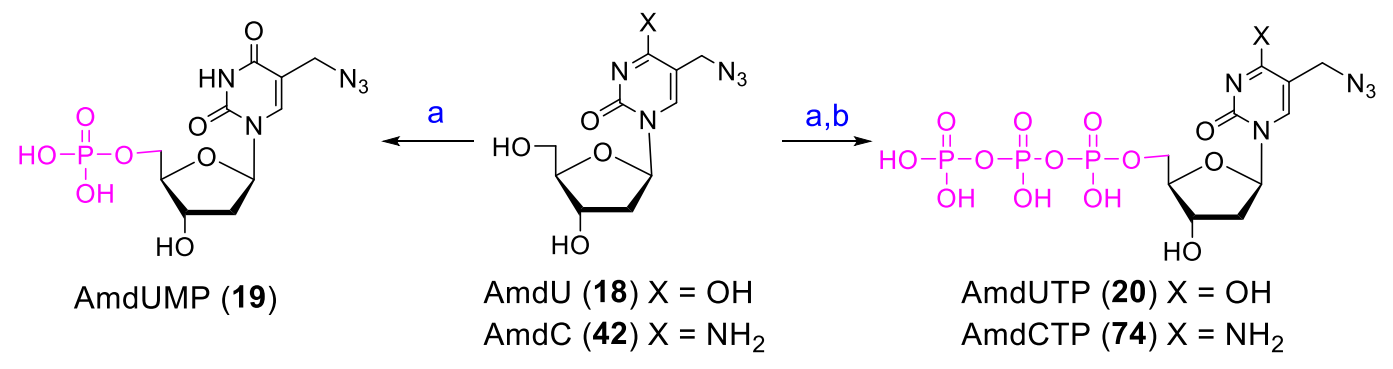

(a) $\mathrm{PO}(\mathrm{OMe})_{3}, \mathrm{POCl}_{3}$, proton sponge, $0{ }^{\circ} \mathrm{C}, 30 \mathrm{~min}$; (b) TBAPP, TBA, DMF, $0{ }^{\circ} \mathrm{C}, 2 \mathrm{~min}$.

Scheme 17. Synthesis of AmdUMP, AmdUTP, and AmdCTP

I was planning to synthesize AvdU 5'-triphosphate (AvdUTP 76, Scheme 18), following the analogous phosphorylation of AvdU 21, but because of the instabilities of azidovinyl unit in AvdU the reactions provided 5-acetyl-2'-deoxyuridine 5'-triphosphate 
$\mathbf{7 5}^{125}$ rather than the desired AvdUTP 76. To circumvent instability of vinylazide moiety in the phosphorylation reactions, post-synthetic route was also designed for the synthesis of 76 (Scheme 19). Thus, 5-ethynyl-2'-deoxyuridine 5'-triphosphate $\mathbf{7 8}$ was prepared from 77 (46\%) employing analogous phosphorylation conditions. However, the hydroazidation of $\mathbf{7 8}$ also yielded 5-acetyl-2'-deoxyuridine 5'-triphosphate 75. Addition of 10 eq. Et $3 \mathrm{~N}$ into the hydroazidation reaction to stabilize the product $\mathbf{7 6}$ also failed. The presence of two peaks at the 5.04 and $5.54 \mathrm{ppm}$ in the crude ${ }^{1} \mathrm{H}$ NMR indicated the formation of desired AvdUTP 76, which was not stable and decompose in the reaction residue. Because of the instabilities of the AvdUTP 76, the enzymatic incorporation of AvdU 21 into DNA fragment could not be carried out.

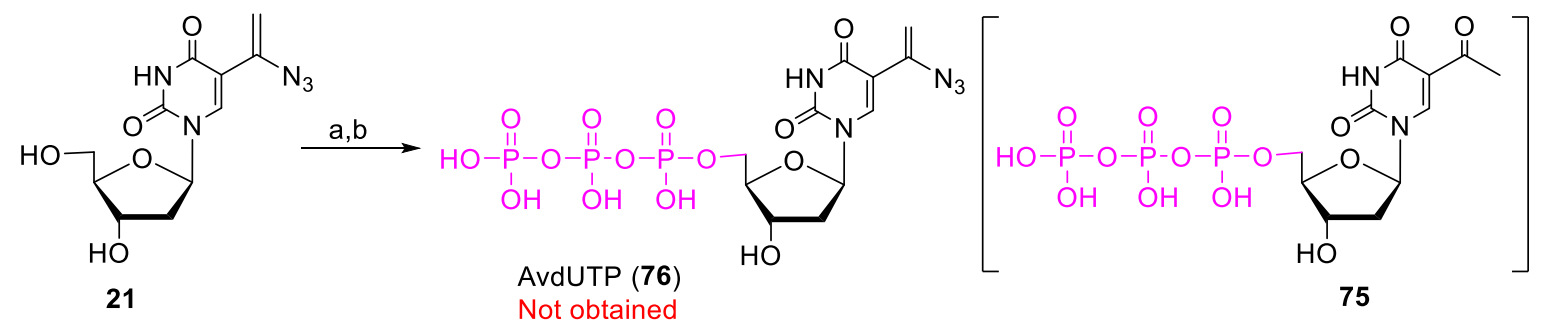

(a) $\mathrm{PO}(\mathrm{OMe})_{3}, \mathrm{POCl}_{3}$, proton sponge, $0^{\circ} \mathrm{C}, 30 \mathrm{~min}$; (b) TBAPP, TBA, DMF, $0{ }^{\circ} \mathrm{C}, 2 \mathrm{~min}$.

Scheme 18. Attempted synthesis of AvdUTP 76

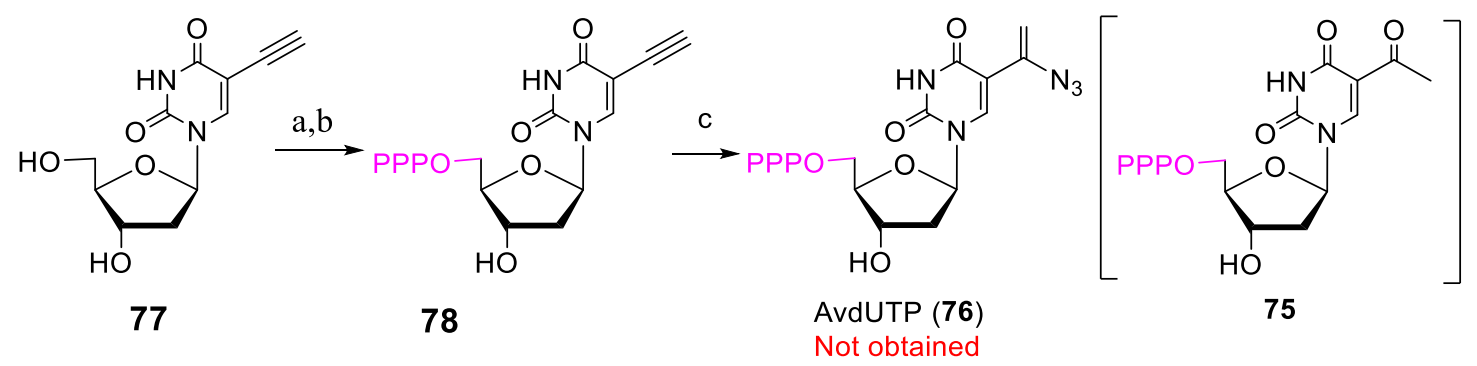

(a) $\mathrm{PO}(\mathrm{OMe})_{3}, \mathrm{POCl}_{3}$, proton sponge, $0{ }^{\circ} \mathrm{C}, 30 \mathrm{~min}$; (b) TBAPP, TBA, DMF, $0{ }^{\circ} \mathrm{C}, 2$ min. (c) $\mathrm{TMSN}_{3}, \mathrm{Ag}_{2} \mathrm{CO}_{3}, \mathrm{H}_{2} \mathrm{O}$, DMF, $80^{\circ} \mathrm{C}, 1 \mathrm{~h}$

Scheme 19. Attempted post-synthetic procedure for AvdUTP 76 


\subsubsection{Polymerase-catalyzed incorporation of AmdUTP and AmdCTP into DNA}

Since DNA replication is essential for proliferation of cancer cells, and cancer radiation therapy can induce DNA damage and initiate DNA repair such as base excision repair (BER) during which nucleotides are incorporated into double-strand DNA (dsDNA) by replication and repair DNA polymerases, it is important to determine whether an AmdUTP can also be incorporated into dsDNA during DNA replication and repair. The incorporation of AmdUTP will provide new insights into the potential application of AmdU 18 in cancer treatment. In collaboration with Dr. Liu from our department, I determined the incorporation of an AmdUTP 20 into dsDNA by the E. coli Klenow fragment of DNA polymerase I (pol I) and human repair DNA polymerase, DNA polymerase $\beta$ (pol $\beta$ ) using AmdUTP 20 and synthesized oligonucleotide substrates that mimic the intermediates formed during DNA replication and repair (see section 4.2 for the DNA fragments sequences and other details). The incorporation of an AmdUTP 20 by the Klenow fragment and pol $\beta$ during DNA leading and lagging strand synthesis, and BER was examined with an open template, one-nucleotide gap substrates, and one-nucleotide substrate containing a 5'-THF (a tetrahydrofuran ring which mimics a sugar residue) at the downstream strand, respectively (Figure 20). The results showed that the Klenow fragment at 0.1-5 U efficiently inserted an AmdUTP 20 with all the substrates to basepair with a template A (Figure 20A, lanes 2-6; Figure 20B, lanes 8-12; Figure 20C, lanes 14-17). With the open template, the Klenow fragment also continuously inserted an AmdUTP 20 to mispair with a template $\mathrm{G}, \mathrm{T}$ and $\mathrm{T}$, respectively (Figure $20 \mathrm{~A}$, lanes 2-6). On the other hand, pol $\beta$ incorporated only one AmdUTP 20 in the open template substrate at a concentration of $10 \mathrm{nM}$ (Figure 20D, lane 6), whereas it efficiently incorporated one AmdUTP to fill in the 
one-nucleotide gap with the gapped substrate at concentrations of 0.5-10 nM (Figure 20E, lanes 8-12). Similarly, AmdUTP 20 was efficiently incorporated into one-nucleotide gapTHF substrate by both pol I (Figure 20C, lanes 14-17) and pol $\beta$ (Figure 20F, lanes 14-17) at $0.5-5 \mathrm{U}$ and 1-25 $\mathrm{nM}$, respectively.
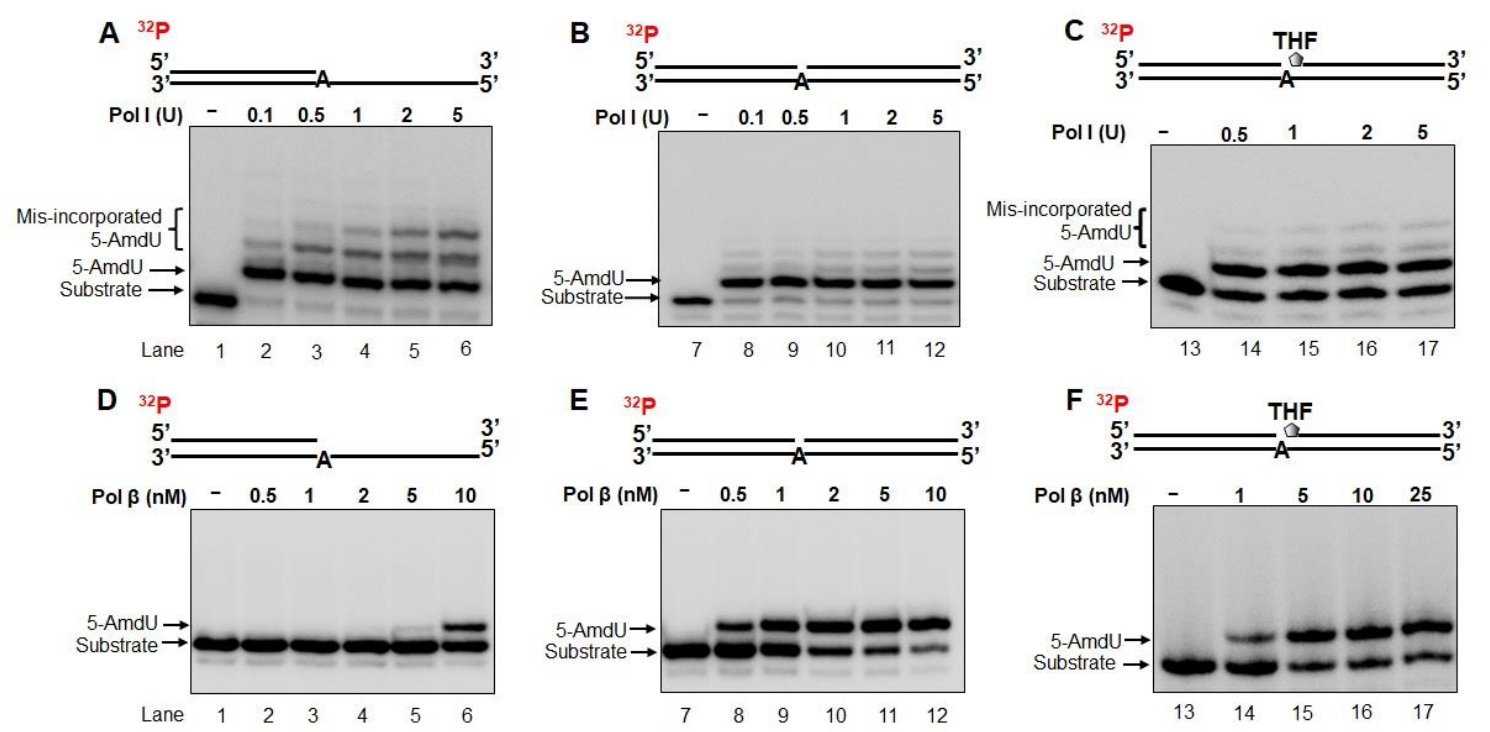

Figure 20. Incorporation of AmdUTP 20 into duplex DNA by pol I and pol $\beta$.

Measurement of incorporation of an AmdUTP by Klenow fragment on the open template (A) and one-nucleotide gap substrate (B), and the one-nucleotide gap substrate containing a 5'-THF at the downstream strand (C). Measurement of incorporation of an AmdUTP by pol $\beta$ on the open template (D) and one-nucleotide gap substrate $(\mathbf{E})$, and substrate containing a 5'-THF at the downstream strand (F). Lanes 1, 7, and 13 represent substrate only. Lanes 2-6, 8-12, and 14-17 represent the products resulting from incorporation of an AmdUTP.

Further characterization of incorporation of the nucleotide in the presence of the other three nucleotides dATP, dGTP and dCTP, showed that an AmdUTP 20 inserted by pol I and pol $\beta$ was further extended by the polymerases. Pol I (0.5-5 U) extended an AmdUTP and continued to perform DNA synthesis to the end of the template with all substrates (Figure 21A-C), whereas pol $\beta$ at the concentrations of 1-25 nM extended the AmdUTP and further synthesized 9-10 nucleotides (Figure 21D-F). The results indicate that the 
polymerase readily inserted the nucleotide into dsDNA and continued to extend the nucleotide during DNA replication and repair.
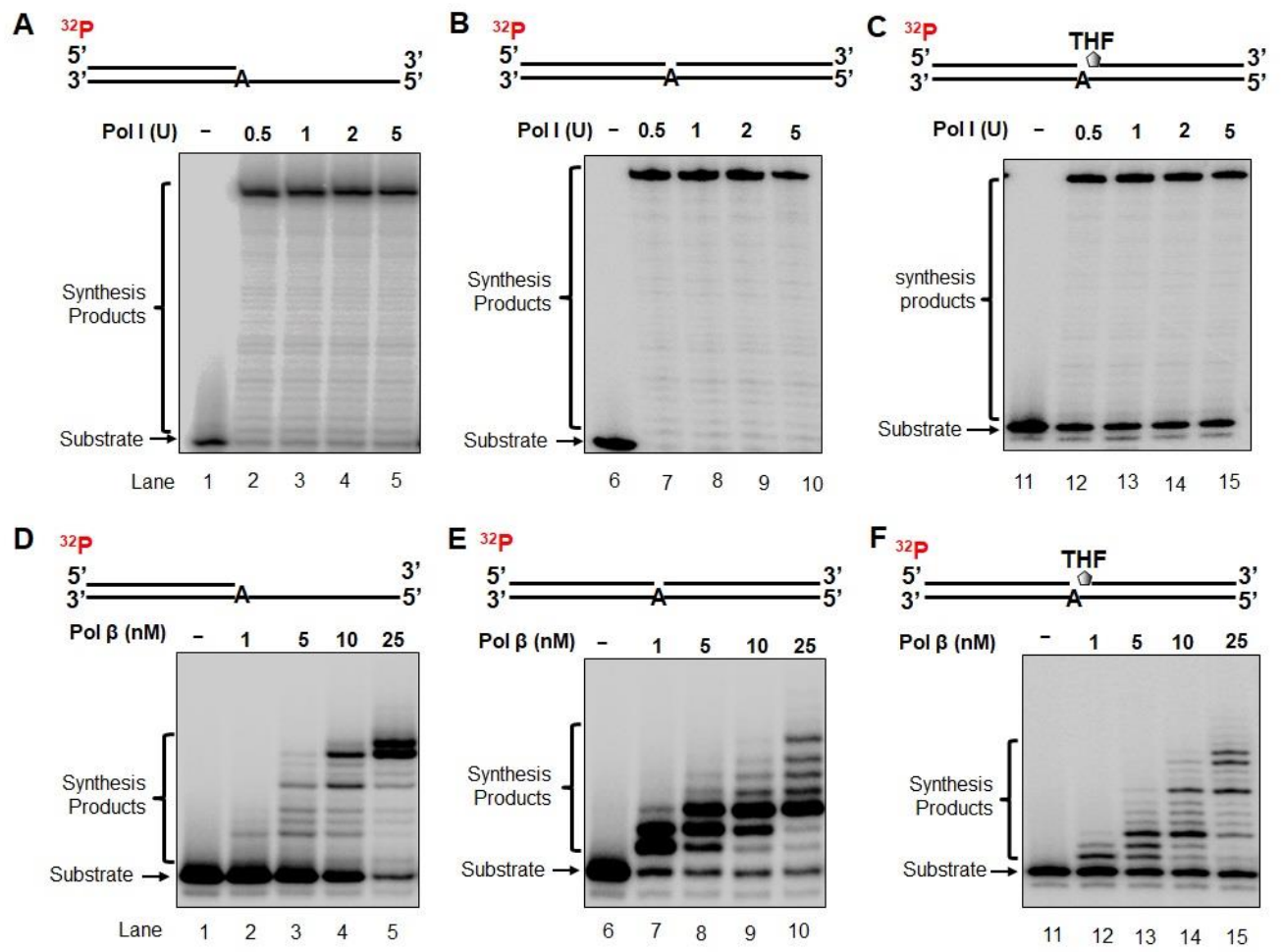

Figure 21. Extension of an incorporated AmdUTP 20 into a duplex DNA by pol I (A-C) and pol $\beta$ (D-E) during DNA leading and lagging strand synthesis and BER.

DNA synthesis by pol I on the open template $(\mathbf{A})$, one-nucleotide gap substrate $(\mathbf{B})$, and onenucleotide gap substrate with a 5'-THF (C). DNA synthesis by pol $\beta$ on the open template (D), onenucleotide gap substrate (E), and one-nucleotide gap substrate with a 5'-THF (F). Lanes 1, 6, and 11 represent substrate only. Lanes 2-5, 7-10, and 12-15 represent DNA synthesis products.

To further examine if AmdU residues incorporated by DNA polymerases can be ligated into duplex DNA during DNA replication and repair, we determined the formation of ligation products resulting from incorporation of AmdUTP in the presence of dATP, dGTP and dCTP with the one-nucleotide gap substrates without or with a THF residue that mimics a sugar residue. We found that with the one-nucleotide gap substrate, pol I ranging from 0.5-5 U efficiently incorporated AmdUTP and other nucleotides, and this allowed conversion of all of the substrates into the ligation products, i.e. ligated products by $10 \mathrm{nM}$ 
DNA ligase I (LIG I; Figure 22A, lanes 2-5). For the one-nucleotide gap substrate, incorporation of AmdUTP by pol $\beta$ at $1 \mathrm{nM}$ only resulted in a small amount of ligated products (Figure 22C, lane 2). With increasing concentrations of pol $\beta$ from $5 \mathrm{nM}$ to 25 $\mathrm{nM}$, the amount of the ligated products significantly increased (Figure 22C, lanes 3-5) indicating that increased incorporation of AmdUTP 20 facilitated the production of ligated products.

A
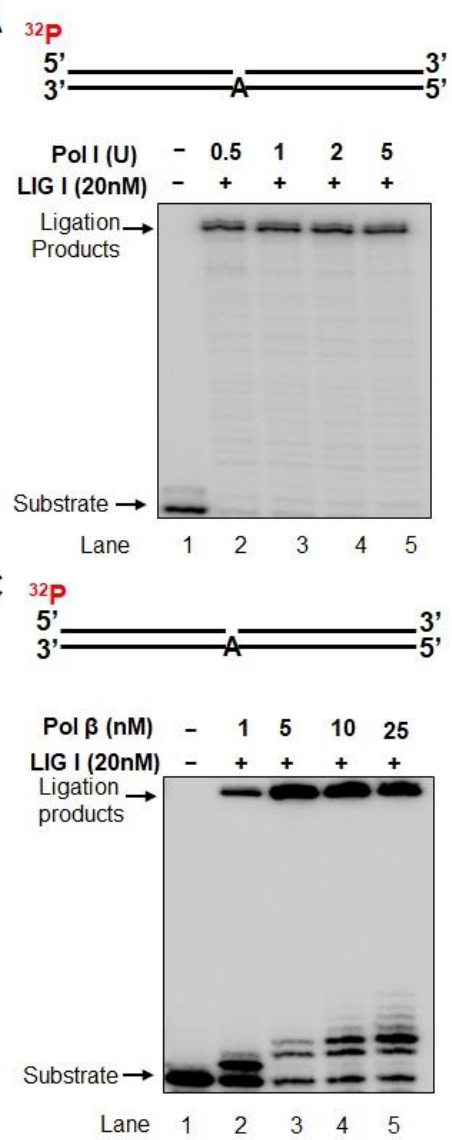

B 32

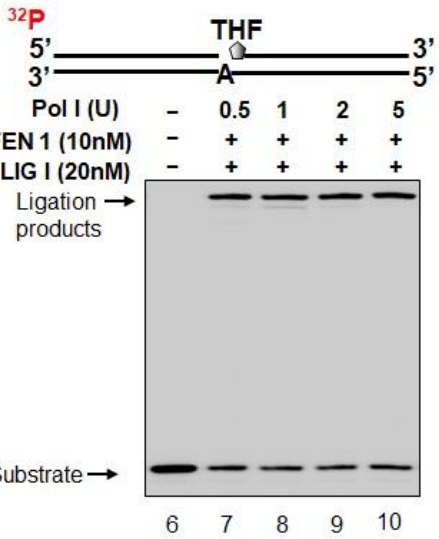

D

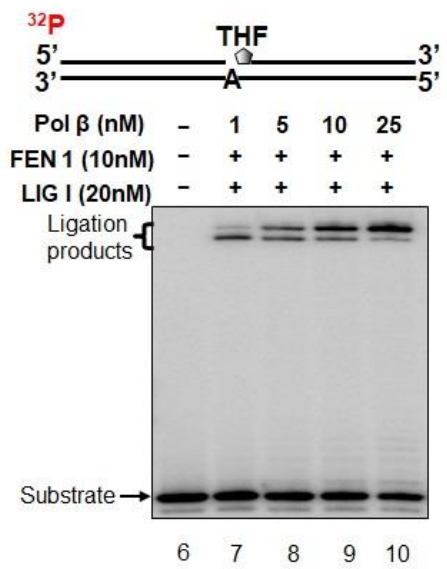

Figure 22. Ligation after incorporation of AmdUTP 20 into duplex DNA during lagging strand maturation and BER.

Measurement of ligation products, i.e. DNA lagging strand maturation products resulting from incorporation of AmdUTP by pol I (A) and pol $\beta$ (C) on the one-nucleotide gap substrate. Lanes 1 represents substrate only. Lanes 2-5 represent the ligation products resulting from incorporation of AmdU. Measurement of repaired products resulting from BER mediated by incorporation of AmdUTP by pol I (B) and pol $\beta$ (D) on the one-nucleotide gap substrate with a 5'-THF at the downstream primer. Lane 6 represents substrate only. Lanes 7-10 represent repaired products resulting from incorporation of AmdUTP. 
To determine if AmdUTP 20 incorporated by pol I and pol $\beta$ can be also ligated into a dsDNA during DNA BER, we further determined the incorporation of $\mathbf{2 0}$ during BER with the one-nucleotide gap substrate with a 5'-phosphorylated THF residue in the presence of $10 \mathrm{nM}$ LIG I and $10 \mathrm{nM}$ flap endonuclease 1 (FEN1). We found that similar to its incorporation of AmdUTP with the one-nucleotide gap substrate, pol I (0.5, 1, 2, and $5 \mathrm{U})$ performed strong DNA synthesis activity leading to the production of the full-length repair products (Figure 22B, lanes 7-10). The results indicate that AmdUTP can be efficiently incorporated into duplex DNA by Pol I during BER. On the other hand, incorporation of AmdUTP by pol $\beta(1,5,10$, and $25 \mathrm{nM})$ also resulted in the repaired products (Figure 22D, lanes 7-10). However, the repaired products resulting from pol $\beta$ contain the repair products with the full-length or with the size that is one-nucleotide shorter than the full-length. With increasing concentrations of pol $\beta$, the amount of the full-length repaired products was significantly increased, whereas that of the short repair products was significantly decreased (Figure 22D, compare lanes 8-10 with lane 7). The result suggests that inefficient incorporation of AmdUTP 20 by a low concentration of pol $\beta$ resulted in a gap during BER. This subsequently allowed the template to loop out leading to ligation and production of the short repaired product during BER.

Our results further indicate that AmdUTP 20 can be efficiently incorporated into dsDNA by DNA replication and repair polymerases during DNA replication and repair. This is consistent with a recent finding showing that AmdU were efficiently incorporated into newly synthesized DNA in human cancer cells. ${ }^{40}$ Our results further demonstrated that the incorporation of AmdU in cancer cells is mediated by DNA replication and repair polymerases. 
The incorporation of a AmdCTP 74 by pol $\beta$ during DNA leading and lagging strand synthesis, and BER was also examined with an open template, one-nucleotide gap substrate, and one-nucleotide gap-THF substrate, respectively (Figure 23; see section 4.2 for the DNA fragments sequences and other details). The results showed that pol $\beta$ at 1-25 nM efficiently inserted a AmdCTP in all three substrates to basepair with a template G (Figure 23A, lanes 2-5; 23B, lanes 6-10; 23C, lanes 12-15). Compared with the incorporation of an AmdUTP by pol $\beta$ (Figure 20), $1 \mathrm{nM}$ pol $\beta$ incorporated a significant amount of an AmdCTP into the open template substrate (Figure 23A, lane 2), whereas the same concentration of pol $\beta$ failed to incorporate an AmdUTP (Figure 20D, lane 3). Also, pol $\beta$ at $10 \mathrm{nM}$ incorporated an AmdUTP on the substrate with significantly reduced amount (Figure 20D, lane 6) compared with its incorporation with AmdCTP (Figure 23A, lane 4). Similarly, for the one-nucleotide gap substrate with or without a 5'-THF pol $\beta$ at $1 \mathrm{nM}$, $5 \mathrm{nM}$, and $10 \mathrm{nM}$, incorporated an AmdUTP 20 with a reduced amount (Figure 20E, lanes 8-12 and Figure 20F, lanes 14-17) compared with its incorporation of an AmdCTP 74 at the same concentrations (Figure 23B, lanes 7-10 and Figure 23C, lanes 12-15).
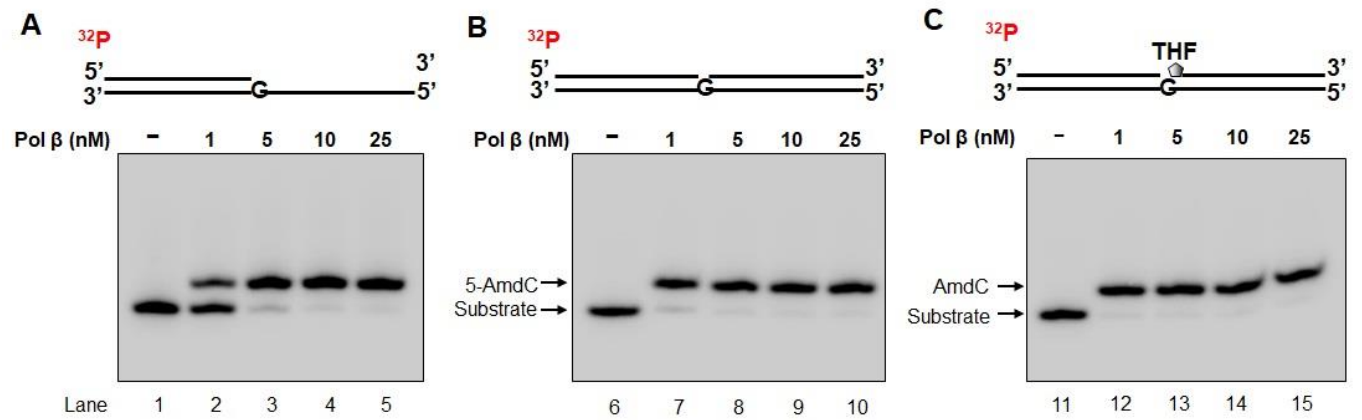

Figure 23. Incorporation of AmdCTP into duplex DNA by pol $\beta$. Incorporation of a AmdCTP by pol $\beta$ on the open template (A), one-nucleotide gap substrates (B), and one-nucleotide gap-THF substrates. Lanes 1, 6, and 11 represent substrate only. Lanes 2-5, 7-10, and 12-15 illustrate the products resulting from incorporation of a AmdCTP by pol $\beta$. 


\subsubsection{One-electron formation of aminyl radicals from 5-azidomethyl and}

\section{5-azidovinyl pyrimidine nucleosides and their subsequent reactions}

The combination of ESR spectral studies and theoretical calculations provide evidences of radiation-produced electron-mediated formation of $\pi$-type aminyl radical (RNH•) and of its conversion to the $\sigma$-type iminyl radical $(\mathrm{R}=\mathrm{N} \bullet$ ) in samples of AmdU 18 (Figure 24), AmdC 42 (Figure 25), AvdU 21 (Figure 26) and AvdC 43 in glassy systems (7.5 M $\left.\mathrm{LiCl} / \mathrm{D}_{2} \mathrm{O}\right)$.

\subsubsection{Formation of $\pi$-type $\mathrm{RNH} \bullet$ and its bimolecular conversion to the $\sigma$-type $\mathrm{R}=\mathrm{N} \bullet$} in AmdU and AmdC

The ESR spectra of AmdU $\mathbf{1 8}$ after radiation-produced prehydrated one-electron attachment at $77 \mathrm{~K}$ and stepwise annealing as well as simulated spectra are shown in Figure 24. Spectra in Figure 24A presents the ESR spectrum (blue) of the radicals formed by radiation $($ absorbed dose $=500 \mathrm{~Gy}$ at $77 \mathrm{~K}$ ) - -produced prehydrated electron attachment to $18(2.2 \mathrm{mg} / \mathrm{mL})$ in supercooled homogeneous glassy $\left(7.5 \mathrm{M} \mathrm{LiCl} / \mathrm{D}_{2} \mathrm{O}\right)$ solutions at $77 \mathrm{~K}$.

Figure 24A has a total hyperfine splitting of ca. 178.5 G. Center of this spectrum does not show the reported doublet ${ }^{126-128}$ due to $\mathrm{U}^{-}$. Wings of this spectrum show line components due to axially symmetric anisotropic nitrogen hyperfine coupling due to a single nitrogen. Sum of two isotropic $\beta$-proton couplings of ca. $93.5 \mathrm{G}$ is assigned to the central doublet. The HFCCs at Figure 24A are nearly-identical to the reported HFCCs values for $\mathrm{T}\left(\mathrm{C}^{\prime}\right)$ ')-ND• generated from 5'-azido-5'-deoxythymidine $\left(5^{\prime}\right.$-AZT $),{ }^{42}$ thus Figure $24 \mathrm{~A}$ is assigned to the $\pi$-type $\mathrm{U}-\left(5-\mathrm{CH}_{2}\right)-\mathrm{ND} \cdot$ generated from AmdU $\mathbf{1 8}$ (Scheme 20). The simulated spectrum (red) superimposed in Figure 24A nicely matches the line components due to nitrogen hyperfine couplings at the wings, the sharp outer peak of the doublet, and 
qualitatively the broad line components at the center of the blue spectrum. Detailed analysis of HFCC will be published elsewhere. ${ }^{129}$

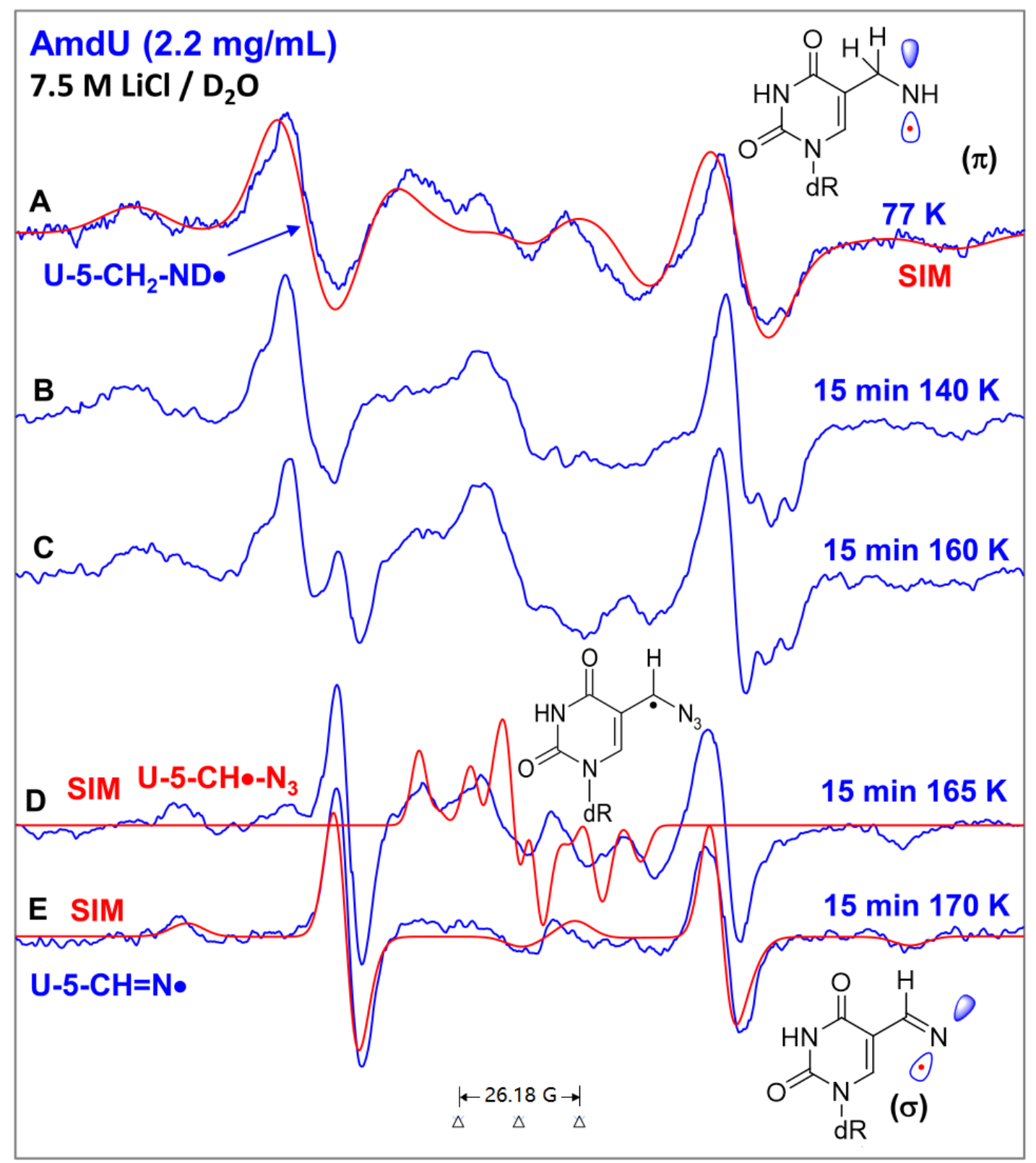

Figure 24. ESR spectra of AmdU 18 after radiation-produced prehydrated one-electron attachment at $77 \mathrm{~K}$ and stepwise annealing as well as simulated spectra

(A) ESR spectrum (blue) after radiation-produced prehydrated one-electron addition to AmdU $\mathbf{1 8}$ at $77 \mathrm{~K}$ in $7.5 \mathrm{M} \mathrm{LiCl} / \mathrm{D}_{2} \mathrm{O}$. Spectra (B) to (E) were obtained via stepwise annealing of the sample for $15 \mathrm{~min}$ at $140,160,165$, and $170 \mathrm{~K}$. All spectra were recorded at $77 \mathrm{~K}$. The red spectra in (A), (D) and in (E) are the simulated spectra. The radiation produced background $\mathrm{Cl}_{2}{ }^{-}{ }^{-}$spectrum has been subtracted from spectra A and B for clarity. 


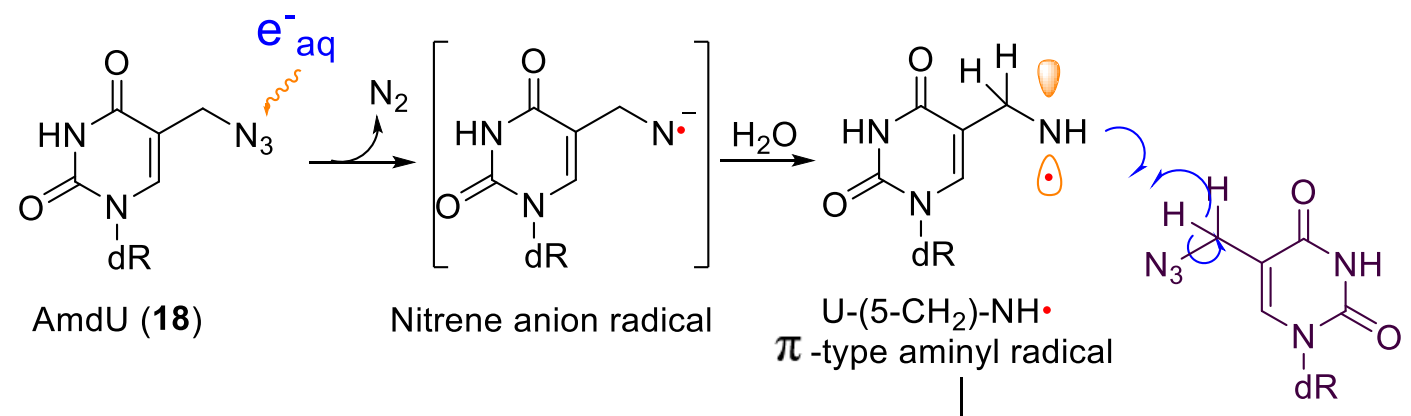

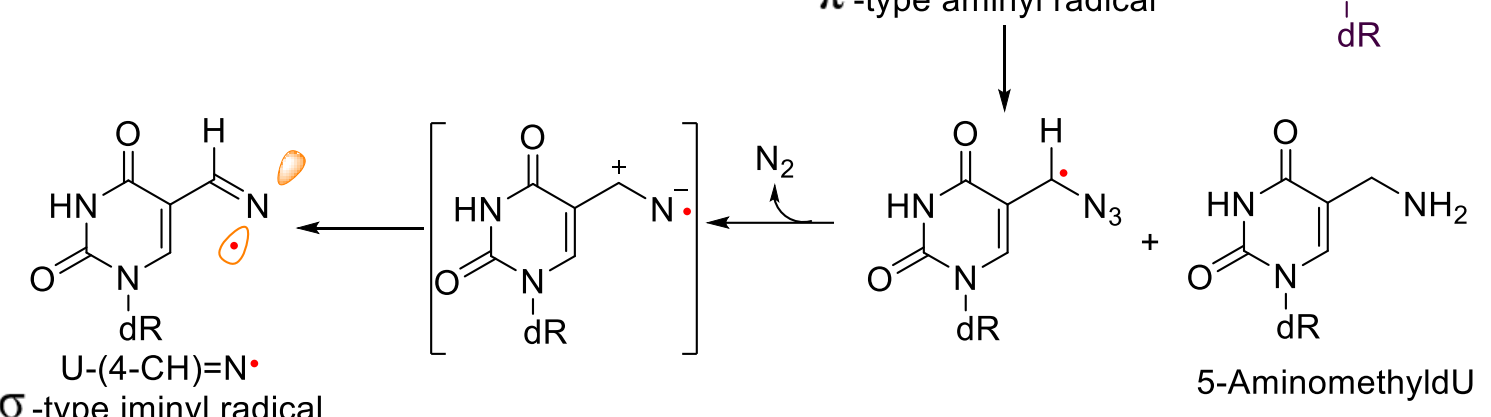
$\sigma$-type iminyl radical

Scheme 20. Formation of $\pi$-type aminyl radical from AmdU 18 and its bimolecular conversion to the $\sigma$-type iminyl radical

After subsequent annealing of AmdU sample at $140 \mathrm{~K}$ in the dark for $15 \mathrm{~min}$, spectrum was recorded at $77 \mathrm{~K}$ and is shown in Figure 24B. Upon stepwise warming, new line components are gradually developed at the center of these spectra. The line components are due to a $\mathrm{C}$-centered $\alpha$-azidoalkyl radical $\mathrm{U}-(5-\mathrm{CH} \bullet)-\mathrm{N}_{3}$ formed via a bimolecular H-atom abstraction by U-(5-CH$)-\mathrm{ND}$ - from a proximate AmdU 18 (Scheme 20). After subsequent stepwise annealing for $15 \mathrm{~min}$ in the dark at $160 \mathrm{~K}, 165 \mathrm{~K}$, and $170 \mathrm{~K}$, spectra have been recorded at $77 \mathrm{~K}$ and are shown in blue color in $(\mathrm{C})$ to $(\mathrm{E})$. Although line components due to the $\mathrm{U}-(5-\mathrm{CH} \bullet)-\mathrm{N}_{3}$ are present at the center of spectrum in $(\mathrm{C})$, these line components become prominent with good resolution at the center of the blue spectrum in (D) but are not observed at the center of the blue spectrum in (E).

The calculated HFCCs of the C-centered radicals (U- $(5-\mathrm{CH} \bullet)-\mathrm{N}_{3}$ using B3LYP/6-31G** method are found to be very similar to the HFCCs of the blue spectrum at Figure 24D. The simulated (red) spectrum of the $\mathrm{U}-(5-\mathrm{CH} \bullet)-\mathrm{N}_{3}$ superimposed on the 
center of blue spectrum in Figure 23D well matches the blue spectrum. See $\operatorname{Ref}^{129}$ for the theoretical calculation details. The $\pi$-type $\mathrm{U}-\left(5-\mathrm{CH}_{2}\right)-\mathrm{ND} \bullet$ from 18 undergoing bimolecular H-atom abstraction (Scheme 20) was studied employing samples of 5'-azido-2'5'dideoxyuridine 79 with different concentrations $(0.5 \mathrm{mg} / \mathrm{mL}$ and $5 \mathrm{mg} / \mathrm{mL})$, which is also detailed in $\operatorname{Ref}^{129}$.

The broad central doublet of $82 \mathrm{G}$ found in the blue spectrum in Figure 24E is due to one $\beta-\mathrm{H}$ of the methylene group that is attached to the $\mathrm{C} 5$ of the uracil base. In addition, anisotropic N HFCCs are very similar to those of $\mathrm{H}_{2} \mathrm{C}=\mathrm{N} \bullet{ }^{130}$ The simulated spectrum superimposed in (E) matched nicely with the blue spectrum. Therefore, the blue spectrum in $(\mathrm{E})$ was assigned to the $\sigma$-type iminyl radical, $\mathrm{U}-(5-\mathrm{CH})=\mathrm{N} \bullet$.

These results show that conversion of $\pi$-type $\mathrm{U}-\left(5-\mathrm{CH}_{2}\right)-\mathrm{ND} \bullet$ to $\sigma$-type $\mathrm{U}(\mathrm{C} 5-\mathrm{H})=\mathrm{N} \bullet$ was bimolecular involving an $\alpha$-azidoalkyl radical as intermediate (Scheme 20). $\alpha$ Azidoalkyl radicals are known to undergo facile conversion to the $\sigma$-iminyl radicals. ${ }^{131-133}$ ESR spectra of AmdC 42 after radiation-produced prehydrated one-electron attachment at $77 \mathrm{~K}$ and stepwise annealing as well as simulated spectra are shown in Figure 25. It is noted that AmdC 42 also shows the formation of $\mathrm{C}-\left(5-\mathrm{CH}_{2}\right)-\mathrm{ND} \cdot$ at $77 \mathrm{~K}$ along with its subsequent conversion to the $\sigma$-type iminyl radical, $\mathrm{C}-(5-\mathrm{CH})=\mathrm{N} \bullet$ in the temperature range (77 to $160 \mathrm{~K}$ ) accompanied with decrease of total hyperfine splitting that is similar to $\mathrm{U}-(5-\mathrm{CH})=\mathrm{N} \cdot($ Figure 25$)$. 


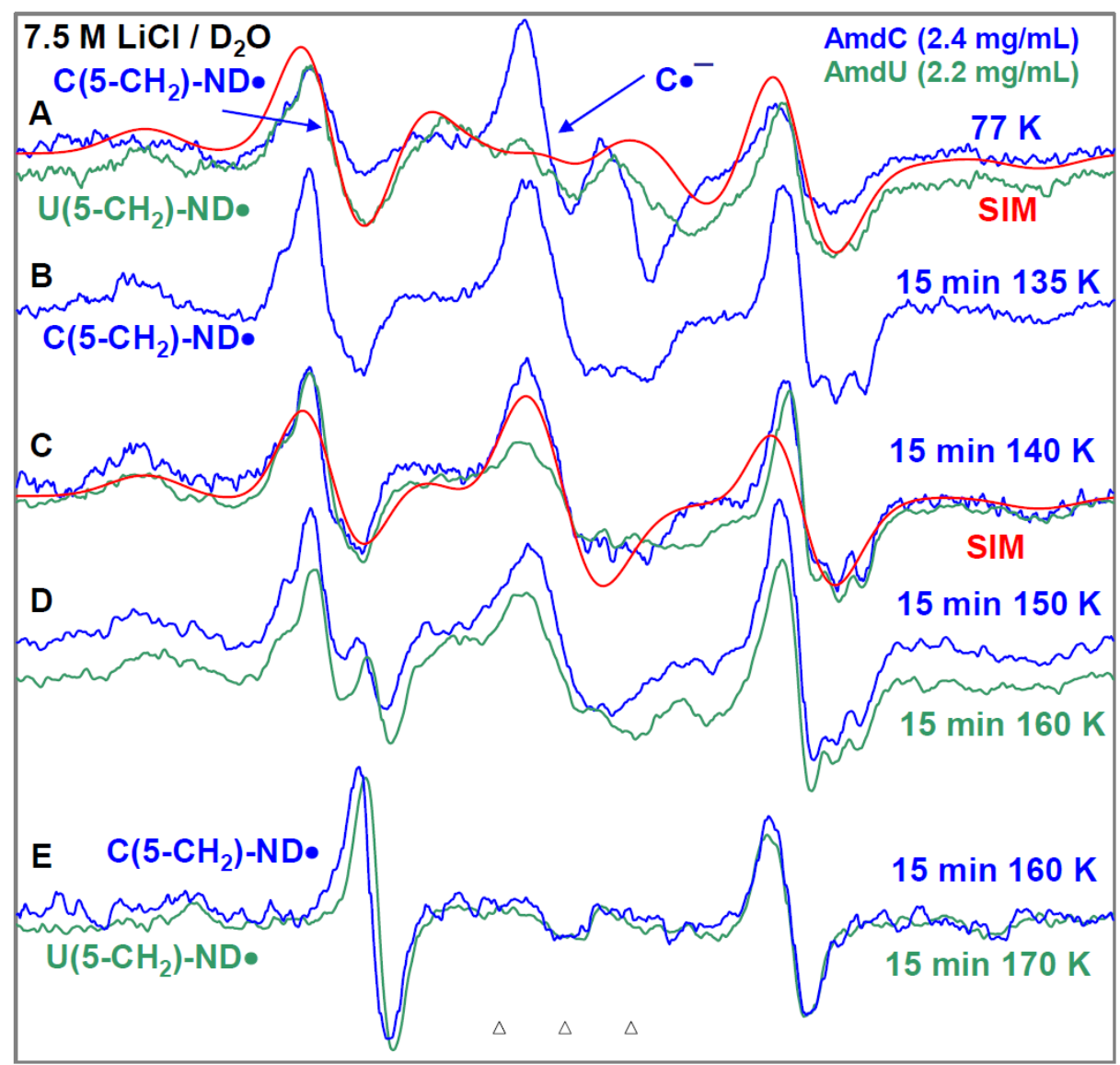

Figure 25. ESR spectra of AmdC after radiation-produced prehydrated one-electron attachment at $77 \mathrm{~K}$ and stepwise annealing as well as simulated spectra Spectra (A-D) were obtained from AmdC $42(2.4 \mathrm{mg} / \mathrm{mL})$ by subtraction of $250 \mathrm{G} \mathrm{Cl}_{2}{ }^{-}$spectrum from the individual experimentally recorded spectrum. (A) ESR spectrum (blue) after radiationproduced prehydrated one-electron addition to $\mathrm{AmdC}$ at $77 \mathrm{~K}$ in $7.5 \mathrm{M} \mathrm{LiCl} / \mathrm{D}_{2} \mathrm{O}$. Spectra (B, blue) to (E, blue) were obtained from the same sample of 7 via stepwise annealing of the sample for 15 min at 134, 140, 150 and at $160 \mathrm{~K}$. All spectra were recorded at $77 \mathrm{~K}$. All spectra were recorded at $77 \mathrm{~K}$. The experimental spectra from AmdU $18(2.2 \mathrm{mg} / \mathrm{mL}$, sea-green) are superimposed in (A), (C), (D), and (E) for comparison. The red spectra in (A) and in (E) are the simulated spectra.

\subsubsection{Formation of $\pi$-type aminyl radical (RNH•) and its unimolecular conversion}

\section{to the $\sigma$-type iminyl radical $(\mathrm{R}=\mathrm{N} \bullet)$ in AvdU and AvdC}

The $77 \mathrm{~K}$ ESR spectrum (black) of the radicals formed by radiation (absorbed dose = $500 \mathrm{~Gy}$ at $77 \mathrm{~K})$-produced prehydrated electron attachment to AvdU $21(1 \mathrm{mg} / \mathrm{mL})$ in supercooled homogeneous glassy $\left(7.5 \mathrm{M} \mathrm{LiCl} / \mathrm{D}_{2} \mathrm{O}\right)$ solutions is shown in Figure 26A. This spectrum shows line components due to D-atoms, and due to axially symmetric anisotropic 
nitrogen HFCCs due to a single nitrogen. Furthermore, it also showed line components due to two anisotropic protons of the $=\mathrm{CH}_{2}$ in AvdU 21 (or AvdC 43). Therefore, the (A) was assigned to the $\pi$-type aminyl radical, $\mathrm{U}-\left(5-\mathrm{C}=\mathrm{CH}_{2}\right)-\mathrm{ND} \bullet$. The ESR spectrum in (A) establishes that formation of $\mathrm{U}-\left(5-\mathrm{C}=\mathrm{CH}_{2}\right)-\mathrm{ND} \bullet$ from 21 (Scheme 21) happens following the same pathway shown in Scheme 20. The simulated a spectrum (red) superimposed in Figure 26(A) nicely matches the line components of the black spectrum and supports the assignment of the black spectrum to the $\pi$-type aminyl radical, $\mathrm{U}-\left(5-\mathrm{C}=\mathrm{CH}_{2}\right)-\mathrm{ND}$.

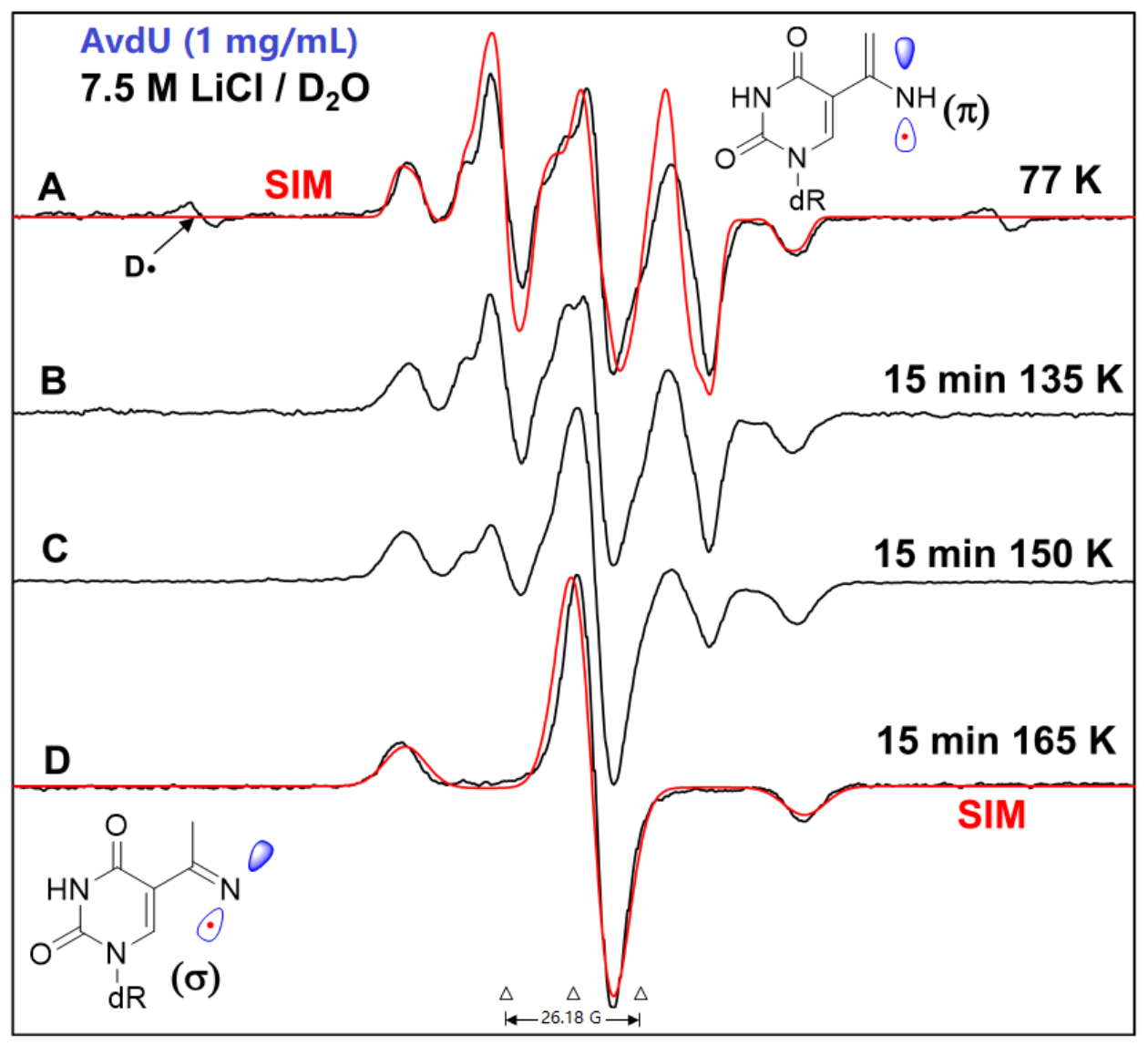

Figure 26. ESR spectra of AvdU 21 after radiation-produced prehydrated one-electron attachment at $77 \mathrm{~K}$ and stepwise annealing as well as simulated spectra

(A) ESR spectrum (black) after radiation-produced prehydrated one-electron addition to AvdU at $77 \mathrm{~K}$ in $7.5 \mathrm{M} \mathrm{LiCl} / \mathrm{D}_{2} \mathrm{O}$. Spectra (B) to (D) were obtained via stepwise annealing of the sample for $15 \mathrm{~min}$ at 135, 150 and $165 \mathrm{~K}$. All spectra were recorded at $77 \mathrm{~K}$. The red spectra in (A) and (D) are the simulated spectra. The background $\mathrm{Cl}_{2}{ }^{-}$spectrum has been subtracted from spectra A and B for clarity. 


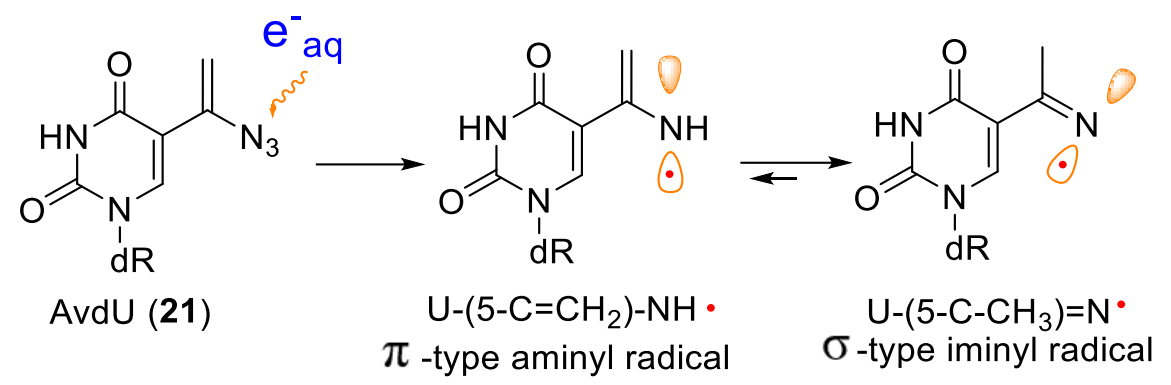

Scheme 21. Tautomerization of the $\pi$-type aminyl radical generated from AvdU 21 to the $\sigma$-type iminyl radical

ESR spectra (black) obtained upon progressively annealing the AvdU sample for 15 min in the dark at $135 \mathrm{~K}$, at $150 \mathrm{~K}$ and at $165 \mathrm{~K}$, are shown in Figure 26B-D. Comparison of the black spectrum in (D) with the black spectra in (A)-(C) shows that upon progressive annealing, height of the singlet at the center increases; concomitantly, height of the line components due to the two anisotropic $-\mathrm{CH}_{2}$ protons decreases and eventually disappears upon annealing at $165 \mathrm{~K}$. The black spectrum in (D) is only due to axially symmetric anisotropic nitrogen HFCCs. We assign this spectrum to the $\sigma$-type iminyl radical, $\mathrm{U}-\left(5-\mathrm{C}-\mathrm{CH}_{3}\right)=\mathrm{N} \cdot$. The simulated a spectrum (red) superimposed on the experimental spectrum in Figure 26D nicely matches the line components of the black spectrum and supports the assignment of the black spectrum to the $\sigma$-type iminyl radical, $\mathrm{U}-\left(5-\mathrm{C}-\mathrm{CH}_{3}\right)=\mathrm{N} \cdot$. Note that the axially symmetric anisotropic nitrogen HFCCs and the $g$-values of $\mathrm{U}-\left(5-\mathrm{C}-\mathrm{CH}_{3}\right)=\mathrm{N} \cdot$ are found to be identical to the reported values of $\sigma$-type iminyl radicals from one-electron oxidized 1-methylcytosine and its derivatives. ${ }^{130}$

Thus, our ESR spectral studies show that the radiation-produced electron mediated $\mathrm{U}-\left(5-\mathrm{C}=\mathrm{CH}_{2}\right)-\mathrm{ND} \bullet$ undergoes a facile tautomerization to $\mathrm{U}-\left(5-\mathrm{C}-\mathrm{CH}_{3}\right)=\mathrm{N} \bullet($ Scheme 21$)$. Nearly identical spectra were obtained from matched samples of $\mathbf{2 1}$ and $\mathbf{4 3}$. Therefore, we conclude that, a facile tautomerization of the radiation-produced electron-mediated $\pi$-type 
aminyl radical, $\mathrm{C}-\left(5-\mathrm{C}=\mathrm{CH}_{2}\right)-\mathrm{ND} \bullet$, to thermodynamically more stable $\sigma$-type iminyl radical, $\mathrm{C}-\left(5-\mathrm{C}-\mathrm{CH}_{2} \mathrm{D}\right)=\mathrm{N} \bullet$, also occurs in $\mathbf{4 3}$.

Increasing the concentration ( 1 to $5 \mathrm{mg} / \mathrm{mL}$ ) of $\mathrm{AvdU} \mathbf{2 1}$ in the solution appeared to have no effect on the extent of facile conversion from $\pi$-type $\mathrm{RNH} \bullet$ to $\sigma$-type iminyl radical from the spectra recorded under the same microwave power, modulation, and gain. From these results, we conclude that the facile tautomerization from $\mathrm{RNH} \bullet$ to iminyl radical observed in the samples of $\mathbf{2 1}$ and $\mathbf{4 3}$ occurs via very rapid intramolecular H-atom transfer from the aminyl group to the double bonded $\mathrm{CH}_{2}$ group in the $\pi$-type $\mathrm{RNH} \bullet$. The rapid H-atom transfer process that is involved in the tautomerization, is, most possibly, the proton-coupled electron transfer process.

\subsubsection{Summary and implication of aminyl radical and its resulting iminyl radicals}

In contrast to the ESR spectral results obtained using samples of 3'-AZT 22, 5'-azido5'-deoxythymidine, $2^{\prime}, 3^{\prime}$-AZddG, and of azidopentoses, ${ }^{42,73}$ that show the evidence of electron-induced $\pi$-type aminyl radical-mediated $\mathrm{H}$-atom abstraction are not observed in the samples of AmdU, AmdC, AvdU, and AvdC. Rather, the $\pi$-type aminyl radicals, in AmdU, AmdC, AvdU, and AvdC undergo facile conversion to the $\sigma$-type iminyl radical. For AmdU and AmdC, the $\pi$-type $\mathrm{RNH} \bullet$ to $\sigma$-type iminyl radical conversion is found to be bimolecular involving an $\alpha$-azidoalkyl radical, while the corresponding conversion, observed for AvdU and AvdC is unimolecular (i.e., tautomerization).

Owing to the high free radical scavenger concentrations in cells, ${ }^{9,16}$ the bimolecular conversion of the $\pi$-type $\mathrm{RNH} \bullet$ to $\sigma$-type iminyl radical from AmdU $\mathbf{1 8}$ and AmdC 42 (Scheme 20) should not take place as it has been observed in case of 5'-azido-5'deoxythymidine. However, the facile unimolecular tautomerization of the $\pi$-type $\mathrm{RNH} \bullet$ to 
б-type iminyl radical from AvdU 21 and AvdC 43 (Scheme 21) should occur. Further, the reactivity of the $\sigma$-type iminyl radical from AvdU 21 and AvdC 43 would be lower than the iminyl radicals obtained from $\mathbf{1 8}$ and $\mathbf{4 2}$ owing to the positive inductive effect of its methyl group (Figure 26 and Scheme 21). Therefore, it is expected that the $\pi$-type RNH• from AmdU 18 and AmdC $\mathbf{4 2}$ should augment the radiation damage more effectively than the $\sigma$-type iminyl radical from AvdU 21 and AvdC 43. Tests of this hypothesis are reported in section 3.1.5.

\subsubsection{Radiosensitizing effect of 5-azidomethyl and 5-azidovinyl pyrimidine nucleosides in aerobic and hypoxic cells}

The radiation response of cells in the presence of $100 \mu \mathrm{M}$ C5 azido-modified pyrimidine nucleosides in vitro was examined in both aerobic and hypoxic EMT6 cells. For the tests in aerobic cells, the cultures were treated with $100 \mu \mathrm{M}$ azido compounds or vehicles for $48 \mathrm{~h}$. For the test in hypoxic cells, hypoxic condition was applied for $4 \mathrm{~h}$ after the $44 \mathrm{~h}$ aerobic incubation with $100 \mu \mathrm{M}$ azido compounds or vehicles. For the radiosensitizing effect tests, cells were irradiated with 7.5 Gy X-ray during the final few minutes of the $48 \mathrm{~h}$ aerobic incubation (aerobic cells) or of the $4 \mathrm{~h}$ hypoxic incubation (hypoxic cells). More experimental details are provided in section 4.4. The results are shown in Figure 27 and Table 4. 

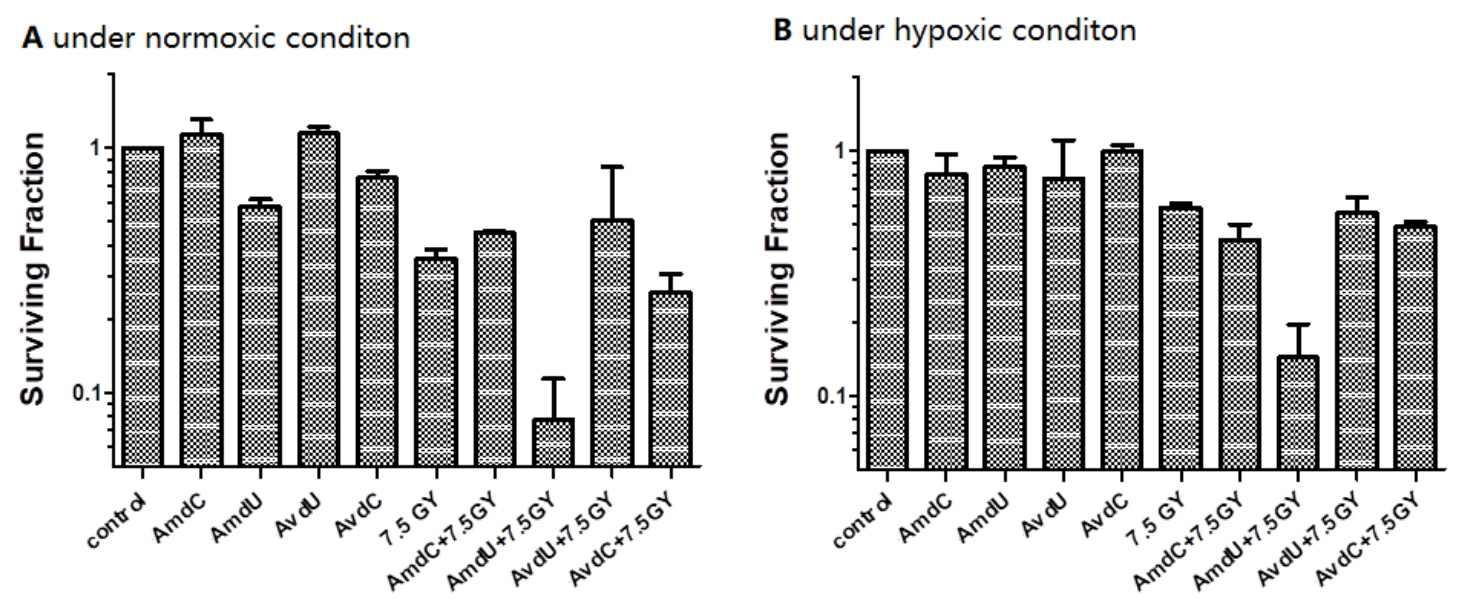

Figure 27. Radiosensitizing effect of 5-azidomethyl and 5-azidovinyl pyrimidine nucleosides at $100 \mu \mathrm{M}$ concentration on EMT6 cells (A) normoxic, (B) hypoxic conditions

AmdU 18 showed radiosensitizing effect under both normoxic and hypoxic

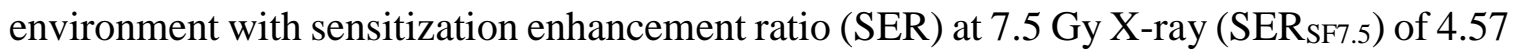
and 4.10, respectively (Figure 27, Table 4). These results showed that one electron-induced aminyl radicals in AmdU $\mathbf{1 8}$ augment radiation damage to cells. In hypoxic microenvironment, $\mathrm{RNH} \bullet$ formed from electron addition to AmdU $\mathbf{1 8}$ can be involved in the $\mathrm{H}$-atom abstraction reactions that might cause DNA-strand breaks and/or crosslink formation ${ }^{9,42,73}$ leading to lesions that can induce apoptosis of cancer cells. ${ }^{16,19,134-136}$ On the other hand, in the aerobic cells, the aminyl radical generated from AmdU $\mathbf{1 8}$ can react with oxygen to generate aminylperoxyl radical RNHOO• and eventually lead to aminoxyl (nitroxyl) radicals RNHO•, ${ }^{137}$ which also can lead to DNA damage. ${ }^{138,139}$ Other azido nucleoside tested showed lower radiosensitizing effect with SERSF7.5 index of 1.35 for AmdC 42 under hypoxic cells and 1.37 for AvdC 43 under aerobic cells.

Reasons for the difference in radiosensitization shown between AmdU 18 and AmdC 42 is unclear. Possible reasons include differences in drug uptake into cells, metabolic phosphorylation, and/or reactivity of the aminyl radical generated at the uracil and cytosine 
base. The higher radiosensitizing effect of AmdU 18 than that of AvdU 21 and AvdC 43 can be explained by the higher reactivity of $\pi$-type $\mathrm{RNH} \bullet$ from AmdU 18 than that of the $\sigma$-type iminyl radical from AvdU 21 and AvdC 43. The optimization of the radiosensitizing effect could involve increasing uptake of these azido-nucleosides into cancerous cells by designing more lipophilic prodrugs and/or skipping metabolic 5'-phosphorylation in cells by synthesizing their ProTides.

Table 4. Radiosensitizing effect of azidomethyl and azidovinyl pyrimidine nucleosides at $100 \mu \mathrm{M}$ concentration in aerobic and hypoxic EMT6 cells

\begin{tabular}{|c|c|c|c|c|c|c|c|c|c|c|}
\hline & \multicolumn{10}{|c|}{ Aerobic Conditions $^{a}$} \\
\hline X-Ray & \multicolumn{5}{|c|}{$0 \mathrm{~Gy}$} & \multicolumn{5}{|c|}{$7.5 \mathrm{~Gy}$} \\
\hline Cmpd & Control & AmdC & AmdU & AvdU & AvdC & Vehicle & AmdC & AmdU & AvdU & AvdC \\
\hline $\mathrm{SF}$ & 1 & 1.135 & 0.577 & 1.145 & 0.753 & 0.352 & 0.449 & 0.077 & 0.502 & 0.256 \\
\hline $\mathrm{DER}^{c}$ & 1 & 0.88 & 1.73 & 0.87 & 1.33 & - & - & - & - & - \\
\hline $\mathrm{SER}_{\mathrm{SF7.5}}{ }^{d}$ & - & - & - & - & - & 1 & 0.78 & 4.57 & 0.70 & 1.37 \\
\hline & \multicolumn{10}{|c|}{ Hypoxic Conditions $^{b}$} \\
\hline X-Ray & \multicolumn{5}{|c|}{$0 \mathrm{~Gy}$} & \multicolumn{5}{|c|}{$7.5 \mathrm{~Gy}$} \\
\hline Cmpd & Control & AmdC & AmdU & AvdU & AvdC & Vehicle & AmdC & AmdU & AvdU & AvdC \\
\hline SF & 1 & 0.800 & 0.857 & 0.769 & 0.995 & 0.587 & 0.434 & 0.143 & 0.561 & 0.492 \\
\hline $\mathrm{DER}^{c}$ & 1 & 1.25 & 1.17 & 1.30 & 1.00 & - & - & - & - & - \\
\hline $\mathrm{SER}_{\mathrm{SF} 7.5^{d}}$ & - & - & - & - & - & 1 & 1.35 & 4.10 & 1.05 & 1.19 \\
\hline
\end{tabular}

${ }^{a}$ Drugs or vehicles were added to the cultures for $48 \mathrm{~h}$ treatment under normoxic condition, followed by 0 or 7.5 Gy X-ray irradiation. ${ }^{b}$ Drugs or vehicles were added to the cultures for $44 \mathrm{~h}$ treatment under normoxic condtion and then for $4 \mathrm{~h}$ under hypoxic condition, followed by 0 or 7.5 Gy X-ray. ${ }^{c}$ DER (drug enhancement ratio) was defined as the ratio of survival fractions (SF) of vehicle and SF of azido compounds. ${ }^{d} \mathrm{SER}_{\mathrm{SF} 7.5}$ (sensitization enhancement ratio) was defined as the ratio of survival fractions at $7.5 \mathrm{~Gy}\left(\mathrm{SF}_{7.5}\right)$ of vehicle and $\mathrm{SF}_{7.5}$ of azido compounds.

\subsection{The 2-azido-2'-deoxyinosine as precursor to study elusive guanine-based aminyl radical}

\subsubsection{Synthesis of 2 -azido-2'-deoxyinosine}

The 2-azido-2'-deoxyinosine (2- $\left.\mathrm{N}_{3} \mathrm{dI}, \mathbf{4 4}\right)$ was synthesized from 2'-deoxyguanosine (dG) as shown in Scheme 23. Acetyl protection of $\mathbf{d G}$ with acetic anhydride at $75{ }^{\circ} \mathrm{C}$ for $4 \mathrm{~h}$ provided 3',5'-di- $O$-acetyl-2'-deoxyguanosine $\mathbf{8 0}$ in $81 \%$ yield. The attempts to convert 
2-amino from 2'-deoxyguanosine (dG) directly to 2-azido via diazotransfer and diazotization were not successful (Scheme 22), which led to the requirement of protection of $\mathrm{O}^{6}$ with $p$-nitrophenethyl alcohol (NPEOH). The $\mathrm{O}^{6}$-NPE protection required absolute anhydrous reaction condition and thus all the starting materials were dried along with $\mathrm{P}_{2} \mathrm{O}_{5}$ in a drying pistol $\left(40^{\circ} \mathrm{C}\right)$ for 12 hours and the solvent 1,4-dioxane was distillated with $\mathrm{CaH}_{2}$ and then collected into a dried flask filled with Ar and activated $3 \mathrm{~A}$ molecular sieves. The $\mathrm{O}^{6}$-NPE protection of $\mathbf{8 0}$ with $p$-nitrophenethyl alcohol via Mitsunobu reaction in the presence of triphenyl phosphite $\left(\mathrm{Ph}_{3} \mathrm{P}\right)$, diisopropyl azodicarboxylate (DIAD), and activated molecular sieves powder at room temperature overnight yielded 3',5'-di-O-acetyl$\mathrm{O}^{6}$-(p-nitrophenethyl)-2'-deoxyguanosine $\mathbf{8 1}$ in $72 \%$ yield. Activated powder molecular sieves are required for the reaction to happen and to give good yield under humid environment. $\mathbf{8 1}$ was easily converted to $\mathbf{8 2}$ in $74 \%$ yield by treatment with tert-butyl nitrite and trimethylsilyl azide $\left(\mathrm{TMSN}_{3}\right)$ in $\mathrm{ACN}$ at $-20^{\circ} \mathrm{C}$ for $12 \mathrm{~h}$ then at $0{ }^{\circ} \mathrm{C}$ for $24 \mathrm{~h}$. Treatment of 82 with 1,8-diazabicyclo[5.4.0]undec-7-ene (DBU) at room temperature for $3 \mathrm{~h}$ followed by treatment with $\mathrm{NH}_{3} / \mathrm{MeOH}$ at room temperature overnight provided the final product $2-\mathrm{N}_{3} \mathrm{dI} 44$ in $83 \%$ yield.

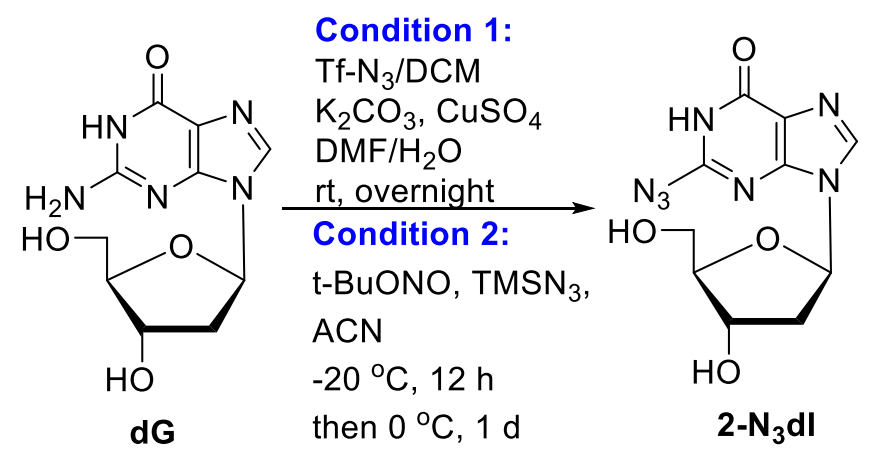

Scheme 22. Attempted one-step synthesis of 2-azido-2'-deoxyinosine 


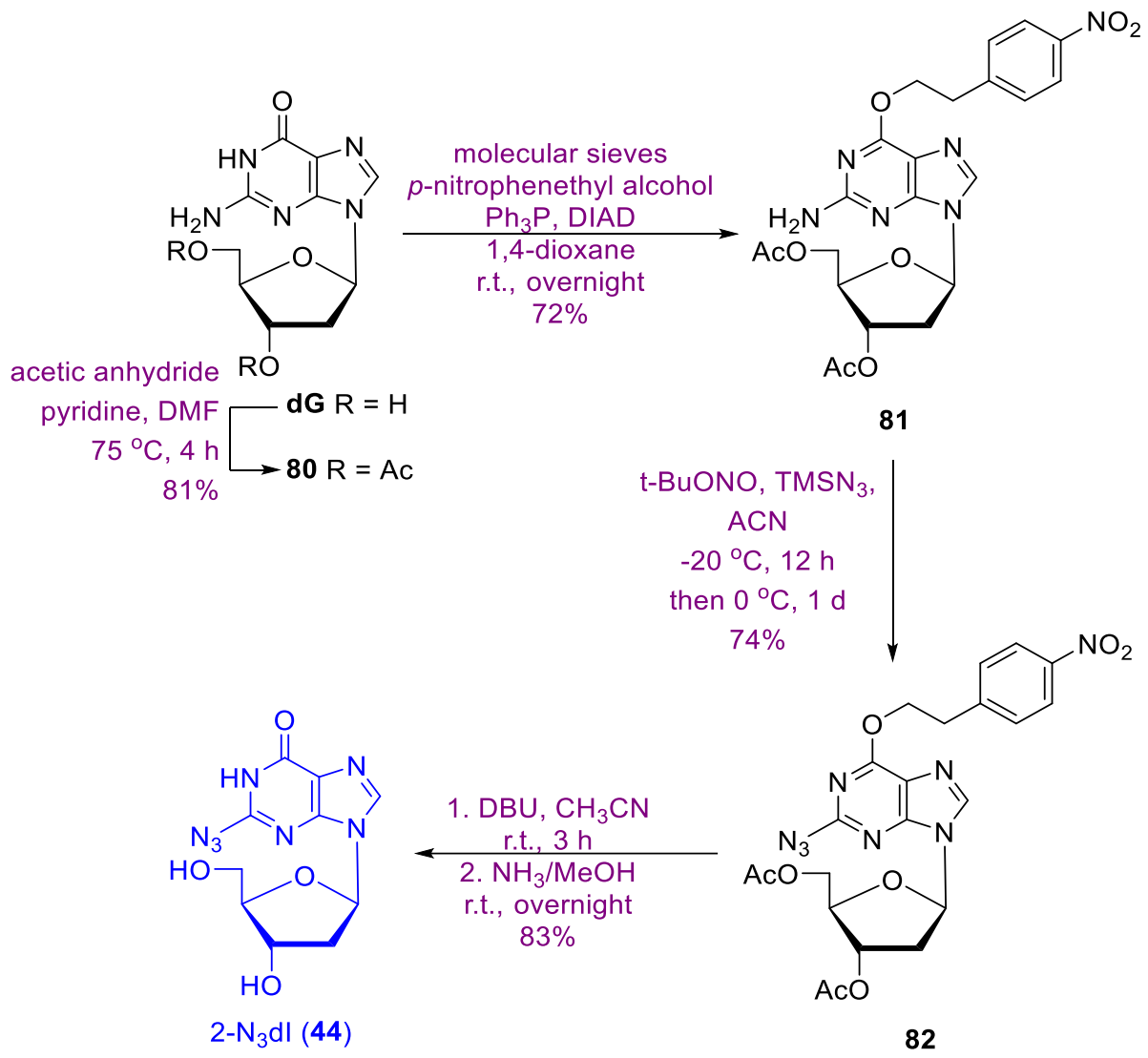

Scheme 23. Synthesis of 2-azido-2'-deoxyinosine

\subsubsection{The formation of 2-aminyl radical from 2-azido-2'-deoxyinosine and subsequent radical transfers characterized using electron spin resonance}

The ESR characterization of the formation of 2'-deoxyguanosin-N2-yl radical (dG(N2-

$\mathrm{H}) \bullet, 45$ ) on electron attachment to $2 \mathrm{~N}_{3} \mathrm{dI} 44$ is under investigation. The $\mathrm{N} 2$-center radical 45 and its tautomers could be expected to be observed using ESR to offer direct evidence of electron-transfer process under $\gamma$-irradiation. 
3.3. Design, synthesis, fluorescent properties, and cell imaging of $1 \mathrm{H}-1,2,3-$-triazol-4yl analogues of $\mathrm{C} 5$ pyrimidine and $\mathrm{C8}$ purine nucleosides

\subsubsection{Synthesis of 5-(1H-1,2,3-triazol-4-yl) pyrimidine and 8-(1H-1,2,3-triazol-4-yl) purine nucleoside analogues}

\subsubsection{Method A catalyzed by $\mathrm{Ag}_{2} \mathrm{CO}_{3}$}

As discussed in Section 3.1.2, during the synthesis of protected AvdC 65 (48\%) from 3',5'-di- $O$-acetyl-5-ethynyl-2'-deoxycytidine $\mathbf{6 3 \mathbf { a } ^ { 1 1 9 , 1 4 0 }}$ (Scheme 13) also the fluorescent 3',5'-di- $O$-acetyl-5-(1H-1,2,3-triazol-4-yl)-2'-deoxycytidine (diAc-5-TrzdC, 83) was obtained in low yield (7\%; Table 5, Entry 1; Method A). Also as was noted above in Section 3.1.2 the analogous hydroazidation of 3',5'-di- $O$-acetyl-5-ethynyl-2'-deoxyuridine $\mathbf{6 2}^{110}$ produced protected AvdU $64(55 \%)$ as the only product without formation of the corresponding triazole product 84 (Table 5, Entry 2; Method A).

Remarkably, contrary to the 5-ethynylpyrimidine nucleosides, hydroazidation of 8-ethynylpurine nucleosides produced triazole adducts as major products. Thus, hydroazidation of 8-ethynyl-2'-deoxyadenosine $\mathbf{8 5}^{141}$ with $\mathrm{TMSN}_{3}$ in the presence of $\mathrm{Ag}_{2} \mathrm{CO}_{3}$ produced 8-(1H-1,2,3-triazol-4-yl)-2'-deoxyadenosine (8-TrzdA, 46, 50\%) as the major product in addition to the vinylazide 89 (8-AvdA, 15\%; Table 6, Entry 1; Method A). The estimated yield of 8-TrzdA $\mathbf{4 6}$ based on the TLC were approximately $70 \%$ (Table 6) but due to the strong binding of triazoles to the silica gel, the products after silica gel column chromatography were isolated in relatively low yields. Interestingly treatment of 3',5'-di-O-TBDMS-8-ethynyl-2'-deoxyadenosine $\mathbf{8 6}^{141}$ by Method A provided 3',5'-di- $O$ TBDMS-8-(1H-1,2,3-triazol-4-yl)-2'-deoxyadenosine (diTBDMS-8-TrzdA， 88，30\%; Table 6, Entry 2) as the only product without a trace of azidovinyl analogue $\mathbf{9 0}$. The 
treatment of 8-ethynyl-2'-deoxyguanosine $\mathbf{8 7}^{142}$ by Method A also yielded 8-(1H-1,2,3triazol-4-yl)-2'-deoxyguanosine (8-TrzdG, 47, 52\%; Entry 3) as the sole product.

Table 5. Synthesis of 5-(1H-1,2,3-triazol-4-yl) pyrimidine nucleoside analogues

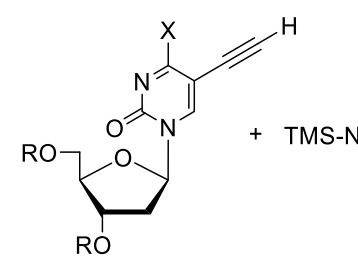

63a $X=\mathrm{NH}_{2}, \mathrm{R}=\mathrm{Ac}$

63b $X=\mathrm{NH}_{2}, \mathrm{R}=\mathrm{H}$

$62 \mathrm{X}=\mathrm{OH}, \mathrm{R}=\mathrm{Ac}$

$77 \mathrm{X}=\mathrm{OH}, \mathrm{R}=\mathrm{H}$

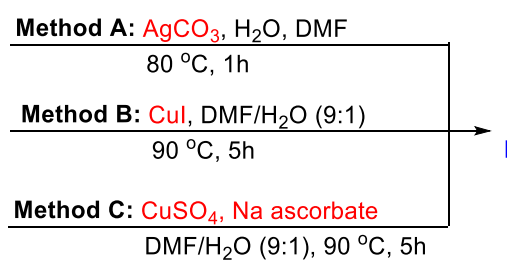

$\mathrm{DMF} / \mathrm{H}_{2} \mathrm{O}(9: 1), 90^{\circ} \mathrm{C}, 5 \mathrm{~h}$

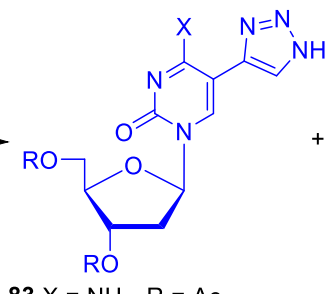

$83 X=\mathrm{NH}_{2}, \mathrm{R}=\mathrm{Ac}$

$48 X=\mathrm{NH}_{2}, \mathrm{R}=\mathrm{H}$

$84 \mathrm{X}=\mathrm{OH}, \mathrm{R}=\mathrm{Ac}$

$39 \mathrm{X}=\mathrm{OH}, \mathrm{R}=\mathrm{H}$

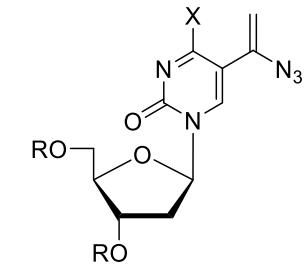

$65 \mathrm{X}=\mathrm{NH}_{2}, \mathrm{R}=\mathrm{Ac}$

$43 \mathrm{X}=\mathrm{NH}_{2}, \mathrm{R}=\mathrm{H}$

$64 X=\mathrm{OH}, \mathrm{R}=\mathrm{Ac}$

$21 \mathrm{X}=\mathrm{OH}, \mathrm{R}=\mathrm{H}$

\begin{tabular}{|c|c|c|c|c|c|c|}
\hline Entry & SM & Method & Trz & Yield $^{\mathrm{a}}[\%]$ & azide & Yield $^{\mathrm{a}}[\%]$ \\
\hline 1 & $63 a$ & $\mathrm{~A}$ & 83 & 7 & 65 & 48 \\
\hline 2 & 62 & A & 84 & 0 & 64 & 55 \\
\hline 3 & $63 a$ & B & 83 & $32(50)$ & 65 & 0 \\
\hline 4 & $63 b$ & B & 48 & $10(20)$ & 43 & 0 \\
\hline 5 & 62 & B & 84 & $55(85)$ & 64 & 0 \\
\hline 6 & 77 & $\mathrm{~B}$ & 39 & $50(85)$ & 3d & 0 \\
\hline 7 & 77 & $\mathrm{~B}^{\mathrm{b}}$ & 39 & $42(75)$ & 3d & 0 \\
\hline 8 & 63a & $\mathrm{C}$ & 83 & $65(80)$ & 65 & 0 \\
\hline 9 & 63b & $\mathrm{C}$ & 48 & $51(85)$ & 43 & 0 \\
\hline 10 & 62 & $\mathrm{C}$ & 84 & $81(95)$ & 64 & 0 \\
\hline 11 & 77 & $\mathrm{C}$ & 39 & $52(90)$ & 3d & 0 \\
\hline
\end{tabular}

${ }^{\mathrm{a}}$ Isolated yields; In parenthesis are estimated yields based on TLC; ${ }^{\mathrm{b}}$ Modified Method B: CuI, 2 eq. $\mathrm{H}_{2} \mathrm{O}, \mathrm{DMF}, 90^{\circ} \mathrm{C}, 5 \mathrm{~h}$.

Since 5-triazolylpyrimidine and 8-triazolylpurine nucleosides show good fluorescent properties (section 3.3.4), it was significant to optimize reaction conditions to synthesize the triazolyl analogues of the four natural bases (i.e. $\mathrm{dU}, \mathrm{dC}, \mathrm{dA}$, and $\mathrm{dG}$ ) of DNA. To optimize the conditions to increase the percent yield of the triazoles and to be applicable for all four nucleosides, several strategies have been designed and performed. 
Table 6. Synthesis of 8-(1H-1,2,3-triazol-4-yl) purine nucleoside analogues

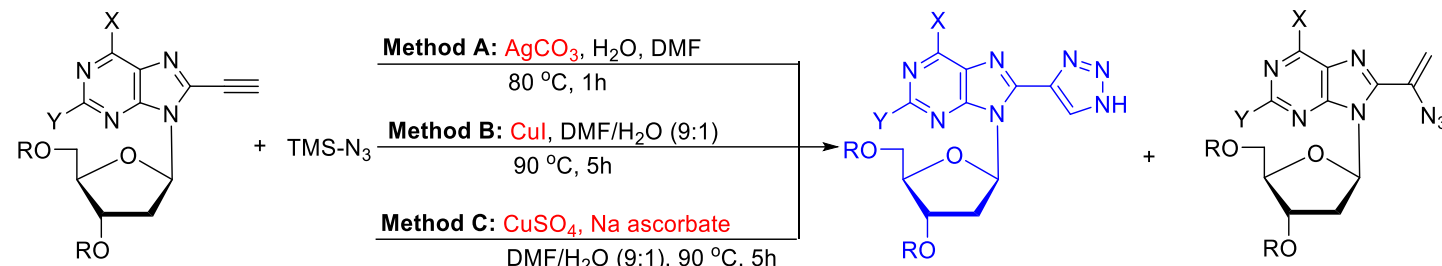

$85 X=\mathrm{NH}_{2}, Y=\mathrm{R}=\mathrm{H}$

$86 \mathrm{X}=\mathrm{NH}_{2}, \mathrm{Y}=\mathrm{H}, \mathrm{R}=\mathrm{TBDMS}$

$87 \mathrm{X}=\mathrm{OH}, \mathrm{Y}=\mathrm{NH}_{2}, \mathrm{R}=\mathrm{H}$

$46 \mathrm{X}=\mathrm{NH}_{2}, \mathrm{Y}=\mathrm{R}=\mathrm{H} \quad 89 \mathrm{X}=\mathrm{NH}_{2}, \mathrm{Y}=\mathrm{R}=\mathrm{H}$

$88 X=\mathrm{NH}_{2}, Y=\mathrm{H}, \mathrm{R}=$ TBDMS $90 \mathrm{X}=\mathrm{NH}_{2}, \mathrm{Y}=\mathrm{H}, \mathrm{R}=\mathrm{TBDMS}$

$47 X=\mathrm{OH}, \mathrm{Y}=\mathrm{NH}_{2}, \mathrm{R}=\mathrm{H} \quad 91 \mathrm{X}=\mathrm{OH}, \mathrm{Y}=\mathrm{NH}_{2}, \mathrm{R}=\mathrm{H}$

\begin{tabular}{lllllll}
\hline Entry & $\mathbf{4}$ & Method & $\mathbf{5}$ & Yield $^{\mathrm{b}}[\%]$ & $\mathbf{6}$ & Yield $^{\mathrm{b}}[\%]$ \\
\hline 1 & $\mathbf{8 5}$ & $\mathrm{A}$ & $\mathbf{4 6}$ & $50(70)$ & $\mathbf{8 9}$ & $15(25)$ \\
2 & $\mathbf{8 6}$ & $\mathrm{A}$ & $\mathbf{8 8}$ & $30(75)$ & $\mathbf{9 0}$ & 0 \\
3 & $\mathbf{8 7}$ & $\mathrm{A}^{\mathrm{a}}$ & $\mathbf{4 7}$ & $52(90)$ & $\mathbf{9 1}$ & 0 \\
\hline 4 & $\mathbf{8 5}$ & $\mathrm{B}$ & $\mathbf{4 6}$ & $17(60)$ & $\mathbf{8 9}$ & 0 \\
5 & $\mathbf{8 6}$ & $\mathrm{B}$ & $\mathbf{8 8}$ & $27(70)$ & $\mathbf{9 0}$ & 0 \\
6 & $\mathbf{8 7}$ & $\mathrm{B}$ & $\mathbf{4 7}$ & $31(65)$ & $\mathbf{9 1}$ & 0 \\
\hline 7 & $\mathbf{8 5}$ & $\mathrm{C}$ & $\mathbf{4 6}$ & $51(85)$ & $\mathbf{8 9}$ & 0 \\
8 & $\mathbf{8 6}$ & $\mathrm{C}$ & $\mathbf{8 8}$ & $58(85)$ & $\mathbf{9 0}$ & 0 \\
9 & $\mathbf{8 7}$ & $\mathrm{C}$ & $\mathbf{4 7}$ & $52(80)$ & $\mathbf{9 1}$ & 0 \\
\hline
\end{tabular}

${ }^{\text {a }}$ Modified Method A: $\mathrm{Ag}_{2} \mathrm{CO}_{3}, \mathrm{H}_{2} \mathrm{O}, \mathrm{DMF}, 80{ }^{\circ} \mathrm{C}, 4 \mathrm{~h}$.

Alkynes bearing electron-withdrawing groups are better substrates for the direct addition to in-situ generated hydrazoic acid. ${ }^{102,143}$ Thus, to increase the yield for the preparation of the unsubstituted 5-triazol-4-yl pyrimidine nucleosides, insertion of electron-withdrawing group to the pyrimidine bases was considered. Initially, the electrondeficiency of the pyrimidine nucleosides were attempted to be increased by preparing Bocprotected analogues (Scheme 24 and Scheme 25). Thus, di- $N^{4}, N^{4}$-Boc-3',5'-di-O-acetyl-5ethynyl-2'-deoxycytidine $\quad(\mathbf{9 2}, \quad 70 \%)$ and $\quad N^{4}$-Boc-3',5'-di-O-acetyl-5-ethynyl-2'deoxycytidine $(\mathbf{9 3}, 10 \%)$ were synthesized by the treatment of 3',5'-di-O-acetyl-5-ethynyl2'-deoxycytidine 63a with (Boc) $)_{2} \mathrm{O}$ as shown in Scheme 24. Similarly, $N^{3}$-Boc-3',5'-di-Oacetyl-5-ethynyl-2'-deoxyuridine $(\mathbf{9 4}, 52 \%)$ was prepared from 3',5'-di- $O$-acetyl-5- 
ethynyl-2'-deoxyuridine (62, Scheme 25). Unfortunately, hydroazidation of the Bocprotected pyrimidine nucleosides $\mathbf{9 2 - 9 4}$ by Method A resulted in unstable fluorescent products which were proved by NMR not to be the expected triazoles. The structures need to be further identified. The electron-withdrawing modification on pyrimidine bases did change the electron density that further led to different products rather than triazoles.

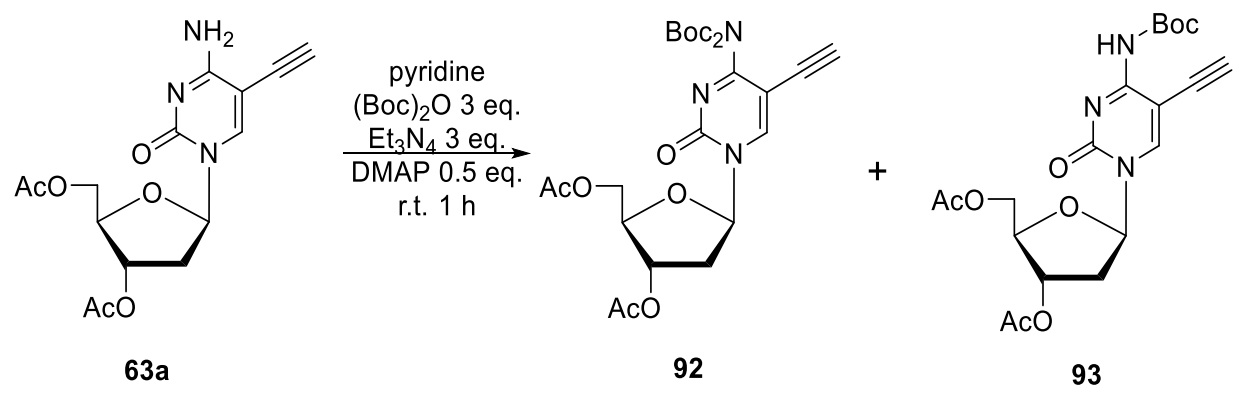

Scheme 24. Synthesis of 4- $\mathrm{N}$-Boc protected 3',5'-di- $O$-acetyl-5-ethynyl-2'-deoxycytidine derivatives 92 and 93

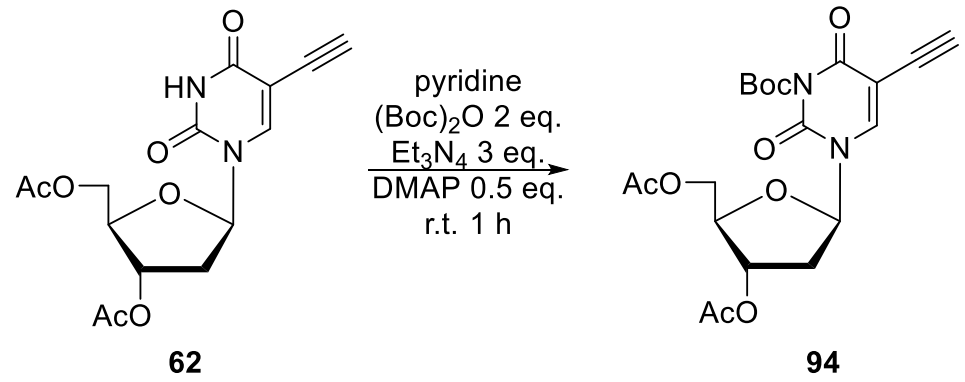

Scheme 25. Synthesis of 3- $N$-Boc-3',5'-di- $O$-acetyl-5-ethynyl-2'-deoxyuridine 94

\subsubsection{Method B catalyzed by CuI}

Cycloaddition of the 5-ethynyl nucleosides and $\mathrm{TMSN}_{3}$ in the presences of $\mathrm{CuI}$ as a catalyst $^{102}$ was found to produce triazoles as the sole products without formation of the vinylazides (Table 5, Entries 3-7; Table 6, Entries, 4-6; Method B). Thus, treatment of protected 5-ethynyl-2'-deoxycytidine 63a with $\mathrm{TMSN}_{3}$ in the presence of CuI gave diAc-5-TrzdC 83 with increased yield (32\%; Table 5, Entry 3; Method B). Analogous 
treatment of the unprotected 5-ethynyl-2'-deoxycytidine $\mathbf{6 3 b}^{140}$ by Method B gave 5-(1H-1,2,3-triazol-4-yl)-2'-deoxycytidine $(5-\operatorname{TrzdC}, 48)$ even though with low isolated yield (10\%; Table 5, Entry 4). Treatment of the uracil counterparts 62 and 77 under analogous reaction conditions yielded 3',5'-di-O-acetyl-5-(1H-1,2,3-triazol-4-yl)-2'deoxyuridine (diAc-5-TrzdU, 84, 55\%;Table 5, Entry 5) and 5-(1H-1,2,3-triazol-4-yl)-2'deoxyuridine (5-TrzdU, 39, 50\%; Entry 6), respectively. In Method B, DMF/ $\mathrm{H}_{2} \mathrm{O}$ (9:1) was used as solvent, in which $\mathrm{H}_{2} \mathrm{O}$ was required for the reaction to give good yield. ${ }^{102}$ Treatment of 77 by modified Method $\mathrm{B}$ in the presence of 2 eq. of $\mathrm{H}_{2} \mathrm{O}$ in DMF (Entry 7) gave 39 (42\%) as sole product, which showed that stoichiometric amount of $\mathrm{H}_{2} \mathrm{O}$ was efficient for the reaction. It is noteworthy that $\mathbf{8 4}$ and $\mathbf{3 9}$ were not accessible under $\mathrm{Ag}_{2} \mathrm{CO}_{3}$ conditions (Method A).

Treatment of the 8-ethynylpurine nucleoside analogues 85-87 with $\mathrm{TMSN}_{3}$ by Method B also yielded their corresponding 8-(1H-1,2,3-triazol-4-yl)-2'-deoxypurine nucleosides 46 (17\%), 88 (27\%), and 47 (31\%; Table 6, Entry 4-6). However, the isolated yields were lower than that of reactions using Method A with $\mathrm{Ag}_{2} \mathrm{CO}_{3}$ as catalyst. There were more unwanted by-products below the triazole products on TLC, which meanwhile troubled the purification. After purification by regular column chromatography, further purification by HPLC (C18; A: 100\% ACN, B: 5\% ACN/ $\mathrm{H}_{2} \mathrm{O} ; 0 \% \mathrm{~A} \rightarrow 15 \%$ A in $30 \mathrm{~min}$, flow rate $=2$ $\mathrm{mL} / \mathrm{min}$ ) was required to obtain pure triazoles.

The explanation of substantial differences of reactions with various substrates and different catalysts $\left(\mathrm{Ag}_{2} \mathrm{CO}_{3}\right.$ and $\left.\mathrm{Cu}(\mathrm{I})\right)$ are still unclear. 


\subsubsection{Method C catalyzed by $\mathrm{CuSO}_{4} /$ sodium ascorbate $^{2}$}

The relatively low yields of $\mathbf{8 3}$ and $\mathbf{4 8}$ from Method B using CuI as catalyst was due to the oxidation of $\mathrm{Cu}$ (I) to $\mathrm{Cu}$ (II) during the reaction, which was indicated by the color change of the reaction mixture from brown to dark green. To avoid the loss of catalytic ability of $\mathrm{Cu}$ (I), Method $\mathrm{C}$ employing in situ generation of $\mathrm{Cu}$ (I) from $\mathrm{CuSO}_{4} /$ sodium ascorbate was proved to be a better strategy for the synthesis of triazolyl nucleosides (Table 5, Entry 8-11; Table 6, Entries 7-9; Method C). The reaction mixtures stayed brown during the 5-hours reaction, which indicated the invariable catalytic activity of the in-situ generated $\mathrm{Cu}(\mathrm{I})$. Thus, the treatment of $\mathbf{6 3 a}$ with $\mathrm{TMSN}_{3}$ in the presence of $\mathrm{CuSO}_{4} /$ sodium ascorbate gave 83, which had a better yield (Table 5, 65\%; Entry 8) than that of reaction using $\mathrm{CuI}$ as catalyst (32\%; Table 5, Entry 3). Compared to the Entry 4, the synthesis of 5-TrzdC 48 using $\mathrm{CuSO}_{4} /$ sodium ascorbate provided a much better yield of 51\% (Entry 9). It is worth noting that the estimated yield based on the TLC was $85 \%$. The hydroazidation of $\mathbf{6 2}$ by Method C gave $\mathbf{8 4}$ with quantitative conversion yield (Entry 10). When $\mathbf{7 7}$ was treated with $\mathrm{TMSN}_{3}$ by Method C, similar yield of 5-TrzdU 39 (52\%; Entry 11) was obtained compared to Entry 6 using Method with $\mathrm{CuI}$ as catalyst.

The treatment of the 8-ethynylpurine nucleoside analogues $85-87$ with $\mathrm{TMSN}_{3}$ by Method C gave their corresponding 8-(1H-1,2,3-triazol-4-yl)-2'-deoxypurine nucleosides 46 (51\%; Table 6, Entry 7), 88 (58\%; Entry 8), and 47 (52\%; Entry 9), which were obviously much better than that given by Method B using CuI as catalyst. The unwanted by-products below the triazole products on TLC were much less.

The substrate scope of Method C for the synthesis of $\mathrm{N}$-unsubstituted triazoles would be broad rather than just ethynyl nucleosides. Three presentative $p$-substituted 
phenylacetylene, i.e. 4-ethynylanisole 95a $\left(\mathrm{CH}_{3} \mathrm{O}-, \mathrm{EDG}\right)$, phenylacetylene 95b $(\mathrm{H}-$, neutral), and 4-ethynyl- $\alpha, \alpha, \alpha$-trifluorotoluene $95 \mathbf{c}\left(\mathrm{F}_{3} \mathrm{C}-, \mathrm{EWG}\right)$ were chosen and applied to this $\mathrm{CuSO}_{4} /$ sodium ascorbate catalyzed procedure, and thus affording the corresponding triaozles in good yields $(63-83 \%, 96 a-96 c$, Table 7). It is noteworthy that phenylacetylene modified with electron-withdrawing group at the $p$-position promotes the formation of triazole, which matched the proposal reported. ${ }^{102,144}$

Table 7. Synthesis of $p$-substituted phenyl triazoles via cycloaddition catalyzed by $\mathrm{CuSO}_{4} /$ sodium ascorbate (Method C)

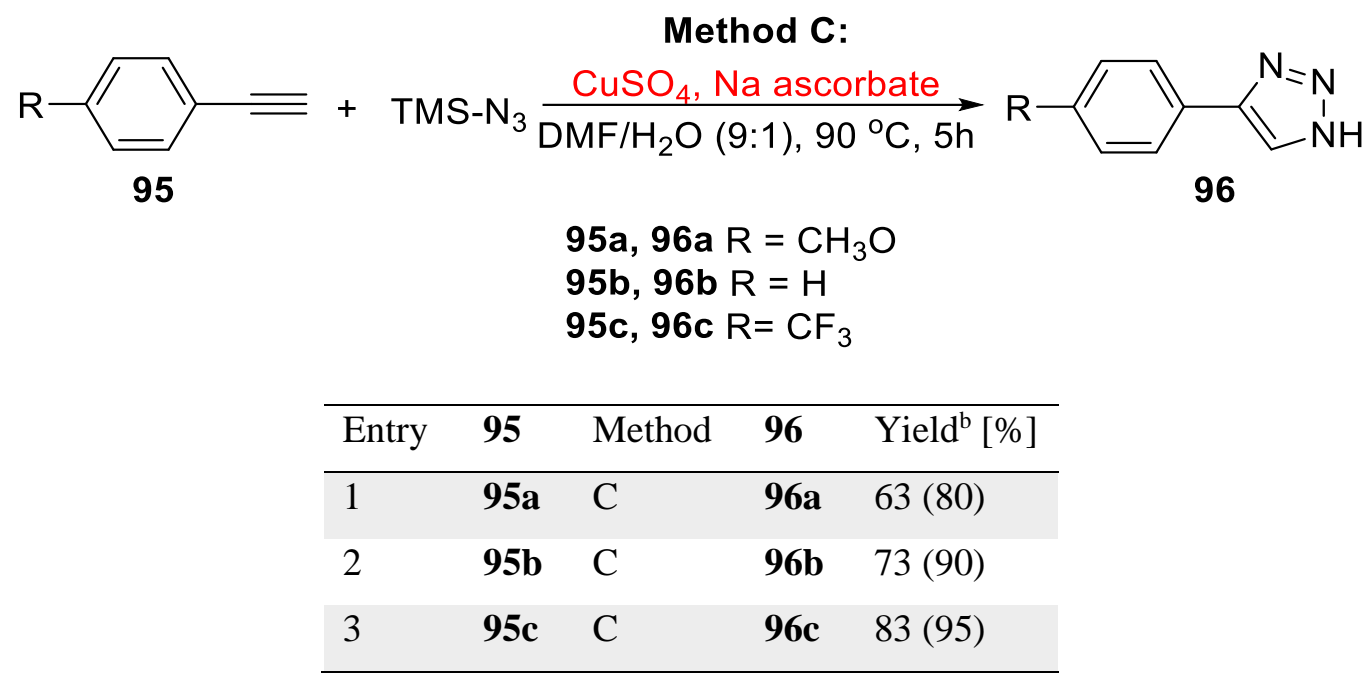

In summary, the fluorescent sugar-protected/unprotected $N$-unsubstituted triazolyl analogues of the four natural bases of DNA can be readily prepared with good yields from the treatment of their corresponding 5- or 8-ethynyl-2'-deoxynucleosides with $\mathrm{TMSN}_{3}$ in the presence of $\mathrm{CuSO}_{4} /$ sodium ascorbate as catalyst. Reactions catalyzed by $\mathrm{CuI}$ can also give triazole adducts as major products but suffered from the relatively low yield because of the loss of catalytic activities of $\mathrm{Cu}$ (I) to $\mathrm{Cu}$ (II) after oxidation. The synthesis of 8 -(1H1,2,3-triazol-4-yl)-2'-deoxyguanosine using $\mathrm{Ag}_{2} \mathrm{CO}_{3}$ as catalyst gave comparable yield and easier purification. 


\subsubsection{Reaction mechanism study}

A tentative reaction mechanism to give the triazoles as sole products might involve first formation of vinylazide followed by 1,5-electrocyclization and tautomerization. However, attempts to validate this mechanism were performed by treatment of AvdU 21 under Method C and treatment of 8-AvdA $\mathbf{8 9}$ under Method A (Scheme 26) and were proved that vinyl azide did not undergo cyclization to 1,2,3-triazoles. Thus, the mechanism involving a [3+2] cycloaddition of the alkyne with in-situ generated $\mathrm{HN}_{3}$ seems more probable (Scheme 27). The terminal alkyne substrate 97 reacts with $\mathrm{Cu}$ (I) or Ag (I) and forms metal activated alkyne 98, which further reacts with hydrazoic acid 99 in-situ generated from TMSN $_{3}$ and $\mathrm{H}_{2} \mathrm{O}$ to produce intermediate $\mathbf{1 0 0}$. Protonation of $\mathbf{1 0 0}$ yields the final product $\mathrm{N}$-unsubstituted 1,2,3-triazol-4-yl nucleosides 101 and releases $\mathrm{Cu}$ (I) or $\mathrm{Ag}$ (I) as catalyst.

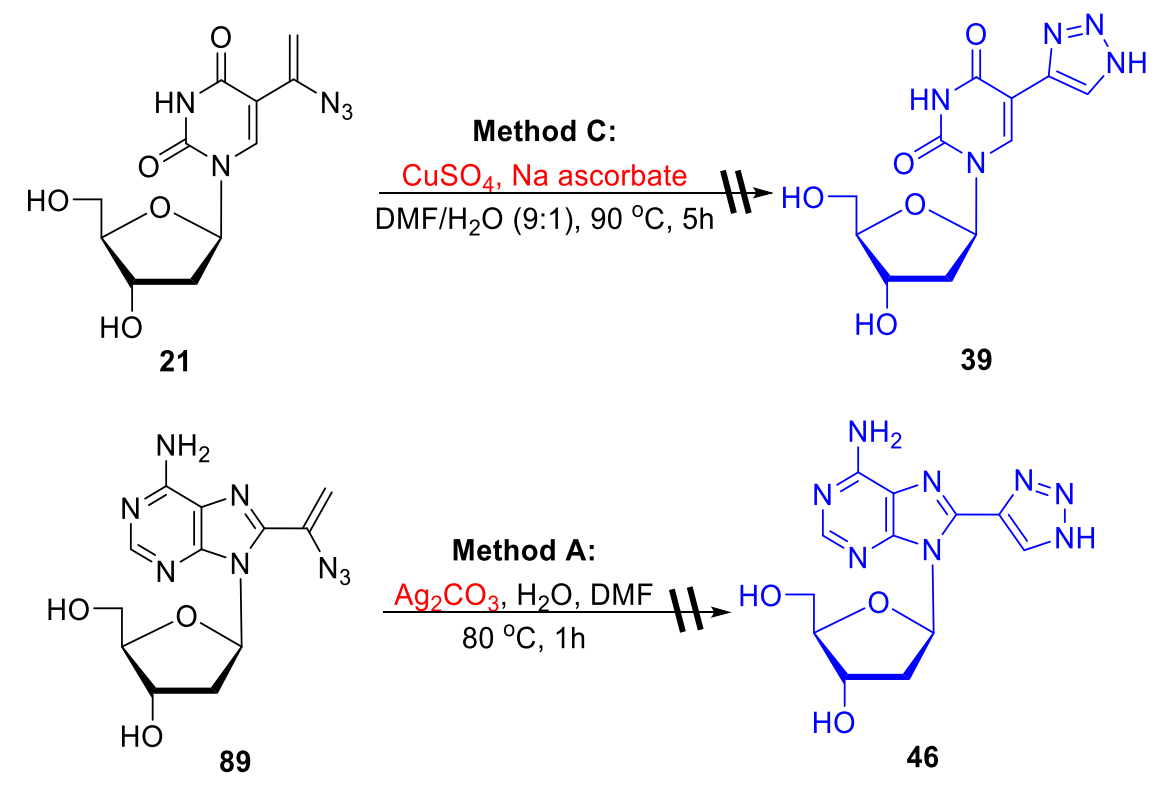

Scheme 26. Attempted conversion of vinylazides to triazoles 


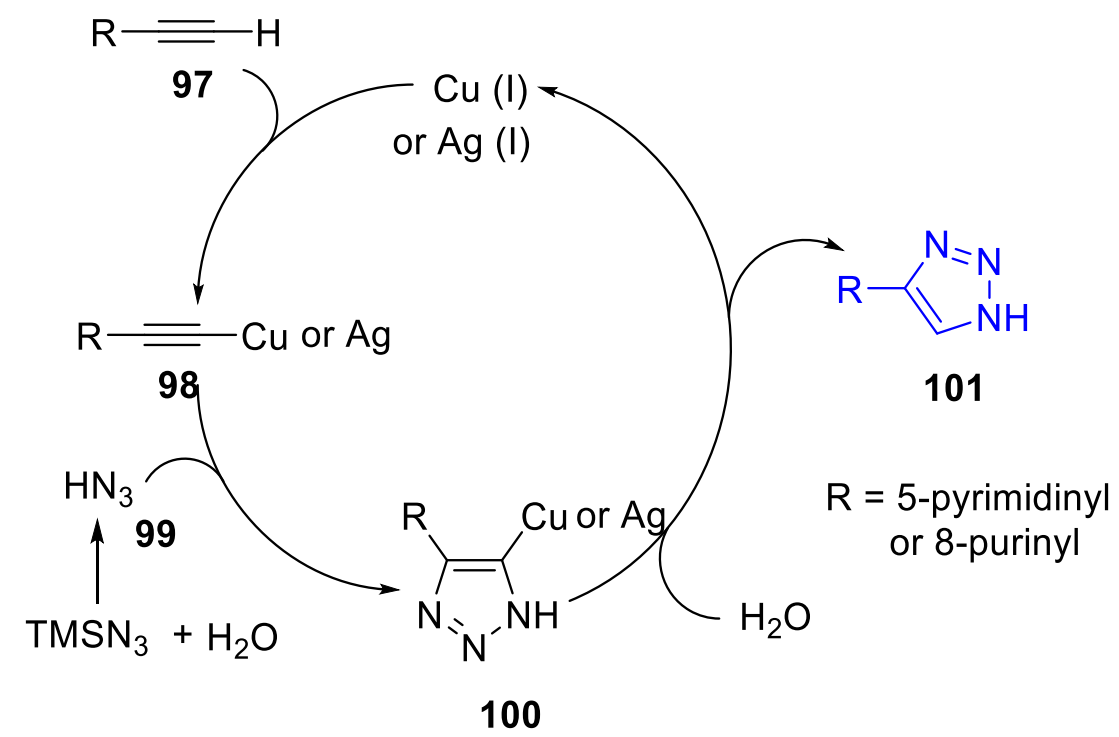

Scheme 27. Mechanism for the formation of $N$-unsubstituted 1,2,3-triazoles

\subsubsection{Stabilities of $N$-unsubstituted triazolyl nucleosides}

The metabolic phosphorylation by kinase in cells and the following incorporation of modified nucleosides into DNA usually requires incubation of the cells with the compounds for more than one hour. ${ }^{145,146}$ Typically, the incubation time is one or two days or even longer. For animal test, the whole process may need several days. As a result, the biological applications demand the compounds be stable under physiological conditions. The chemical stabilities of 8-TrzdA 46, 8-TrzdG 47, 5-TrzdC 48, and 5-TrzdU 39 were evaluated in $\mathrm{D}_{2} \mathrm{O} / \mathrm{DMSO}-d_{6}(500 \mu \mathrm{L} / 50 \mu \mathrm{L})$ by monitoring the decomposition using ${ }^{1} \mathrm{H}$ NMR. The samples were kept in a $37{ }^{\circ} \mathrm{C}$ oil bath in the dark (covered with aluminum

foil). The ${ }^{1} \mathrm{H}$ NMR spectra were recorded at $0 \mathrm{~h}, 20 \mathrm{~h}$, and $48 \mathrm{~h}$. The ${ }^{1} \mathrm{H}$ NMR spectra of 8-TrzdA was shown in Figure 28A and the fraction remaining of the four compounds over the time was shown in Figure 28B. The results showed that 8-TrzdA 46, 8-TrzdG 47, 5-TrzdC 48, and 5-TrzdU 39 were very stable and exhibited no detectable decomposition in aqueous solution after $48 \mathrm{~h}$ at $37^{\circ} \mathrm{C}$. 


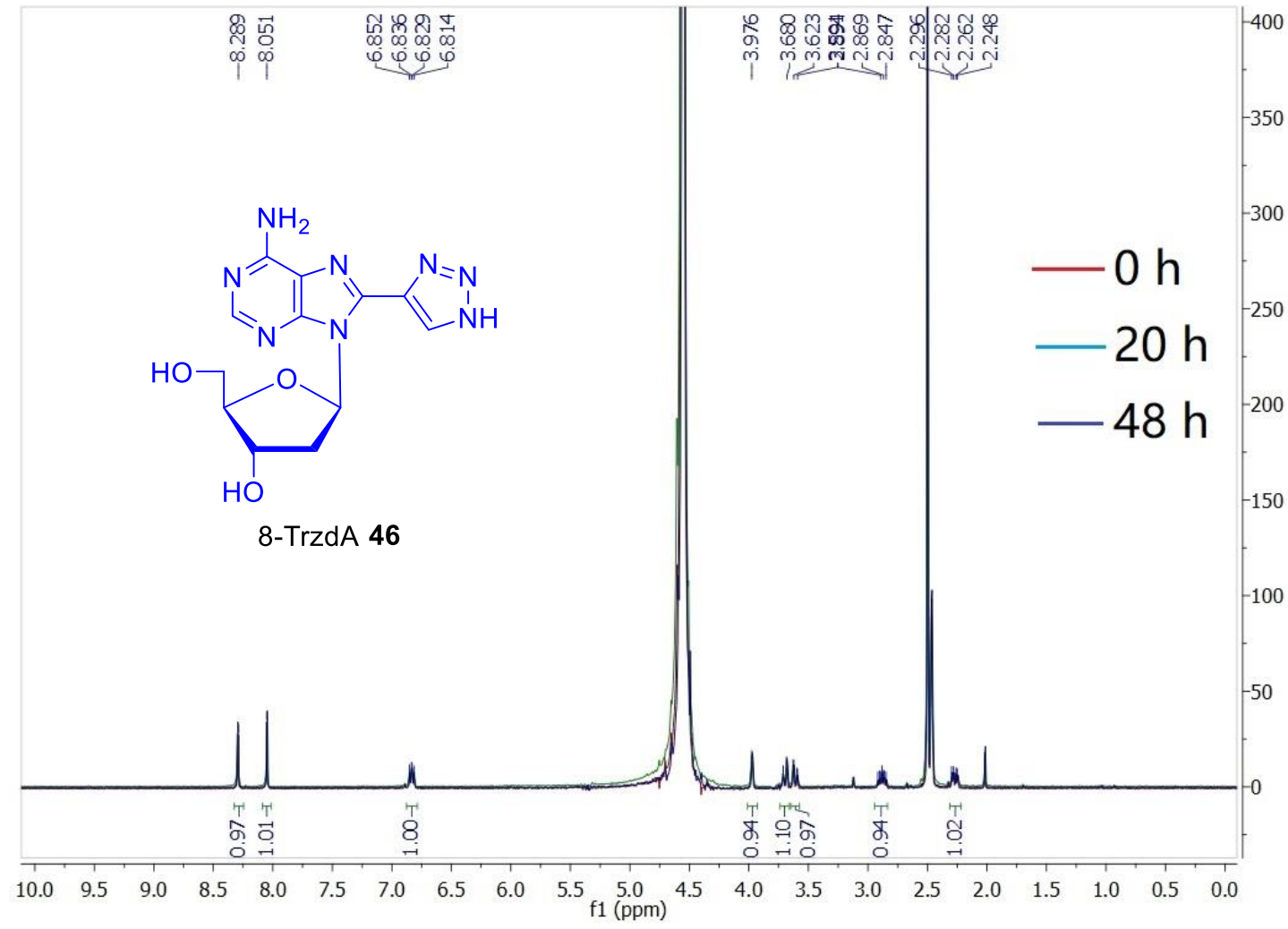

\section{Stabilities of triazolyl nucleosides at $37^{\circ} \mathrm{C}$ in aqueous solution}

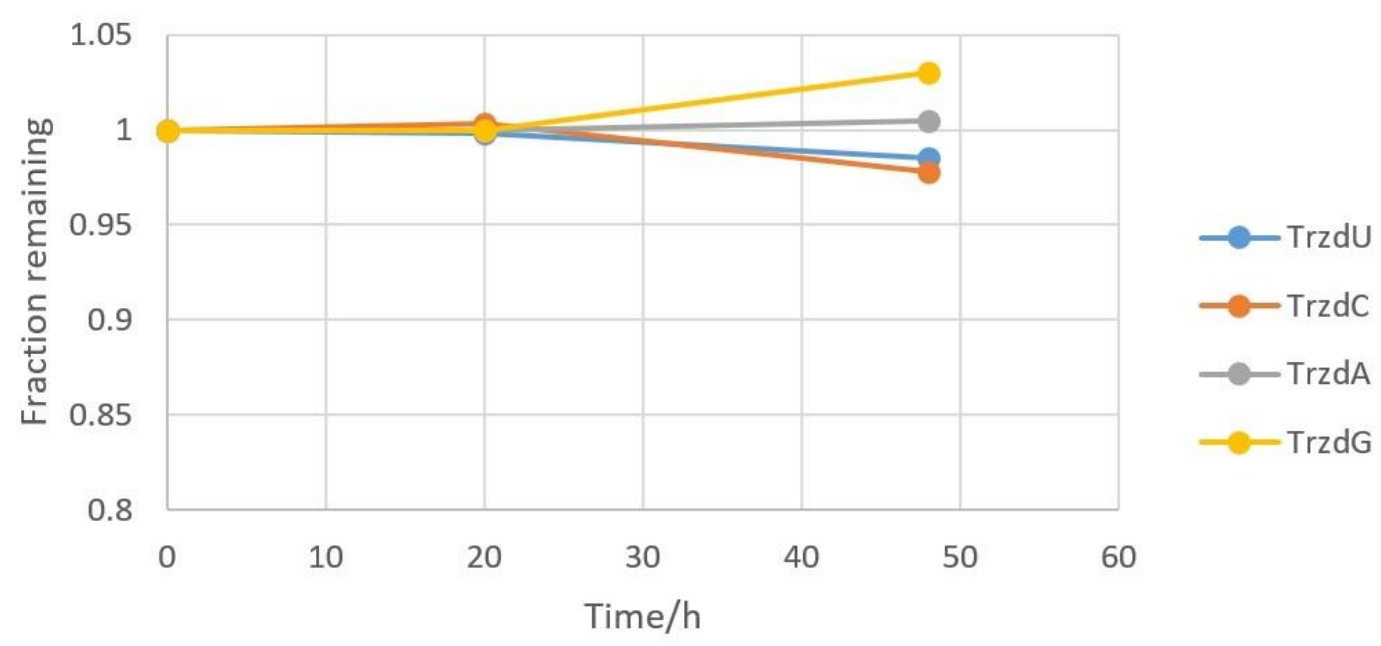

Figure 28. Stability of triazolyl nucleosides at $37^{\circ} \mathrm{C}$ in aqueous solution

(A) ${ }^{1} \mathrm{H}$ NMR of 8-TrzdA in $\mathrm{D}_{2} \mathrm{O}$ solution (10\% DMSO) incubated at $37{ }^{\circ} \mathrm{C}$ for $0 \mathrm{~h}, 20 \mathrm{~h}$, and $48 \mathrm{~h}$. (B) Fraction remaining of 8-TrzdA, 8-TrzdG, 5-TrzdU, and 5-TrzdC in $\mathrm{D}_{2} \mathrm{O}$ solution (10\% DMSO) incubated at $37^{\circ} \mathrm{C}$ vs. time 


\subsubsection{Inhibition of cell proliferation}

For effective metabolic labeling, the cytotoxicity of the labeling probe is an important consideration. ${ }^{146}$ Moreover, I was also interested in the potential application in anticancer of this group of novel nucleosides. Thus, 8-TrzdA 46, 8-TrzdG 47, 5-TrzdC 48, and 5-TrzdU 39 were examined for their antiproliferative activity in HEL, HeLa, Vero, and MDCK cells. The results showed that all the compounds exhibited no cytotoxicity with $\mathrm{CC}_{50}>100 \mu \mathrm{M}$.

\subsubsection{Fluorescent properties of triazolyl nucleosides}

The normalized fluorescence emission, absorption, and excitation spectra for the four 1H-1,2,3-triazol-4-yl nucleosides in methanol were shown in Figure 29. Their photophysical data are summarized in Table 8 . As expected, 8-TrzdA 46 with the $\mathrm{C} 4$ of triazolyl attaching to the $\mathrm{C} 8$ of adenine exhibits the high quantum yield $\left(\Phi_{\mathrm{F}}\right)$ of $44 \%$. 8-TrzdA 46 emits at 300-480 $\mathrm{nm}$ with the maximum emission at $355 \mathrm{~nm}$. The diTBDMSprotected 8-TrzdA analogue $\mathbf{8 8}$ exhibits matching fluorescent properties with a $\Phi_{\mathrm{F}}$ of $48 \%$, which is reasonable since protection at sugar moiety does not change to the conjugated system and thus no difference would be expected. Similarly, the emission of 8-TrzdG 47 starts at $300 \mathrm{~nm}$ but extends to $540 \mathrm{~nm}$ and the maximum emission is at $364 \mathrm{~nm}$. Compared to the $\Phi_{\mathrm{F}}$ of 8 -TrzdA 46 , the $\Phi_{\mathrm{F}}$ of 8 -TrzdG 88 is a little bit smaller as $9 \%$. 

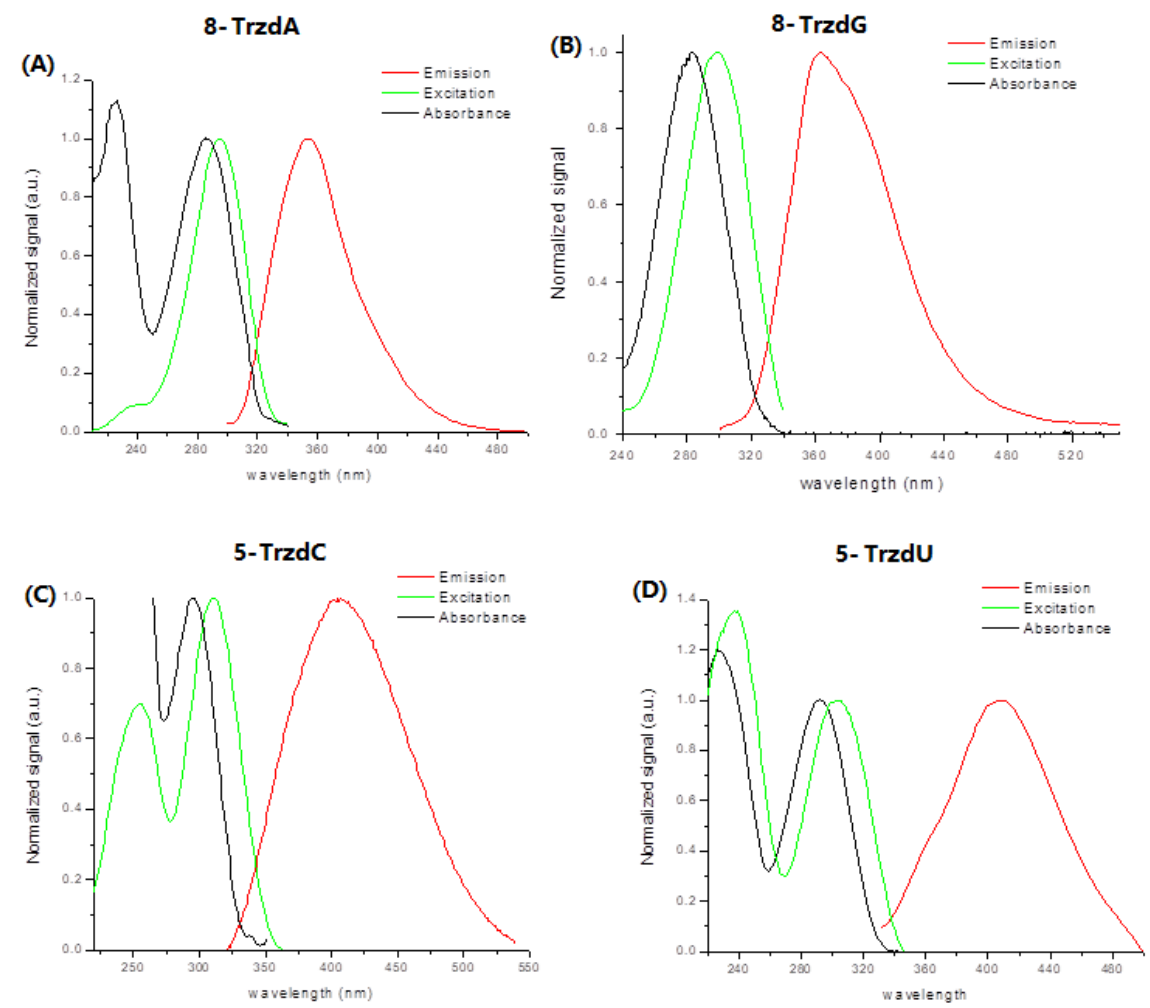

Figure 29. Normalized fluorescence emission, absorption, and excitation spectra for (A) 8-TrzdA, (B) 8-TrzdG, (C) 5-TrzdC, and (D) 5-TrzdU in MeOH

Table 8. Photophysical data for 8-TrzdA (46), 8-TrzdG (47), 5-TrzdC (48), 5-TrzdU (39), and their analogues

\begin{tabular}{llllllll}
\hline Comp'd & $\mathbf{8 3}$ & $\mathbf{4 8}$ & $\mathbf{8 4}$ & $\mathbf{3 9}$ & $\mathbf{4 6}$ & $\mathbf{8 8}$ & $\mathbf{4 7}$ \\
\hline$\varepsilon_{\max }\left(\mathrm{M}^{-1} \mathrm{~cm}^{-1}\right)$ & 4150 & 18750 & 10700 & 12400 & 17950 & 14100 & 14800 \\
$\lambda_{\max }(\mathrm{abs})(\mathrm{nm})$ & 293 & 295 & 291 & 291 & 287 & 285 & 283 \\
$\lambda_{\max }(\mathrm{exc})(\mathrm{nm})$ & 259 & 311 & 239 & 238 & 295 & 232 & 299 \\
$\lambda_{\max }(\mathrm{exc})(\mathrm{nm})$ & 312 & 254 & 294 & 302 & 235 & 292 & - \\
$\lambda_{\max }(\mathrm{emi})(\mathrm{nm})$ & 421 & 407 & 400 & 408 & 355 & 355 & 364 \\
Stokes shift $(\mathrm{nm})$ & 128 & 112 & 109 & 117 & 68 & 70 & 81 \\
$\Phi_{\mathrm{F}}$ & 0.02 & 0.02 & 0.003 & 0.004 & 0.44 & 0.48 & 0.09 \\
$\tau_{1}(\mathrm{~ns})$ & 0.46 & 0.10 & 0.05 & 0.14 & 0.69 & 1.01 & 0.61 \\
$\tau_{2}(\mathrm{~ns})$ & 4.48 & 4.35 & 1.59 & 1.06 & 2.07 & 2.82 & 3.22 \\
$\tau_{\text {average }}(\mathrm{ns})$ & 4.20 & 3.72 & 0.82 & 0.805 & 1.55 & 2.22 & 2.47 \\
$\mathrm{f}_{1}(\%)$ & 0.07 & 0.15 & 0.50 & 0.27 & 0.37 & 0.33 & 0.28 \\
$\mathrm{f}_{2}(\%)$ & 0.93 & 0.85 & 0.50 & 0.73 & 0.63 & 0.67 & 0.71 \\
\hline
\end{tabular}


In contrast, the 5-pyrimidine analogues 5-TrzdU 39 and 5-TrzdC 48 showed a large Stokes shift of $\sim 110 \mathrm{~nm}$ with the maximum emission approximately at $408 \mathrm{~nm}$ and much lower quantum yields. 5-TrzdC 48 emits at $320-550 \mathrm{~nm}\left(\Phi_{\mathrm{F}}=2 \%\right)$, while 5-TrzdU 39 emits at $320-500 \mathrm{~nm}\left(\Phi_{\mathrm{F}}=0.3 \%\right)$. Even though the quantum yield of 5-TrzdU is relatively low, it is still good enough to show bright fluorescence in solution and in cells (see cell imaging results in section 3.3.5). Similarly, the acetyl-protection at sugar doesn't alter the fluorescent properties of the triazolyl pyrimidine nucleosides.

All triazoles showed biphasic fluorescence decay. The four unprotected triazoles present a fast lifetime of 0.1-4.4 ns (Table 8). 5-TrzdC $\mathbf{4 8}$ shows the longest lifetime of $4.35 \mathrm{~ns}$ and longest average life time of $3.7 \mathrm{~ns} .8$-TrzdA (63\%), 8-TrzdG (71\%), 5-TrzdC (85\%), and 5-TrzdU (73\%) showed the larger contribution of the long lifetime $\left(\tau_{2}\right)$.

The application of these fluorescent nucleosides with the minimalistic modification at heterocyclic bases to cell imaging and DNA modifications will be discussed below.

\subsubsection{Cell imaging}

Primary mouse astrocytes were treated with vehicle (0.05\% DMSO) or 10, 100, 1000 $\mathrm{uM}$ of triazoles (with $0.05 \%$ DMSO) for 24 hours. The live cells were imaged using FV10i Confocal Laser Scanning Microscope from Olympus. The selected cell images were shown in Figure 30. In the negative controls, background fluorescence was indistinguishable in cells (Figure 30A). Due to the relatively high $\lambda$ (exc) of the excitation filter at $405 \mathrm{~nm}$ while the $\lambda_{\max }$ (exc) of those triazoles were at around $290-310 \mathrm{~nm}$, the fluorescence was somewhat weak in Figure 30B-E. Nevertheless, we could still observe clear blue fluorescence from the triazoles in the cytosol of live cells rather than in the nucleus, which match our previous result on live cell imaging using in-situ generated fluorescent triazoles in cells. ${ }^{51}$ 

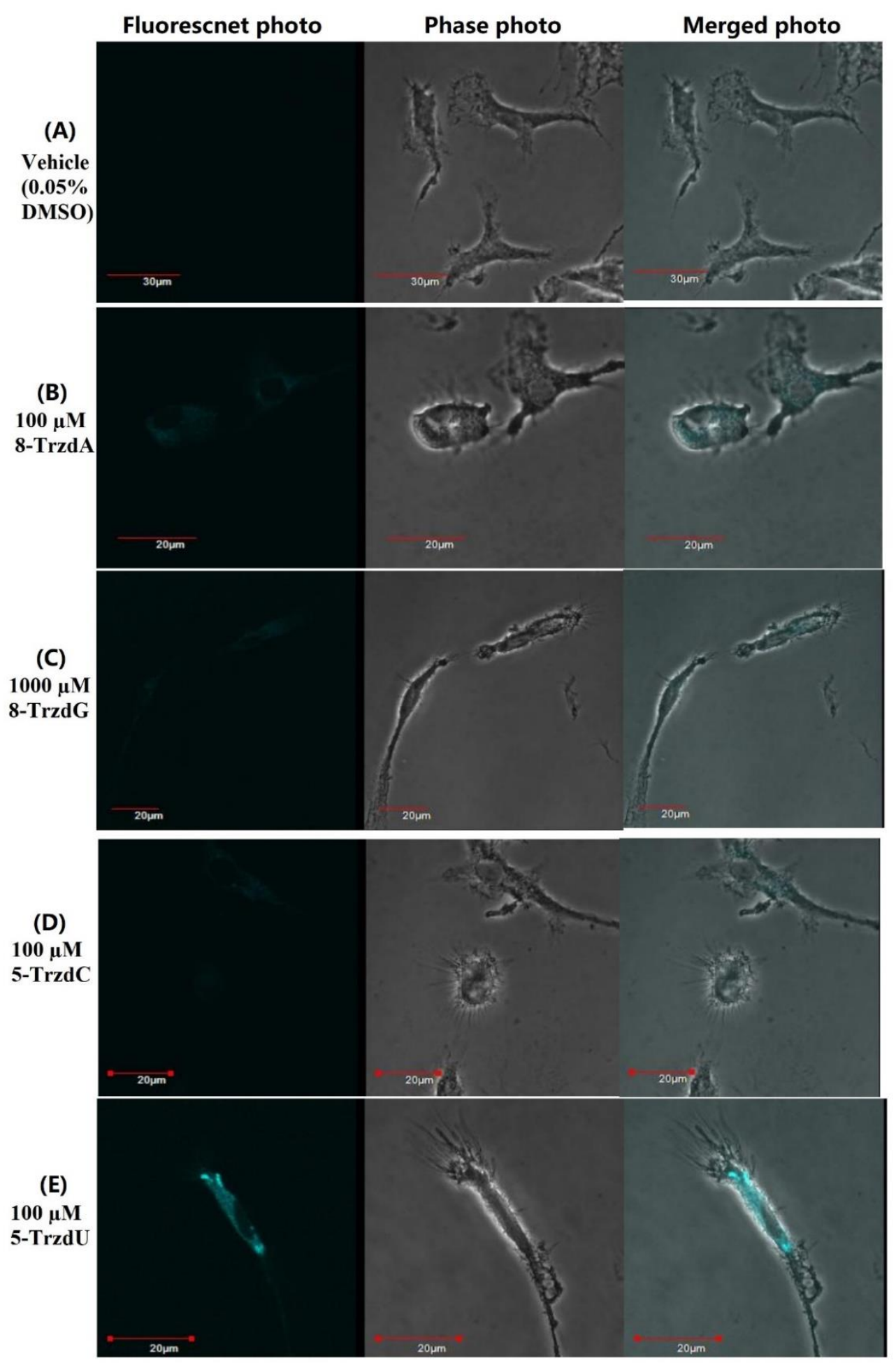

Figure 30. Fluorescence microscopy images and phase photos of primary mouse astrocytes cells treated with 8-TrzdA, 8-TrzdG, 5-TrzdC, and 5-TrzdU 
To further prove that the fluorescent triazoles showed fluorescence in the cytosol, 3T3-L1 mouse pre-adipocytes (Zen-bio \#SP-L1-F) transfected with pMX-puro-GFP were employed to show clearly the edge of cells and to localize the cell nucleus with its green fluorescence. 3T3-L1 mouse pre-adipocytes transfected with pMX-puro-GFP were treated with the vehicle (0.05\% DMSO), $200 \mathrm{uM}$ of 8-TrzdA, or $200 \mathrm{uM}$ of 5-TrzdU (with $0.05 \%$ DMSO) for 24 hours. Fixed cells were mounted with ProLong ${ }^{\text {TM }}$ Gold Antifade Mountant (Thermo Fisher Scientific) and observed under the Olympus FV 1200 confocal microscope $(\mathrm{Ex} / \mathrm{Em}=473 / 519 \mathrm{~nm}$ for imaging of GFP; $\mathrm{Ex} / \mathrm{Em}=405 / 461 \mathrm{~nm}$ for triazoles $)$. Figure 31 showed clearly the cells and the nucleus. In the negative controls, background fluorescence was indistinguishable in cells incubated without any triazoles. The fluorescent 8-TrzdA (Figure 31B) and 5-TrzdU (Figure 31C) were localized at cytosol.

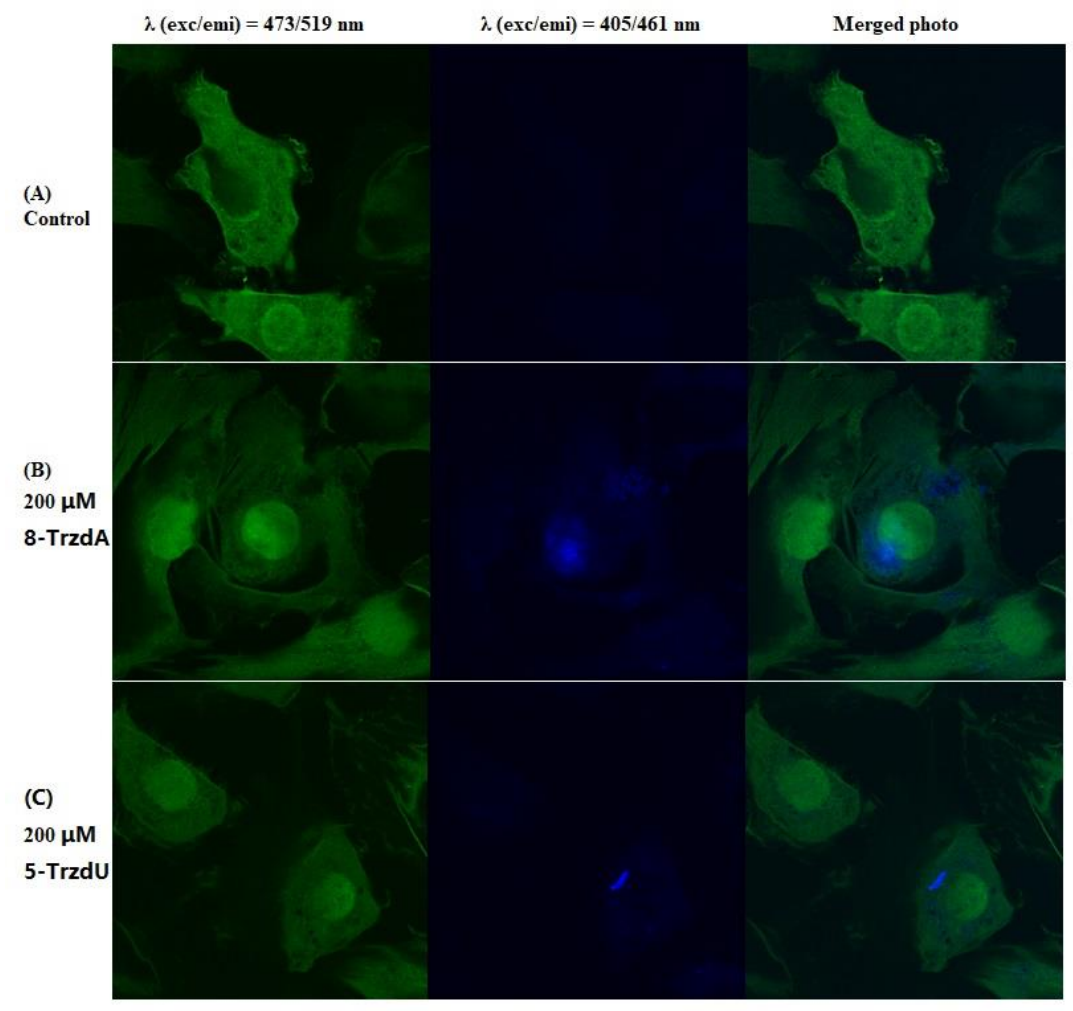

Figure 31. Fluorescence microscopy images of fixed pMX-puro-GFP transfected 3T3-L1 mouse pre-adipocytes treated with 8-TrzdA and 5-TrzdU 
The reasons why the fluorescent stain was only found in cell cytosol rather than in the nucleus is still unclear. The possible reasons may be a) The triazolyl nucleosides are not substrates for polymerases, b) the triazoles are sensitive to the microenvironment and the fluorescence is quenched after being incorporated into duplex DNA.

\subsubsection{Polymerase-catalyzed incorporation of 8-TrzdA into DNA and fluorescent} sensitivities to varied microenvironments

\subsubsection{Synthesis of TrzdATP}

The 8-TrzdATP 102 was synthesized following the triphosphorylation reported in section 3.1.3. The reaction of 8 -TrzdA 46 with $\mathrm{POCl}_{3}$ in the presence of proton sponge followed by addition of TBAPP 73 and then TBA yielded 8-TrzdATP $(\mathbf{1 0 2}, 30 \%$, Scheme 28) after DEAE-Sephadex purification. The phosphates were characterized by ${ }^{1} \mathrm{H}$ (Figure 32A), ${ }^{13} \mathrm{C},{ }^{31} \mathrm{P}$ NMR (Figure 32B) as well as HR-MS (details at experimental section 4.1.4).

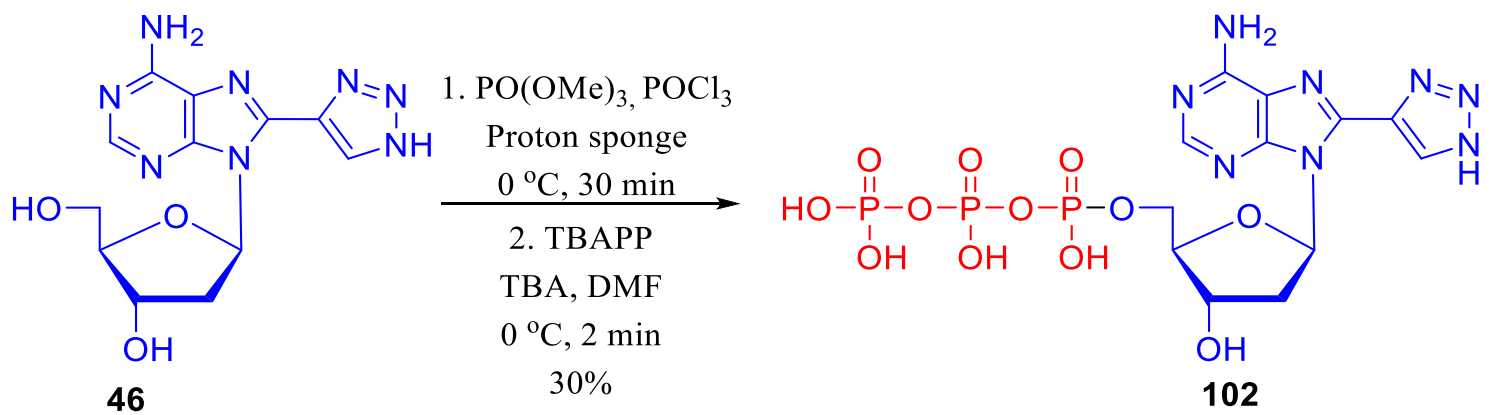

Scheme 28. Synthesis of TrzdATP 


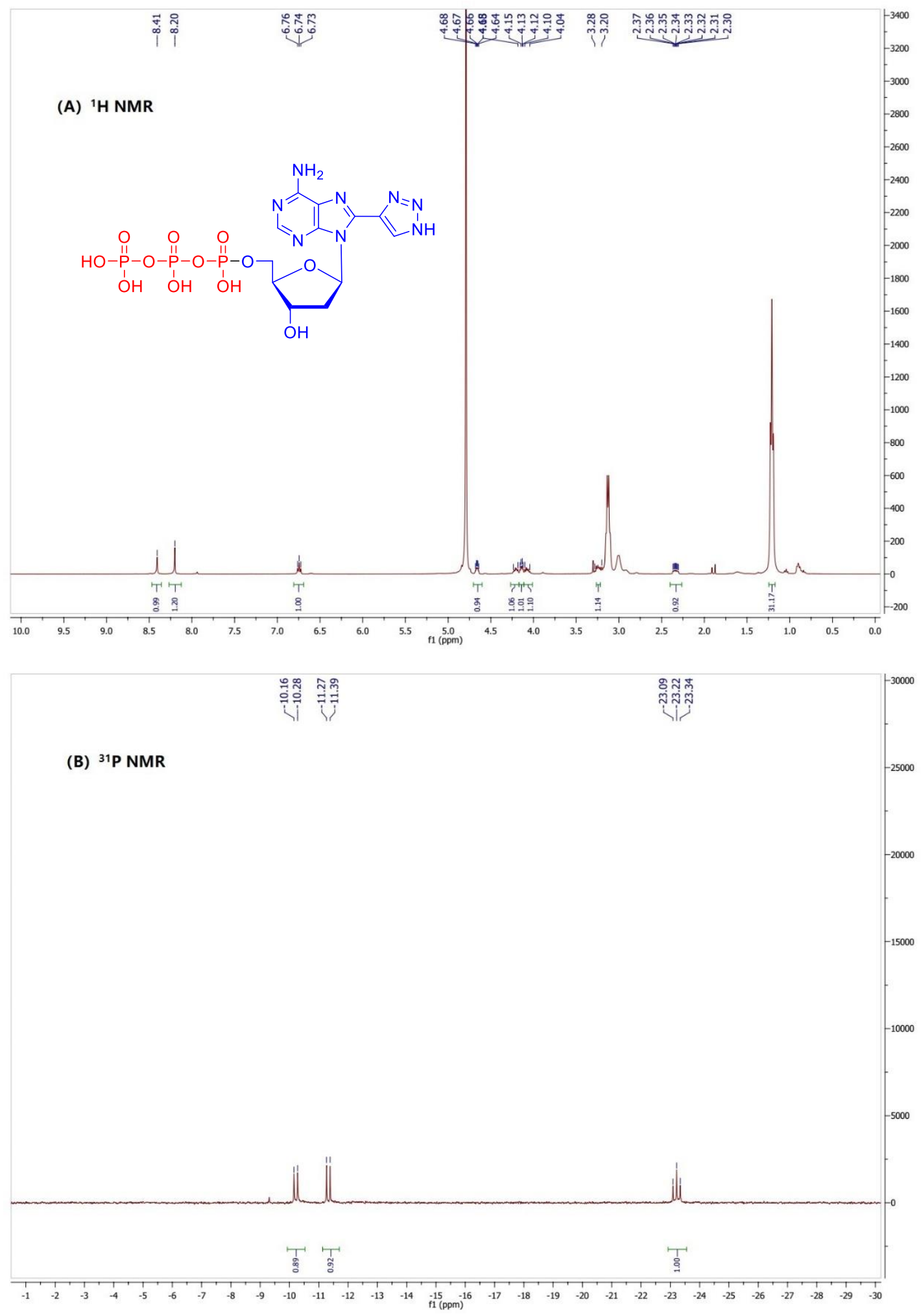

Figure 32. ${ }^{1} \mathrm{H}(\mathrm{A})$ and ${ }^{31} \mathrm{P}(\mathrm{B}) \mathrm{NMR}$ of 8 -TrzdATP 


\subsubsection{Enzymatic incorporation of 8-TrzdATP into DNA}

To determine the reasons leading to fluorescent stain localization to the cell cytosol rather than in the nucleus, 8-TrzdATP $\mathbf{1 0 2}$ was prepared to investigate if it could be substrate for polymerases and also to test the changes of fluorescent properties of the triazoles before and after being incorporated into duplex DNA (Figure 33).

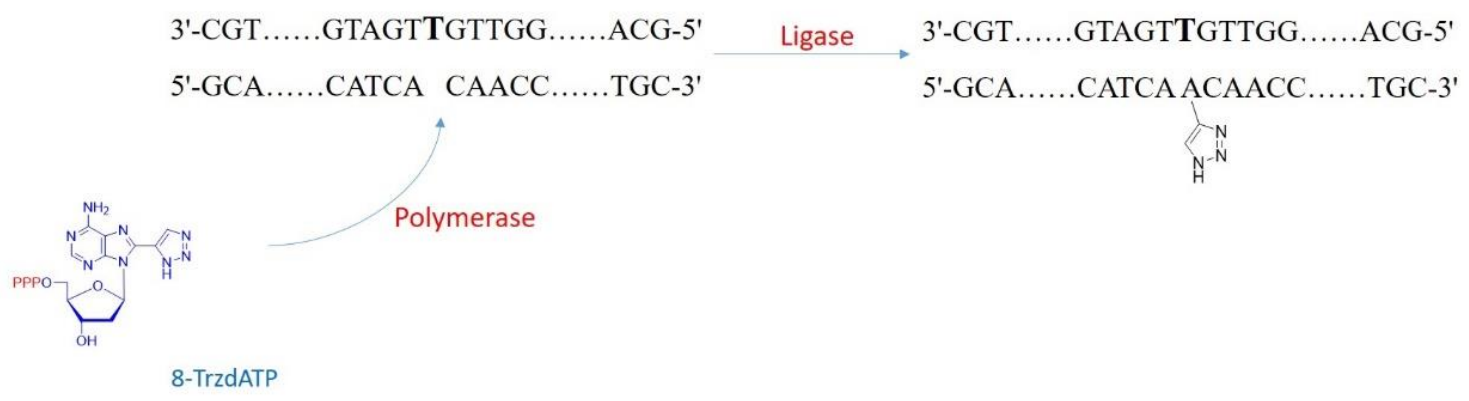

Figure 33. Proposed incorporation of 8-TrzdATP into DNA

\subsection{Antiviral and cytostatic evaluation of 5-(1-halo-2-sulfonylvinyl) and 5-(2-furyl) uracil nucleosides}

The work on section 3.4 as well as experimental section 4.1.5, 4.7 and 4.8 was published as an original paper at Arch Pharm/Wiley (Z. Wen, S. H. Suzol, J. Peng, Y. Liang, R. Snoeck, G. Andrei, S. Liekens, S. F. Wnuk, Archiv der Pharmazie 2017, 350, e1700023$\mathrm{n} / \mathrm{a}) .{ }^{147}$

\subsubsection{Chemistry}

Tetrabutylammonium fluoride (TBAF)-mediated direct $\mathrm{C}-\mathrm{H}$ arylation of 5-iodouracil nucleosides (103 or 105) with furan yielded 5-(fur-2-yl)-2'-deoxyuridine $106(73 \%)^{111}$ or 2',3',5'-tri- $O$-acetyl-5-(fur-2-yl)uridine 107 (67\%, Scheme 29). Treatment of 5-iodo-2'deoxyuridine 103 with 2-heptylfuran gave 2'-deoxy-5-(5-heptylfur-2-yl)uridine 108 (61\%) as a single isomer. Analogous cross-coupling of the protected 2'-deoxyuridine 104 or 
uridine 105 with 2-heptylfuran provided regioselectively acetyl protected 5-(5-heptylfur2-yl) derivatives $109(60 \%)$ and 110 (55\%). Deacetylation of 110 with methanolic ammonia afforded 5-(5-heptylfur-2-yl)uridine (111; 81\%). Esterification of 106 with undecanoic anhydride yielded 5'-O-undecanoyl- and 3',5'-di- $O$-undecanoyl-5-(fur-2-yl)-2'deoxyuridine 112 and 113. Analogously 108 was converted to 5-(5-heptylfur-2-yl) esters

\section{4 and 115.}

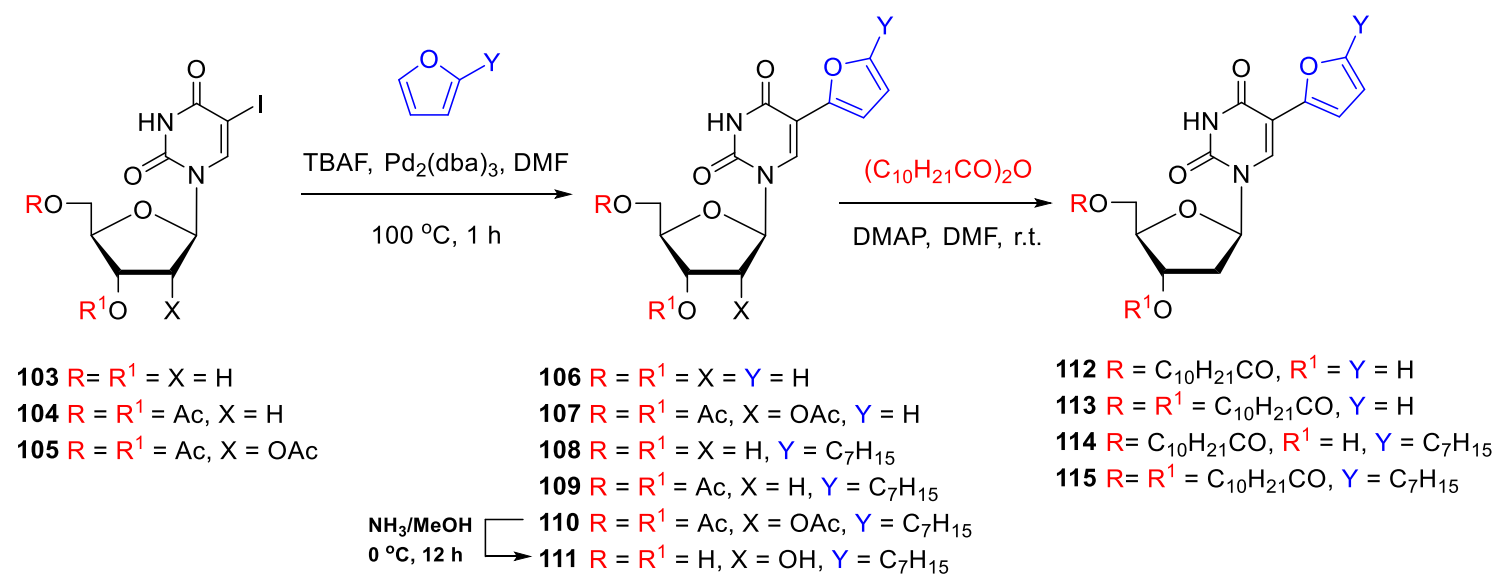

Scheme 29. Synthesis of 5-(fur-2-yl)- or 5-(5-heptylfur-2-yl)uracil nucleosides by direct C-H arylation

For the synthesis of 5'-monoesters of the 5-furyl substituted uridines (e.g., 119 and 120), I have developed a three-step protocol starting from 2',3'-O-isopropylideneuridine $\mathbf{1 1 6}$ (Scheme 30). Thus, treatment of $\mathbf{1 1 6}$ with undecanoic acid in the presence of DCC gave 2',3'-O-isopropylidene-5'-O-undecanoyluridine (117) in 90\% yield. Iodination of $\mathbf{1 1 7}$ with $\mathrm{ICl}$ in $\mathrm{CH}_{2} \mathrm{Cl}_{2}$ yielded 5'-O-undecanoyl-5-iodouridine (118). Direct $\mathrm{C}-\mathrm{H}$ cross-coupling of 118 with furan or 2-heptylfuran in the presence of $\mathrm{TBAF}^{111}$ gave 5'-O-undecanoyl-5-(fur2-yl)uridine $(\mathbf{1 1 9}, 63 \%)$ or 5'-O-undecanoyl-5-(5-heptylfur-2-yl)uridine $(\mathbf{1 2 0}, 44 \%)$, respectively. 


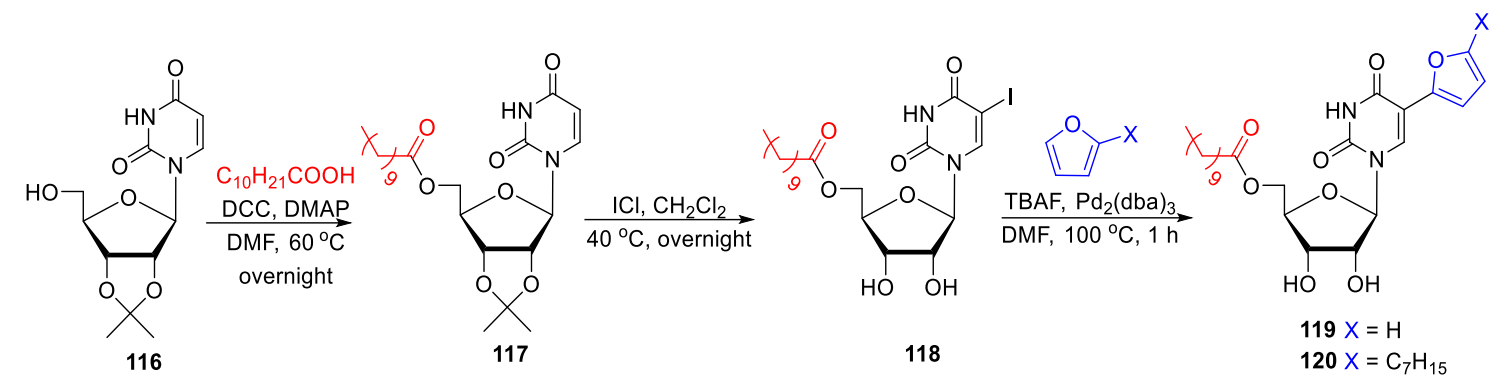

Scheme 30. Synthesis of 5-(fur-2-yl)- or 5-(5-heptylfur-2-yl)uridine and their 5'-esters

The 5-vinyl sulfone analogues: (E)-5-(1-bromo-2-tosylvinyl)-2'-deoxyuridine (121), (E)-3',5'-di-O-acetyl-5-(1-chloro-2-tosylvinyl)-2'-deoxyuridine (122), (E)-5-(1-chloro-2tosylvinyl)uridine $\quad(\mathbf{1 2 3}), \quad(E)-5-(1-b r o m o-2-t o s y l v i n y l) u r i d i n e \quad(\mathbf{1 2 4}), \quad(E)-1-(\beta$-Darabinofuranosyl)-5-(1-chloro-2-tosylvinyl)uracil $\quad$ (125), $\quad(E)-5-(1-p r o p y l t h i o-2-$ tosylvinyl)-2'-deoxyuridine (126), and (E)-5-(1-propylthio-2-tosylvinyl)uridine (127) were prepared as reported. ${ }^{110}$ The 5-heteroarene analogues: 3',5'-di-O-acetyl-5-(fur-2-yl)-2'deoxyuridine (128), 5-(fur-2-yl)uridine (129), 1-( $\beta$-D-arabinofuranosyl)-5-(fur-2-yl)uracil (130), 1-(2,3,5-tri- $O$-acetyl- $\beta$-D-arabinofuranosyl)-5-(fur-2-yl)uracil (131), 5-(thiophen-2yl)uridine (132), and 5-(5-methylthiophen-2-yl)uridine (133) were prepared as reported ${ }^{111}$ (Figure 34).
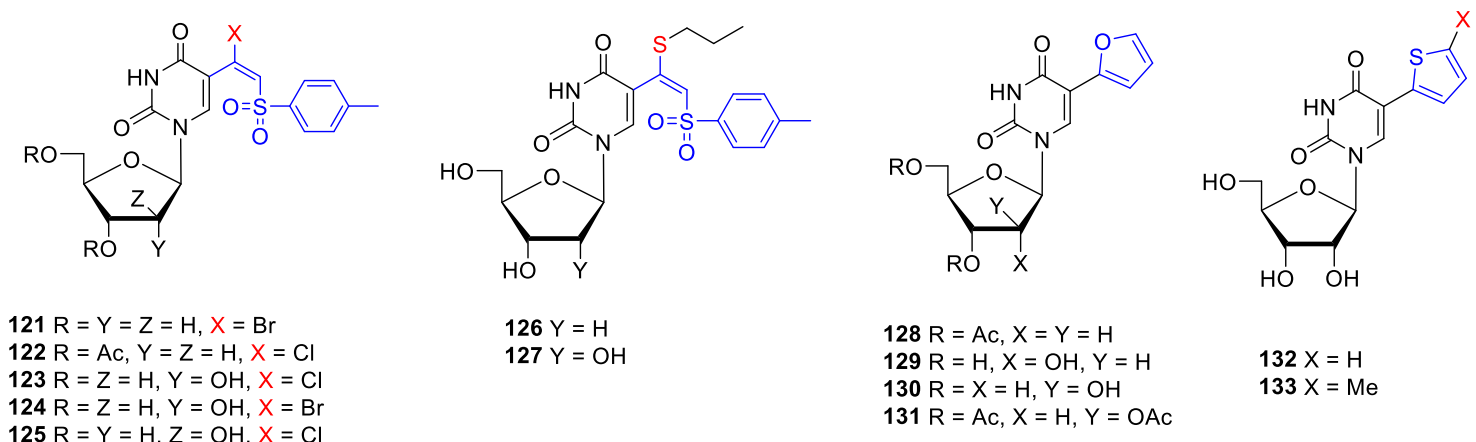

$$
\begin{aligned}
& 126 Y=H \\
& 127 Y=O H
\end{aligned}
$$

$128 \mathrm{R}=\mathrm{Ac}, \mathrm{X}=\mathrm{Y}=\mathrm{H}$

$129 \mathrm{R}=\mathrm{H}, \mathrm{X}=\mathrm{OH}, \mathrm{Y}=\mathrm{H}$ $130 \mathrm{R}=\mathrm{X}=\mathrm{H}, \mathrm{Y}=\mathrm{OH}$ $131 \mathrm{R}=\mathrm{Ac}, \mathrm{X}=\mathrm{H}, \mathrm{Y}=\mathrm{OAC}$
$132 \mathrm{X}=\mathrm{H}$ $133 X=M e$

Figure 34. Structures of 5-(1-substituted-2-tosylvinyl) 121-127 and 5-(2-heteroaryl) 128133 uracil nucleosides tested 


\subsubsection{Inhibition of cell proliferation}

The C5 substituted pyrimidine nucleosides $(\mathbf{1 0 6}-\mathbf{1 1 5}, \mathbf{1 1 9 - 1 3 3 )}$ were first examined for their antiproliferative activity in murine leukemia (L1210), human leukemia (CEM) and human cervical carcinoma (HeLa) cells. From the ( $\beta$-halo)vinyl sulfones tested (121-125), only the acetyl protected 2'-deoxyuridine ( $\beta$-chloro)vinyl sulfone $\mathbf{1 2 2}$ inhibited the growth of these cell lines in the lower $\mu \mathrm{M}$ range (Table 9). From the 5-(fur-2-yl) analogues tested (106-115, 119, 120, 128-131), the 2'-deoxy-5-(5-heptylfur-2-yl)uridine 108 inhibited the growth of CEM cell lines in the $\mu \mathrm{M}$ range.

Table 9. Inhibitory effects of 5-(1-substituted-2-tosylvinyl) and 5-(2-heteroaryl)uracil nucleosides on the proliferation of murine leukemia cells (L1210), human T-lymphocyte cells (CEM), and human cervix carcinoma cells (HeLa)

\begin{tabular}{|c|c|c|c|}
\hline \multirow{2}{*}{ Compound } & \multicolumn{3}{|c|}{$\mathrm{IC}_{50}{ }^{\mathrm{a}}(\mu \mathrm{M})$} \\
\cline { 2 - 4 } & $\mathrm{L} 1210$ & $\mathrm{CEM}$ & $\mathrm{HeLa}$ \\
\hline $\mathbf{1 0 6}$ & $>100$ & $>100$ & $32 \pm 1$ \\
\hline $\mathbf{1 0 7}$ & $>100$ & $80 \pm 8$ & $>100$ \\
\hline $\mathbf{1 0 8}$ & $48 \pm 6$ & $16 \pm 4$ & $>100$ \\
\hline $\mathbf{1 0 9}$ & $65 \pm 10$ & $36 \pm 3$ & $>100$ \\
\hline $\mathbf{1 1 0}$ & $88 \pm 17$ & $53 \pm 1$ & $>100$ \\
\hline $\mathbf{1 1 1}$ & $95 \pm 8$ & $42 \pm 2$ & $>100$ \\
\hline $\mathbf{1 1 4}$ & $>100$ & $93 \pm 4$ & $>100$ \\
\hline $\mathbf{1 1 5}$ & $>100$ & $78 \pm 16$ & $>100$ \\
\hline $\mathbf{1 1 9}$ & $43 \pm 8$ & $70 \pm 2$ & $64 \pm 5$ \\
\hline $\mathbf{1 2 2}$ & $5.6 \pm 4.7$ & $11 \pm 10$ & $23 \pm 8$ \\
\hline $\mathbf{1 2 5}$ & $>100$ & $>100$ & $>100$ \\
\hline $\mathbf{1 2 7}$ & $>100$ & $>100$ & $93 \pm 14$ \\
\hline $\mathbf{1 2 9}$ & $>100$ & $60 \pm 27$ & $83 \pm 25$ \\
\hline $\mathbf{1 3 0}$ & $>100$ & $>100$ & $>100$ \\
\hline $\mathbf{1 3 1}$ & $40 \pm 10$ & $63 \pm 3$ & $>100$ \\
\hline $\mathbf{1 3 2}$ & $>100$ & $86 \pm 6$ & $>100$ \\
\hline $\mathbf{1 3 3}$ & $>100$ & $>100$ & $>100$ \\
\hline
\end{tabular}

a $50 \%$ inhibitory concentration. 


\subsubsection{Antiviral activity}

The antiviral activity of all compounds was tested against a broad range of DNA and RNA viruses and the human immunodeficiency (HIV) virus. Some of the compounds proved active against herpesviruses though they were less potent than the reference antiherpesvirus drugs (Table 10). The 5-(5-heptylfur-2-yl) (108) and 3',5'-Di- $O$-acetyl-5-(5heptylfur-2-yl) (109) derivatives inhibited the replication of human cytomegalovirus (HCMV) and varicella-zoster virus (VZV) bearing a wild-type thymidine kinase $\left(\mathrm{TK}^{+}\right)$ with $50 \%$ effective concentrations $\left(\mathrm{EC}_{50}\right.$ 's) in the range of 10-20 $\mu \mathrm{M}$. Compound 108 was equally active against $\mathrm{TK}^{+}$and $\mathrm{TK}$-deficient $\left(\mathrm{TK}^{-}\right) \mathrm{VZV}$ strains while compound $\mathbf{1 0 9}$ failed to inhibit a $\mathrm{TK}^{-} \mathrm{VZV}$ mutant virus. Neither compound $\mathbf{1 0 8}$ nor $\mathbf{1 0 9}$ were able to decrease herpes simplex virus 1 (HSV-1) and 2 (HSV-2) induced cytopathic effect. In contrast, the 5-(fur-2-yl)uracil nucleoside $\mathbf{1 0 6}$ emerged among the compounds synthesized as the most potent inhibitor of the $\mathrm{HSV}-1 \mathrm{TK}^{+}$strain Kos with an $\mathrm{EC}_{50}$ of $4 \mu \mathrm{M}$. Compound $\mathbf{1 0 6}$ was less active against HCMV, HSV-2 and the VZV TK ${ }^{+}$Oka strain than against HSV-1 while it lacked activity against $\mathrm{TK}^{-} \mathrm{HSV}-1$ and VZV. The spectrum of activity of compound $\mathbf{1 3 0}$ only included HSV-1 and VZV TK ${ }^{+}$strains. The ( $\beta$-chloro)vinyl sulfone 122 showed an $\mathrm{EC}_{50}$ of $4 \mu \mathrm{M}$ for the Oka strain $\left(\mathrm{VZV} \mathrm{TK}^{+}\right)$and marginal activity against HCMV. Except for compound $\mathbf{1 0 8}$ that displayed antiviral activity against parainfluenza virus (Table 11), none of the compounds showed activity against the other tested viruses. 
Table 10. Anti-herpesvirus activity of 5-(1-substituted-2-tosylvinyl) and 5-(2-heteroaryl)uracil nucleosides in HEL (human embryonic lung) fibroblasts

\begin{tabular}{|c|c|c|c|c|c|c|c|c|}
\hline \multirow[b]{2}{*}{ Compound } & $\begin{array}{l}\text { Cytotoxicity } \\
(\mu \mathrm{M})\end{array}$ & \multicolumn{7}{|c|}{$\mathrm{EC}_{50}(\mu \mathrm{M})^{\mathrm{a}}$} \\
\hline & $\mathrm{MCC}^{\mathrm{b}}$ & $\begin{array}{l}\text { HSV-1 } \\
\text { (KOS) }\end{array}$ & $\begin{array}{l}\mathrm{HSV}-2 \\
(\mathrm{G})\end{array}$ & $\begin{array}{l}\mathrm{HSV}- \\
1 \mathrm{TK}^{-} \\
\left(\mathrm{KOS}^{-}\right. \\
\left.\mathrm{ACV}^{\mathrm{r}}\right) \\
\end{array}$ & $\begin{array}{c}\text { HCMV } \\
\text { (AD- } \\
169)\end{array}$ & $\begin{array}{l}\text { HCMV } \\
\text { (Davis) }\end{array}$ & $\begin{array}{c}\text { VZV } \\
\mathrm{TK}^{+} \\
(\text {Oka) }\end{array}$ & $\begin{array}{c}\text { VZV } \\
\mathrm{TK}^{-} \\
(07-1)\end{array}$ \\
\hline 106 & $>100$ & $4 \pm 0$ & $47 \pm 37$ & $>100$ & 45 & 20 & 32 & $>100$ \\
\hline 108 & 100 & $>100$ & $>100$ & $>100$ & 10 & 20 & $13 \pm 2$ & $12 \pm 5$ \\
\hline 109 & 100 & $>100$ & $>100$ & $>100$ & $10 \pm 2$ & $12 \pm 4$ & 20 & $>20$ \\
\hline 122 & 100 & $>100$ & $>100$ & $>100$ & $>20$ & 20 & 4 & $>20$ \\
\hline 130 & $>100$ & $14 \pm 8$ & $>100$ & $>100$ & $>100$ & $>100$ & 25 & $>100$ \\
\hline Acyclovir & $>440$ & $\begin{array}{c}0.4 \pm \\
0.1 \\
\end{array}$ & $\begin{array}{c}0.3 \pm \\
0.1 \\
\end{array}$ & $\begin{array}{c}110 \pm \\
104 \\
\end{array}$ & ND & ND & $\begin{array}{c}0.7 \pm \\
0.1 \\
\end{array}$ & $44 \pm 7$ \\
\hline Brivudin & $>300$ & $\begin{array}{c}0.04 \pm \\
0\end{array}$ & $\begin{array}{c}188 \pm \\
88\end{array}$ & $\begin{array}{c}27 \pm \\
32\end{array}$ & ND & ND & $\begin{array}{c}0.02 \pm \\
0.01\end{array}$ & $\begin{array}{c}29 \pm \\
10\end{array}$ \\
\hline Ganciclovir & $>350$ & $\begin{array}{c}0.06 \pm \\
0.04\end{array}$ & $\begin{array}{c}0.07 \pm \\
0.03\end{array}$ & $\begin{array}{c}4.4 \pm \\
3.4 \\
\end{array}$ & $\begin{array}{c}7.9 \pm \\
2.4 \\
\end{array}$ & $\begin{array}{c}4.3 \pm \\
3.6 \\
\end{array}$ & ND & ND \\
\hline Cidofovir & $>350$ & $\begin{array}{c}2.7 \pm \\
1.0\end{array}$ & $\begin{array}{l}1.5 \pm \\
0.7\end{array}$ & $\begin{array}{c}1.4 \pm \\
0.9\end{array}$ & $\begin{array}{c}0.9 \pm \\
0.6\end{array}$ & $\begin{array}{c}0.8 \pm \\
0.6\end{array}$ & ND & ND \\
\hline
\end{tabular}

${ }^{a}$ Required to reduce virus-induced cytopathogenicity by $50 \%$.

${ }^{\mathrm{b}}$ Minimum cytotoxic concentration (MCC) required to cause a microscopically detectable alteration of normal cell morphology.

Table 11. Activity of 5-(5-heptylfur-2-yl)-2'-deoxyuridine against Parainfluenza virus

\begin{tabular}{|c|c|c|}
\hline \multirow{2}{*}{ Compound } & Cytotoxicity $(\mu \mathrm{M})$ & $\mathrm{EC}_{50}(\mu \mathrm{M})^{\mathrm{a}}$ \\
\cline { 2 - 3 } & $\mathrm{MCC}^{\mathrm{b}}$ & Parainfluenza-3 virus \\
\hline $\mathbf{1 0 8}$ & $>100$ & $14 \pm 8$ \\
\hline
\end{tabular}

${ }^{a}$ Required to reduce virus-induced cytopathogenicity by $50 \%$.

${ }^{\mathrm{b}}$ Minimum cytotoxic concentration (MCC) required to cause a microscopically detectable alteration of normal cell morphology. 


\section{EXPERIMENTAL SECTION}

\subsection{Synthesis}

\subsubsection{General Procedure}

${ }^{1} \mathrm{H}(400 \mathrm{MHz})$ and ${ }^{13} \mathrm{C}(100.6 \mathrm{MHz}) \mathrm{NMR}$ spectra were recorded in solutions of $\mathrm{CDCl}_{3}$ unless otherwise noted. Reaction progress was monitored by TLC on Merck Kieselgel $60-\mathrm{F}_{254}$ sheets with product detection by $254-\mathrm{nm}$ light. Products were purified by column chromatography using Merck Kiselgel 60 (230-400 mesh) or by automated flash chromatography using a CombiFlash system. Reagent grade chemicals were used and solvents were dried by reflux and distillation from $\mathrm{CaH}_{2}$ under $\mathrm{N}_{2}$ unless otherwise specified. All reactions were carried out under the Argon atmosphere.

\subsubsection{Synthesis of pyrimidine nucleosides with azidomethyl and azidovinyl modification at $\mathrm{C} 5$ position and their 5'-phosphates}

5-Azidomethyl-2'-deoxyuridine 5'-monophosphate (AmdUMP, 19). Phosphoryl chloride $(11.2 \mu \mathrm{L}, 18.4 \mathrm{mg}, 0.12 \mathrm{mmol})$ was added to a stirred solution of AmdU $\mathbf{1 8}^{40}(28.3$ $\mathrm{mg}, 0.1 \mathrm{mmol})$ and proton sponge $(32 \mathrm{mg}, 0.15 \mathrm{mmol})$ in trimethyl phosphate $(1 \mathrm{~mL})$ at 0 ${ }^{\circ} \mathrm{C}$. The resulting mixture was stirred at $0{ }^{\circ} \mathrm{C}$ for $30 \mathrm{~min}$ and then quenched by adjusting the $\mathrm{pH}$ to 7.5 with $2 \mathrm{M}$ TEAB buffer. The residue was dissolved in water $(5 \mathrm{~mL})$ and was extracted with EtOAc ( 3 x $5 \mathrm{~mL})$. The water layer was evaporated and coevaporated with mixture of $\mathrm{EtOH} / \mathrm{H}_{2} \mathrm{O}(1: 1,5 \mathrm{~mL})$. The residue was column chromatographed (DEAESephadex ${ }^{\circledR}$, TEAB $\left.0.1 \mathrm{M} \rightarrow 0.4 \mathrm{M}\right)$ and the appropriate fractions were evaporated in vacuum and coevaporate 5 times with mixture of $\mathrm{EtOH} / \mathrm{H}_{2} \mathrm{O}(1: 1,10 \mathrm{~mL})$ to remove excess of TEAB salt to give AmdU monophosphate triethylammonium salt 19. (25.5 mg, 70.4\%): ${ }^{1} \mathrm{H}$ NMR $\left(\mathrm{D}_{2} \mathrm{O}\right) \delta$ 2.36-2.39 (m, 2H, H2',2"), 3.99-4.08 (m, 2H, H5',5"), 4.16-4.20 (m, 1H, 
H4'), 4.18 (s, 2H, CH$)_{2}, 4.55-4.59$ (m, 1H, H3'), 6.31 (t, J = 6.4 Hz, 1H, H1'), 8.09 (s, 1H, $\mathrm{H} 6) ;{ }^{31} \mathrm{P}$ NMR $\left(\mathrm{D}_{2} \mathrm{O}\right) \delta 1.16(\mathrm{~s}) ;{ }^{13} \mathrm{C} \mathrm{NMR}\left(\mathrm{D}_{2} \mathrm{O}\right) \delta 39.1,47.0,64.6,71.0,85.6,85.8,109.6$, 141.0, 151.5, 165.2; HRMS calcd for $\mathrm{C}_{10} \mathrm{H}_{14} \mathrm{~N}_{5} \mathrm{O} 8 \mathrm{P}[\mathrm{M}-\mathrm{H}]^{-} 362.05072$, found 362.05042.

5-Azidomethyl-2'-deoxyuridine 5'-triphosphate (AmdUTP, 20). Phosphoryl chloride $(11.2 \mu \mathrm{L}, 18.4 \mathrm{mg}, 0.12 \mathrm{mmol})$ was added to a stirred solution of AmdU $\mathbf{1 8}^{40}(28.3$ $\mathrm{mg}, 0.1 \mathrm{mmol})$ and proton sponge $(32 \mathrm{mg}, 0.15 \mathrm{mmol})$ in trimethyl phosphate $(1 \mathrm{~mL})$ at 0 ${ }^{\circ} \mathrm{C}$. The resulting mixture was stirred at $0{ }^{\circ} \mathrm{C}$ for $30 \mathrm{~min} .0 .5 \mathrm{M}$ tributylammomium pyrophosphate solution in DMF ( $1 \mathrm{~mL}, 0.5 \mathrm{mmol})$ and then tributylamine $(71.2 \mu \mathrm{L}, 55.6$ $\mathrm{mg}, 0.3 \mathrm{mmol}$ ) were added to the reaction mixture and stirred at $0{ }^{\circ} \mathrm{C}$ for $2 \mathrm{~min}$. The reaction was quenched by adjusting the $\mathrm{pH}$ to 7.5 with $2 \mathrm{M}$ TEAB buffer. The residue was dissolved in water $(5 \mathrm{~mL})$ and was extracted with EtOAc $(3 \times 5 \mathrm{~mL})$. The water layer was evaporated and coevaporated with mixture of $\mathrm{EtOH} / \mathrm{H}_{2} \mathrm{O}(1: 1,5 \mathrm{~mL})$. The residue was column chromatographed (DEAE-Sephadex ${ }^{\circledR}$, TEAB $0.1 \mathrm{M} \rightarrow 0.6 \mathrm{M}$ ) and the appropriate fractions were evaporated in vacuum and coevaporate 5 times with mixture of $\mathrm{EtOH} / \mathrm{H}_{2} \mathrm{O}$ $(1: 1,10 \mathrm{~mL})$ to give AmdU triphosphate triethylammonium salt 20. $(39.5 \mathrm{mg}, 75.6 \%) .{ }^{1} \mathrm{H}$ NMR ( $\left.\mathrm{D}_{2} \mathrm{O}\right) \delta$ 2.37-2.41 (m, 2H, H2',2"), 4.20 (s, 2H, $\mathrm{CH}_{2}$ ), 4.20-4.29 (m, 3H, H4',5',5"), 4.64-4.67 (m, 1H, H3'), 6.32 (t, $\left.J=6.0,1 \mathrm{H}, \mathrm{H} 1^{\prime}\right), 8.06(\mathrm{~s}, 1 \mathrm{H}, \mathrm{H} 6) ;{ }^{31} \mathrm{P} \mathrm{NMR}\left(\mathrm{D}_{2} \mathrm{O}\right) \delta$ $23.25(\mathrm{t}, J=19.7,1 \mathrm{P}, \beta),-11.64(\mathrm{~d}, J=19.8,1 \mathrm{P}, \alpha),-10.80(\mathrm{~d}, J=19.8,1 \mathrm{P}, \gamma) ;{ }^{13} \mathrm{C} \mathrm{NMR}$ $\left(\mathrm{D}_{2} \mathrm{O}\right) \delta 38.9,47.1,65.4,70.8,85.5,85.8,109.7,141.0,151.5,165.2$; HRMS calcd for $\mathrm{C}_{10} \mathrm{H}_{16} \mathrm{~N}_{5} \mathrm{O}_{14} \mathrm{P}_{3}[\mathrm{M}-\mathrm{H}]^{-} 521.98338$, found 521.98262.

5-(1-Azidovinyl)-2' -deoxyuridine (AvdU, 21). Procedure A. Step a: $\mathrm{Ag}_{2} \mathrm{CO}_{3}(5.5 \mathrm{mg}$, $0.02 \mathrm{mmol})$ was added to a solution of $\mathbf{6 2}^{110}(67.3 \mathrm{mg}, 0.2 \mathrm{mmol}), \mathrm{TMSN}_{3}(52.5 \mu \mathrm{L}, 46$ mg, $0.4 \mathrm{mmol})$, and $\mathrm{H}_{2} \mathrm{O}(7 \mu \mathrm{L}, 7 \mathrm{mg}, 0.4 \mathrm{mmol})$ in DMF (2 mL). The resulting mixture 
was stirred at $80{ }^{\circ} \mathrm{C}$ for 1 hour. After cooling to ambient temperature, the volatiles were evaporated under the reduced pressure and the residue was column chromatographed (hexane/EtOAc 50:50) to give 64 (39 mg, 52\%): ${ }^{1} \mathrm{H}$ NMR $\delta 2.07$ (s, 6H, Ac), 2.33-2.46 (m, 2H, H2',2"), 4.24-4.29 (m, 3H, H4', 5',5"), 5.06 (s, 1H, = $\mathrm{CH}_{2}$ ), 5.19-5.21 (m, 1H, H3'), 6.00 (s, $\left.1 \mathrm{H},=\mathrm{CH}_{2}\right), 6.14\left(\mathrm{t}, J=6.4 \mathrm{~Hz}, 1 \mathrm{H}, \mathrm{H} 1\right.$ ') $7.83(\mathrm{~s}, 1 \mathrm{H}, \mathrm{H} 6), 11.73(\mathrm{~s}, 1 \mathrm{H}, \mathrm{NH}) ;{ }^{13} \mathrm{C} \mathrm{NMR}$ $\delta 20.37,20.81,36.71,63.75,74.19,81.84,85.36,101.58,107.30,136.87,138.33,149.26$, 160.88, 170.09, 170.17. Step $b$ : Methanolic ammonia (4 mL) was added to $64(38.9 \mathrm{mg}$, $0.1 \mathrm{mmol})$ in $2 \mathrm{~mL} \mathrm{MeOH}$ and the resulting mixture was stirred at $0{ }^{\circ} \mathrm{C} \rightarrow$ r.t for 12 hours. Volatiles were evaporated and the residue was column chromatographed (EtOAc/MeOH 95:5) gave AvdU 21 (27.4 mg, 90\%): UV (MeOH) $\lambda_{\max }$ 227, 248 (sh), $286 \mathrm{~nm}(\varepsilon$ 10650, 7600, 8700), $\lambda_{\min }$ 204, $264 \mathrm{~nm}(\varepsilon 4050,7200) ;{ }^{1} \mathrm{H}$ NMR (DMSO-d6) $\delta 2.09-2.19$ (m, 2H, H2' \& 2"), 3.54-3.64 (m, 2H, H5' \& 5"), 3.82 (q, J= 3.1, 1H, H4'), 4.23-4.27 (m, 1H, H3'), $5.00\left(\mathrm{~d}, J=0.7 \mathrm{~Hz}, 1 \mathrm{H},=\mathrm{CH}_{2}\right), 5.11\left(\mathrm{t}, J=4.5 \mathrm{~Hz}, 1 \mathrm{H}, 5^{\prime}-\mathrm{OH}\right), 5.28\left(\mathrm{~d}, J=4.2 \mathrm{~Hz}, 3^{\prime}-\mathrm{OH}\right)$, $5.91\left(\mathrm{~d}, J=0.8 \mathrm{~Hz}, 1 \mathrm{H},=\mathrm{CH}_{2}\right), 6.16(\mathrm{t}, J=6.4 \mathrm{~Hz}, 1 \mathrm{H}, \mathrm{H1}$ '), $8.26(\mathrm{~s}, 1 \mathrm{H}, \mathrm{H6}), 11.60(\mathrm{~s}$, 1H, NH); ${ }^{13} \mathrm{C}$ NMR (DMSO-d6) $\delta 40.2,61.0,70.3,84.8,87.6,101.3,107.1,137.3,139.4$, 149.4, 161.0; HRMS calcd for $\mathrm{C}_{11} \mathrm{H}_{13} \mathrm{~N}_{5} \mathrm{O}_{5} \mathrm{Na}[\mathrm{M}+\mathrm{Na}]^{+} 318.0809$, found 318.0784.

5-Azidomethyl-2'-deoxycytidine (AmdC, 42). Step a: TIPBS-Cl (59 mg, $0.2 \mathrm{mmol}$ ) was added to a stirring solution of $\mathbf{5 4}^{40}(67 \mathrm{mg}, 0.13 \mathrm{mmol})$, DMAP (2 mg, $\left.0.016 \mathrm{mmol}\right)$, and triethylamine $(27 \mu \mathrm{L}, 19.7 \mathrm{mg}, 0.2 \mathrm{mmol})$ in $\mathrm{CH}_{2} \mathrm{Cl}_{2}(1.5 \mathrm{~mL})$ at ambient temperature. After $1 \mathrm{~h}$, the residue was partitioned between $\mathrm{CH}_{2} \mathrm{Cl}_{2}$ and $\mathrm{H}_{2} \mathrm{O}$. The organic layer was washed with $\mathrm{NaHCO}_{3} / \mathrm{H}_{2} \mathrm{O}$ and brine. Then $2.5 \mathrm{~mL}$ THF and $4 \mathrm{~mL}$ of aq. $\mathrm{NH}_{3}$ was added into the reaction residue and stirred at rt overnight. The volatiles were evaporated and the residue was partitioned between EtOAc and saturated brine and was column 
chromatographed $\left(\mathrm{CHCl}_{3} / \mathrm{MeOH}, 0: 100 \rightarrow 85: 15\right)$ to give $\mathbf{5 5}(57.4 \mathrm{mg}, 86 \%)$ of sufficient purity to be used in next step: ${ }^{1} \mathrm{H}$ NMR (DMSO- $d_{6}$ ) $\delta 0.07$ (s, 6H, $2 \times \mathrm{CH}_{3}$ ), 0.08 (s, 6H, 2 x $\mathrm{CH}_{3}$ ), 0.87 (s, 9H, $3 \times \mathrm{CH}_{3}$ ), 0.88 (s, 9H, $3 \times \mathrm{CH}_{3}$ ), 2.00-2.07 (m, 1H, H2'), 2.15 (ddd, $J$ $\left.=13.6,6.5,3.4 \mathrm{~Hz}, 1 \mathrm{H}, \mathrm{H} 2^{\prime \prime}\right), 3.71-3.72\left(\mathrm{~m}, 2 \mathrm{H}, \mathrm{H} 5^{\prime}, 5 "\right), 3.82(\mathrm{q}, J=4.2 \mathrm{~Hz}, \mathrm{H} 4$ '), $4.22(\mathrm{~s}$, 2H, $\mathrm{CH}_{2} \mathrm{~N}_{3}$ ), 4.32-4.35 (m, 1H, H3'), 6.14 (t, $J=6.8 \mathrm{~Hz}, \mathrm{H} 1$ '), 7.13 (s, 1H, NH), 7.54 (s, $1 \mathrm{H}, \mathrm{NH}), 7.70(\mathrm{~s}, 1 \mathrm{H}, \mathrm{H} 6) ;{ }^{13} \mathrm{C}$ NMR (DMSO- $\left.d_{6}\right) \delta-5.5,-5.0,-4.8,17.6,17.9,25.6,25.7$, 40.0, 47.3, 62.8, 72.2, 84.8, 86.9, 100.0, 141.4, 154.4, 164.0 Step b: 1 M TBAF/THF (330 uL, $0.33 \mathrm{mmol}$ ) was added to a stirring solution of $\mathbf{5 5}(57.4 \mathrm{mg}, 0.11 \mathrm{mmol})$ in THF (5 $\mathrm{mL}$ ). After $4 \mathrm{~h}$, volatiles were evaporated and the residue was column chromatographed $\left(\mathrm{CHCl}_{3} / \mathrm{MeOH}, 100: 0 \rightarrow 85: 15\right)$ and further purified by HPLC (C18; A: 100\% ACN, B: 5\% $\mathrm{ACN} / \mathrm{H}_{2} \mathrm{O} ; 0 \% \mathrm{~A} \rightarrow 5 \% \mathrm{~A}$ in $30 \mathrm{~min}$, flow rate $\left.=2 \mathrm{~mL} / \mathrm{min}\right)$ to give $\mathbf{4 2}(27.3 \mathrm{mg}, 88 \%):$ $\mathrm{UV}(\mathrm{MeOH}) \lambda_{\max } 206,276 \mathrm{~nm}(\varepsilon 18000,6300), \lambda_{\min } 256 \mathrm{~nm}(\varepsilon 4800) ;{ }^{1} \mathrm{H}$ NMR (DMSO- $d_{6}$ ) $\delta$ 1.91-1.98 (m, 1H, H2'), 2.14 (ddd, $J=13.4,5.9,3.5 \mathrm{~Hz}, \mathrm{H} 2 "), 3.52-3.62$ (m, 2H, H5',5"), $3.78\left(\mathrm{q}, J=4.0 \mathrm{~Hz}, 1 \mathrm{H}, \mathrm{H} 4{ }^{\prime}\right), 4.19-4.23\left(\mathrm{~m}, 1 \mathrm{H}, \mathrm{H} 3^{\prime}\right), 4.23\left(\mathrm{~s}, 2 \mathrm{H}, \mathrm{CH}_{2} \mathrm{~N}_{3}\right), 5.01(\mathrm{t}, J=4.8$ $\left.\mathrm{Hz}, 1 \mathrm{H}, 5^{\prime}-\mathrm{OH}\right), 5.22\left(\mathrm{~d}, J=4.0 \mathrm{~Hz}, 1 \mathrm{H}, 3^{\prime}-\mathrm{OH}\right), 6.12\left(\mathrm{t}, J=6.1,1 \mathrm{H}, \mathrm{H} 1^{\prime}\right), 7.12(\mathrm{~s}, 1 \mathrm{H}$, NH), 7.49 (s, 1H, NH), 7.97 (s, 1H, H6); ${ }^{13} \mathrm{C}$ NMR (DMSO- $\left.d_{6}\right) \delta$ 40.4, 47.4, 61.3, 70.2, 85.0, 87.3, 99.9, 142.0, 154.6, 164.0; HRMS calcd for $\mathrm{C}_{10} \mathrm{H}_{14} \mathrm{~N}_{6} \mathrm{O}_{4} \mathrm{Na}[\mathrm{M}+\mathrm{Na}]^{+}$305.0969, found 305.0969.

5-(1-Azidovinyl)-2'-deoxycytidine (AvdC, 43). Method A. Step a: Treatment of 63a ${ }^{119}$ (297 mg, $0.88 \mathrm{mmol}$ ) with $\mathrm{TMSN}_{3}$ by procedure A, step a, (column chromatography; $\mathrm{CHCl}_{3} / \mathrm{MeOH}, 100: 0 \rightarrow$ 90:10) gave 3',5'-di-O-acetyl-5-(1-azidovinyl)-2'-deoxycytidine 65 (169 mg, 51\%): ${ }^{1} \mathrm{H}$ NMR $\delta 2.03$ (s, 3H, Ac), 2.06 (s, 3H, Ac), 2.32-2.42 (m, 2H, H2',2"), 4.19-4.28 (m, 3H, H4',5',5"), $5.06\left(\mathrm{~d}, J=1.5 \mathrm{~Hz}, 1 \mathrm{H},=\mathrm{CH}_{2}\right),\left(\mathrm{d}, J=1.4 \mathrm{~Hz}, 1 \mathrm{H},=\mathrm{CH}_{2}\right)$, 
5.16-5.18 (m, 1H, H3'), 6.15 (t, J= 6.5 Hz, 1H, H1'), 7.05 (s, 1H, NH), 7.64 (s, 1H, NH), 7.69 (s, 1H, H6). Step b: Treatment of $65(160 \mathrm{mg}, 0.42 \mathrm{mmol})$ with methanolic ammonia by Procedure A, step b, (HPLC, C18; A: 100\% ACN, B: 5\% ACN/H $20 ; 0 \% \mathrm{~A} \rightarrow 5 \% \mathrm{~A}$ in $50 \mathrm{~min}$, flow rate $\left.=2 \mathrm{~mL} / \mathrm{min} ; \mathrm{R}_{\mathrm{t}}=15.6 \mathrm{~min}\right)$ gave AvdC $43(59 \mathrm{mg}, 48 \%): \mathrm{UV}(\mathrm{MeOH})$ $\lambda_{\max } 213,244$ (sh), $283 \mathrm{~nm}(\mathrm{sh})\left(\varepsilon\right.$ 18500, 10800, 5350); ${ }^{1} \mathrm{H}$ NMR (DMSO-d6) $\delta 1.98-2.00$ (m, 1H, H2'), 2.16 (s, J=3.8, 1H, H2"), 3.52-3.63 (m, 2H, H5' \& 5"), 3.79 (q, J = 3.3, 1H, H4'), 4.20-4.23 (m, 1H, H3'), $5.00\left(\mathrm{~d}, J=1.7 \mathrm{~Hz}, 1 \mathrm{H},=\mathrm{CH}_{2}\right), 5.05(\mathrm{~d}, J=1.7 \mathrm{~Hz}, 1 \mathrm{H}$, $\left.=\mathrm{CH}_{2}\right), 5.06\left(\mathrm{~s}, 1 \mathrm{H}, 5^{\prime}-\mathrm{OH}\right), 5.22\left(\mathrm{~s}, 1 \mathrm{H}, 3^{\prime}-\mathrm{OH}\right), 6.11\left(\mathrm{t}, J=7.1 \mathrm{~Hz}, 1 \mathrm{H}, \mathrm{H} 1^{\prime}\right), 6.93(\mathrm{~s}, 1 \mathrm{H}$, NH), 7.52 (s, 1H, NH), 8.05 (s, 1H, H6); ${ }^{13} \mathrm{C}$ NMR (DMSO-d6) $\delta$ 40.7, 60.9, 70.0, 85.2, 87.4, 101.8, 103.5, 139.2, 141.5, 154.1, 162.4; HRMS calcd for $\mathrm{C}_{11} \mathrm{H}_{14} \mathrm{~N}_{6} \mathrm{O}_{4} \mathrm{Na}[\mathrm{M}+\mathrm{Na}]^{+}$ 317.0969, found 317.0976.

Method B. Treatment of 5-ethynyl-2'-deoxycytidine $\mathbf{6 3 b}^{120}$ (40 mg, $0.16 \mathrm{mmol}$ ) with TMS-N $\mathrm{N}_{3}$ by procedure A step a (column chromatography; $\mathrm{CHCl}_{3} / \mathrm{MeOH}, 95: 5 \rightarrow$ 85:15) gave 43 (16 mg, 34\%).

Method C. TIPBSCl (68 mg, $0.22 \mathrm{mmol})$ was added to a stirring solution of 64 (56.7 mg, $0.15 \mathrm{mmol})$, DMAP (2.3 mg, $0.018 \mathrm{mmol})$, and TEA (32 $\mu \mathrm{L}, 22.8 \mathrm{mg}, 0.22 \mathrm{mmol})$ in $\mathrm{CH}_{2} \mathrm{Cl}_{2}(1.5 \mathrm{~mL})$ at ambient temperature. After $1 \mathrm{~h}$, the residue was partitioned between $\mathrm{CH}_{2} \mathrm{Cl}_{2}$ and $\mathrm{H}_{2} \mathrm{O}$. The organic layer was washed with $\mathrm{NaHCO}_{3} / \mathrm{H}_{2} \mathrm{O}$ and brine. Then $3 \mathrm{~mL}$ THF and $4.5 \mathrm{~mL}$ of aq. $\mathrm{NH}_{3}$ was added into the reaction residue and stirred at $\mathrm{rt}$ overnight. The volatiles were evaporated and the residue was column chromatographed $\left(\mathrm{CHCl}_{3} / \mathrm{MeOH}, 100: 0 \rightarrow 85: 15\right)$ to give $\mathbf{4 3}(28 \mathrm{mg}, 63 \%)$

3',5'-di-O-acetyl-5-azidomethyl-2'-deoxyuridine (diAcAmdU, 56). Into a solution of $\mathrm{AmdU} \mathbf{1 8}^{40}(85 \mathrm{mg}, 0.3 \mathrm{mmol})$ and 4-dimehtylaminopyridine $(3.7 \mathrm{mg}, 0.03 \mathrm{mmol})$ in 3 
$\mathrm{mL}$ acetonitrile was added triethylamine $(209 \mu \mathrm{L}, 151.8 \mathrm{mg}, 1.5 \mathrm{mmol})$. The resulting mixture was stirred for $5 \mathrm{~min}$. Acetic anhydride $(85 \mu \mathrm{L}, 91.9 \mathrm{mg}, 0.9 \mathrm{mmol})$ was added and the reaction mixture was stirred at room temperature for $1 \mathrm{~h}$. The volatiles were evaporated and the residue was dissolved in EtOAc and was extracted with $\mathrm{NaHCO}_{3}$ aqueous solution. The organic layer was collected and dried over $\mathrm{Na}_{2} \mathrm{SO}_{4}$. The volatiles were evaporated under the reduced pressure and the residue was column chromatographed (hexane/EtOAc 70:30 $\rightarrow$ 40:60) to give $56(71.3 \mathrm{mg}, 65 \%):{ }^{1} \mathrm{H}$ NMR $\delta$ 2.11-2.20 (m, $1 \mathrm{H}$, H2'), 2.12 (s, 3H, $\left.\mathrm{CH}_{3}\right), 2.14$ (s, 3H, $\mathrm{CH}_{3}$ ), 2.53 (ddd, $\left.J=14.2,5.3,1.7 \mathrm{~Hz}, 1 \mathrm{H}, \mathrm{H} 2 "\right), 4.13$ $\left(\mathrm{d}, J=5.2 \mathrm{~Hz}, 1 \mathrm{H}, \mathrm{CH}_{2} \mathrm{~N}_{3}\right), 4.24\left(\mathrm{~d}, J=3.9 \mathrm{~Hz}, 1 \mathrm{H}, \mathrm{CH}_{2} \mathrm{~N}_{3}\right), 4.27-4.33\left(\mathrm{~m}, 2 \mathrm{H}, \mathrm{H}^{\prime}, 5^{\prime}\right)$, $4.42(\mathrm{dd}, J=12.6,5.3 \mathrm{~Hz}, 1 \mathrm{H}, \mathrm{H} 5 "), 5.21-5.24(\mathrm{~m}, 1 \mathrm{H}, \mathrm{H} 3$ '), 6.31 (dd, $J=9.3,6.0 \mathrm{~Hz}, 1 \mathrm{H}$, H1'), 7.56 (s, 1H, H6), 9.04 (s, 1H, NH). ${ }^{13} \mathrm{C}$ NMR $\delta 20.9,21.1,38.0,47.3,64.0,74.3,77.4$, $82.7,85.5,110.5,137.2,149.9,162.2,170.5,170.6$.

5-(Dimethoxymethyl)-2'-deoxyuridine (58). The solution of thymidine 41 (72.7 mg, $0.3 \mathrm{mmol}$ ), $\mathrm{NaHCO}_{3}(25.2 \mathrm{mg}, 0.3 \mathrm{mmol})$, and $\mathrm{Na}_{2} \mathrm{~S}_{2} \mathrm{O}_{8}(213 \mathrm{mg}, 0.9 \mathrm{mmol})$ in $\mathrm{H}_{2} \mathrm{O} / \mathrm{MeCN}$ (2:3, $4 \mathrm{~mL})$ was degassed for $15 \mathrm{~min}$. Tosyl azide $(69 \mu \mathrm{L}, 88.8 \mathrm{mg}, 0.45 \mathrm{mmol})$ was added into the resulting mixture and then the reaction was stirred under $80{ }^{\circ} \mathrm{C}$ for $1 \mathrm{~h}$. After the reaction, the temperature was lower down to room temperature and $0.5 \mathrm{~mL}$ aqueous solution $\mathrm{Na}_{2} \mathrm{~S}_{2} \mathrm{O}_{3}$ (268mg, $1.08 \mathrm{mmol}$ ) and $\mathrm{NaI}(45 \mathrm{mg}, 0.3 \mathrm{mmol})$ was added to quench the excess $\mathrm{Na}_{2} \mathrm{~S}_{2} \mathrm{O}_{8}$. The volatiles were evaporated and the residue was column chromatographed $\left(\mathrm{CHCl}_{3} / \mathrm{MeOH}, 100: 0 \rightarrow 85: 15\right)$ and further purified by HPLC (C18; A: $100 \% \mathrm{ACN}, \mathrm{B}: 5 \% \mathrm{ACN} / \mathrm{H}_{2} \mathrm{O} ; 0 \% \mathrm{~A} \rightarrow 5 \% \mathrm{~A}$ in $60 \mathrm{~min}$, flow rate $=2 \mathrm{~mL} / \mathrm{min}$ ) to give 58 (58.1 mg, 64\%): ${ }^{1} \mathrm{H}$ NMR (DMSO- $\left.d_{6}\right) \delta$ 2.02-2.09 (m, 1H, H2'), 2.14 (ddd, $J=13.3$, 6.1, $3.4 \mathrm{~Hz}, \mathrm{H} 2 "), 3.22$ (s, 3H, $\mathrm{CH}_{3}$ ), 3.24 (s, 3H, $\mathrm{CH}_{3}$ ), 3.52-3.58 (m, 2H, H5',5"), 3.80 (q, 
$\left.J=3.3 \mathrm{~Hz}, 1 \mathrm{H}, \mathrm{H} 4^{\prime}\right), 4.20-4.25\left(\mathrm{~m}, 1 \mathrm{H}, \mathrm{H} 3{ }^{\prime}\right), 4.97$ (t, $\left.J=4.7 \mathrm{~Hz}, 1 \mathrm{H}, 5^{\prime}-\mathrm{OH}\right), 5.17$ (s, 1H, CH), $5.25\left(\mathrm{~d}, J=4.2 \mathrm{~Hz}, 1 \mathrm{H}, 3^{\prime}-\mathrm{OH}\right), 6.16(\mathrm{t}, J=6.9,1 \mathrm{H}, \mathrm{H} 1$ '), 7.92 (s, 1H, H6), 11.39 (s, $1 \mathrm{H}, \mathrm{NH})$.

5'-DMT-5-azidomethyl-2'-deoxyuridine (5'-DMTAmdU, 59). AmdU $18^{40}$ (337 mg, $1.19 \mathrm{mmol}$ ) and 4,4'-dimethoxytrityl chloride (484 mg, $1.43 \mathrm{mmol}$ ) were dissolved in $6 \mathrm{~mL}$ of pyridine. The resulting solution was stirred at $\mathrm{rt}$ for $2 \mathrm{~h}$. The volatiles were removed. The residue was dissolved in EtOAc and washed with $\mathrm{NaHCO}_{3}$ solution followed by saturated $\mathrm{NaCl}$ solution and was column chromatographed (hexane/EtOAc/ triethylamine, 70:30:2 $\rightarrow$ 80:20:2) to give compound 5'-DMT-5-azidomethyl-2'-deoxyuridine 59 (501.8 mg, 72\%): ${ }^{1} \mathrm{H}$ NMR $\left(\mathrm{CD}_{2} \mathrm{Cl}_{2}\right) \delta$ 2.28-2.33 (m, 1H, H2'), $2.41(\mathrm{ddd}, J=13.9,6.2,3.9 \mathrm{~Hz}$, 1H, H2"), 3.36-3.40 (m, 3H, $\left.\mathrm{CH}_{2}, \mathrm{H}^{\prime}, 5^{\prime \prime}\right), 3.59$ (d, $\left.J=15.0,1 \mathrm{H}, \mathrm{CH}_{2}\right), 3.79\left(\mathrm{~s}, 6 \mathrm{H}, 2 \times \mathrm{OCH}_{3}\right)$, 4.04 (q, $\left.J=3.3,1 \mathrm{H}, \mathrm{H} 4{ }^{\prime}\right), 4.60$ (quin, $\left.J=3.3,1 \mathrm{H}, \mathrm{H} 3^{\prime}\right), 6.32$ (dd, $\left.J=7.7,6.2 \mathrm{~Hz}, 1 \mathrm{H}, \mathrm{H} 1^{\prime}\right)$, 6.84-6.88 (m, 4H, Ph), 7.26-7.34 (m, 7H, Ph), 7.39-7.41 (m, 2H, Ph), $7.75(\mathrm{~s}, 1 \mathrm{H}, \mathrm{H} 6) ;{ }^{13} \mathrm{C}$ $\operatorname{NMR}\left(\mathrm{CD}_{2} \mathrm{Cl}_{2}\right) \delta 41.6,47.4,55.8,64.0,72.7,85.6,86.8,87.6,110.2,113.9,127,8,128.6$ $128.7,130.7,135.6,136.1,139.5,145.1,150,5,159,5 ;$ HRMS calcd for $\mathrm{C}_{31} \mathrm{H}_{31} \mathrm{~N}_{5} \mathrm{O}_{7} \mathrm{Na}$ $[\mathrm{M}+\mathrm{Na}]^{+}$608.2116, found 608.2127.

3'-CEP-5'-DMT-5-azidomethyl-2'-deoxyuridine (3'-CEP-5'-DMTAmdU， 60). 2-Cyanoethyl $\mathrm{N}, \mathrm{N}$-diisopropylchlorophosphoramidite $(54 \mu \mathrm{L}, 56.8 \mathrm{mg}, 0.24 \mathrm{mmol})$ was added to a solution of 5'-DMT-5-azidomethyl-2'-deoxyuridine $\mathbf{5 9}$ (117 mg, $0.2 \mathrm{mmol})$ and DIPEA (52 $\mu \mathrm{L}, 38.8 \mathrm{mg}, 0.3 \mathrm{mmol})$ in DCM $(2 \mathrm{~mL})$. The resulting solution was stirred at rt for 10 min. The residue was diluted with $\mathrm{CH}_{2} \mathrm{Cl}_{2}$ and washed with saturated $\mathrm{NaHCO}_{3}$ solution followed by brine solution and the organic layer was dried with anhydrous $\mathrm{Na}_{2} \mathrm{SO}_{4}$. The solvent was removed with high vacuum evaporator under ice/acetone bath $\left(-10{ }^{\circ} \mathrm{C}\right)$. 
The residue was column chromatographed (hexane/EtOAc/triethylamine, 50:50:2 $\rightarrow$ 40:60:2) to give compound 3'-CEP-5'-DMT-5-azidomethyl-2'-deoxyuridine $\mathbf{6 0}$ (118 mg, 75\%): ${ }^{1} \mathrm{H}$ NMR $\left(\mathrm{CD}_{2} \mathrm{Cl}_{2}\right) \delta 1.17\left(\mathrm{~d}, J=2.2 \mathrm{~Hz}, 6 \mathrm{H}, 2 \mathrm{xCH}_{3}\right), 1.19(\mathrm{~d}, J=2.0 \mathrm{~Hz}, 6 \mathrm{H}$, $\left.2 \mathrm{CCH}_{3}\right), 2.31-2.38\left(\mathrm{~m}, 1 \mathrm{H}, \mathrm{H} 2\right.$ '), $2.46\left(\mathrm{t}, J=6.4 \mathrm{~Hz}, 2 \mathrm{H}, \mathrm{CH}_{2} \mathrm{CN}\right), 2.46-2.54(\mathrm{~m}, 1 \mathrm{H}, \mathrm{H} 2 ")$, $3.32\left(\mathrm{~d}, J=13.4,1 \mathrm{H}, \mathrm{CH}_{2} \mathrm{~N}_{3}\right), 3.37(\mathrm{dd},, J=10.6,3.1 \mathrm{~Hz}, 1 \mathrm{H}, \mathrm{H} 5$ '), $3.46(\mathrm{dd},, J=10.6$, $2.8 \mathrm{~Hz}, 1 \mathrm{H}, \mathrm{H} 5 "), 3.57$ (d, $\left.J=13.4,1 \mathrm{H}, \mathrm{CH}_{2} \mathrm{~N}_{3}\right), 3.55-3.71\left(\mathrm{~m}, 4 \mathrm{H}, \mathrm{OCH}_{2}, 2 \times C H\right.$ ), 3.79 (s, 6H, $\mathrm{OCH}_{3}$ ), 4.19 (q, $J=2.6,1 \mathrm{H}, \mathrm{H} 4$ '), 4.70 (ddd, $J=13.6,6.4,3.1 \mathrm{~Hz}, 1 \mathrm{H}, \mathrm{H} 3$ '), 6.33 (dd, $J=7.3,6.3 \mathrm{~Hz}, 1 \mathrm{H}, \mathrm{H1}$ '), 6.84-6.88 (m, 4H, ph), 7.27-7.35 (m, 7H, ph), 7.40-7.42 (m, 2H, ph), $7.81(\mathrm{~s}, 1 \mathrm{H}, \mathrm{H} 6)) ;{ }^{31} \mathrm{P}$ NMR $\left(\mathrm{CD}_{2} \mathrm{Cl}_{2}\right) \delta 148.85(\mathrm{~s}) ;{ }^{13} \mathrm{C}$ NMR $\left(\mathrm{CD}_{2} \mathrm{Cl}_{2}\right) \delta 24.9$, $40.6,47.4,55.8,59.0,63.6,73.8,85.7,86.4,87.6,110.2,113.9,118.2,127.8,128.6,128.8$, 130.8, 135.9, 136.0, 139.6, 145.0, 150.4, 159.5, 163.0; HRMS calcd for $\mathrm{C}_{40} \mathrm{H}_{48} \mathrm{~N}_{7} \mathrm{O}_{8} \mathrm{PNa}$ $[\mathrm{M}+\mathrm{Na}]^{+}$808.3194, found 808.3154.

\section{5-Formyl-2'-deoxyuridine (67) and 5-azirinyl-2'-deoxyuridine (68) from the UV}

decomposition of AvdU 21. The solution of AvdU 21 (16.3 mg, $0.055 \mathrm{mmol})$ in $5 \mathrm{~mL}$ $\mathrm{MeOH}$ in a dark box was irradiated by a $254 \mathrm{~nm}$ UV lamp (UVG-11, $4 \mathrm{~W}, 0.16 \mathrm{Amps}$ ) for $1.5 \mathrm{~h}$., The volatiles were evaporated under the reduced pressure and the residue was column chromatographed $\left(\mathrm{CHCl}_{3} / \mathrm{MeOH}, 100: 0 \rightarrow 95: 5\right)$ to give 5-formyl-2'-deoxyuridine (67, $5.7 \mathrm{mg}, 40.7 \%)$ and 5-azirinyl-2'-deoxyuridine (68, $5.1 \mathrm{mg}, 34.7 \%)$. 5-Formyl-2'deoxyuridine (67) has ${ }^{1} \mathrm{H}$ NMR (DMSO-d6) $\delta$ 2.12-2.29 (m, 2H, H2',2"), 3.56-3.66 (m, 2H, H5',5"), 3.86 (q, $\left.J=3.2 \mathrm{~Hz}, 1 \mathrm{H}, \mathrm{H} 4^{\prime}\right), 4.22-4.26\left(\mathrm{~m}, 1 \mathrm{H}, \mathrm{H} 3^{\prime}\right), 5.12$ (t, $J=5.2 \mathrm{~Hz}, 1 \mathrm{H}, 5^{\prime}-$ OH), $5.28\left(\mathrm{~d}, J=4.4 \mathrm{~Hz}, 1 \mathrm{H}, 3^{\prime}-\mathrm{OH}\right), 6.09(\mathrm{t}, J=6.4,1 \mathrm{H}, \mathrm{H1}$ '), $8.71(\mathrm{~s}, 1 \mathrm{H}, \mathrm{H} 6), 9.76(\mathrm{~s}$, 1H, CHO), 11.75 (s, 1H, NH). ${ }^{13} \mathrm{C}$ NMR (DMSO-d6) $\delta$ 40.6, 60.7, 69.8, 85.9, 87.9, 110.7, 147.1, 149.5, 161.6, 186.1. 5-Azirinyl-2'-deoxyuridine (68) has ${ }^{1} \mathrm{H}$ NMR (DMSO-d6) $\delta$ 
$1.27(\mathrm{~d}, J=8.4 \mathrm{~Hz}, 1 \mathrm{H}$, azirinyl), $1.31(\mathrm{~d}, J=8.4 \mathrm{~Hz}, 1 \mathrm{H}$, azirinyl), 2.20-2.30 (m, 2H, H2',2"), 3.57-3.71 (m, 2H, H5',5"), 3.84 (q, $J=3.2 \mathrm{~Hz}, 1 \mathrm{H}, \mathrm{H} 4$ '), 4.27 (quin, $J=5.6 \mathrm{~Hz}$, 1H, H3'), 5.21 (t, $\left.J=4.8 \mathrm{~Hz}, 1 \mathrm{H}, 5^{\prime}-\mathrm{OH}\right), 5.29$ (d, $\left.J=4.4 \mathrm{~Hz}, 1 \mathrm{H}, 3^{\prime}-\mathrm{OH}\right), 6.12$ (t, $J=6.0$, 1H, H1'), 8.81 (s, 1H, H6), 11.82 (s, 1H, NH). ${ }^{13} \mathrm{C}$ NMR (DMSO-d6) $\delta ~ 14.7, ~ 40.6,60.3$, $69.2,85.6,87.7,101.1,148.3,149.4,158.0,159.4$.

5'-DMT-5-(1-azidovinyl)-2'-deoxyuridine (69). AvdU 21 (24.8 mg, $0.084 \mathrm{mmol})$ and 4,4'-dimethoxytrityl chloride (34 mg, $0.1 \mathrm{mmol}$ ) were dissolved in $0.5 \mathrm{~mL}$ of pyridine. The resulting solution was stirred at $\mathrm{rt}$ for $2 \mathrm{~h}$. The volatiles were removed. The residue was dissolved in EtOAc and washed with $\mathrm{NaHCO}_{3}$ solution followed by saturated $\mathrm{NaCl}$ solution and was column chromatographed (hexane/EtOAc/ triethylamine, 70:30:2) to give compound 5'-DMT-5-(1-azidovinyl)-2'-deoxyuridine 69 (30 mg, 60\%): ${ }^{1} \mathrm{H} \mathrm{NMR}\left(\mathrm{CD}_{2} \mathrm{Cl}_{2}\right)$ $\delta 2.23(\mathrm{~m}, J=13.7,7.2,6.4 \mathrm{~Hz}, 1 \mathrm{H}, \mathrm{H} 2 '), 2.42(\mathrm{ddd}, J=13.7,6.4,4.0 \mathrm{~Hz}, 1 \mathrm{H}, \mathrm{H} 2 "), 3.33$ (dd, $\left.J=10.2,4.0 \mathrm{~Hz}, 1 \mathrm{H}, \mathrm{H} 5^{\prime}\right), 3.44$ (dd, $\left.J=10.4,4.0 \mathrm{~Hz}, 1 \mathrm{H}, \mathrm{H} 5 "\right), 3.78$ (s, 6H, 2xOCH 3 ), $4.05(\mathrm{q}, J=3.5 \mathrm{~Hz}, 1 \mathrm{H}, \mathrm{H} 4$ '), 4.43 (quin, $J=3.3 \mathrm{~Hz}, 1 \mathrm{H}, \mathrm{H} 3$ '), 4.92 (d, $J=2.0 \mathrm{~Hz}, 1 \mathrm{H}$, $\left.\mathrm{CH}_{2}\right), 6.10\left(\mathrm{~d}, J=1.8 \mathrm{~Hz}, 1 \mathrm{H}, \mathrm{CH}_{2}\right), 6.28(\mathrm{dd}, J=7.3,6.0 \mathrm{~Hz}, 1 \mathrm{H}, \mathrm{H} 1$ '), 6.82-6.85 (m, 4H, $\mathrm{Ph})$, 7.21-7.35 (m, 7H, Ph), 7.43-7.46 (m, 2H, Ph), 7.97 (s, 1H, H6); ${ }^{13} \mathrm{C} \mathrm{NMR}\left(\mathrm{CD}_{2} \mathrm{Cl}_{2}\right) \delta$ $41.3,55.6,63.9,72.5,85.8,86.6,87.1,101.5,108.8,113.5,127.3,128.2,128.4,130.4$ $136.0,136.1,137.0,138.2,145.0,149.6,159.2,160.9,171.2$.

3'-CEP-5'-DMT-5-(1-azidovinyl)-2' -deoxyuridine (70) (not obtained after column due to the Staudinger reaction). 2-Cyanoethyl $N, N$-diisopropylchlorophosphoramidite (9 $\mu \mathrm{L}, 9.5 \mathrm{mg}, 0.04 \mathrm{mmol})$ was added to a solution of 5'-DMT-5-(1-azidovinyl)-2'deoxyuridine 69 (20 mg, $0.033 \mathrm{mmol})$ and DIPEA (9 $\mu \mathrm{L}, 6.5 \mathrm{mg}, 0.05 \mathrm{mmol})$ in DCM (1 $\mathrm{mL}$ ). The resulting solution was stirred at $\mathrm{rt}$ for $10 \mathrm{~min}$. The residue was diluted with 
$\mathrm{CH}_{2} \mathrm{Cl}_{2}$ and washed with saturated $\mathrm{NaHCO}_{3}$ solution followed by brine solution and the organic layer was dried with anhydrous $\mathrm{Na}_{2} \mathrm{SO}_{4}$. The solvent was removed with high vacuum evaporator under ice/acetone bath $\left(-10 \quad{ }^{\circ} \mathrm{C}\right)$. The residue was column chromatographed (hexane/EtOAc/triethylamine, 70:30:2) to give compound, which was characterized as non-70(16.4 mg, 63\%). The NMR data of the isomer with higher $\mathrm{R}_{\mathrm{f}}$ of 0.71 after column are provided: ${ }^{1} \mathrm{H}$ NMR $\left(\mathrm{CD}_{2} \mathrm{Cl}_{2}\right) \delta 1.19-1.20\left(\mathrm{~m}, 12 \mathrm{H}, 4 \mathrm{xCH}_{3}\right), 2.47-$ 2.65 (m, 4H, $\left.\mathrm{CH}_{2} \mathrm{CN}, \mathrm{H} 2^{\prime}, 2^{\prime \prime}\right), 3.30-3.46$ (m, 2H, H5',5"), 3.39 (s, 6H, $\mathrm{OCH}_{3}$ ), 3.95-4.04 (m, 4H, $\mathrm{OCH}_{2}, 2$ x CH), 4.30-4.33 (m, 1H, H4'), 4.88 (d, J = 2.0 Hz, $\left.\mathrm{CH}_{2}\right), 4.92-4.96$ (m, 1H, H3'), 6.06 (d, $\left.J=2.0 \mathrm{~Hz}, \mathrm{CH}_{2}\right), 6.31(\mathrm{dd}, J=8.8,5.6 \mathrm{~Hz}, 1 \mathrm{H}, \mathrm{H} 1$ '), 6.82-6.84 (m, 4H, ph), 7.21-7.36 (m, 7H, ph), 7.42-7.47 (m, 2H, ph), 8.02 (s, 1H, H6); ${ }^{31} \mathrm{P}$ NMR $\left(\mathrm{CD}_{2} \mathrm{Cl}_{2}\right) \delta$ 7.52 (s, major) 148.85 (s); Based on the ${ }^{1} \mathrm{H}$ and ${ }^{31} \mathrm{P}$ NMR, it was concluded that the phosphoramidite was oxidized to P (IV) through the Staudinger reaction.

5-Azidomethyl-2'-deoxycytidine triphosphate (AmdCTP, 74). $\mathrm{POCl}_{3}(19 \mu \mathrm{L}, 31.2$ $\mathrm{mg}, 0.2 \mathrm{mmol})$ was added to a stirred solution of AmdC $42(24 \mathrm{mg}, 0.085 \mathrm{mmol})$ and proton sponge $(54.6 \mathrm{mg}, 0.255 \mathrm{mmol})$ in trimethyl phosphate $(1 \mathrm{~mL})$ at $0{ }^{\circ} \mathrm{C}$. The resulting mixture was stirred at $0{ }^{\circ} \mathrm{C}$ for $30 \mathrm{~min} .0 .5 \mathrm{M}$ tributylammomium pyrophosphate solution in DMF $(1.275 \mathrm{~mL}, 0.5 \mathrm{mmol})$ and then tributylamine $(90.9 \mu \mathrm{L}, 70.9 \mathrm{mg}, 0.38 \mathrm{mmol})$ were added to the reaction mixture and stirred at $0{ }^{\circ} \mathrm{C}$ for $2 \mathrm{~min}$. The reaction was quenched by adjusting the $\mathrm{pH}$ to 7.5 with $2 \mathrm{M}$ TEAB buffer. The residue was dissolved in water $(5 \mathrm{~mL})$ and was extracted with EtOAc $(3 \times 5 \mathrm{~mL})$. The water layer was evaporated and coevaporated with mixture of $\mathrm{EtOH} / \mathrm{H}_{2} \mathrm{O}(1: 1,5 \mathrm{~mL})$. The residue was column chromatographed (DEAE-Sephadex ${ }^{\circledR}$, TEAB $\left.0.1 \mathrm{M} \rightarrow 0.6 \mathrm{M}\right)$ and the appropriate fractions were evaporated in vacuum and coevaporate 5 times with mixture of $\mathrm{EtOH} / \mathrm{H}_{2} \mathrm{O}$ 
$(1: 1,10 \mathrm{~mL})$ to give AmdC triphosphate triethylammonium salt 74. $(10.2 \mathrm{mg}, 23 \%) .{ }^{1} \mathrm{H}$ NMR $\left(\mathrm{D}_{2} \mathrm{O}\right) \delta 2.36-2.43(\mathrm{~m}, 1 \mathrm{H}, \mathrm{H} 2$ '), 2.49 (ddd, $J=14.4,6.7,4.4 \mathrm{~Hz}, 1 \mathrm{H}, \mathrm{H} 2 "), 4.19-4.28$ (m, 3H, H4',5',5"), $4.41\left(\mathrm{~d}, J=15.0,1 \mathrm{H}, \mathrm{CH}_{2} \mathrm{~N}_{3}\right), 4.48\left(\mathrm{~d}, J=14.6,1 \mathrm{H}, \mathrm{CH}_{2} \mathrm{~N}_{3}\right), 4.61-4.64$ (m, 1H, H3'), $6.24\left(\mathrm{t}, J=5.9,1 \mathrm{H}, \mathrm{H} 1^{\prime}\right), 8.33(\mathrm{~s}, 1 \mathrm{H}, \mathrm{H} 6) ;{ }^{31} \mathrm{P} \mathrm{NMR}\left(\mathrm{D}_{2} \mathrm{O}\right) \delta-23.41(\mathrm{t}, J=$ 19.7, 1P, $\beta),-11.72(\mathrm{~d}, J=20.5,1 \mathrm{P}, \alpha),-10.93(\mathrm{~d}, J=20.0 \mathrm{~Hz}, 1 \mathrm{P}, \gamma) ;{ }^{13} \mathrm{C} \mathrm{NMR}\left(\mathrm{D}_{2} \mathrm{O}\right) \delta$ $39.6,47.4,65.1,70.3,86.2,86.9,101.9,144.6,148.0,158.3$; HRMS calcd for $\mathrm{C}_{10} \mathrm{H}_{16} \mathrm{~N}_{5} \mathrm{O}_{14} \mathrm{P}_{3}[\mathrm{M}-\mathrm{H}]^{-5} 520.99937$, found 520.99934.

5-Acetyl-2'-deoxyuridine triphosphate (75). $\mathrm{POCl}_{3}(22.4 \mu \mathrm{L}, 36.8 \mathrm{mg}, 0.24 \mathrm{mmol})$ was added to a stirred solution of AvdU $21(59 \mathrm{mg}, 0.2 \mathrm{mmol})$ and proton sponge (64.3 $\mathrm{mg}, 0.3 \mathrm{mmol})$ in trimethyl phosphate $(1.5 \mathrm{~mL})$ at $0{ }^{\circ} \mathrm{C}$. The resulting mixture was stirred at $0{ }^{\circ} \mathrm{C}$ for $30 \mathrm{~min} .0 .5 \mathrm{M}$ tributylammomium pyrophosphate solution in DMF (2 mL, 1 mmol) and then tributylamine $(142.5 \mu \mathrm{L}, 111.2 \mathrm{mg}, 0.6 \mathrm{mmol})$ were added to the reaction mixture and stirred at $0{ }^{\circ} \mathrm{C}$ for $2 \mathrm{~min}$. The reaction was quenched by adjusting the $\mathrm{pH}$ to 7.5 with $2 \mathrm{M}$ TEAB buffer. The residue was dissolved in water $(5 \mathrm{~mL})$ and was extracted with EtOAc ( $3 \times 5 \mathrm{~mL})$. The water layer was evaporated and coevaporated with mixture of $\mathrm{EtOH} / \mathrm{H}_{2} \mathrm{O}(1: 1,5 \mathrm{~mL})$. The residue was column chromatographed (DEAE-Sephadex®, TEAB $0.1 \mathrm{M} \rightarrow 0.6 \mathrm{M})$ and further purified by HPLC (C18; A: $20 \mathrm{mM}$ TEAA buffer $(\mathrm{pH}$ $=7.1$, in $\left.\mathrm{ACN} / \mathrm{H}_{2} \mathrm{O}=1: 1\right)$, B: $20 \mathrm{mM}$ TEAA buffer $\left(\mathrm{pH}=7.1\right.$, in $\left.\mathrm{H}_{2} \mathrm{O}\right) ; 0 \% \mathrm{~A} \rightarrow 25 \% \mathrm{~A}$ in $20 \mathrm{~min}$, flow rate $=1 \mathrm{~mL} / \mathrm{min}$ then stay with $25 \%$ A for $40 \mathrm{~min}$ ). The appropriate fractions were evaporated in vacuum and coevaporate 5 times with mixture of $\mathrm{EtOH} / \mathrm{H}_{2} \mathrm{O}$ $(1: 1,5 \mathrm{~mL})$. to give 5-acetyl-2'-deoxyuridine triphosphate triethylammonium salt $\mathbf{7 5}^{125}$ (23.4 mg, 23\%). ${ }^{1} \mathrm{H}$ NMR $\left(\mathrm{D}_{2} \mathrm{O}\right) \delta 2.40-2.53\left(\mathrm{~m}, 5 \mathrm{H}, \mathrm{H} 2\right.$ ',2", $\left.\mathrm{CH}_{3}\right), 4.22-4.25(\mathrm{~m}, 2 \mathrm{H}$, H5',5"), 4.28-4.30 (m, 1H, H4'), 4.64-4.67 (m, 1H, H3'), 6.25 (t, J = 6.0, 1H, H1'), 8.65 (s, 
1H, H6); ${ }^{31} \mathrm{P}$ NMR $\left(\mathrm{D}_{2} \mathrm{O}\right) \delta-23.35$ ("s", 1P, $\left.\beta\right),-11.64$ ("s", 1P, $\left.\alpha\right),-10.97$ ("s", 1P, $\left.\gamma\right) ;{ }^{13} \mathrm{C}$ NMR $\left(\mathrm{D}_{2} \mathrm{O}\right) \delta 28.7,39.5,65.5,70.4,86.4,87.1,112.3,148.5,150.5,162.4,197.8$.

5-Ethynyl-2'-deoxyuridine triphosphate (78). $\mathrm{POCl}_{3}(44.7 \mu \mathrm{L}, 73.6 \mathrm{mg}, 0.48 \mathrm{mmol})$ was added to a stirred solution of 5-ethynyl-2'-deoxyuridine $\mathbf{7 7}^{110}$ (100 $\left.\mathrm{mg}, 0.4 \mathrm{mmol}\right)$ and proton sponge $(128.6 \mathrm{mg}, 0.6 \mathrm{mmol})$ in trimethyl phosphate $(3 \mathrm{~mL})$ at $0{ }^{\circ} \mathrm{C}$. The resulting mixture was stirred at $0{ }^{\circ} \mathrm{C}$ for $30 \mathrm{~min} .0 .5 \mathrm{M}$ tributylammomium pyrophosphate solution in $\mathrm{DMF}(4 \mathrm{~mL}, 2 \mathrm{mmol})$ and then tributylamine $(285 \mu \mathrm{L}, 222.4 \mathrm{mg}, 1.2 \mathrm{mmol})$ were added to the reaction mixture and stirred at $0{ }^{\circ} \mathrm{C}$ for $2 \mathrm{~min}$. The reaction was quenched by adjusting the $\mathrm{pH}$ to 7.5 with $2 \mathrm{M}$ TEAB buffer. The residue was dissolved in water $(10 \mathrm{~mL})$ and was extracted with EtOAc (3 x $10 \mathrm{~mL})$. The water layer was evaporated and coevaporated with mixture of $\mathrm{EtOH} / \mathrm{H}_{2} \mathrm{O}(1: 1,5 \mathrm{~mL})$. The residue was column chromatographed (DEAE-Sephadex ${ }^{\circledR}$, TEAB $\left.0.1 \mathrm{M} \rightarrow 0.6 \mathrm{M}\right)$ and the appropriate fractions were evaporated in vacuum and coevaporate 5 times with mixture of EtOH/ $\mathrm{H}_{2} \mathrm{O}$ $(1: 1,10 \mathrm{~mL})$ to give 5-ethynyl-2'-deoxyuridine triphosphate triethylammonium salt $\mathbf{7 8}$ (104 mg, 53\%). ${ }^{1} \mathrm{H}$ NMR $\left(\mathrm{D}_{2} \mathrm{O}\right) \delta$ 2.28-2.37 (m, 2H, H2',2"), 3.55 (s, 1H, CH), 4.09-4.16 (m, 3H, H4',5',5"), 4.53-4.56 (m, 1H, H3'), 6.20 (t, $\left.J=6.8,1 \mathrm{H}, \mathrm{H} 11^{\prime}\right), 8.15$ (s, 1H, H6); ${ }^{31} \mathrm{P}$ $\operatorname{NMR}\left(\mathrm{D}_{2} \mathrm{O}\right) \delta-23.46(\mathrm{t}, J=20.9,1 \mathrm{P}, \beta),-11.68(\mathrm{~d}, J=19.9,1 \mathrm{P}, \alpha),-10.86(\mathrm{~d}, J=20.7$, $1 \mathrm{P}, \gamma) ;{ }^{13} \mathrm{C} \mathrm{NMR}\left(\mathrm{D}_{2} \mathrm{O}\right) \delta 38.8,65.3,70.6,83.4,85.6,85.8,98.7,145.6,150.5,164.5$.

\subsubsection{Synthesis of 2-azido-2'-deoxyinosine}

3',5'-di-O-acetyl-2'-deoxyguanosine (80). Acetyl anhydrite (1.5 mL, $1.65 \mathrm{~g}, 16.5$ mmol) was added to a solution of 2'-deoxyguanosine ( $\mathbf{d G}, 1.3 \mathrm{~g}, 5 \mathrm{mmol})$ and pyridine (1.5 $\mathrm{ml}$ ) in DMF (4 mL). The resulting mixture was stirred at $75{ }^{\circ} \mathrm{C}$ for $4 \mathrm{~h}$. After cooling to ambient temperature, the volatiles were evaporated under the reduced pressure and the 
residue was column chromatographed $\left(\mathrm{CHCl}_{3} / \mathrm{MeOH}, 100: 0 \rightarrow 85: 15\right)$ to give $\mathbf{8 0}^{148}(1.4 \mathrm{~g}$, 81\%): ${ }^{1} \mathrm{H}$ NMR (DMSO-d6) $\delta 2.04$ (s, 3H, Ac), 2.08 (s, 3H, Ac), 2.42-2.48 (m, 1H, H2'), 2.88-2.95 (m, 1H, H2"), 4.16 (m, 3H, H4',5',5"), 5.28-5.29 (m, 1H, H3'), 6.13 (dd, J = 8.4, $5.6 \mathrm{~Hz}, 1 \mathrm{H}, \mathrm{H} 1$ '), 6.52 (s, 2H, NH 2$), 7.92$ (s, 1H, H8), 10.69 (s, 1H, NH).

3',5'-di-O-acetyl-O'-(p-nitrophenethyl)-2'-deoxyguanosine (81). 3',5'-di-O-acetyl2'-deoxyguanosine 80 (703 mg, 2 mmol), $\mathrm{PPh}_{3}$ (840 mg, $3.2 \mathrm{mmol}$ ), p-nitrophenethyl alcohol (500 mg, $3 \mathrm{mmol}$ ), and activated molecular sieves were dispersed in $40 \mathrm{~mL}$ 1,4-dioxane and stirred for $30 \mathrm{~min}$. Then DIAD $(630 \mu \mathrm{L}, 646 \mathrm{mg}, 3.2 \mathrm{mmol})$ was added to the mixture and stirred at room temperature overnight. Molecular sieves were filtrated and the volatiles were evaporated under reduced pressure. The solid residue was washed with $\mathrm{Et}_{2} \mathrm{O}$ to remove triphenylphosphate and then column chromatographed $\left(\mathrm{CHCl}_{3} / \mathrm{MeOH}\right.$, 100:0 $\rightarrow$ 95:5) to give $81^{148}(720 \mathrm{~g}, 72 \%):{ }^{1} \mathrm{H}$ NMR (DMSO-d6) $\delta 2.02(\mathrm{~s}, 3 \mathrm{H}, \mathrm{Ac}), 2.08$ (s, 3H, Ac), 2.43-2.47 (m, 1H, H2'), 2.97-3.04 (m, 1H, H2"), 3.25 (t, , J = 7.2 Hz, 2H, $\mathrm{CH}_{2}$ ), 4.16-4.22 (m, 2H, 5',5"), 4.28 (t, $J=6.4 \mathrm{~Hz}, 1 \mathrm{H}, \mathrm{H} 4$ '), 4.67 (t, , $\left.J=6.8 \mathrm{~Hz}, 2 \mathrm{H}, \mathrm{CH}_{2}\right), 5.30-$ $5.33\left(\mathrm{~m}, 1 \mathrm{H}, \mathrm{H} 3{ }^{\prime}\right), 6.22\left(\mathrm{dd}, J=7.6,6.4 \mathrm{~Hz}, 1 \mathrm{H}, \mathrm{H} 1\right.$ '), $6.53\left(\mathrm{~s}, 2 \mathrm{H}, \mathrm{NH}_{2}\right), 7.63(\mathrm{~d}, J=8.4$ $\mathrm{Hz}, 2 \mathrm{H}, \mathrm{Ph}), 8.07$ (s, 1H, H8), 8.18 (d, J = 8.4 Hz, 2H, Ph).

3',5'-di-O-acetyl-2-azido-O'-(p-nitrophenethyl)-2'-deoxyinosine (82). 3',5'-di- $O$ acetyl-O ${ }^{6}$-( $p$-nitrophenethyl)-2'-deoxyguanosine 81 (200 mg, $\left.0.4 \mathrm{mmol}\right)$ was dissolved in $5 \mathrm{~mL}$ acetonitrile. The mixture was cooled down to $-10{ }^{\circ} \mathrm{C}$ (acetone/ice bath) and then tertbutyl nitrite (264 $\mu \mathrm{L}, 206 \mathrm{mg}, 2 \mathrm{mmol})$ and trimethylsilyl azide $\left(\mathrm{TMSN}_{3}, 262 \mu \mathrm{L}, 230 \mathrm{mg}\right.$, $2 \mathrm{mmol}$ ) were added. The resulting mixture was kept in $-20{ }^{\circ} \mathrm{C}$ freezer and $12 \mathrm{~h}$ and then 4 ${ }^{\circ} \mathrm{C}$ refrigerator for $24 \mathrm{~h}$. The volatiles were evaporated under the reduced pressure and the residue was column chromatographed $\left(\mathrm{CHCl}_{3} / \mathrm{MeOH}, 100: 0 \rightarrow\right.$ 95:5) to give 82 (155.4 mg, 
74\%): ${ }^{1} \mathrm{H}$ NMR (DMSO-d6) $\delta 1.99$ (s, 3H, Ac), 2.09 (s, 3H, Ac), 2.56 (ddd, $J=14.4,6.4$, $3.2 \mathrm{~Hz}, 1 \mathrm{H}, \mathrm{H} 2$ '), 3.04-3.11 (m, 1H, H2"), 3.29-3.30 (m, 2H, $\left.\mathrm{CH}_{2}\right), 4.16-4.30$ (m, 3H, H4',5',5"), $4.81\left(\mathrm{t},, J=6.8 \mathrm{~Hz}, 2 \mathrm{H}, \mathrm{CH}_{2}\right), 5.38-5.41(\mathrm{~m}, 1 \mathrm{H}, \mathrm{H} 3$ '), $6.35(\mathrm{t}, J=6.4 \mathrm{~Hz}, 1 \mathrm{H}$, H1'), 7.63 (d, $J=9.2 \mathrm{~Hz}, 2 \mathrm{H}, \mathrm{Ph}), 8.18$ (d, $J=8.0 \mathrm{~Hz}, 2 \mathrm{H}, \mathrm{Ph}), 8.49$ (s, 1H, H8).

2-azido-2'-deoxyinosine (2-N3dI, 44). To a solution of 82 (79 $\mathrm{mg}, 0.15 \mathrm{mmol})$ in acetonitrile was added 1,8-diazabicyclo[5.4.0]undec-7-ene (DBU, $449 \mu \mathrm{L}, 456 \mathrm{mg}, 3$ $\mathrm{mmol})$. The resulting mixture was stirred at room temperature for $3 \mathrm{~h}$. The volatiles were evaporated under the reduced pressure and dried under high vacuum. $2 \mathrm{~mL} \mathrm{MeOH}$ was added to the reaction residue and cooled down to $0{ }^{\circ} \mathrm{C}$ (ice bath), followed by adding $3 \mathrm{~mL}$ $\mathrm{NH}_{3} / \mathrm{MeOH}$. The resulting mixture was stirred at $0{ }^{\circ} \mathrm{C}$ to room temperature overnight. The volatiles were evaporated under the reduced pressure and the residue was column chromatographed $\left(\mathrm{CHCl}_{3} / \mathrm{MeOH}, 100: 0 \rightarrow 85: 25\right)$ and further purified by HPLC (C18; A: $100 \%$ ACN, B: $100 \% \mathrm{H}_{2} \mathrm{O} ; 0 \%$ A then $0 \% \mathrm{~A} \rightarrow 5 \% \mathrm{~A}$ in $30 \mathrm{~min}$, flow rate $=2 \mathrm{~mL} / \mathrm{min}$ ) to give $44^{149}$ (36.6 mg, 83\%): ${ }^{1} \mathrm{H}$ NMR (DMSO-d6) $\delta 2.21$ (ddd, $J=12.9,6.3,3.1 \mathrm{~Hz}, 1 \mathrm{H}$, H2'), 2.68 (ddd, $J=13.7,8.6,6.3 \mathrm{~Hz}, 1 \mathrm{H}, \mathrm{H} 2 "), 3.49-3.55$ (m, 1H, H5'), 3.59-3.64 (m, 1H, H5"), 3.86 (q, J=4.3 Hz, 1H, H4'), 4.37-4.40 (m, 1H, H3'), 5.24-5.29 (m, 2H, 3'OH,5' $\mathrm{OH}$ ), $6.29(\mathrm{dd}, J=7.8,5.9 \mathrm{~Hz}, 1 \mathrm{H}, \mathrm{H1}$ ), 8.03 (s, $1 \mathrm{H}, \mathrm{H} 8) ;{ }^{13} \mathrm{C}$ NMR (DMSO-d6) $\delta$ 39.2, 48.6, $62.0,71.1,83.4,87.8,115.1,137.6,150.4,152.2,156.3$. MS (ESI): $\mathrm{m} / \mathrm{z}$ calcd for $\left[\mathrm{C}_{10} \mathrm{H}_{12} \mathrm{~N}_{7} \mathrm{O}_{4}\right]^{+}$, 294.1; found 294.3. 


\subsubsection{Preparation of triazolyl nucleoside analogues}

\section{3',5'-di-O-acetyl-5-(1H-1,2,3-triazol-4-yl)-2'-deoxycytidine (diAc-5-TrzdC, 83)}

\section{Procedure A using $\mathrm{Ag}_{2} \mathrm{CO}_{3}$ as catalyst}

$\mathrm{Ag}_{2} \mathrm{CO}_{3}(2.8 \mathrm{mg}, 0.01 \mathrm{mmol})$ was added to a solution of $\mathbf{6 3 \mathbf { a } ^ { 1 1 9 }}(33.5 \mathrm{mg}, 0.1 \mathrm{mmol})$, azidotrimethylsilane ( $26.3 \mu \mathrm{L}, 23 \mathrm{mg}, 0.2 \mathrm{mmol})$, and $\mathrm{H}_{2} \mathrm{O}(3.6 \mu \mathrm{L}, 3.6 \mathrm{mg}, 0.2 \mathrm{mmol})$ in DMF $(1 \mathrm{~mL})$. The resulting mixture was stirred at $80^{\circ} \mathrm{C}$ for 1 hour. After cooling to ambient temperature, the volatiles were evaporated under the reduced pressure and the residue was column chromatographed $\left(\mathrm{CHCl}_{3} / \mathrm{MeOH}, 100: 0 \rightarrow 90: 10\right)$ to give $\mathbf{8 3}(2.6 \mathrm{mg}$, 7\%): UV (MeOH) $\lambda_{\max } 208,238,293 \mathrm{~nm}(\varepsilon 13050,9400,4150), \lambda_{\min } 225,271 \mathrm{~nm}(\varepsilon 8350$, 3150); ${ }^{1} \mathrm{H}$ NMR (DMSO- $\left.d_{6}\right) \delta 1.99$ (s, 3H, $\mathrm{CH}_{3}$ ), 2.08 (s, 3H, $\mathrm{CH}_{3}$ ), 2.36 (ddd, $J=14.1$, 5.8, 2.0 Hz, 1H, H2"), 2.47-2.44 (m, 1H, H2'), 4.23-4.20 (m, 1H, H4'), 4.35-4.26 (m, 2H, H5', 5"), 5.22-5.20 (m, 1H, H3'), 6.21 (dd, J = 7.6, 6.2 Hz, 1H, H1'), 7.67 (s, 1H, NH), 7.90 (s, 1H, NH), 8.07 (s, 1H, H6), $8.24(\mathrm{~s}, 1 \mathrm{H}, \mathrm{CH}), 15.28(\mathrm{~s}, 1 \mathrm{H}, \mathrm{NH}) ;{ }^{13} \mathrm{C}$ NMR (DMSO- $\left.d_{6}\right)$

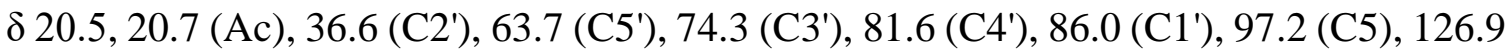
(triazolyl), 139.8 (C6), 153.6 (C4), 162.4 (C2), 170.0, 170.2 (Ac); HRMS (ESI): m/z calcd for $\mathrm{C}_{15} \mathrm{H}_{19} \mathrm{~N}_{6} \mathrm{O}_{6}[\mathrm{M}+\mathrm{H}]^{+} 379.1361$; found 379.1372.

\section{Procedure B using CuI as catalyst}

The stirred solution of 63a (33.5 mg, $0.1 \mathrm{mmol})$ in $1 \mathrm{~mL} \mathrm{DMF} / \mathrm{H}_{2} \mathrm{O}(9 / 1)$ was degassed with argon for $15 \mathrm{~min}$. Azidotrimethylsilane $(26.3 \mu \mathrm{L}, 23 \mathrm{mg}, 0.2 \mathrm{mmol})$ and $\mathrm{CuI}(1 \mathrm{mg}$, $0.005 \mathrm{mmol}$ ) were added to the solution, which was further degassed for another $5 \mathrm{~min}$. The resulting mixture was stirred at $90^{\circ} \mathrm{C}$ for $5 \mathrm{~h}$. After cooling to ambient temperature, the volatiles were evaporated and the residue was column chromatographed $\left(\mathrm{CHCl}_{3} / \mathrm{MeOH}\right.$, $100: 0 \rightarrow 90: 10)$ to give $\mathbf{8 3}(12.0 \mathrm{mg}, 32 \%)$ with the spectroscopic data as described above. 


\section{Procedure $\mathrm{C}$ using $\mathrm{CuSO}_{4} /$ sodium ascorbate as catalyst}

63a $(33.5 \mathrm{mg}, 0.1 \mathrm{mmol})$ and $\mathrm{CuSO}_{4} \cdot 5 \mathrm{H}_{2} \mathrm{O}(2.5 \mathrm{mg}, 0.01 \mathrm{mmol})$ were dissolved in $1 \mathrm{~mL} \mathrm{DMF} / \mathrm{H}_{2} \mathrm{O}(9 / 1)$ at ambient temperature. The stirred solution was degassed with argon for $15 \mathrm{~min}$. Azidotrimethylsilane $(26.3 \mu \mathrm{L}, 23 \mathrm{mg}, 0.2 \mathrm{mmol})$ and sodium ascorbate (4 mg, $0.02 \mathrm{mmol}$ ) were added to the solution, which was further degassed for another 5 min. The resulting mixture was stirred at $90^{\circ} \mathrm{C}$ for $5 \mathrm{~h}$. After cooling to ambient temperature, the volatiles were evaporated and the residue was column chromatographed $\left(\mathrm{CHCl}_{3} / \mathrm{MeOH}\right.$, $100: 0 \rightarrow 90: 10)$ to give $\mathbf{8 3}(24.6 \mathrm{mg}, 65 \%)$ with the spectroscopic data as described above.

5-(1H-1,2,3-triazol-4-yl)-2'-deoxyuridine (5-TrzdU, 39). Treatment of $\mathbf{7 7}^{110}(25.1$ mg, $0.1 \mathrm{mmol}$ ) with $\mathrm{CuI}$ by Procedure B (column chromatography; $\mathrm{CHCl}_{3} / \mathrm{MeOH}, 100: 0$ $\rightarrow$ 85:15) gave 39 (14.8 mg, 50\%): UV (MeOH) $\lambda_{\max } 231,292 \mathrm{~nm}(\varepsilon 12400,11450), \lambda_{\min }$ $259 \mathrm{~nm}\left(\varepsilon\right.$ 3700); ${ }^{1} \mathrm{H}$ NMR (DMSO-d6) $\delta 2.18\left(\mathrm{dd}, J=6.3,4.7 \mathrm{~Hz}, 2 \mathrm{H}, \mathrm{H} 2 ', 2^{\prime \prime}\right), 3.63-3.55$ (m, 2H, H5',5"), 3.84 (q, J=3.4 Hz, 1H, H4'), 4.31-4.25 (m, 1H, H3'), 5.04 ("s", 1H, 3'-OH), $5.29\left(\mathrm{~d}, J=4.1 \mathrm{~Hz}, 1 \mathrm{H}, 5{ }^{\prime}-\mathrm{OH}\right), 6.22\left(\mathrm{t}, J=6.6 \mathrm{~Hz}, 1 \mathrm{H}, \mathrm{H} 1^{\prime}\right), 8.14(\mathrm{~s}, 1 \mathrm{H}, \mathrm{NH}), 8.49$ (s, 1H, H6), 11.68 (s, 1H, 3-NH), $15.10(\mathrm{~s}, 1 \mathrm{H}, \mathrm{NH}) ;{ }^{13} \mathrm{C}$ NMR (DMSO-d $) \delta 39.7$ (C2'), 61.3 (C5'), 70.5 (C3'), 84.7 (C1'), 87.6 (C4'), 136.4 (C6), 149.7 (C2), 161.3 (C4); HRMS (ESI): $\mathrm{m} / \mathrm{z}$ calcd for $\mathrm{C}_{11} \mathrm{H}_{14} \mathrm{~N}_{5} \mathrm{O}_{5}[\mathrm{M}+\mathrm{H}]^{+}$296.0989; found 296.0983.

Treatment of $77(25.1 \mathrm{mg}, 0.1 \mathrm{mmol})$ with CuI by modified Procedure B with 2 equivalents of $\mathrm{H}_{2} \mathrm{O}$ and $\mathrm{DMF}$ as solvent (column chromatography; $\mathrm{CHCl}_{3} / \mathrm{MeOH}, 100: 0$ $\rightarrow 85: 15)$ gave $39(12.5 \mathrm{mg}, 42 \%)$ with the spectroscopic data as described above. 
Treatment of $77(25.1 \mathrm{mg}, 0.1 \mathrm{mmol})$ with $\mathrm{CuSO}_{4} /$ sodium ascorbate by Procedure $\mathrm{C}$ (column chromatography; $\left.\mathrm{CHCl}_{3} / \mathrm{MeOH}, 100: 0 \rightarrow 85: 15\right)$ gave $39(15.3 \mathrm{mg}, 52 \%$ ) with the spectroscopic data as described above.

8-(1H-1,2,3-triazol-4-yl)-2' -deoxyadenosine (8-TrzdA, 46). Treatment of $85^{141}(27.5$ mg, $0.1 \mathrm{mmol}$ ) with $\mathrm{Ag}_{2} \mathrm{CO}_{3}$ by Procedure A (column chromatography; $\mathrm{CHCl}_{3} / \mathrm{MeOH}$, 100:0 $\rightarrow$ 85:15) gave 46 (15.4 mg, 50\%): UV (MeOH) $\lambda_{\max } 203,228,287 \mathrm{~nm}(\varepsilon 15900$ $16050,17950), \lambda_{\min } 213,250 \mathrm{~nm}(\varepsilon 13800,5100) ;{ }^{1} \mathrm{H}$ NMR (DMSO- $\left.d_{6}\right) \delta 2.20$ (ddd, J = 12.9, 5.9, $1.7 \mathrm{~Hz}, 1 \mathrm{H}, \mathrm{H} 2 "), 3.18-3.12$ (m, 1H, H2'), 3.55-3.49 (m, 1H, H5"), 3.72-2.69 (m, 1H, H5'), 3.90 (q, J=3.7 Hz, 1H, H4'), 4.51-4.46 (m, 1H, H3'), 5.27 (d, J= 3.7 Hz, 1H, 3'$\mathrm{OH}), 5.80-5.77$ (m, 1H, 5'-OH), 7.08 (t, $\left.J=7.2 \mathrm{~Hz}, 1 \mathrm{H}, \mathrm{H} 11^{\prime}\right), 7.48$ (s, 2H, NH 2$), 8.13$ (s, 1H, H2), $8.42(\mathrm{~s}, 1 \mathrm{H}, \mathrm{NH}), 15.64(\mathrm{~s}, 1 \mathrm{H}, \mathrm{NH}) ;{ }^{13} \mathrm{C}$ NMR (DMSO-d $) \delta 38.1(\mathrm{C} 2$ '), 62.4 (C5'), 71.5 (C3'), 85.9 (C1'), 88.4 (C4'), 119.4 (C5), 130.3 (triazolyl), 141.5 (C8), 149.8 (C4), 152.1 (C2), 156.2 (C6); HRMS (ESI): m/z calcd for $\mathrm{C}_{12} \mathrm{H}_{14} \mathrm{~N}_{8} \mathrm{O}_{3} \mathrm{Na}[\mathrm{M}+\mathrm{Na}]^{+}$ 341.1081; found 341.1062.

Treatment of $85(27.5 \mathrm{mg}, 0.1 \mathrm{mmol})$ with $\mathrm{CuI}$ by Procedure B (column chromatography; $\mathrm{CHCl}_{3} / \mathrm{MeOH}, 100: 0 \rightarrow 85: 15$; HPLC: C18, A: 100\% ACN, B: 5\% $\mathrm{ACN} / \mathrm{H}_{2} \mathrm{O} ; 0 \% \mathrm{~A} \rightarrow 15 \% \mathrm{~A}$ in $30 \mathrm{~min}$, flow rate $\left.=2 \mathrm{~mL} / \mathrm{min}\right)$ gave $46(5.3 \mathrm{mg}, 17 \%)$ with the spectroscopic data as described above.

Treatment of 85 (27.5 mg, $0.1 \mathrm{mmol})$ with $\mathrm{CuSO}_{4} /$ sodium ascorbate by Procedure $\mathrm{C}$ (column chromatography; $\mathrm{CHCl}_{3} / \mathrm{MeOH}, 100: 0 \rightarrow 85: 15$; HPLC: C18, A: 100\% ACN, B: $5 \% \mathrm{ACN} / \mathrm{H}_{2} \mathrm{O} ; 0 \% \mathrm{~A} \rightarrow 15 \% \mathrm{~A}$ in $30 \mathrm{~min}$, flow rate $\left.=2 \mathrm{~mL} / \mathrm{min}\right)$ gave $46(16.2 \mathrm{mg}, 51 \%)$ with the spectroscopic data as described above. 
8-(1H-1,2,3-triazol-4-yl)-2' -deoxyguanosine (8-TrzdG, 47). Treatment of $87^{142}(29.1$ mg, $0.1 \mathrm{mmol}$ ) with $\mathrm{Ag}_{2} \mathrm{CO}_{3}$ by Procedure A (column chromatography; $\mathrm{CHCl}_{3} / \mathrm{MeOH}$, 100:0 $\rightarrow$ 80:20) gave 47 (17.4 mg, 52\%): UV (MeOH) $\lambda_{\max } 205,283 \mathrm{~nm}(\varepsilon 14450,14800)$ $\lambda_{\min } 238$ (ع 2600); ${ }^{1} \mathrm{H}$ NMR (DMSO- $\left.d_{6}\right) \delta$ 2.13-2.07 (m, 1H, H2"), 3.19-3.12 (m, 1H, H2'), $3.50(\mathrm{dd}, J=11.7,5.3 \mathrm{~Hz}, 1 \mathrm{H}, \mathrm{H} 5 "), 3.65$ (dd, $J=11.8,4.8 \mathrm{~Hz}, 1 \mathrm{H}, \mathrm{H} 5$ '), 3.81-3.78 (m, 1H, H4'), 4.44-4.38 (m, 1H, H3'), 5.05 ("s", 1H, 5'-OH), 5.18 (d, J=3.7 Hz, 1H, 3'-OH), $6.43\left(\mathrm{~s}, 2 \mathrm{H}, \mathrm{NH}_{2}\right), 8.34$ (t, J=7.8 Hz, 1H, H1'), $10.83(\mathrm{~s}, 1 \mathrm{H}, \mathrm{NH}), 15.42(\mathrm{~s}, 1 \mathrm{H}, \mathrm{NH}) ;{ }^{13} \mathrm{C}$ NMR (DMSO- $\left.d_{6}\right) \delta 37.4\left(\mathrm{C}^{\prime}\right), 62.3$ (C5'), $71.4\left(\mathrm{C}^{\prime}\right), 84.8$ (C1'), 88.0 (C4'), 117.6 (C5), 128.8 (triazolyl), 151.9 (C4), 153.1 (C2), 154.0 (C6), 156.5 (C8); HRMS (ESI): m/z calcd for $\mathrm{C}_{12} \mathrm{H}_{15} \mathrm{~N}_{8} \mathrm{O}_{4}[\mathrm{M}+\mathrm{H}]^{+}$, 335.1211; found 335.1214.

Treatment of 87 (29.1 mg, $0.1 \mathrm{mmol})$ with CuI by Procedure B (column chromatography; $\mathrm{CHCl}_{3} / \mathrm{MeOH}, 100: 0 \rightarrow$ 80:20; HPLC: C18, A: 100\% ACN, B: 5\% $\mathrm{ACN} / \mathrm{H}_{2} \mathrm{O} ; 0 \% \mathrm{~A} \rightarrow 15 \% \mathrm{~A}$ in $30 \mathrm{~min}$, flow rate $\left.=2 \mathrm{~mL} / \mathrm{min}\right)$ gave $47(10.2 \mathrm{mg}, 31 \%)$ with the spectroscopic data as described above.

Treatment of $87(29.1 \mathrm{mg}, 0.1 \mathrm{mmol})$ with $\mathrm{CuSO}_{4} /$ sodium ascorbate by Procedure $\mathrm{C}$ (column chromatography; $\mathrm{CHCl}_{3} / \mathrm{MeOH}, 100: 0 \rightarrow 80: 20$; HPLC: C18, A: 100\% ACN, B: $5 \% \mathrm{ACN} / \mathrm{H}_{2} \mathrm{O} ; 0 \% \mathrm{~A} \rightarrow 15 \% \mathrm{~A}$ in $30 \mathrm{~min}$, flow rate $\left.=2 \mathrm{~mL} / \mathrm{min}\right)$ gave $47(26.0 \mathrm{mg}, 52 \%)$ with the spectroscopic data as described above.

5-(1H-1,2,3-triazol-4-yl)-2'-deoxycytidine (5-TrzdC, 48). Treatment of $63 b^{120}(25.1$ mg, $0.1 \mathrm{mmol}$ ) with $\mathrm{CuI}$ by Procedure B (column chromatography; $\mathrm{CHCl}_{3} / \mathrm{MeOH}, 100: 0$ $\rightarrow$ 80:20) gave 48 (2.9 mg, 10\%): UV (MeOH) $\lambda_{\max } 207,238,296 \mathrm{~nm}(\varepsilon 18750,13900,5$ $500), \lambda_{\min } 224,273 \mathrm{~nm}(\varepsilon 11900,3500) ;{ }^{1} \mathrm{H}$ NMR (DMSO- $\left.d_{6}\right) \delta 2.14-2.08$ (m, 1H, H2"), 
2.21 (ddd, $J=13.2,6.1,4.7 \mathrm{~Hz}, 1 \mathrm{H}, \mathrm{H} 2$ '), 3.66-3.59 (m, 1H, H5"), 3.75-3.68 (m, 1H, H5'), $3.82(\mathrm{q}, J=3.3 \mathrm{~Hz}, 1 \mathrm{H}, \mathrm{H} 4$ '), 4.30-4.24 (m, 1H, H3'), 7.68 (s, 1H, 3'-OH), 5.29 (s, 1H, 5'-OH), $6.18(\mathrm{t}, J=6.1 \mathrm{~Hz}, 1 \mathrm{H}, \mathrm{H1}$ '), $7.68(\mathrm{~s}, 1 \mathrm{H}, \mathrm{NH}), 7.80(\mathrm{~s}, 1 \mathrm{H}, \mathrm{NH}), 8.07(\mathrm{~s}, 1 \mathrm{H}, \mathrm{NH})$,

8.60 (s, 1H, H6), 15.18 (s, 1H, NH), ${ }^{13} \mathrm{C}$ NMR (DMSO- $\left.d_{6}\right) \delta 40.9$ (C2'), 60.6 (C5'), 69.5 (C3'), 85.4 (C1'), 87.3 (C4'), 96.4 (C5), 128.0 (triazolyl), 140.1 (C6), 153.7 (C4), 162.2 (C2); HRMS (ESI): $\mathrm{m} / \mathrm{z}$ calcd for $\mathrm{C}_{11} \mathrm{H}_{15} \mathrm{~N}_{6} \mathrm{O}_{4}[\mathrm{M}+\mathrm{H}]^{+}$295.1149; found 295.1160.

Treatment of 63b $(25.1 \mathrm{mg}, 0.1 \mathrm{mmol})$ with $\mathrm{CuSO}_{4} /$ sodium ascorbate by Procedure C (column chromatography; $\left.\mathrm{CHCl}_{3} / \mathrm{MeOH}, 100: 0 \rightarrow 80: 20\right)$ gave $\mathbf{4 8}(15.0 \mathrm{mg}, 51 \%)$ with the spectroscopic data as described above.

3',5'-di-O-acetyl-5-(1H-1,2,3-triazol-4-yl)-2'-deoxyuridine (diAc-5-TrzdU, 84). Treatment of $\mathbf{6 2}^{110}$ (33.6 mg, $0.1 \mathrm{mmol}$ ) with CuI by Procedure B (column chromatography; $\left.\mathrm{CHCl}_{3} / \mathrm{MeOH}, 100: 0 \rightarrow 92: 8\right)$ gave 84 (20.8 mg, 55\%): UV (MeOH) $\lambda_{\max } 231,293 \mathrm{~nm}(\varepsilon$ 10700, 9600), $\lambda \min 258 \mathrm{~nm}\left(\varepsilon\right.$ 2900); ${ }^{1} \mathrm{H}$ NMR (DMSO-d $\left.d_{6}\right) \delta 2.08$ (s, 3H, $\mathrm{CH}_{3}$ ), 2.13 (s, $\left.3 \mathrm{H}, \mathrm{CH}_{3}\right), 2.46-2.36$ (m, 2H, H2',2"), 4.26-4.22 (m, 2H, H5', 5"), 4.31-4.27 (m, 1H, H4'), 5.26-5.21 (m, 1H, H3'), 6.25 (t, $J=6.3 \mathrm{~Hz}, 1 \mathrm{H}, \mathrm{H1}$ '), 8.18 (s, 1H, NH), 8.31 (s, 1H, H6), $11.82(\mathrm{~s}, 1 \mathrm{H}, 3-\mathrm{NH}), 15.19(\mathrm{~s}, 1 \mathrm{H}, \mathrm{NH}) ;{ }^{13} \mathrm{C}$ NMR (DMSO- $\left.d_{6}\right) \delta 20.7,20.8$ (Ac), 36.7 (C2'), 63.8 (C5'), 74.2 (C3'), 81.7 (C4'), 84.9 (C1'), 105.5 (C5), 135.8 (C6), 149.6 (C2), 161.2 (C4), 170.1, 170.4 (Ac); HRMS (ESI): $\mathrm{m} / \mathrm{z}$ calcd for $\left[\mathrm{C}_{15} \mathrm{H}_{18} \mathrm{~N}_{5} \mathrm{O}_{7}\right]^{+}, 380.1201$; found 380.1208.

Treatment of $62(33.6 \mathrm{mg}, 0.1 \mathrm{mmol})$ with $\mathrm{CuSO}_{4} /$ sodium ascorbate by Procedure $\mathrm{C}$ (column chromatography; $\left.\mathrm{CHCl}_{3} / \mathrm{MeOH}, 100: 0 \rightarrow 92: 8\right)$ gave $84(30.6 \mathrm{mg}, 81 \%$ ) with the spectroscopic data as described above. 
3',5'-diTBDMS-8-(1H-1,2,3-triazol-4-yl)-2'-deoxyadenosine (diTBDMS-8-TrzdA, 88). Treatment of $\mathbf{8 6}^{141}$ (50.4 mg, $0.1 \mathrm{mmol}$ ) with $\mathrm{Ag}_{2} \mathrm{CO}_{3}$ by Procedure A (column chromatography; hexane/EtOAc 50:50 $\rightarrow$ 0:100) gave 88 (16.4 mg, 30\%): UV (MeOH) $\lambda_{\max } 225,285 \mathrm{~nm}(\varepsilon 17500,14100), \lambda_{\min } 247 \mathrm{~nm}(\varepsilon 3900) ;{ }^{1} \mathrm{H}$ NMR (DMSO- $\left.d_{6}\right) \delta-0.08$ (s, 3H, $\left.\mathrm{CH}_{3}\right),-0.02\left(\mathrm{~s}, 3 \mathrm{H}, \mathrm{CH}_{3}\right), 0.170\left(\mathrm{~s}, 3 \mathrm{H}, \mathrm{CH}_{3}\right), 0.173\left(\mathrm{~s}, 3 \mathrm{H}, \mathrm{CH}_{3}\right), 0.80(\mathrm{~s}, 9 \mathrm{H}, 3 \mathrm{x}$ $\left.\mathrm{CH}_{3}\right), 0.94$ (s, 9H, $\left.3 \times \mathrm{CH}_{3}\right), 2.28-2.35$ (m, 1H, H2'), 3.73 (dd, $\left.J=11.3,5.4 \mathrm{~Hz}, 1 \mathrm{H}, \mathrm{H} 5^{\prime}\right)$, 3.83-3.90 (m, 1H, H2"), 3.96 (dd, $J=11.3,5.9$ Hz, 1H, H5"), 4.05 ("q", $J=4.9,1 \mathrm{H}, \mathrm{H} 4$ '), $5.05(\mathrm{q}, J=5.9 \mathrm{~Hz}, 1 \mathrm{H}, \mathrm{H} 3$ '), $6.72(\mathrm{t}, J=6.9 \mathrm{~Hz}, 1 \mathrm{H}, \mathrm{H1}$ '), $8.37(\mathrm{~s}, 1 \mathrm{H}, \mathrm{H} 2), 8.53(\mathrm{~s}, 1 \mathrm{H}$, Htrz); ${ }^{13} \mathrm{C}$ NMR (DMSO- $\left.d_{6}\right) \delta-5.4\left(\mathrm{CH}_{3}\right),-5.3\left(\mathrm{CH}_{3}\right),-4.6\left(\mathrm{CH}_{3}\right),-4.4\left(\mathrm{CH}_{3}\right), 18.2\left(\mathrm{CH}_{3}\right)$, $18.5\left(\mathrm{CH}_{3}\right), 25.98\left(\mathrm{CH}_{3}\right), 26.01\left(\mathrm{CH}_{3}\right), 37.2\left(\mathrm{C}^{\prime}\right), 62.9\left(\mathrm{C}^{\prime}\right), 72.5\left(\mathrm{C}^{\prime}\right), 85.3\left(\mathrm{Cl}^{\prime}\right), 87.8$ (C4), 119.7 (C5), 133.1(Htrz), 143.8 (C8), 151.0 (C4), 152.8 (C2), 155.4 (C6); HRMS calcd for $\mathrm{C}_{24} \mathrm{H}_{43} \mathrm{~N}_{8} \mathrm{O}_{3} \mathrm{Si}_{2}[\mathrm{M}+\mathrm{H}]^{+}$547.2991, found 547.3004.

Treatment of 86 (50.4 mg, $0.1 \mathrm{mmol}$ ) with CuI by Procedure B (column chromatography; hexane/EtOAc 50:50 $\rightarrow$ 0:100) gave $88(14.8 \mathrm{mg}, 27 \%)$ with the spectroscopic data as described above.

Treatment of $\mathbf{8 6}$ (50.4 mg, $0.1 \mathrm{mmol}$ ) with $\mathrm{CuSO}_{4} /$ sodium ascorbate by Procedure $\mathrm{C}$ (column chromatography; hexane/EtOAc 50:50 $\rightarrow$ 0:100) gave $\mathbf{8 8}(31.7 \mathrm{mg}, 58 \%)$ with the spectroscopic data as described above.

8-(1H-1,2,3-triazol-4-yl)-2'-deoxyadenosine 5'-triphosphate (8-TrzdATP, 102). Phosphoryl chloride ( $28 \mu \mathrm{L}, 46 \mathrm{mg}, 0.3 \mathrm{mmol}$ ) was added to a stirred solution of 8-TrzdA $46(48 \mathrm{mg}, 0.15 \mathrm{mmol})$ and proton sponge $(80 \mathrm{mg}, 0.375 \mathrm{mmol})$ in trimethyl phosphate $(2 \mathrm{~mL})$ at $0{ }^{\circ} \mathrm{C}$. The resulting mixture was stirred at $0{ }^{\circ} \mathrm{C}$ for $30 \mathrm{~min} .0 .5 \mathrm{M}$ tributylammomium pyrophosphate solution in DMF $(1.5 \mathrm{~mL}, 0.75 \mathrm{mmol})$ and then 
tributylamine $(106.8 \mu \mathrm{L}, 83.4 \mathrm{mg}, 0.45 \mathrm{mmol})$ were added to the reaction mixture and stirred at $0{ }^{\circ} \mathrm{C}$ for $2 \mathrm{~min}$. The reaction was quenched by adjusting the $\mathrm{pH}$ to 7.5 with $2 \mathrm{M}$ TEAB buffer. The residue was dissolved in water $(5 \mathrm{~mL})$ and was extracted with EtOAc $\left(3 \times 5 \mathrm{~mL}\right.$ ). The water layer was evaporated and coevaporated with mixture of $\mathrm{EtOH} / \mathrm{H}_{2} \mathrm{O}$ $(1: 1,5 \mathrm{~mL})$. The residue was column chromatographed (DEAE-Sephadex®, TEAB $0.1 \mathrm{M}$ $\rightarrow 0.6 \mathrm{M})$ and the appropriate fractions were evaporated in vacuum and coevaporate 5 times with mixture of $\mathrm{EtOH} / \mathrm{H}_{2} \mathrm{O}(1: 1,10 \mathrm{~mL})$ to give 8-TrzdATP triethylammonium salt 102. $(33.4 \mathrm{mg}, 30 \%) .{ }^{1} \mathrm{H}$ NMR $\left(\mathrm{D}_{2} \mathrm{O}\right) \delta 2.33(\mathrm{ddd}, J=13.4,6.5,3.9,1 \mathrm{H}, \mathrm{H} 2$ '), 3.22-3.26 (m, 1H, H2"), 4.04-4.10 (m, 1H, H5'), 4.14 (q, J= 5.2 Hz, 1H, H4'), 4.18-4.24 (m, 1H, H5"), 4.66 (quin, $J=3.9 \mathrm{~Hz}, 1 \mathrm{H}, \mathrm{H} 3$ '), 6.74 (t, $J=7.8,1 \mathrm{H}, \mathrm{H} 1$ '), 8.20 (s, 1H, H2), 8.41 (s, 1H, Trz); ${ }^{31} \mathrm{P}$ NMR $\left(\mathrm{D}_{2} \mathrm{O}\right) \delta-23.22(\mathrm{t}, J=21.0,1 \mathrm{P}, \beta),-11.34(\mathrm{~d}, J=21.0,1 \mathrm{P}, \alpha),-10.22(\mathrm{~d}, J$ $=21.0,1 \mathrm{P}, \gamma) ;{ }^{13} \mathrm{C}$ NMR $\left(\mathrm{D}_{2} \mathrm{O}\right) \delta 36.2,65.2,70.6,84.3,84.8,118.6,128.8,136.1,143.0$, 149.9, 152.6, 155.0; HRMS calcd for $\mathrm{C}_{12} \mathrm{H}_{16} \mathrm{~N}_{8} \mathrm{O}_{12} \mathrm{P}_{3}[\mathrm{M}-\mathrm{H}]^{-}$557.0106, found 557.0091.

\subsubsection{Synthesis of 5-(1-halo-2-sulfonylvinyl) and 5-(2-furyl) uracil nucleoside analogues}

2',3',5'-Tri- $\boldsymbol{O}$-acetyl-5-(fur-2-yl)uridine (107). Procedure B. Furan $(0.7$ mL, 680 mg, $10 \mathrm{mmol})$ and TBAF (1 M/THF, $3.5 \mathrm{~mL}, 3.5 \mathrm{mmol})$ were added to a stirred solution of $\mathbf{1 0 5}^{150} \quad(248 \mathrm{mg}, \quad 0.5 \mathrm{mmol}) \quad$ in $\quad$ DMF $\quad(5 \quad \mathrm{~mL})$ containing tris(dibenzylideneacetone)dipalladium $(22.9 \mathrm{mg}, 0.025 \mathrm{mmol})$ at ambient temerature. The resulting suspension was stirred for $1 \mathrm{~h}$ at $100^{\circ} \mathrm{C}$. The volatiles were evaporated under reduced pressure and the residue was dissolved in EtOAc and washed with saturated $\mathrm{NaHCO}_{3} / \mathrm{H}_{2} \mathrm{O}$ and brine and the organic layer was dried over anhydrous $\mathrm{Na}_{2} \mathrm{SO}_{4}$. The residue was column chromatographed $\left(\mathrm{CHCl}_{3} / \mathrm{MeOH}, 95: 5\right)$ to give 107 (146 mg, 67\%): 
${ }^{1} \mathrm{H}$ NMR $\delta 2.10\left(\mathrm{~s}, 3 \mathrm{H}, \mathrm{CH}_{3}\right), 2.15\left(\mathrm{~s}, 3 \mathrm{H}, \mathrm{CH}_{3}\right), 2.22\left(\mathrm{~s}, 3 \mathrm{H}, \mathrm{CH}_{3}\right), 4.38-4.40(\mathrm{~m}, 3 \mathrm{H}$, H4',5',5"), 5.38-5.42 (m, 2H, H2',3'), 6.24-6.28 (m, 1H, H1'), 6.47 (dd, J = 3.3, 1.8 Hz, 1H, furan), 7.09 (d, $J=3.4,1 \mathrm{H}$, furan), 7.33 (d, $J=1.4,1 \mathrm{H}$, furan), 7.91 (s, 1H, H6), 9.20 (s, $1 \mathrm{H}, \mathrm{NH}) ;{ }^{13} \mathrm{C}$ NMR $\delta 20.5,20.7,20.8,64.6,70.9,73.0,80.6,86.8,108.4,110.2,112.3$, $132.5,141.3,145.6,149.6,157.8,169.77,169.83,170.4$; HRMS calcd for $\mathrm{C}_{19} \mathrm{H}_{21} \mathrm{~N}_{2} \mathrm{O}_{10}$ $[\mathrm{M}+\mathrm{H}]^{+}$437.1191, found 437.1178.

5-(5-Heptylfur-2-yl)-2'-deoxyuridine (108). Treatment of 5-iodo-2'-deoxyuridine $\mathbf{1 0 3}^{111}$ (53 mg, $\left.0.15 \mathrm{mmol}\right)$ with 2-heptylfuran $(0.29 \mathrm{~mL}, 249 \mathrm{mg}, 1.5 \mathrm{mmol})$ as described by Procedure B (column chromatography; hexane/EtOAc, 20:80) gave 108 (35 mg, 61\%): UV (MeOH) $\lambda_{\max } 256,326 \mathrm{~nm}(\varepsilon 14250,11300), \lambda_{\min } 287 \mathrm{~nm}(\varepsilon 4000) ;{ }^{1} \mathrm{H}$ NMR (DMSO- $d_{6}$ ) $\delta 0.86\left(\mathrm{t}, J=6.7 \mathrm{~Hz}, 3 \mathrm{H}, \mathrm{CH}_{3}\right), 1.24-1.31\left(\mathrm{~m}, 8 \mathrm{H}, 4 \times \mathrm{CH}_{2}\right.$ ), 1.60 (quin, $J=6.7$ $\mathrm{Hz}, 2 \mathrm{H}$, heptyl), 2.17 ("dd", $J=6.6,4.9 \mathrm{~Hz}, 2 \mathrm{H}, \mathrm{H2}$ '2"), 2.60 (t, $J=7.4 \mathrm{~Hz}, 2 \mathrm{H}, \mathrm{CH}_{2}$ ), 3.60-3.62 (m, 2H, H5',5"), 3.83 (q, $J=3.3 \mathrm{~Hz}, 1 \mathrm{H}, \mathrm{H} 4$ '), 4.29 (quin, $J=4.2,1 \mathrm{H}, \mathrm{H} 3$ '), 5.05 (t, $\left.J=5.0 \mathrm{~Hz}, 1 \mathrm{H}, 5^{\prime}-\mathrm{OH}\right), 5.28\left(\mathrm{~d}, J=4.1 \mathrm{~Hz}, 1 \mathrm{H}, 3^{\prime}-\mathrm{OH}\right), 6.11(\mathrm{~d}, J=3.1 \mathrm{~Hz}, 1 \mathrm{H}$, furan), $6.21\left(\mathrm{t}, J=6.6 \mathrm{~Hz}, 1 \mathrm{H}, \mathrm{H} 1^{\prime}\right), 6.72(\mathrm{~d}, J=3.1 \mathrm{~Hz}, 1 \mathrm{H}$, furan), 8.27 (s, 1H, H6), $11.58(\mathrm{~s}, 1 \mathrm{H}$, $\mathrm{NH}) ;{ }^{13} \mathrm{C}$ NMR $\delta 14.2,22.1,27.0,28.6,31.1,39.4,60.8,70.3,84.5,87.4,105.7,106.8$, 108.6, 133.6, 144.5, 149.6, 154.8, 160.0; HRMS calcd for $\mathrm{C}_{20} \mathrm{H}_{29} \mathrm{~N}_{2} \mathrm{O}_{6}[\mathrm{M}+\mathrm{H}]^{+}$393.2020, found 393.2023.

3',5'-Di-O-acetyl-5-(5-heptylfur-2-yl)-2'-deoxyuridine (109). Treatment of $\mathbf{1 0 4}^{118}$ (150 mg, $0.34 \mathrm{mmol})$ with 2-heptylfuran $(0.6 \mathrm{~mL}, 565 \mathrm{mg}, 3.4 \mathrm{mmol})$ as described by Procedure B (column chromatography; hexane/EtOAc, 80:20 $\rightarrow$ 60:40) gave 109 (86 mg, 60\%): ${ }^{1} \mathrm{H}$ NMR $\delta 0.87\left(\mathrm{t}, J=7.1 \mathrm{~Hz}, 3 \mathrm{H}, \mathrm{CH}_{3}\right), 1.22-1.37\left(\mathrm{~m}, 8 \mathrm{H}, 4 \times \mathrm{CH}_{2}\right), 1.61(\mathrm{q}, J=$ $7.4 \mathrm{~Hz}, 2 \mathrm{H}, \mathrm{CH}_{2}$ ), 2.11 (s, 3H, $\mathrm{CH}_{3}$ ), 2.12 (s, 3H, $\mathrm{CH}_{3}$ ), 2.25 ("ddd", $J=16.6,8.7,2.2 \mathrm{~Hz}$, 
1H, H2'), 2.50-2.57 (m, 1H, H2"), 2.59 (t, $\left.J=7.5 \mathrm{~Hz}, 2 \mathrm{H}, \mathrm{CH}_{2}\right), 4.30-4.34\left(\mathrm{~m}, 1 \mathrm{H}, \mathrm{H} 4^{\prime}\right)$, 4.38-4.42 (m, 2H, H5',5"), 5.28 ("dt", $J=6.4,1.6 \mathrm{~Hz}, 1 \mathrm{H}, \mathrm{H} 3$ '), 6.05 (d, $J=3.3 \mathrm{~Hz}, 1 \mathrm{H}$, furan), $6.40(\mathrm{dd}, J=8.6,5.5 \mathrm{~Hz}, 1 \mathrm{H}, \mathrm{H1}$ '), $6.98(\mathrm{~d}, J=3.3 \mathrm{~Hz}, 1 \mathrm{H}$, furan), $7.85(\mathrm{~s}, 1 \mathrm{H}, \mathrm{H} 6)$, 9.30 (s, 1H, NH); ${ }^{13} \mathrm{C}$ NMR $\delta 14.2\left(\mathrm{CH}_{3}\right), 20.9,21.1$ (Ac), 22.8, 28.1, 28.2, 29.2, 29.3, 31.9 (CH2), 38.1(C2'), 61.2 (C5'), 74.7 (C3'), 82.7 (C4'), 85.7 (C1'), 107.4 (furan), 108.2 (C5), 111.0 (furan), 131.3 (C6), 143.8, 149.4 (furan), 156.2 (C2), 159.9 (C4), 170.3, 170.5 (Ac); HRMS calcd for $\mathrm{C}_{24} \mathrm{H}_{32} \mathrm{~N}_{2} \mathrm{NaO}_{8}[\mathrm{M}+\mathrm{Na}]^{+}$499.2056, found 499.2078.

2',3',5'-Tri- $O$-acetyl-5-(5-heptylfur-2-yl)uridine (110). Treatment of 2',3',5'-tri- $O$ acetyl-5- iodouridine 105 (400 mg, $0.8 \mathrm{mmol}$ ) with 2-heptylfurane $(1.5 \mathrm{~mL}, 665 \mathrm{mg}, 4.0$ mmol) by Procedure B (column chromatography; hexane/EtOAc, 50:50) gave 110 (236 $\mathrm{mg}, 55 \%):{ }^{1} \mathrm{H} \mathrm{NMR} \delta 0.88\left(\mathrm{t}, J=6.7 \mathrm{~Hz}, 3 \mathrm{H}, \mathrm{CH}_{3}\right), 1.25-1.34\left(\mathrm{~m}, 8 \mathrm{H}, 4 \times \mathrm{CH}_{2}\right.$ ), 1.62 (quin, $\left.J=7.8 \mathrm{~Hz}, 2 \mathrm{H}, \mathrm{CH}_{2}\right), 2.10(\mathrm{~s}, 3 \mathrm{H}, \mathrm{Ac}), 2.15(\mathrm{~s}, 3 \mathrm{H}, \mathrm{Ac}), 2.18(\mathrm{~s}, 3 \mathrm{H}, \mathrm{Ac}), 2.59(\mathrm{t}, J=7.8$ $\mathrm{Hz}, 2 \mathrm{H}, \mathrm{CH}_{2}$ ), 4.38-4.40 (m, 3H, H4',5',5"), 5.40-5.44 (m, 2H, H2',3'), 6.05 (d, J = 3.6 Hz, $1 \mathrm{H}$, furan), $6.21(\mathrm{~d}, J=5.5 \mathrm{~Hz}, 1 \mathrm{H}, \mathrm{H1}$ '), $6.99(\mathrm{~d}, J=3.3 \mathrm{~Hz}, 1 \mathrm{H}$, furan), $7.75(\mathrm{~s}, 1 \mathrm{H}, \mathrm{H} 6)$, 9.03 (s, 1H, NH); ${ }^{13} \mathrm{C}$ NMR $\delta 14.0\left(\mathrm{CH}_{3}\right), 20.4,20.6,20.8$ (Ac), 22.6, 28.0, 28.1, 29.0, 29.2, $31.7\left(\mathrm{CH}_{2}\right), 63.4$ (C5'), 70.8 (C3'), $72.7\left(\mathrm{C} 2^{\prime}\right), 80.4\left(\mathrm{C}^{\prime}\right), 87.0$ (C1'), 107.3 (furan), 108.5 (C5), 111.2 (furan), 131.2 (C6), 143.5, 149.4 (furan), 156.1 (C2), 160.0 (C4), 169.7, 169.7, 170.1 (Ac); HRMS calcd for $\mathrm{C}_{26} \mathrm{H}_{35} \mathrm{~N}_{2} \mathrm{O}_{10}[\mathrm{M}+\mathrm{H}]^{+}$535.2286, found 535.2288.

5-(5-Heptylfur-2-yl)uridine (111). Methanolic ammonia (6.4 $\mathrm{mL})$ was added to $\mathbf{1 1 0}$ $(100 \mathrm{mg}, 0.19 \mathrm{mmol})$ in $1.6 \mathrm{~mL} \mathrm{MeOH}$ and the resulting mixture was stirred at $0{ }^{\circ} \mathrm{C} \rightarrow \mathrm{rt}$ for 12 hours. Volatiles were evaporated and the residue was column chromatographed (EtOAc/MeOH, 95:5) to give 111 (62 mg, 81\%): UV (MeOH) $\lambda_{\max } 254,326 \mathrm{~nm}(\varepsilon 13600$, $10950), \lambda_{\min } 287 \mathrm{~nm}\left(\varepsilon\right.$ 3850); ${ }^{1} \mathrm{H}$ NMR (DMSO- $\left.d_{6}\right) \delta 0.86\left(\mathrm{t}, J=6.6 \mathrm{~Hz}, 3 \mathrm{H}, \mathrm{CH}_{3}\right), 1.24-$ 
$1.31\left(\mathrm{~m}, 8 \mathrm{H}, 4 \times \mathrm{CH}_{2}\right.$ ), 1.60 (quin, $J=6.9,2 \mathrm{H}, \mathrm{CH}_{2}$ ), 2.60 (t, $J=7.3 \mathrm{~Hz}, 2 \mathrm{H}, \mathrm{CH}_{2}$ ), 3.60 (ddd, $\left.J=12.0,4.8,3.1 \mathrm{~Hz}, 1 \mathrm{H}, \mathrm{H} 5^{\prime}\right), 3.68$ (ddd, $\left.J=12.0,4.8,2.9 \mathrm{~Hz}, 1 \mathrm{H}, \mathrm{H} 5 "\right), 3.89-3.91$ (m, 1H, H4'), 4.02 (q, $\left.J=4.8 \mathrm{~Hz}, 1 \mathrm{H}, \mathrm{H} 3^{\prime}\right), 4.10\left(\mathrm{q}, J=5.0 \mathrm{~Hz}, 1 \mathrm{H}, \mathrm{H} 2^{\prime}\right), 5.11(\mathrm{~d}, J=5.2$ $\mathrm{Hz}, 1 \mathrm{H}, 3$ '-OH), 5.15 (t, $J=4.8 \mathrm{~Hz}, 1 \mathrm{H}, 5$ '-OH), 5.44 (d, J=5.6 Hz, 1H, 2'-OH), 5.86 (d, $J=4.8 \mathrm{~Hz}, 1 \mathrm{H}, \mathrm{H} 1 '), 6.11(\mathrm{~d}, J=3.1 \mathrm{~Hz}, 1 \mathrm{H}$, furan), $6.73(\mathrm{~d}, J=3.1 \mathrm{~Hz}, 1 \mathrm{H}$, furan $), 8.36$ (s, 1H, H6), $11.60(\mathrm{~s}, 1 \mathrm{H}, \mathrm{NH}) .{ }^{13} \mathrm{C}$ NMR (DMSO-d $\left.d_{6}\right) \delta 13.9,22.0,27.2,27.3,28.3,28.5$, 31.2 (heptyl), 60.6 (C5'), 69.9 (C3'), 74.0 (C2'), 84.9 (C1'), 88.3 (C4'), 105.9 (C5), 106.7 (furan), 108.7 (furan), 133.9 (C6), 144.5 (furan), 149.6 (furan), 154.7 (C2), 160.1 (C4); HRMS calcd for $\mathrm{C}_{20} \mathrm{H}_{29} \mathrm{~N}_{2} \mathrm{O}_{7}[\mathrm{M}+\mathrm{H}]^{+} 409.1969$, found 409.1982 .

5'-O-Undecanoyl-5-(fur-2-yl)-2'-deoxyuridine (112). Treatment of $106^{111}$ (25 mg, $0.08 \mathrm{mmol}$ ) with undecanoic anhydride by Procedure A (column chromatography; hexane/EtOAc, 100:0 $\rightarrow$ 70:30) gave $112(18 \mathrm{mg}, 52 \%)$ and $\mathbf{1 1 3}(5 \mathrm{mg}, 10 \%)$ in addition to unchanged $106\left(\sim 15 \%\right.$; TLC). Compound 112 had: ${ }^{1} \mathrm{H}$ NMR $\delta 0.88$ (t, $J=7.1 \mathrm{~Hz}, 3 \mathrm{H}$, $\mathrm{CH}_{3}$ ), 1.22-1.40 (m, 14H, 7 x CH $\left.\mathrm{CH}_{2}\right), 1.60$ ("quin", $\left.J=7.3 \mathrm{~Hz}, 2 \mathrm{H}, \mathrm{CH}_{2}\right), 2.10-2.17(\mathrm{~m}, 1 \mathrm{H}$, H2'), 2.35 (t, $J=7.6 \mathrm{~Hz}, 2 \mathrm{H}, \mathrm{CH}_{2}$ ), 2.50 (ddd, $\left.J=13.7,6.3,3.9 \mathrm{~Hz}, 1 \mathrm{H}, \mathrm{H} 2 "\right), 3.05$ (br s, 1H, 3'-OH), $4.15\left(\mathrm{q}, J=3.9,1 \mathrm{H}, \mathrm{H} 4^{\prime}\right), 4.25\left(\mathrm{dd}, J=12.1,3.3 \mathrm{~Hz}, 1 \mathrm{H}, \mathrm{H} 5^{\prime}\right), 4.36-4.42$ (m, 2H, H3',5"), 6.26 (t, $\left.J=6.3 \mathrm{~Hz}, 1 \mathrm{H}, \mathrm{H} 1^{\prime}\right), 6.60$ (dd, $J=3.3,1.8 \mathrm{~Hz}, 1 \mathrm{H}$, furan), 7.05 (d, $J$ $=3.5 \mathrm{~Hz}, 1 \mathrm{H}$, furan), $7.38(\mathrm{~d}, J=1.2 \mathrm{~Hz}, 1 \mathrm{H}$, furan $), 8.25(\mathrm{~s}, 1 \mathrm{H}, \mathrm{H} 6), 8.38(\mathrm{~s}, 1 \mathrm{H}, \mathrm{NH})$; HRMS calcd for $\mathrm{C}_{24} \mathrm{H}_{34} \mathrm{~N}_{2} \mathrm{NaO}_{7}[\mathrm{M}+\mathrm{Na}]^{+}$485.2264; found 485.2271.

3',5'-Di-O-undecanoyl-5-(fur-2-yl)-2'-deoxyuridine (113). Treatment of $\mathbf{1 0 6}^{111}$ (25 $\mathrm{mg}, 0.08 \mathrm{mmol})$ with undecanoic anhydride $(84 \mathrm{mg}, 0.24 \mathrm{mmol})$ by Procedure A (6 h) gave 113 (38.5 mg, 77\%): ${ }^{1} \mathrm{H}$ NMR $\delta$ 0.82-0.91 (m, 6H, $\left.2 \times \mathrm{CH}_{3}\right), 1.20-1.40\left(\mathrm{~m}, 28 \mathrm{H}, 14 \times \mathrm{CH}_{2}\right)$, 1.60-1.68 (m, 4H, 2 x CH 2$), 2.24$ (ddd, $J=14.6,8.6,6.5 \mathrm{~Hz}, 1 \mathrm{H}, \mathrm{H} 2$ '), 2.33-2.40 (m, 4H, 
$2 \times \mathrm{CH}_{2}$ ), 2.54 (ddd, $\left.J=14.1,5.6,1.3 \mathrm{~Hz}, 1 \mathrm{H}, \mathrm{H} 2 "\right), 4.30$ ("q", $J=2.7 \mathrm{~Hz}, 1 \mathrm{H}, \mathrm{H} 4$ '), 4.36 (dd, $J=12.2,2.8 \mathrm{~Hz}, 1 \mathrm{H}, \mathrm{H5}$ '), 4.45 (dd, $J=11.8,3.5 \mathrm{~Hz}, 1 \mathrm{H}, \mathrm{H} 5 "), 5.27$ ("dt", $J=6.4$, $\left.1.6 \mathrm{~Hz}, 1 \mathrm{H}, \mathrm{H} 3{ }^{\prime}\right), 6.40$ (dd, $J=8.8,6.1 \mathrm{~Hz}, 1 \mathrm{H}, \mathrm{H1}$ '), 6.47 (dd, $J=3.3,1.8 \mathrm{~Hz}, 1 \mathrm{H}$, furan), $7.05(\mathrm{~d}, J=3.4 \mathrm{~Hz}, 1 \mathrm{H}$, furan), $7.33(\mathrm{~d}, J=1.6 \mathrm{~Hz}, 1 \mathrm{H}$, furan), $8.00(\mathrm{~s}, 1 \mathrm{H}, \mathrm{H6}), 8.95(\mathrm{~s}$, $1 \mathrm{H}, \mathrm{NH}) ;{ }^{13} \mathrm{C}$ NMR $\delta 14.5,23.0,25.1,25.2,29.3,29.4,29.6,29.7,29.9,32.3,34.1,34.3$, 34.5, 39.0 (C2'), 64.0 (C5'), 74.6 (C3'), 83.2 (C4'), 86.0 (C1'), 108.0 (C5), 110.0 (furan), 112.5 (furan), 133.0 (C6), 142.0 (furan), 146.0 (furan), 149.5 (C2), 160.2 (C4), 173.2, $173.4(\mathrm{C}=\mathrm{O})$; HRMS calcd for $\mathrm{C}_{35} \mathrm{H}_{54} \mathrm{~N}_{2} \mathrm{NaO}_{8}[\mathrm{M}+\mathrm{Na}]^{+}$653.3778, found 653.3778.

5'-O-Undecanoyl-5-(5-heptylfur-2-yl)-2'-deoxyuridine (114). Treatment of 108 (25 mg, $0.064 \mathrm{mmol}$ ) with undecanoic anhydride by Procedure A (hexane/EtOAc, 100:0 $\rightarrow$ 80:20) gave 114 [17 mg, 48\%; TLC ( $\left.\left.\mathrm{CHCl}_{3} / \mathrm{MeOH}, 95: 5\right), \mathrm{R}_{f}=0.50\right), 115$ (4.7 mg, 10\%; $\left.\mathrm{R}_{f}=0.90\right)$ and unchanged $108\left(\sim 15 \%, \mathrm{TLC} ; \mathrm{R}_{f}=0.10\right)$. Compound 114 had: ${ }^{1} \mathrm{H}$ NMR $\delta$ 0.85-0.90 (m, 6H, $\left.2 \times \mathrm{CH}_{3}\right), 1.28-1.31\left(\mathrm{~m}, 22 \mathrm{H}, 11 \times \mathrm{CH}_{2}\right), 1.54-1.64\left(\mathrm{~m}, 4 \mathrm{H}, 2 \times \mathrm{CH}_{2}\right)$, 2.13-2.16 (m, 1H, H2'), 2.27-2.32 (m, 2H, $\mathrm{CH}_{2}$ ), 2.46 (ddd, $\left.J=13.9,6.4,4.3 \mathrm{~Hz}, 1 \mathrm{H}, \mathrm{H} 2 "\right)$, $2.56\left(\mathrm{t}, J=7.4 \mathrm{~Hz}, 2 \mathrm{H}, \mathrm{CH}_{2}\right), 2.98\left(\mathrm{~s}, 1 \mathrm{H}, 3^{\prime}-\mathrm{OH}\right), 4.19(\mathrm{q}, J=3.5,1 \mathrm{H}, \mathrm{H} 4)$ ), 4.28 (dd, $J=$ 12.3, 3.4 Hz, 1H, H5'), 4.33-4.41 (m, 2H, H3',5"), 6.05 (d, $J=3.2 \mathrm{~Hz}, 1 \mathrm{H}-$ furan), 6.28 (t, $J=6.4 \mathrm{~Hz}, 1 \mathrm{H}, \mathrm{H1}$ ) $), 6.90(\mathrm{~d}, J=3.2 \mathrm{~Hz}, 1 \mathrm{H}-$ furan $), 8.10(\mathrm{~s}, 1 \mathrm{H}, \mathrm{H6}), 8.44(\mathrm{~s}, 1 \mathrm{H}, \mathrm{NH}) ;{ }^{13} \mathrm{C}$ NMR $\delta$ 14.2, $22.9\left(\mathrm{CH}_{3}\right), 24.9,28.1,28.2,29.2,29.2,29.3,29.4,29.5,29.6,29.7,31.9$, 32.1, 34.2, 34.3, $34.4\left(\mathrm{CH}_{2}\right), 40.7$ (C2'), 63.6 (C5'), 71.8 (C3'), $84.4\left(\mathrm{C}^{\prime}\right), 85.5\left(\mathrm{C}^{\prime}\right), 108.2$ (C5), 110.6 (furan), 113.0 (furan), 129.0 (furan), 133.0 (C6), 149 (C2), 156.0 (furan), 159.6 (C4), $174.0(\mathrm{C}=\mathrm{O})$; HRMS calcd for $\mathrm{C}_{31} \mathrm{H}_{48} \mathrm{~N}_{2} \mathrm{NaO}_{7}[\mathrm{M}+\mathrm{Na}]^{+}$583.3359, found 583.3375. 
Note: Also isolated from column chromatography was a product $\left(2 \mathrm{mg}, 5 \%\right.$; TLC, $\mathrm{R}_{f}=$ $0.55)$ whose structure was tentatively assigned as 3'-O-undecanoyl-5-(5-heptylfur-2-yl)-2'deoxyuridine $\left[{ }^{1} \mathrm{H}\right.$ NMR $\delta 5.39$ ("dt", $J=8.1,1.6 \mathrm{~Hz}, 1 \mathrm{H}, \mathrm{H} 3$ ').

3',5'-Di-O-undecanoyl-5-(5-heptylfur-2-yl)-2'-deoxyuridine (115). Treatment of $108(25 \mathrm{mg}, 0.064 \mathrm{mmol})$ with undecanoic anhydride $(65 \mathrm{mg}, 0.19 \mathrm{mmol})$ by Procedure A (6 h) gave 115 (36 mg, 80\%). Compound 115 had: ${ }^{1} \mathrm{H}$ NMR $\delta$ 0.83-0.92 (m, 9H, $\left.3 \times \mathrm{CH}_{3}\right)$, $1.22-1.38\left(\mathrm{~m}, 36 \mathrm{H}, 18 \times \mathrm{CH}_{2}\right), 1.55-1.70\left(\mathrm{~m}, 6 \mathrm{H}, 3 \times \mathrm{CH}_{2}\right), 2.25$ (ddd, $J=14.7,8.5,6.6$ $\mathrm{Hz}, 1 \mathrm{H}, \mathrm{H} 2$ '), 2.30-2.40 (m, 4H, 2 x CH 2$), 2.53-2.57$ (m, 1H, H2"), $2.60(\mathrm{t}, J=7.6 \mathrm{~Hz}, 2 \mathrm{H}$, $\left.\mathrm{CH}_{2}\right), 4.31\left(\mathrm{q}, J=3.01 \mathrm{H}, \mathrm{H} 4{ }^{\prime}\right), 4.38\left(\mathrm{dd}, J=12.2,2.8 \mathrm{~Hz}, 1 \mathrm{H}, \mathrm{H} 5^{\prime}\right), 4.42(\mathrm{dd}, J=11.3,3.8$ Hz, 1H, H5"), 5.26 ("dt", $J=6.8,1.6 \mathrm{~Hz}, 1 \mathrm{H}, \mathrm{H3}$ '), 6.05 (d, $J=3.2 \mathrm{~Hz}, 1 \mathrm{H}$, furan), 6.37 (dd, $\left.J=8.8,6.1 \mathrm{~Hz}, 1 \mathrm{H}, \mathrm{H}^{\prime}\right), 6.95(\mathrm{~d}, J=3.3 \mathrm{~Hz}, 1 \mathrm{H}$, furan), 7.88 (s, 1H, H6), 9.00 (s, 1H, NH); HRMS calcd for $\mathrm{C}_{42} \mathrm{H}_{68} \mathrm{~N}_{2} \mathrm{NaO}_{8}[\mathrm{M}+\mathrm{Na}]^{+} 751.4873$, found 751.4851 .

5'-O-Undecanoyl-5-(fur-2-yl)uridine (119). Step $a$. DDC (516 mg, $1.25 \mathrm{mmol})$ was added to a stirred solution of 2',3'-O-isopropylideneuridine 116 (142 mg, $0.5 \mathrm{mmol})$, undecanoic acid (163 mg, $0.875 \mathrm{mmol}$ ), and 4-dimethylaminopyridine (91.6 mg, 0.375 $\mathrm{mmol})$ in DMF (2 mL) at $\mathrm{rt}$ The resulting mixture was stirred at $60{ }^{\circ} \mathrm{C}$ overnight. Volatiles were evaporated and the residue was partitioned between EtOAc and $0.1 \mathrm{M} \mathrm{HCl}$ solution. The organic layer was washed with saturated solutions of $\mathrm{NaHCO}_{3}$ and brine and then was column chromatographed (hexane/EtOAc, 50:50) to give 2',3'-O-isopropylidene-5'-Oundecanoyluridine (117; $203 \mathrm{mg}, 90 \%)$ of sufficient purity to be used in next step: ${ }^{1} \mathrm{H}$ NMR $\delta 0.88\left(\mathrm{t}, J=7.1 \mathrm{~Hz}, 3 \mathrm{H}, \mathrm{CH}_{3}\right), 1.22-1.65\left(\mathrm{~m}, 22 \mathrm{H}, 8 \times \mathrm{CH}_{2}, 2 \times \mathrm{CH}_{3}\right), 2.31(\mathrm{t}, J=7.5 \mathrm{~Hz}$, 2H, $\mathrm{CH}_{2}$ ), 4.26-4.38 (m, 3H, H4',5',5"), 4.80 (dd, $J=5.7,3.8 \mathrm{~Hz}, 1 \mathrm{H}, \mathrm{H} 3$ '), 4.98 (dd, $J=$ 6.2, 1.4 Hz, 1H, H2'), 5.65 (d, $\left.J=1.3 \mathrm{~Hz}, 1 \mathrm{H}, \mathrm{H1} 1^{\prime}\right), 5.72(\mathrm{~d}, J=8.2 \mathrm{~Hz}, 1 \mathrm{H}, \mathrm{H} 5), 7.28$ (d, 
$J=8.2 \mathrm{~Hz}, 1 \mathrm{H}, \mathrm{H} 6), 8.98(\mathrm{~s}, 1 \mathrm{H}, \mathrm{NH})$. Step $b . \mathrm{ICl}\left(1 \mathrm{M} / \mathrm{CH}_{2} \mathrm{Cl}_{2} ; 0.75 \mathrm{~mL}, 0.75 \mathrm{mmol}\right)$ was added to a stirred solution of $117(224 \mathrm{mg}, 0.5 \mathrm{mmol})$ in $\mathrm{CH}_{2} \mathrm{Cl}_{2}(4.3 \mathrm{~mL})$ at ambient temperature and the resulting mixture was stirred at $40^{\circ} \mathrm{C}$ (oil-bath) overnight. The reaction solution was washed with $2 \% \mathrm{NaHSO}_{3}$ until the color turn into light yellow. The organic layer was washed with saturated solutions of $\mathrm{NaHCO}_{3}$ and brine and then was column chromatographed (hexane/EtOAc, $60: 40 \rightarrow 10: 90$ ) to give 5'-O-undecanoyl-5-iodouridine (118; $66 \mathrm{mg}, 25 \%):{ }^{1} \mathrm{H} \mathrm{NMR} \delta 0.87\left(\mathrm{t}, J=6.6 \mathrm{~Hz}, 3 \mathrm{H}, \mathrm{CH}_{3}\right), 1.25-1.31\left(\mathrm{~m}, 14 \mathrm{H}, 7 \times \mathrm{CH}_{2}\right)$, 1.67 (quin, $J=7.0 \mathrm{~Hz}, 2 \mathrm{H}, \mathrm{CH}_{2}$ ), 2.42-2.57 (m, 2H, $\mathrm{CH}_{2}$ ), 4.22-4.48 (m, 5H, H2', 3',4',5',5"), $5.91\left(\mathrm{~d}, J=2.9 \mathrm{~Hz}, 1 \mathrm{H}, \mathrm{H} 1{ }^{\prime}\right), 8.02$ (s, 1H, H6), 10.69 (s, 1H, NH). Step c. Treatment of 118 (27 mg, $0.05 \mathrm{mmol}$ ) with furan by Procedure B (column chromatography; hexane/EtOAc, 20:80) gave $119(15 \mathrm{mg}, 63 \%) ;{ }^{1} \mathrm{H}$ NMR $\delta 0.87\left(\mathrm{t}, J=6.7 \mathrm{~Hz}, 3 \mathrm{H}, \mathrm{CH}_{3}\right), 1.23-1.25(\mathrm{~m}$, 14H, 7 x CH 2 ), 1.59 (quin, $J=6.8,2 \mathrm{H}, \mathrm{CH}_{2}$ ), 2.35 (t, $J=7.5 \mathrm{~Hz}, 2 \mathrm{H}, \mathrm{CH}_{2}$ ), 4.24 ("t", $J=$ 4.9 Hz, 1H, H3'), 4.35-4.40 (m, 4H, H2',4',5',5"), 5.95 (d, J=4.1 Hz, 1H, H1'), 6.40 (dd, J = 3.3, 1.8 Hz, 1H, furan), 6.97 (d, $J=3.2 \mathrm{~Hz}, 1 \mathrm{H}$, furan), 7.27 ("s", 1H, furan), 7.96 (s, 1H, H6), 9.89 (s, 1H, NH); HRMS calcd for $\mathrm{C}_{24} \mathrm{H}_{35} \mathrm{~N}_{2} \mathrm{O}_{8}[\mathrm{M}+\mathrm{H}]^{+} 479.2388$, found 479.2397

5'-O-Undecanoyl-5-(5-heptylfur-2-yl)uridine (120). Treatment of 118 (27 mg, 0.05 mmol) with 2-heptylfurane (96 $\mu \mathrm{L}, 83 \mathrm{mg}, 0.5 \mathrm{mmol}$ ) by Procedure B (column chromatography; hexane/EtOAc, 30:70) gave $120(13 \mathrm{mg}, 44 \%):{ }^{1} \mathrm{H}$ NMR (DMSO- $\left.d_{6}\right) \delta$ 0.82-0.87 (m, 6H, $2 \times \mathrm{CH}_{3}$ ), 1.18-1.30 (m, 22H, $11 \times \mathrm{CH}_{2}$ ), 1.48 (quin, $J=6.9,2 \mathrm{H}, \mathrm{CH}_{2}$ ), 1.58 (quin, $\left.J=7.2,2 \mathrm{H}, \mathrm{CH}_{2}\right), 2.22-2.37\left(\mathrm{~m}, 2 \mathrm{H}, \mathrm{CH}_{2}\right), 2.58\left(\mathrm{t}, J=7.5 \mathrm{~Hz}, 2 \mathrm{H}, \mathrm{CH}_{2}\right), 3.95$ $\left(\mathrm{q}, J=5.0 \mathrm{~Hz}, 1 \mathrm{H}, \mathrm{H} 3^{\prime}\right), 4.08-4.13\left(\mathrm{~m}, 2 \mathrm{H}, \mathrm{H} 2^{\prime}, 4^{\prime}\right), 4.22\left(\mathrm{dd}, J=12.5,2.2 \mathrm{~Hz}, 1 \mathrm{H}, \mathrm{H}^{\prime}\right)$, $4.30\left(\mathrm{dd}, J=12.5,5.6 \mathrm{~Hz}, 1 \mathrm{H}, \mathrm{H} 5^{\prime \prime}\right), 5.32$ (d, $\left.J=5.9 \mathrm{~Hz}, 1 \mathrm{H}, 3^{\prime}-\mathrm{OH}\right), 5.54(\mathrm{~d}, J=5.0 \mathrm{~Hz}$, $\left.1 \mathrm{H}, 2^{\prime}-\mathrm{OH}\right), 5.82(\mathrm{~d}, J=5.3 \mathrm{~Hz}, 1 \mathrm{H}, \mathrm{H} 1$ '), $6.14(\mathrm{~d}, J=3.4 \mathrm{~Hz}, 1 \mathrm{H}$, furan), 6.77 (d, $J=3.7$ 
$\mathrm{Hz}, 1 \mathrm{H}$, furan $), 7.78$ (s, 1H, H6), $11.68(\mathrm{~s}, 1 \mathrm{H}, \mathrm{NH}) ;{ }^{13} \mathrm{C}$ NMR (DMSO-d $\left.d_{6}\right) \delta 13.87\left(\mathrm{CH}_{3}\right)$, $13.90\left(\mathrm{CH}_{3}\right), 22.0,24.4,27.3,27.4,28.35,28.37,28.58,28.61,28.8,28.9,31.18,31.23$, $33.2\left(\mathrm{CH}_{2}\right), 63.4\left(\mathrm{C}^{\prime}\right), 69.9\left(\mathrm{C}^{\prime}\right), 73.3\left(\mathrm{C}^{\prime}\right), 81.5\left(\mathrm{C}^{\prime}\right), 88.9\left(\mathrm{C} 1{ }^{\prime}\right), 101.1(\mathrm{C} 5), 106.9$ (furan), 109.2 (furan), 132.8 (C6), 144.3 (furan), 149.5 (furan), 154.7 (C2), 160.0 (C4), 172.6 $(\mathrm{C}=\mathrm{O})$; HRMS calcd for $\mathrm{C}_{31} \mathrm{H}_{49} \mathrm{~N}_{2} \mathrm{O}_{8}[\mathrm{M}+\mathrm{H}]^{+}$577.3483, found 577.3509

\subsection{Polymerase-catalyzed synthesis of azidomethyl-modified DNA \\ Materials of enzymatic reactions}

All DNA primers and templates were synthesized by Integrated DNA Technologies (Coralville, IA). The radionucleotides $\left[\gamma^{3}{ }^{32} \mathrm{P}\right]$ ATP $(6000 \mathrm{mCi} / \mathrm{mmol})$ was purchased from MP biomedicals Inc. (Santa Ana, CA). T4 polynucleotide kinase and deoxynucleoside 5'triphosphates (dNTPs) were purchased from Thermo Scientific (Pittsburgh, PA). Micro Bio-Spin TM 6 Columns were from Bio-Rad (Hercules, CA). All other chemicals were from Thermo Scientific (Pittsburgh, PA) and Sigma-Aldrich (St. Louis, MO). Purified human DNA polymerase $\beta$ (pol $\beta$ ), flap endonuclease 1 (FEN1) and DNA ligase I (LIG I) were purified according to the procedures described previously. ${ }^{151,152}$ The Klenow fragment of E. Coli DNA polymerase I (Pol I) was purchased from New England Biolabs (Ipswitch, MA).

\section{Oligonucleotide substrates}

Substrates with an upstream primer annealed to the template strand were designated as open template substrates. The substrates were made by annealing an upstream primer (31nt) with the template strand (71 nt) at a molar ratio of $1: 3$. The substrate containing onenucleotide gap were made by annealing an upstream primer and downstream primer (Table 12, Downstream primer 1) with the template strand at the molar ratio of 1:3:3. The open 
template and one-nucleotide gap substrates were employed to mimic the intermediates formed during DNA replication. The substrate containing one-nucleotide gap with a 5'-sugar at the downstream strand were made by annealing an upstream primer, a downstream primer with a 5'-tetrahydrofuran (THF), an analogue of a sugar (Table 12, Downstream primer 2) with the template strand at a molar ratio of 1:3:3. Substrates were labeled with $\gamma^{32} \mathrm{P}$ at the $5^{\prime}$-end of the upstream primers. Template 1 was designed for incorporation of AmdUTP 20, whereas Template 2 was for AmdCTP 74.

Table 12. Oligonucleotide Sequences of primers and templates for polymerase-catalyzed synthesis of azido-modified DNA

\begin{tabular}{|c|c|c|}
\hline Oligonucleotide & nt & Sequence (5'-3') \\
\hline Upstream primer & 31 & GCA GTC CTC TAG TCG TAG TAG CAG ATC ATC A \\
\hline $\begin{array}{l}\text { Downstream } \\
\text { primer } 1\end{array}$ & 39 & CAA CCG GCA TTA GGT GTA GTA GCT AGA CTT ACT CAT TGC \\
\hline $\begin{array}{l}\text { Downstream } \\
\text { primer } 2\end{array}$ & 39 & THF CAA CCG GCA TTA GGT GTA GTA GCT AGA CTT ACT CAT TGC \\
\hline Template 1 & 71 & $\begin{array}{l}\text { GCA ATG AGT AAG TCT AGC TAC TAC ACC TAA TGC CGG TTG ATG } \\
\text { ATG ATC TGC TAC TAC GAC TAG AGG ACT GC }\end{array}$ \\
\hline Template 2 & 71 & $\begin{array}{l}\text { GCA ATG AGT AAG TCT AGC TAC TAC ACC TAA TGC CGG TTG GTG } \\
\text { ATG ATC TGC TAC TAC GAC TAG AGG ACT GC }\end{array}$ \\
\hline
\end{tabular}

Note: THF denotes tetrahydrofuran, an abasic sugar analogue.

\section{Enzymatic activity assay and BER reconstitution assay}

Nucleotides incorporation by DNA polymerases was performed by incubating different concentrations of pol $\beta$ or Klenow fragment with $25 \mathrm{nM}{ }^{32} \mathrm{P}$ labeled substrates at $37^{\circ} \mathrm{C}$ for $15 \mathrm{~min}$. The enzymatic reactions were assembled with $50 \mu \mathrm{M}$ AmdUTP 20 alone or with $50 \mu \mathrm{M}$ AmdUTP 20 along with $50 \mu \mathrm{M}$ dATP, $50 \mu \mathrm{M}$ dCTP and $50 \mu \mathrm{M}$ dGTP. To examine if an AmdUTP residue can be directly incorporated into a double-strand DNA through DNA lagging strand maturation and base excision repair (BER) via ligation, ligation reactions with the gapped substrates were performed in the presence of various concentrations of pol $\beta$ or Klenow fragment and 10 nM LIG I along with $50 \mu \mathrm{M}$ AmdUTP 
20 and $50 \mu \mathrm{M}$ dATP, $50 \mu \mathrm{M}$ dCTP and $50 \mu \mathrm{M}$ dGTP. BER was reconstituted by incubating $25 \mathrm{nM}$ substrate containing a 5'-THF with 5 nM FEN1, 10 nM LIG I, 10 nM and 25 nM of pol $\beta$ in the presence of $50 \mu \mathrm{M}$ AmdUTP, $50 \mu \mathrm{M}$ dATP, $50 \mu \mathrm{M}$ dCTP and $50 \mu \mathrm{M}$ dGTP. Reaction mixtures $(20 \mu \mathrm{l})$ contained $5 \mathrm{mM} \mathrm{Mg}^{2+}, 50 \mathrm{mM}$ Tris- $\mathrm{HCl}(\mathrm{pH} 7.5), 50 \mathrm{mM} \mathrm{KCl}$, $0.1 \mathrm{mg} / \mathrm{ml} \mathrm{BSA,} 0.1 \mathrm{mM}$ EDTA and $0.01 \% \mathrm{NP}-40$. For the reactions that contained LIG I, $2 \mathrm{mM}$ ATP were included in the reaction mixtures. Reactions were terminated with $20 \mu \mathrm{l}$ 2X stopping buffer contained $95 \%$ formamide and 10 mM EDTA. Reaction mixtures were subsequently denatured at $95{ }^{\circ} \mathrm{C}$ for $10 \mathrm{~min}$. DNA synthesis and ligation products were separated in a $15 \%$ urea denaturing polyacrylamide gel and were detected by Pharos FX Plus PhosphorImager (Bio-Rad Laboratory, CA).

Incorporation of a AmdCTP $\mathbf{7 4}$ by pol $\beta$ was measured by incubating various concentrations of pol $\beta(1 \mathrm{nM}, 5 \mathrm{nM}, 10 \mathrm{nM}$ and $25 \mathrm{nM})$ with $25 \mathrm{nM}$ open template substrate, one-nucleotide gap substrate and one-nucleotide gap substrate containing a 5'-THF along with $50 \mu \mathrm{M}$ of a AmdCTP. Substrates were ${ }^{32} \mathrm{P}$-labeled at the 5'-end of the upstream primer.

\subsection{ESR studies of aminyl radical and its conversion to iminyl radical}

\section{Sample preparation and methods}

As per the well-established methodologies, ${ }^{42,73,153}$ transparent glassy samples of AmdU 18, AmdC 42, AvdU 21, and AvdC 43 were prepared. Subsequently, $\gamma$-irradiation and ESR spectral analyses of these samples were performed.

Compounds purchased: Lithium chloride ( $\mathrm{LiCl}$ ) (ultra-dry, 99.995\% (metals basis)) was obtained from Alfa Aesar (Ward Hill, MA, USA). Deuterium oxide ( $\left.\mathrm{D}_{2} \mathrm{O}\right)(99.9$ atom \% 
D) was purchased from Aldrich Chemical Company Inc. (Milwaukee, WI, USA). All compounds were used without further purification.

\section{Glassy sample preparation:}

(i) Preparation of homogeneous solutions: First, homogeneous solution was prepared by dissolving ca. 2.2 to $2.4 \mathrm{mg} / \mathrm{mL}$ of a compound (e.g., 18) in either $7.5 \mathrm{M} \mathrm{LiCl}$ in $\mathrm{D}_{2} \mathrm{O}$. The native $\mathrm{pH}$ of $7.5 \mathrm{M} \mathrm{LiCl}$ in $\mathrm{D}_{2} \mathrm{O}$ is ca. 5 and $\mathrm{pH}$ of these solutions was not adjusted. $^{73}$

(ii) Preparation of glassy samples and their storage: Homogenous solutions of azido compounds were thoroughly bubbled with nitrogen gas. Subsequently, those solutions were immediately drawn into $4 \mathrm{~mm}$ Suprasil quartz tubes (Catalog no. 734-PQ-8, WILMAD Glass Co., Inc., Buena, NJ, USA). Thereafter, the quartz tubes containing these solutions were rapidly immersed in liquid nitrogen $(77 \mathrm{~K})$. Owing to rapid cooling at $77 \mathrm{~K}$, the homogeneous liquid solutions formed transparent homogeneous glassy solutions. Subsequently, these transparent homogeneous glassy solutions of azido compounds were $\gamma$-irradiated at $77 \mathrm{~K}$ and were subjected to progressive annealing experiments along with ESR spectral studies. All glassy samples were stored in the dark at $77 \mathrm{~K}$ in Teflon containers prior to and after $\gamma$-irradiation.

$\gamma$-Irradiation of glassy samples and their storage: As per our well-established methodology of $\gamma$-irradiation of glassy samples of DNA and RNA-models, ${ }^{42,73,153}$ the glassy samples were $\gamma\left({ }^{60} \mathrm{Co}\right)$-irradiated (absorbed dose $=375-500 \mathrm{~Gy}(1.5$ to $2 \mathrm{~h}$ )) at $77 \mathrm{~K}$ and stored at $77 \mathrm{~K}$ in Teflon containers in the dark. Owing to 2.2 to $2.4 \mathrm{mg}$ per $\mathrm{mL}$ of 7.5 $\mathrm{M} \mathrm{LiCl}$ glass $\left(\mathrm{D}_{2} \mathrm{O}\right)$ and as per our previous work with $3^{\prime}-\mathrm{AZT}^{42}$ and azidopentofuranoses, ${ }^{73}$ the radiation-produced prehydrated electrons in the glass ${ }^{153}$ are 
scavenged by the azide solute and $\mathrm{Cl}_{2}{ }^{-}$is formed owing to scavenging of radiationinduced holes by the matrix $(7.5 \mathrm{M} \mathrm{LiCl}){ }^{42,73,153}$

Annealing of glassy samples: As per our previous studies, ${ }^{42,73,153}$ a variable temperature assembly that passed liquid nitrogen cooled dry nitrogen gas past a thermister and over the glassy sample was employed for annealing. Stepwise (either 5 K or $10 \mathrm{~K}$ step) annealing of each glassy sample was conducted in the range $(140-170) \mathrm{K}$ for 15 min. The matrix radical, $\mathrm{Cl}_{2} \bullet^{-}$, did not react with sample. ${ }^{42,73,153}$ Thus, by employing ESR spectroscopy, we were able to study directly the formation of $\mathrm{RNH} \bullet$ via reaction of radiation-produced prehydrated electron with azido compounds and subsequent reactions of RNH•.

Electron Spin Resonance: As per ongoing studies in our laboratory, ${ }^{42,73,153}$ we used a Varian Century Series X-band $(9.3 \mathrm{GHz})$ ESR spectrometer with an E-4531 dual cavity, 9-inch magnet, and a $200 \mathrm{~mW}$ Klystron. For the field calibration, Fremy's salt ( $g_{\text {center }}=$ 2.0056, $\boldsymbol{A}(\mathrm{N})=13.09 \mathrm{G})$ was employed. All ESR spectra were recorded at $77 \mathrm{~K}$ and at 45 $\mathrm{dB}(6.3 \mu \mathrm{W})$ as well as $40 \mathrm{~dB}(20 \mu \mathrm{W})$. We note here that recording of ESR spectra at 77 K maximizes the signal height and allows for comparison of signal intensities. ${ }^{73}$

Employing the Bruker programs (WIN-EPR and SimFonia) and our ongoing studies on DNA and RNA-radicals, ${ }^{73,153}$ anisotropic simulations of experimentally recorded ESR spectra were carried out. The ESR parameters (e.g., hyperfine coupling constant (HFCC) values, linwidth, etc.) were adjusted to obtain the "best fit" simulated spectrum that matched the experimental ESR spectrum well (see our previous works ${ }^{42,73,153}$ ). In addition, each ESR spectrum reported are obtained after subtraction of line components due to $\mathrm{Cl}_{2}{ }^{-}$.

Method of theoretical Calculations: Employing optimized geometries of radicals, energies of radicals and hyperfine coupling constant (HFCC) values were calculated using 
DFT/B3LYP/6-31+G** method in Gaussian 09. Theoretically predicted HFCC values obtained employing B3LYP/6-31+G** method agree well with those obtained using experiment. ${ }^{73,154} \mathrm{Jmol}$ molecular modeling freeware was used to plot optimized molecular structures. ${ }^{155,129}$

\subsection{Radiosensitizing effect of 5-azidomethyl and 5-azidovinyl pyrimidine nucleosides in aerobic and hypoxic cells}

The radiation response of cells in the presence of azido-modified nucleosides in vitro was examined using exponentially growing monolayers in Perma-nox Contour dishes (Lux Scientific). ${ }^{156}$ Clonogenic assay was used to do cell death assay. EMT6 mouse cells were allowed to grow for 1 day to produce cultures in mid exponential growth. For the tests in aerobic cells, the cultures were treated with $100 \mu \mathrm{M}$ azido compounds in DMSO in small volumes or vehicles for $48 \mathrm{~h}$. For the test in hypoxic cells, after the $44 \mathrm{~h}$ treatment under aerobic condition, hypoxia was produced by placing uncovered dishes, containing the monolayers overlaid with $2 \mathrm{~mL}$ of medium containing azido compounds or vehicle, into a pressure vessel and gassing the vessel at $37{ }^{\circ} \mathrm{C}$ with a humidified mixture of $95 \% \mathrm{~N}_{2} / 5 \%$ $\mathrm{CO}_{2}$ for $4 \mathrm{~h}$. The radiosensitizing effect tests were divided into following groups: (a) Control: without azido compounds and without irradiation treatment under aerobic or hypoxic condition. (b) Drug: the cultures were treated with $100 \mu \mathrm{M}$ azido compounds in small volumes for $44 \mathrm{~h}$ under aerobic followed by $4 \mathrm{~h}$ under aerobic or hypoxic condition. (c) Drug and irradiation in aerobic cells: the cultures were treated with $100 \mu \mathrm{M}$ azido compounds in small volumes or vehicles for $48 \mathrm{~h}$ and irradiated with 7.5 Gy radiation during the final few minutes of the $48 \mathrm{~h}$ incubation. Cells were irradiated with $320 \mathrm{kV}$ X-rays produced by an XRAD irradiator (Precision X-ray, Branford CT, USA) at $12.5 \mathrm{~mA}$, 
$2 \mathrm{~mm} \mathrm{Al}$ filtration, and a dose rate of $2.4 \mathrm{~Gy} / \mathrm{min}$. (d) Drug and irradiation in hypoxic cells: the cultures were treated with $100 \mu \mathrm{M}$ azido compounds in small volumes or vehicles for $44 \mathrm{~h}$ under aerobic condition and then $4 \mathrm{~h}$ under hypoxia condition. Cultures were irradiated with $7.5 \mathrm{GY}$ radiation. Cells were irradiated with $320 \mathrm{kV}$ X-rays produced by an XRAD irradiator at $12.5 \mathrm{~mA}, 2 \mathrm{~mm} \mathrm{Al}$ filtration, and a dose rate of $1.9 \mathrm{~Gy} / \mathrm{min}$.

\subsection{Fluorescent properties of triazolyl nucleosides}

The fluorescent properties of the four $N$-unsubstituted triazolyl nucleosides (8-TrzdA 46, 8-TrzdG 47, 5-TrzdC 48, and 5-TrzdU 39) and their lipophilic analogues (diTBDMS8-TrzdA 88, diAc-5-TrzdU 84, and diAc-5-TrzdC 83) were determined following the general procedure reported in the paper reported from our group. ${ }^{51}$ Triazoles samples were tested with varying concentration. The whose absorbance at the excitation wavelength did not exceed 0.1 absorbance units. For determination of quantum yield $\Phi_{\mathrm{F}}$, the absorbance of the sample solution was kept below 0.06. Quinine sulfate $\left(\Phi_{\mathrm{F}}=0.55\right)$ in $100 \mathrm{mM} \mathrm{H}_{2} \mathrm{SO}_{4}$ was used as reference standard to quantify the quantum yield. All the triazoles were soluble enough in the methanol and thus were prepared in HPLC grade methanol. The test was performed in a $2 \times 10 \mathrm{~mm}$ quartz cuvette at room temperature. Absorption spectra were measured using Cary 100Bio UV-Visible Spectrophotometer. Steady-state excitation and emission spectra were investigated on a PC1 spectrofluorometer with bandwidth and slit width for ex/em set at $2 \mathrm{~nm}$. Frequency-domain fluorescence lifetime were measured using a ChronosFD spectrofluorometer. Sample solutions were excited using a frequency modulated $280 \mathrm{~nm}$ LED. The emission was gathered with a $305 \mathrm{~nm}$ long-pass filter (Andover). 2,5-diphenyloxazole ( $\tau=1.4 \mathrm{~ns}$ ) solution in EtOH was employed as a lifetime reference. A multiple-exponential decay model employing GlobalsWE software were used 
to fit the modulation phase data. The residual and $\chi^{2}$ parameter were employed as criteria for goodness of fit.

\subsection{Cell microscopy studies of triazoles}

\subsubsection{Using primary mouse astrocytes}

Primary mouse astrocytes were plated on coverslips and acclimated for 24 hours. $1 \mathrm{M}$ stock solution of compounds were prepared in DMSO. The cells were treated with the vehicle (0.05\% DMSO) or $10 \mathrm{uM}, 100 \mathrm{uM}, 1 \mathrm{mM}$ of compounds (each with $0.05 \%$ DMSO) in 10\% FBS P-S DMEM F-12 media for 24 hours. The cells were mounted using Prolong Mounting Medium. Nail polish was used to seal. The live cells were imaged using FV10i Confocal Laser Scanning Microscope from Olympus (10x \& 60x objectives with 405 laser and phase contrast).

\subsubsection{Using mouse pre-adipocytes transfected with pMX-puro-GFP cDNA Construction and cell transfection.}

cDNA of GFP was cloned into the pMX-puro vector at EcoRI and NotI restriction sites and plasmid DNA was purified according to the QIAprep Spin Miniprep Kit. The pMX-puro-GFP vector was then transfected into the Plat-A (Cell Biolabs, INC. \# RV102) monolayer using Lipofectamine ${ }^{\circledR} 2000$ Transfection Reagent (Thermo Fisher Scientific). Plat-A cells were grown in Plat-A growth media (1\% penicillin/streptomycin, $1 \mu \mathrm{g} / \mathrm{mL}$ puromycin, $10 \mu \mathrm{g} / \mathrm{mL}$ blasticidin and $10 \%$ fetal bovine serum in Dulbecco's modified Eagle's medium (DMEM)) and incubated under a humid atmosphere containing $5 \% \mathrm{CO}_{2}$ under $37^{\circ} \mathrm{C} .48 \mathrm{~h}$ after transfection, the supernatant of Plat-A media was filtered with $0.2 \mathrm{~nm}$ filter and applied to $90 \%$ confluent 3T3-L1 cells grown in 3T3-L1 growth media (1\% penicillin/streptomycin, 1\% L-glutamine and 10\% FBS in DMEM). After 24h 
of incubation, 3T3-L1 cells been transfected with pMX-puro-GFP will be selected with the 3T3-L1 selection media $(5 \mu \mathrm{g} / \mathrm{mL}$ puromycin in 3T3-L1 growth media).

Confocal Microscopy. 3T3-L1 mouse pre-adipocytes (Zen-bio \#SP-L1-F) that have been transfected with pMX-puro-GFP were seeded on glass coverslips at $1.0 \times 10^{5}$ per 3.8 $\mathrm{cm}^{2}$ well for 24 hours in 3T3-L1 selection media. Stock solution of 8-TrzdA 46 and 5-TrzdU 39 were prepared in DMSO. Then the cells were treated with the vehicle $(0.05 \%$ DMSO), $200 \mathrm{uM}$ of 8-TrzdA, or $200 \mathrm{uM}$ of 5-TrzdU (with 0.05\% DMSO) in 3T3-L1 selection media for 24 hours. After the $24 \mathrm{~h}$ incubation, cells were washed with PBS and fixed in 4\% paraformaldehyde for 20 minutes. Fixed cells were mounted with ProLongTM Gold Antifade Mountant (Thermo Fisher Scientific) and observed under the Olympus FV 1200 confocal microscope. $\mathrm{Ex} / \mathrm{Em}=473 / 519 \mathrm{~nm}$ were used for imaging of GFP and Ex/Em $=405 / 461 \mathrm{~nm}$ were used for imaging of the triazoles, respectively.

\subsection{Proliferation Assays}

Human cervical carcinoma (HeLa) cells were seeded in 96-well plates at 15,000 cells/well in the presence of 5-fold dilutions of the compounds. After 4 days of incubation, the cells were trypsinized and counted by means of a Coulter counter (Analis, Belgium). Suspension cells (Mouse leukemia L1210 and human lymphoid CEM cells) were seeded in 96-well plates at 60,000 cells/well in the presence of the compounds. L1210 and CEM cells were allowed to proliferate for $48 \mathrm{~h}$ or $96 \mathrm{~h}$, respectively and then counted. The $50 \%$ inhibitory concentration $\left(\mathrm{IC}_{50}\right)$ was defined as the compound concentration required to reduce cell proliferation by $50 \%$. 


\subsection{Antiviral Assays}

The compounds were evaluated against the following viruses: herpes simplex virus type 1 (HSV-1) strain KOS, thymidine kinase-deficient (TK') HSV-1 KOS strain resistant to ACV $\left(A C V^{1}\right)$, herpes simplex virus type $2(\mathrm{HSV}-2)$ strain $\mathrm{G}$, varicella-zoster virus $(\mathrm{VZV})$ strain

Oka, TK ${ }^{-}$VZV strain 07-1, human cytomegalovirus (HCMV) strains AD-169 and Davis, vaccinia virus Lederle strain, respiratory syncytial virus (RSV) strain Long, vesicular stomatitis virus (VSV), Coxsackie B4, parainfluenza 3, influenza virus A (subtypes H1N1, H3N2), influenza virus B, Sindbis, reovirus-1, Punta Toro, human immunodeficiency virus type 1 strain IIIB and human immunodeficiency virus type 2 strain ROD. The antiviral, other than anti-HIV, assays were based on inhibition of virus-induced cytopathicity or plaque formation in human embryonic lung (HEL) fibroblasts, African green monkey cells (Vero), human epithelial cells (HeLa) or Madin-Darby canine kidney cells (MDCK). Confluent cell cultures in microtiter 96-well plates were inoculated with 100 CCID50 of virus $\left(1 \mathrm{CCID}_{50}\right.$ being the virus dose to infect $50 \%$ of the cell cultures) or with 20 or 100 plaque forming units (PFU) (VZV or HCMV) in the presence of varying concentrations of the test compounds. Viral cytopathicity or plaque formation was recorded as soon as it reached completion in the control virus-infected cell cultures that were not treated with the test compounds. Antiviral activity was expressed as the $\mathrm{EC}_{50}$ or compound concentration required to reduce virus-induced cytopathogenicity or viral plaque formation by $50 \%$. Cytotoxicity of the test compounds was expressed as the minimum cytotoxic concentration (MCC) or the compound concentration that caused a microscopically detectable alteration of cell morphology. 


\section{CONCLUSION}

In this dissertation, I explored the C5 azido-modified pyrimidine nucleosides (AmdU 18, AvdU 21, AmdC 42, and AvdC 43) as potential radiosensitizer under normoxic and hypoxic environment. I also synthesized 2-azido-2'-deoxyinosine (2- $\left.\mathrm{N}_{3} \mathrm{dI}, 44\right)$ for the sitespecific formation and characterization of the elusive 2'-deoxyguanosin-N2-yl radical $(\mathrm{dG}(\mathrm{N} 2-\mathrm{H}) \cdot, 45)$ to investigate the nucleic acid damage pathways induced by $\gamma$-radiolysis. Moreover, novel fluorescent $N$-unsubstituted 1,2,3-triazol-4-yl nucleosides (5-TrzdU 39, 8-TrzdA 46, 8-TrzdG 47, and 5-TrzdC 48) were designed and synthesized as potential tools for investigating the perturbations to nucleic acids.

Two classes of C5 azido-modified pyrimidine nucleosides were synthesized and explored as radiosensitizers. 5-Azidomethyl-2'-deoxyuridine (AmdU, 18) was prepared from thymidine and was converted to its cytosine counterpart (AmdC, 42). The 5-(1-azidovinyl)-2'-deoxyuridine (AvdU, 21) and 5-(1-azidovinyl)-2'-deoxycytidine (AvdC, 43) have been prepared by the regioselective Ag-catalyzed hydroazidation of the 5-ethynyl substrates with $\mathrm{TMSN}_{3}$. Using Yoshikawa protocol followed by coupling with pyrophosphate, the AmdU 18 and AmdC 43 were converted to their 5'-triphosphate, i.e. AmdUTP 20 and AmdCTP 74, which were enzymatically incorporated into DNA fragment during DNA replication and base excision repair (BER). $\gamma$-Irradiation-mediated prehydrated electrons formed in homogeneous aqueous glassy $(7.5 \mathrm{M} \mathrm{LiCl})$ systems in the absence of oxygen at $77 \mathrm{~K}$ led to site-specific formation of novel and neutral $\pi$-type aminyl radicals (RNH•) from AmdU 18, AmdC 42, AvdU 21, and AvdC 43. The ESR spectral studies and DFT calculations showed that $\mathrm{RNH} \bullet$ undergo facile conversion to thermodynamically more stable $\sigma$-type iminyl radicals, $\mathrm{R}=\mathrm{N} \bullet$. For AmdU 18 and AmdC 
42, conversion of aminyl $\mathrm{RNH} \bullet$ to iminyl radiacl $\mathrm{R}=\mathrm{N} \bullet$ was found to be bimolecular involving an $\alpha$-azidoalkyl radical as intermediate. On the other hand, aminyl radicals RNH• derived from AvdU 21 and AvdC 43 tautomerized to the iminyl radical $\mathrm{R}=\mathrm{N} \bullet$. Our work provides the first evidence for the formation of aminyl radical $\mathrm{RNH} \bullet$ attached to $\mathrm{C} 5$ position of azidopyrimidine nucleoside and its facile conversion to $\mathrm{R}=\mathrm{N} \bullet$ under a reductive environment. These aminyl and iminyl radicals can generate DNA damage via oxidative pathways. Owing to the high free radical scavenger concentrations in cells, the bimolecular conversion of the $\pi$-type $\mathrm{RNH} \bullet$ to $\sigma$-type iminyl radical from $\mathbf{1 8}$ and $\mathbf{4 2}$ should not take place. However, the facile unimolecular tautomerization of the $\pi$-type RNH• to $\sigma$-type iminyl radical from $\mathbf{2 1}$ and $\mathbf{4 3}$ should occur. Therefore, it is expected that the $\pi$-type RNH• from 18 and 42 should augment the radiation damage more effectively than the $\sigma$-type iminyl radical from 21 and $\mathbf{4 3}$, which was proved by the radiosensitizing effect tests. AmdU 18 showed radiosensitizing effect under both normoxic and hypoxic environment with SER $_{\text {SF7.5 }}$ of 4.57 and 4.10, respectively. Other azido-modified nucleosides tested showed lower radiosensitizing effect with SER SF7.5 of 1.35 for AmdC 42 under hypoxic cells and 1.37 for AvdC 43 under aerobic cells.

To explore the generation and reactivity of 2'-deoxyguanosin-N2-yl radical $(\mathrm{dG}(\mathrm{N} 2-\mathrm{H}) \bullet)$ postulated to be generated during the ambidient reactivity of the guanine moiety in 2'-deoxyguanosine towards hydroxyl radicals (HO•), I prepared 2-azido-2'deoxyinosine $\left(2-\mathrm{N}_{3} \mathrm{dI}, \mathbf{4 4}\right)$ serving as convenient substrate to generate site-specific elusive guaninyl aminyl radical. Using ESR, the structure of guaninyl aminyl radical and its subsequent reactions as well as DNA-hole transfer processes were investigated to understand nucleic acid damage pathways induced by $\gamma$-radiolysis. I synthesized the 
2-azido-2'-deoxyinosine $\mathbf{4 4}$ by conversion of 2-amino group in the protected 2'-deoxyguanosine into 2-azido group via diazotization reaction with tert-butyl nitrite followed by nucleophilic displacement with azide and deprotection.

The fluorescent $N$-unsubstituted 1,2,3-triazol-4-yl analogues of the four natural bases of DNA (i.e. 5-TrzdU 39, 5-TrzdC 48, 8-TrzdA 46, and 8-TrzdG 47) have been synthesized by metal-catalyzed reactions between the 5-ethynylpyrimidine or 8-ethynylpurine nucleosides with trimethylsilyl azide $\left(\mathrm{TMSN}_{3}\right)$. CuI catalyzed cycloaddition $\left(\mathrm{DMF} / \mathrm{H}_{2} \mathrm{O}\right.$, $90{ }^{\circ} \mathrm{C}, 5 \mathrm{~h}$ ) gave $1,2,3$-triazoles as sole products however in low to moderate yield (10\% for 5 -TrzdC to $50 \%$ for 5 -TrzdU) due to the oxidation of $\mathrm{Cu}$ (I) to $\mathrm{Cu}$ (II) during the reaction. Combination of $\mathrm{CuSO}_{4} /$ sodium ascorbate gave triazoles in improved yields (38\% for 5 -TrzdC to $52 \%$ for 5-TrzdU). Interestingly, $\mathrm{Ag}_{2} \mathrm{CO}_{3}$ catalyzed cycloaddition (DMF, 2 eq. $\mathrm{H}_{2} \mathrm{O}, 80{ }^{\circ} \mathrm{C}, 1 \mathrm{~h}$ ) of 8 -ethynylpurine nucleosides with $\mathrm{TMSN}_{3}$ produced 8-triazolylpurines as sole products in good yields (8-TrzdG, 55\%), while analogous cycloadditions of 5-ethynylpyrimidine nucleosides produced mixture of 5-triazolylpyrimidine nucleosides (5-TrzdC, 7\%) and the corresponding 5-(1-azidovinyl)pyrimidine byproducts (5-(1-azidovinyl)-2'-deoxycytidine, 48\%). The novel $N$-unsubstituted 1,2,3-triazol-4-yl nucleoside analogues showed excellent fluorescent properties in $\mathrm{MeOH}$. The 8-purine analogue 8-TrzdA 46 exhibits the highest quantum yield of $44 \%$ while the 8 -TrzdG 47 had quantum yield of $9 \%$. In contrast, the 5-pyrimidine analogues 5-TrzdU 39 and 5-TrzdC 48 showed a large Stokes shift of $\sim 110$ $\mathrm{nm}$ with the maximum emission approximately at $408 \mathrm{~nm}$ and quantum yield of $2 \%$. The fluorescent triazoles could enter living cells (primary mouse astrocytes and pre-adipocytes transfected with PMX-puro-GFG) and show fluorescence in the cytosol. 
Transition metal-catalyzed halosulfonylation of 5-ethynyl uracil nucleosides provided (E)-5-(1-chloro-2-tosylvinyl)uridines. Tetrabutylammonium fluoride-mediated direct C-H arylation of 5-iodouracil nucleosides with furan or 2-heptylfuran gave 5-furyl-substituted nucleosides without the necessity of using the organometallic substrates. These two classes of 5-substituted uracil nucleosides as well their corresponding ester derivatives were tested against a broad range of DNA and RNA viruses and the human immunodeficiency virus (HIV). The 3',5'-di-O-acetyl-5-(E)-(1-chloro-2-tosylvinyl)-2'-deoxyuridine 122 inhibited the growth of L1210, CEM and HeLa cancer cells in the lower micromolar range. The ( $\beta$-chloro)-vinyl sulfone 122 and 5-(5-heptylfur-2-yl)-2'-deoxyuridine 108 displayed micromolar activity against varicella zoster virus (VZV). The 5-(5-heptylfur-2-yl) analog 108 and its 3',5'-di-O-acetyl-protected derivative showed similar activity against the cytomegalovirus (CMV). The 5-(fur-2-yl) derivatives of 2'-deoxyuridine and arabino-uridine inhibited the replication of herpes simplex virus (HSV) $\mathrm{TK}^{+}$strains while the 5-(5-heptylfur-2-yl) derivative $\mathbf{1 0 8}$ displayed antiviral activity against the parainfluenza virus. 


\section{REFERENCES}

(1) American Cancer Society. Cancer Facts \& Figures 2018

(2) Jordheim, L. P.; Durantel, D.; Zoulim, F.; Dumontet, C. Nat. Rev. Drug Discov. 2013, 12, 447-464.

(3) Lawrence, T. S.; Blackstock, A. W.; McGinn, C. Semin. Radiat. Oncol. 2003, 13, 13-21.

(4) Barton, M. B.; Jacob, S.; Shafiq, J.; Wong, K.; Thompson, S. R.; Hanna, T. P.; Delaney, G. P. Radiother. Oncol. 2014, 112, 140-144.

(5) Polgár, C.; Ott, O. J.; Hildebrandt, G.; Kauer-Dorner, D.; Knauerhase, H.; Major, T.; Lyczek, J.; Guinot, J. L.; Dunst, J.; Miguelez, C. G.; Slampa, P.; Allgäuer, M.; Lössl, K.; Polat, B.; Kovács, G.; Fischedick, A.-R.; Fietkau, R.; Resch, A.; Kulik, A.; Arribas, L.; Niehoff, P.; Guedea, F.; Schlamann, A.; Pötter, R.; Gall, C.; Uter, W.; Strnad, V. Lancet Oncol. 2017, 18, 259-268.

(6) Types of Cancer Treatment. NCI/NIH: https://www.cancer.gov/aboutcancer/treatment/types

(7) Schurmann, R.; Vogel, S.; Ebel, K.; Bald, I. Chemistry 2018.

(8) Wang, H.; Mu, X.; He, H.; Zhang, X.-D. Trends Pharmacol. Sci. 2018, 39, 24-48.

(9) Sonntag, C. v. Free-radical-induced DNA Damage and Its Repair; Springer-Verlag: Springer-Verlag: Berlin, 2006.

(10) Nguyen, J.; Ma, Y.; Luo, T.; Bristow, R. G.; Jaffray, D. A.; Lu, Q.-B. Proc. Natl. Acad. Sci. U. S. A. 2011, 108, 11778-11783.

(11) Jones, G. D. D.; Symonds, P. Molecular, cellular and tissue effects of radiotherapy. https://radiologykey.com/molecular-cellular-and-tissue-effects-of-radiotherapy/.

(12) Hatzi, V. I.; Laskaratou, D. A.; Mavragani, I. V.; Nikitaki, Z.; Mangelis, A.; Panayiotidis, M. I.; Pantelias, G. E.; Terzoudi, G. I.; Georgakilas, A. G. Cancer Lett. 2015, 356, 34-42.

(13) Sridharan, D. M.; Asaithamby, A.; Bailey, S. M.; Costes, S. V.; Doetsch, P. W.; Dynan, W. S.; Kronenberg, A.; Rithidech, K. N.; Saha, J.; Snijders, A. M.; Werner, E.; Wiese, C.; Cucinotta, F. A.; Pluth, J. M. Radiat. Res. 2015, 183, 1-26.

(14) Roos, W. P.; Kaina, B. Trends Mol. Med. 2006, 12, 440-450. 
(15) Markus, L.; Jürgen, K. Int. J. Cancer 2006, 118, 2652-2656.

(16) Wardman, P. Clin. Oncol. 2007, 19, 397-417.

(17) Rak, J.; Chomicz, L.; Wiczk, J.; Westphal, K.; Zdrowowicz, M.; Wityk, P.; Żyndul, M.; Makurat, S.; Golon, Ł. J. Phys. Chem. B 2015, 119, 8227-8238.

(18) Baccarelli, I.; Bald, I.; Gianturco, F. A.; Illenberger, E.; Kopyra, J. Phys. Rep. 2011, $508,1-44$.

(19) Lehnert, S. Radiosensitizers and Radiochemotherapy in the Treatment of Cancer; CRC Press, Taylor \& Francis Group: Boca Raton 2015, 93-118.

(20) Rich, T. A. Oncology (Williston Park) 1999, 13, 131-134.

(21) Whittington, R.; Neuberg, D.; Tester, W. J.; 3rd, A. B. B.; Haller, D. G. J. Clin. Oncol. 1995, 13, 227-232.

(22) Sawada, N.; Ishikawa, T.; Sekiguchi, F.; Tanaka, Y.; Ishitsuka, H. Clin. Cancer Res. 1999, 5, 2948-2953.

(23) British national formulary : BNF 69 (69 ed.). British Medical Association. 2015. pp. 585, 588. ISBN 9780857111562

(24) Shewach, D. S.; Hahn, T. M.; Chang, E.; Hertel, L. W.; Lawrence, T. S. Cancer Res. 1994, 54, 3218-3223.

(25) Ma, P. a.; Xiao, H.; Li, C.; Dai, Y.; Cheng, Z.; Hou, Z.; Lin, J. Mater. Today 2015, $18,554-564$.

(26) Richmond, R. C. Radiat. Res. 1984, 99, 596-608.

(27) Yang, L.-X.; Douple, E. B.; Wang, H.-j. Int. J. Radiat. Oncol. Biol. Phys. 1995, 33, 641-646.

(28) Amorino, G. P.; Freeman, M. L.; Carbone, D. P.; Lebwohl, D. E.; Choy, H. Int. J. Radiat. Oncol. Biol. Phys. 1999, 44, 399-405.

(29) Dewhirst, M. W. Radiat. Res. 2009, 172, 653-665.

(30) Brown, J. M.; Wilson, W. R. Nat. Rev. Cancer 2004, 4, 437-447.

(31) Wilson, W. R.; Hay, M. P. Nat. Rev. Cancer 2011, 11, 393-410.

(32) Thomlinson, R. H.; Gray, L. H. Br. J. Cancer 1955, 9, 539-549. 
(33) Peters, K. B.; Brown, J. M. Cancer Res. 2002, 62, 5248-5253.

(34) Ahn, G. O.; Ware, D. C.; Denny, W. A.; Wilson, W. R. Radiat. Res. 2004, 162, 315-325.

(35) Kriste, A. G.; Tercel, M.; Anderson, R. F.; Ferry, D. M.; Wilson, W. R. Radiat. Res. 2002, 158, 753-762.

(36) Shibamoto, Y.; Zhou, L.; Hatta, H.; Mori, M.; Nishimoto, S.-i. Jpn. J. Cancer Res. 2000, 91, 433-438.

(37) Brase, S.; Gil, C.; Knepper, K.; Zimmermann, V. Angew. Chem. Int. Ed. Engl. 2005, $44,5188-5240$.

(38) Chen, Y.; Kamlet, A. S.; Steinman, J. B.; Liu, D. R. Nat. Chem. 2011, 3, 146-153.

(39) Amblard, F.; Cho, J. H.; Schinazi, R. F. Chem. Rev. (Washington, DC, U. S.) 2009, 109, 4207-4220.

(40) Neef, A. B.; Luedtke, N. W. ChemBioChem 2014, 15, 789-793.

(41) Shiau, G. T.; Schinazi, R. F.; Chen, M. S.; Prusoff, W. H. J. Med. Chem. 1980, 23, 127-133.

(42) Adhikary, A.; Khanduri, D.; Pottiboyina, V.; Rice, C. T.; Sevilla, M. D. J. Phys. Chem. B 2010, 114, 9289-9299.

(43) Prescher, J. A.; Bertozzi, C. R. Nat. Chem. Biol. 2005, 1, 13-21.

(44) Rostovtsev, V. V.; Green, L. G.; Fokin, V. V.; Sharpless, K. B. Angew. Chem. Int. Ed. 2002, 41, 2596-2599.

(45) Tornøe, C. W.; Christensen, C.; Meldal, M. J. Org. Chem. 2002, 67, 3057-3064.

(46) Agard, N. J.; Prescher, J. A.; Bertozzi, C. R. J. Am. Chem. Soc. 2004, 126, 1504615047.

(47) Chang, P. V.; Prescher, J. A.; Sletten, E. M.; Baskin, J. M.; Miller, I. A.; Agard, N. J.; Lo, A.; Bertozzi, C. R. Proc. Natl. Acad. Sci. U. S. A. 2010, 107, 1821-1826.

(48) Hein, C. D.; Liu, X.-M.; Wang, D. Pharm. Res. 2008, 25, 2216-2230.

(49) Nwe, K.; Brechbiel, M. W. Cancer Biother. Radiopharm. 2009, 24, 289-302. 
(50) Yang, P.-Y.; Wang, M.; He, C. Y.; Yao, S. Q. Chem. Commun. (Cambridge, U. K.) 2012, 48, 835-837.

(51) Zayas, J.; Annoual, M.; Das, J. K.; Felty, Q.; Gonzalez, W. G.; Miksovska, J.; Sharifai, N.; Chiba, A.; Wnuk, S. F. Bioconjug. Chem. 2015, 26, 1519-1532.

(52) Gourdain, S.; Martinez, A.; Petermann, C.; Harakat, D.; Clivio, P. J. Org. Chem. 2009, 74, 6885-6887.

(53) Liu, Y.; Wang, X.-F.; Chen, Y.; Zhang, L.-H.; Yang, Z.-J. MedChemComm 2012, $3,506-511$.

(54) Krim, J.; Taourirte, M.; Grünewald, C.; Krstic, I.; Engels, J. W. Synthesis 2013, 45, 396-405.

(55) Xu, X.; Yan, S.; Hu, J.; Guo, P.; Wei, L.; Weng, X.; Zhou, X. Tetrahedron 2013, 69, 9870-9874.

(56) Haque, M. M.; Sun, H.; Liu, S.; Wang, Y.; Peng, X. Angew. Chem., Int. Ed. Engl. 2014, 53, 7001-7005.

(57) Ren, X.; El-Sagheer, A. H.; Brown, T. Analyst 2015, 140, 2671-2678.

(58) Horwitz, J. P.; Chua, J.; Noel, M. J. Org. Chem. 1964, 29, 2076-2078.

(59) Tárkányi, I.; Aradi, J. Biochimie 2008, 90, 156-172.

(60) Housri, N.; Yarchoan, R.; Kaushal, A. Cancer 2010, 116, 273-283.

(61) Kampf, A.; Barfknecht, R. L.; Shaffer, P. J.; Osaki, S.; Mertes, M. P. J. Med. Chem. 1976, 19, 903-908.

(62) Balzarini, J.; De Clercq, E.; Mertes, M. P.; Shugar, D.; Torrence, P. F. Biochem. Pharmacol. 1982, 31, 3673-3682.

(63) Kampf, A.; Pillar, C. J.; Woodford, W. J.; Mertes, M. P. J. Med. Chem. 1976, 19, 909-915.

(64) Balzarini, J.; De Clercq, E.; Torrenc, P. F.; Mertes, M. P.; Park, J. S.; Schmidt, C. L.; Shugar, D.; Barra, P. J.; Jones, A. S.; Verhelst, G.; Walker, R. T. Biochem. Pharmacol. 1982, 31, 1089-1095.

(65) Reefschläger, J.; Bärwolff, D.; Engelmann, P.; Langen, P.; Rosenthal, H. A. Antiviral Res. 1982, 2, 41-52. 
(66) De clercq, E.; Descamps, J.; Schmidt, C. L.; Mertes, M. P. Biochem. Pharmacol. 1979, 28, 3249-3254.

(67) Kumar, P.; Hornum, M.; Nielsen, L. J.; Enderlin, G.; Andersen, N. K.; Len, C.; Hervé, G.; Sartori, G.; Nielsen, P. J. Org. Chem. 2014, 79, 2854-2863.

(68) Balzarini, J.; Andrei, G.; Kumar, R.; Knaus, E. E.; Wiebe, L. I.; De Clercq, E. FEBS Lett. 1995, 373, 41-44.

(69) Srivastav, N. C.; Manning, T.; Kunimoto, D. Y.; Kumar, R. Med. Chem. 2006, 2, 287-293.

(70) Zhou, F.-X.; Liao, Z.-K.; Dai, J.; Xiong, J.; Xie, C.-H.; Luo, Z.-G.; Liu, S.-Q.; Zhou, Y.-F. Biochem. Biophys. Res. Commun. 2007, 354, 351-356.

(71) Liao, Z. K.; Zhou, F. X.; Luo, Z. G.; Zhang, W. J.; Xiong, J.; Bao, J.; Han, G.; Zhang, M. S.; Xie, C. H.; Zhou, Y. F. Oncol. Rep. 2008, 19, 281-286.

(72) Coucke, P. A.; Cottin, E.; Decosterd, L. A. Acta Oncol. 2007, 46, 612-620.

(73) Mudgal, M.; Rishi, S.; Lumpuy, D. A.; Curran, K. A.; Verley, K. L.; Sobczak, A. J.; Dang, T. P.; Sulimoff, N.; Kumar, A.; Sevilla, M. D.; Wnuk, S. F.; Adhikary, A. J. Phys. Chem. B 2017, 121, 4968-4980.

(74) Greenberg, M. M. Acc. Chem. Res. 2012, 45, 588-597.

(75) Jagetia, G. C.; Aruna, R. Toxicol. Lett. 2003, 139, 33-43.

(76) Erik, H. R.; J., D. P.; K., B. J. Angew. Chem. Int. Ed. 1997, 36, 2714-2730.

(77) Chatgilialoglu, C.; Caminal, C.; Altieri, A.; Vougioukalakis, G. C.; Mulazzani, Q. G.; Gimisis, T.; Guerra, M. J. Am. Chem. Soc. 2006, 128, 13796-13805.

(78) Candeias, L. P.; Steenken, S. J. Am. Chem. Soc. 1989, 111, 1094-1099.

(79) Steenken, S. Chem. Rev. (Washington, DC, U. S.) 1989, 89, 503-520.

(80) P., C. L.; Steen, S. Chem. Eur. J. 2000, 6, 475-484.

(81) Chatgilialoglu, C.; D'Angelantonio, M.; Guerra, M.; Kaloudis, P.; Mulazzani, Q. G. Angew. Chem. Int. Ed. 2009, 48, 2214-2217.

(82) Mundy, C. J.; Colvin, M. E.; Quong, A. A. J. Phys. Chem. A 2002, 106, 1006310071. 
(83) Chryssostomos, C.; Clara, C.; Maurizio, G.; G., M. Q. Angew. Chem. 2005, 117, 6184-6186.

(84) Chryssostomos, C.; Clara, C.; Maurizio, G.; G., M. Q. Angew. Chem. Int. Ed. 2005, $44,6030-6032$.

(85) Zheng, L.; Lin, L.; Qu, K.; Adhikary, A.; Sevilla, M. D.; Greenberg, M. M. Org. Lett. 2017, 19, 6444-6447.

(86) Daniels, M.; Hauswirth, W. Science 1971, 171, 675-677.

(87) Greco, N. J.; Tor, Y. J. Am. Chem. Soc. 2005, 127, 10784-10785.

(88) Holz, B.; Klimasauskas, S.; Serva, S.; Weinhold, E. Nucleic Acids Res. 1998, 26, 1076-1083.

(89) Srivatsan, S. G.; Tor, Y. J. Am. Chem. Soc. 2007, 129, 2044-2053.

(90) Srivatsan, S. G.; Tor, Y. Tetrahedron 2007, 63, 3601-3607.

(91) Tanpure, A. A.; Pawar, M. G.; Srivatsan, S. G. Isr. J. Chem. 2013, 53, 366-378.

(92) Wilhelmsson, L. M. Q. Rev. Biophys. 2010, 43, 159-183.

(93) Xu, W.; Chan, K. M.; Kool, E. T. Nat. Chem. 2017, 9, 1043.

(94) Seo, Y. J.; Ryu, J. H.; Kim, B. H. Org. Lett. 2005, 7, 4931-4933.

(95) Ozols, K.; Cīrule, D.; Novosjolova, I.; Stepanovs, D.; Liepinsh, E.; Bizdēna, Ē.; Turks, M. Tetrahedron Lett. 2016, 57, 1174-1178.

(96) Kavoosi, S.; Rayala, R.; Walsh, B.; Barrios, M.; Gonzalez, W. G.; Miksovska, J.; Mathivathanan, L.; Raptis, R. G.; Wnuk, S. F. Tetrahedron Lett. 2016, 57, 4364-4367.

(97) Lawson, C. P.; Dierckx, A.; Miannay, F.-A.; Wellner, E.; Wilhelmsson, L. M.; Grotli, M. Org. Biomol. Chem. 2014, 12, 5158-5167.

(98) Dyrager, C.; Börjesson, K.; Dinér, P.; Elf, A.; Albinsson, B.; Wilhelmsson, L. M.; Grøtli, M. Eur. J. Org. Chem. 2009, 2009, 1515-1521.

(99) Redwan, I. N.; Bliman, D.; Tokugawa, M.; Lawson, C.; Grøtli, M. Tetrahedron 2013, 69, 8857-8864.

(100) Kočalka, P.; Andersen, N. K.; Jensen, F.; Nielsen, P. ChemBioChem 2007, 8, 21062116. 
(101) Hatano, A.; Kurosu, M.; Yonaha, S.; Okada, M.; Uehara, S. Org. Biomol. Chem. 2013, 11, 6900-6905.

(102) Jin, T.; Kamijo, S.; Yamamoto, Y. Eur. J. Org. Chem. 2004, 2004, 3789-3791.

(103) Barluenga, J.; Valdés, C.; Beltrán, G.; Escribano, M.; Aznar, F. Angew. Chem. Int. Ed. 2006, 45, 6893-6896.

(104) Quan, X.-J.; Ren, Z.-H.; Wang, Y.-Y.; Guan, Z.-H. Org. Lett. 2014, 16, 5728-5731.

(105) Kalisiak, J.; Sharpless, K. B.; Fokin, V. V. Org. Lett. 2008, 10, 3171-3174.

(106) Cha, H.; Lee, K.; Chi, D. Y. Tetrahedron 2017, 73, 2878-2885.

(107) Hicks, K. O.; Pruijn, F. B.; Sturman, J. R.; Denny, W. A.; Wilson, W. R. A Pharmacokinetic/Pharmacodynamic Study in HT29 Multicellular Layer Cultures 2003, 63, 5970-5977.

(108) Huttunen, K. M.; Raunio, H.; Rautio, J. Pharmacol. Rev. 2011, 63, 750-771.

(109) Pradere, U.; Garnier-Amblard, E. C.; Coats, S. J.; Amblard, F.; Schinazi, R. F. Chem. Rev. (Washington, DC, U. S.) 2014, 114, 9154-9218.

(110) Liang, Y.; Suzol, S. H.; Wen, Z.; Artiles, A. G.; Mathivathanan, L.; Raptis, R. G.; Wnuk, S. F. Org. Lett. 2016, 18, 1418-1421.

(111) Liang, Y.; Gloudeman, J.; Wnuk, S. F. J. Org. Chem. 2014, 79, 4094-4103.

(112) Zhang, X.; Yang, H.; Tang, P. Org. Lett. 2015, 17, 5828-5831.

(113) Fan, X.; Zhang, X.; Zhou, L.; Keith, K. A.; Kern, E. R.; Torrence, P. F. J. Med. Chem. 2006, 49, 3377-3382.

(114) Fomich, M. A.; Kvach, M. V.; Navakouski, M. J.; Weise, C.; Baranovsky, A. V.; Korshun, V. A.; Shmanai, V. V. Org. Lett. 2014, 16, 4590-4593.

(115) Liu, Z.; Liao, P.; Bi, X. Org. Lett. 2014, 16, 3668-3671.

(116) Kumar, R.; Wiebe, L. I.; Knaus, E. E. Can. J. Chem. 1996, 74, 1609-1615.

(117) Fu, J.; Zanoni, G.; Anderson, E. A.; Bi, X. Chem. Soc. Rev. 2017, 46, 7208-7228.

(118) Robins, M. J.; Barr, P. J. J. Org. Chem. 1983, 48, 1854-1862. 
(119) Suzol, S. H.; Howlader, A. H.; Wen, Z.; Ren, Y.; Laverde, E. E.; Garcia, C.; Liu, Y.; Wnuk, S. F. ACS Omega 2018, 3, 4276-4288.

(120) Guan, L.; van der Heijden, G. W.; Bortvin, A.; Greenberg, M. M. ChemBioChem 2011, 12, 2184-2190.

(121) Hu, B.; DiMagno, S. G. Org. Biomol. Chem. 2015, 13, 3844-3855.

(122) Hoard, D. E.; Ott, D. G. J. Am. Chem. Soc. 1965, 87, 1785-1788.

(123) Kovács, T.; Ötvös, L. Tetrahedron Lett. 1988, 29, 4525-4528.

(124) von Watzdorf, J.; Leitner, K.; Marx, A. Angew. Chem. Int. Ed. 2016, 55, 3229-3232.

(125) Röthlisberger, P.; Levi-Acobas, F.; Hollenstein, M. Bioorg. Med. Chem. Lett. 2017, 27, 897-900.

(126) Bernhard, W. A. Wiley Ser. React. Intermed. Chem. Biol. 2009, 2, 41-68.

(127) Sagstuen, E.; Hole, E. O.; John Wiley \& Sons, Inc.: 2009, p 325-382.

(128) Close, D. Radiation Induced Molecular Phenomena in Nucleic Acids; Shukla, M., Leszczynski, J., Eds.; Springer Netherlands: 2008; Vol. 5, p 493-529.

(129) Wen, Z.; Peng, J.; Tuttle, P.; Debnath, D.; Rishi, S.; Hanson, C.; Ward, S.; Ren, Y.; Garcia, C.; Liu, Y.; Liu, Y.; Zhao, W.; Glazer, P. M.; Kumar, A.; Sevilla, M. D.; Adhikary, A.; Wnuk, S. F. Radiation Damage to Hypoxic Cells Augmented by Aminyl Radicals Formed via Electron Addition to 5-Azido-modified Pyrimidine Nucleosides. To be submitted.

(130) Adhikary, A.; Kumar, A.; Bishop, C. T.; Wiegand, T. J.; Hindi, R. M.; Adhikary, A.; Sevilla, M. D. J. Phys. Chem. B 2015, 119, 11496-11505.

(131) Mandel, S. M.; Singh, P. N. D.; Muthukrishnan, S.; Chang, M.; Krause, J. A.; Gudmundsdóttir, A. D. Org. Lett. 2006, 8, 4207-4210.

(132) Bencivenni, G.; Lanza, T.; Leardini, R.; Minozzi, M.; Nanni, D.; Spagnolo, P.; Zanardi, G. J. Org. Chem. 2008, 73, 4721-4724.

(133) Electron Spin Resonace; Ayscough, P. B., Ed.

(134) Dextraze, M. E.; Wagner, J. R.; Hunting, D. J. Biochemistry 2007, 46, 9089-9097.

(135) Greenberg, M. M. Radiat. Phys. Chem. 2016, 128, 82-91. 
(136) McGinn, C. J.; Shewach, D. S.; Lawrence, T. S. J. Natl. Cancer Inst. 1996, 88, 1193-1203.

(137) A. Gottinger, H.; E. Zubarev, V.; Brede, O. J. Chem. Soc., Perkin Trans. 2 1997, 2167-2172.

(138) Hohman, W. F.; Palcic, B.; Skarsgard, L. D. Int. J. Radiat. Biol. Relat. Stud. Phys. Chem. Med. 1976, 30, 247-261.

(139) Millar, B. C.; Fielden, E. M.; Smithen, C. E. Br. J. Cancer Suppl. 1978, 3, 73-79.

(140) Dodd, D. W.; Swanick, K. N.; Price, J. T.; Brazeau, A. L.; Ferguson, M. J.; Jones, N. D.; Hudson, R. H. E. Org. Biomol. Chem. 2010, 8, 663-666.

(141) Reddy, M. R.; Shibata, N.; Kondo, Y.; Nakamura, S.; Toru, T. Angew. Chem. 2006, $118,8343-8346$.

(142) Shinohara, Y.; Matsumoto, K.; Kugenuma, K.; Morii, T.; Saito, Y.; Saito, I. Bioorg. Med. Chem. Lett. 2010, 20, 2817-2820.

(143) Sheehan, J. C.; Robinson, C. A. J. Am. Chem. Soc. 1949, 71, 1436-1440.

(144) Journet, M.; Cai, D.; Kowal, J. J.; Larsen, R. D. Tetrahedron Lett. 2001, 42, 91179118.

(145) Salic, A.; Mitchison, T. J. Proc. Natl. Acad. Sci. U. S. A. 2008, 105, 2415-2420.

(146) Neef, A. B.; Luedtke, N. W. Proc. Natl. Acad. Sci. U. S. A. 2011, 108, 20404-20409.

(147) Wen, Z.; Suzol, S. H.; Peng, J.; Liang, Y.; Snoeck, R.; Andrei, G.; Liekens, S.; Wnuk, S. F. Arch. Pharm. 2017, e1700023-n/a.

(148) Acedo, M.; Fàbrega, C.; Aviño, A.; Goodman, M.; Fagan, P.; Wemmer, D.; Eritja, R. Nucleic Acids Res. 1994, 22, 2982-2989.

(149) Fabrega, C.; Guimil Garcia, R.; Diaz, A. R.; Eritja, R. Biol. Chem. 1998, 379, 527533.

(150) Claudio-Montero, A.; Pinilla-Macua, I.; Fernández-Calotti, P.; Sancho-Mateo, C.; Lostao, M. a. P.; Colomer, D.; Grandas, A.; Pastor-Anglada, M. Mol. Pharm. 2015, 12, 2158-2166.

(151) Liu, Y.; Prasad, R.; Beard, W. A.; Hou, E. W.; Horton, J. K.; McMurray, C. T.; Wilson, S. H. J. Biol. Chem. 2009, 284, $28352-28366$. 
(152) Xu, M.; Lai, Y.; Torner, J.; Zhang, Y.; Zhang, Z.; Liu, Y. Nucleic Acids Res. 2014, 42, 3675-3691.

(153) Petrovici, A.; Adhikary, A.; Kumar, A.; Sevilla, M. Molecules 2014, 19, 13486.

(154) Adhikary, A.; Becker, D.; Sevilla, M. D. In Applications of EPR in Radiation Research; Lund, A., Shiotani, M., Eds.; Springer International Publishing: 2014, p 299352.

(155) http://jmol.sourceforge.net

(156) Rockwell, S.; Keyes, S. R.; Sartorelli, A. C. Radiat. Res. 1988, 116, 100-113. 
VITA

ZHIWEI WEN

Born, Quanzhou, China

2018

FIU Graduate School, Dissertation Year Fellowship

2013-2018

Ph.D. candidate, Organic Chemistry

Florida International University

Miami, Florida, U.S.

2009-2012

Master, Analytical Chemistry

CIAC, Chinese Academy of Sciences

Changchun, P. R. China

2005-2009

Bachelor, Chemistry

Fuzhou University

Fuzhou, P. R. China

PUBLICATIONS (Citations: 537, Web of Science 03/30/2018)

1. Z. Wen, J. Peng, P. Tuttle, A. Petrovici, S. Rishi, C. Hanson, Y. Ren, C. Garcia, Y. Liu, M. D. Sevilla, A. Adhikary, and S. F. Wnuk. Radiation Damage to Cells Augmented by Electron-induced Aminyl Radicals in 5-Azido-modified Pyrimidine Nucleosides Incorporated into DNA-fragments. Submitted to JACS.

2. Z. Wen, P. Tuttle, A. Vasilyeva, A. Tangar, J. Miksovska, and S. F. Wnuk. 5-Pyrimidine and 8-Purine Nucleosides Modified with $N$-unsubstituted 1,2,3-Triazol4-yl: Synthesis and Fluorescent Properties. To be submitted to Org. Lett.

3. M.L.S. Guther, R. Lowden, Z. Wen, L. Stojanovski, K. Read, S. F. Wnuk, and M.A.J. Ferguson. In Vivo and in Vitro Studies with 6'-E-Chlorohomovinyladenosine Aiming Treatment of Human African Sleeping Sickness, Leishmaniasis and Chagas Disease. In preparation.

4. S. H. Suzol, A. H. Howlader, Z. Wen, Y. Ren, E. E. Laverde, C. Garcia, Yuan Liu, and S. F. Wnuk. ACS Omega 2018, (3), 4276-4288

5. Z. Wen, S. H. Suzol, J. Peng, Y. Liang, R. Snoeck, G. Andrei, S. Liekens, and S. F. Wnuk. Arch. Pharm. (Weinheim, Ger.) 2017, e1700023-n/a.

6. Y. Liang, S. H. Suzol, Z. Wen, A. G. Artiles, L. Mathivathanan, R. G. Raptis, and S. F. Wnuk. Org. Lett. 2016 (18): 1418-1421.

7. Y. Sun, Z. Wen, F. Xu, Y. Zhang, Y. Shi, H. Dai, and Z. Li. Anal. Methods. 2014 (6): 337-340.

8. Y. Shi, J. Wu, Y. Sun, Y. Zhang, Z. Wen, H. Dai, H. Wang, and Z. Li. Biosens. Bioelectron. 2012 (38): 31-36. 
9. F. Xu, Y. Zhang, Y. Sun, Y. Shi, Z. Wen, and Z. Li. J. Phys. Chem. C 2011 (115): 9977-9983.

10. F. Xu, Y. Sun, Y. Zhang, Y. Shi, Z. Wen, and Z. Li. Electrochem. Commun. 2011 (13): 1131-1134.

11. Y. Zhang, F. Xu, Y. Sun, Y. Shi, Z. Wen, and Z. Li. J. Mater. Chem. 2011 (21): 1694916954.

12. Y. Sun, F. Xu, Y. Zhang, Y. Shi, Z. Wen, and Z. Li. J. Mater. Chem. 2011 (21): 16675-16685.

13. Y. Shi, C. Guo, Y. Sun, Z. Liu, F. Xu, Y. Zhang, Z. Wen, and Z. Li. Biomacromolecules 2011 (12): 797-803.

14. Y. Zhang, Y. Sun, Z. Liu, F. Xu, K. Cui, Y. Shi, Z. Wen, and Z. Li. J. Electroanal. Chem. 2011 (656): 23-28.

15. Y. Shi, Z. Liu, B. Zhao, Y. Sun, F. Xu, Y. Zhang, Z. Wen, H. Yang, and Z. Li. J. Electroanal. Chem. 2011 (656): 29-33.

16. Y. Zhang, F. Xu, Y. Sun, C. Guo, Y. Shi, Z. Wen, and Z. Li. Chem-Eur. J. 2010 (16): 9248-9256.

17. Z. Li, Z. Wen, Y. Zhang, F. Xu, Y. Sun, Y. Shi, H. Dai. Surface Enhanced Raman Scattering (SERS) Substrate and Preparation Method Thereof. 2014. China. CN102608103 B. CN 201210091092.

18. Z. Li, F. Xu, Y. Sun, Y. Zhang, Y. Shi, Z. Wen. Method for Detecting Melamine. 2011. China. CN102156118 A. CN 201110068576.

19. Z. Li, F. Xu, Y. Zhang, Y. Sun, Y. Shi, Z. Wen. Substrate for Surface Enhanced Raman Scattering and Preparation Method Thereof. 2011. China. CN102156117 A. CN 201110068574.

20. Z. Wen, P. Tuttle, A. Vasilyeva, A. Tangar, J. Miksovska, and S. F. Wnuk. $255^{\text {th }}$ ACS national meeting (oral presentation). Mar. 2018, New Orleans.

21. P. Tuttle, Z. Wen, A. Vasilyeva, and S. F. Wnuk. $255^{\text {th }}$ ACS national meeting (poster). Mar. 2018, New Orleans.

22. Z. Wen, J. Peng, P. Tuttle, Y. Liang, S. Rishi, A. Adhikary, M. D. Sevilla, C. Garcia, Y. Ren, Y. Liu, and S. F. Wnuk. $253^{\text {rd }}$ ACS national meeting (oral presentation). Apr. 2017, San Francisco.

23. C. Garcia, Y. Ren, Z. Wen, S. F. Wnuk, and Y. Liu. $253^{\text {rd }}$ ACS national meeting (poster). Apr. 2017, San Francisco.

24. S. F. Wnuk, M. Mudgal, Z. Wen, A. Adhikary, and M.D. Sevilla. $22^{\text {nd }}$ International Round Table Symposium: Nucleosides, Nucleotides and their Biological Applications (poster presentation). Jul. 2016, Paris, France.

25. Y. Liang, S. H. Suzol, Z. Wen, A. Artiles, I. Jesus da Silva, M. Dinh, A. Akinniyi, and S. F. Wnuk. $251^{\text {st }}$ ACS national meeting (oral presentation). 2016, San Diego.

26. Z. Wen, F. Xu, Y. Zhang, Y. Sun, Y. Shi, H. Dai and Z. Li. The $13^{\text {th }}$ International Symposium on Electroanalytical Chemistry (poster). 2011, 193. Changchun.

27. F. Xu, Z. Wen, Y. Sun, Y. Zhang, Y. Shi, Z. Li. The $13^{\text {th }}$ International Symposium on Electroanalytical Chemistry (poster). 2011, 114. Changchun. 